\title{
Method of Determining Smoke Detector Spacing in High Ceiling Applications
}

\author{
A thesis submitted to \\ the Faculty of Graduate Studies and Research \\ in Partial Fulfillment of the requirements for the degree
}

Master of Applied Science

by

\section{William Kuffner}

\section{Department of Civil and Environmental Engineering \\ Carleton University}

Ottawa-Carleton Institute of Civil and Environmental Engineering

April 2009

(C)2009 William Kuffner 
Library and

Archives Canada

Published Heritage

Branch

395 Wellington Street

Ottawa ON K1A 0N4

Canada
Bibliothèque et

Archives Canada

Direction du

Patrimoine de l'édition

395 , rue Wellington

Ottawa ON K1A 0N4

Canada

Your file Votre référence

ISBN: 978-0-494-52036-9

Our file Notre référence

ISBN: 978-0-494-52036-9

NOTICE:

The author has granted a nonexclusive license allowing Library and Archives Canada to reproduce, publish, archive, preserve, conserve, communicate to the public by telecommunication or on the Internet, loan, distribute and sell theses worldwide, for commercial or noncommercial purposes, in microform, paper, electronic and/or any other formats.

The author retains copyright ownership and moral rights in this thesis. Neither the thesis nor substantial extracts from it may be printed or otherwise reproduced without the author's permission.
AVIS:

L'auteur a accordé une licence non exclusive permettant à la Bibliothèque et Archives Canada de reproduire, publier, archiver, sauvegarder, conserver, transmettre au public par télécommunication ou par l'Internet, prêter, distribuer et vendre des thèses partout dans le monde, à des fins commerciales ou autres, sur support microforme, papier, électronique et/ou autres formats.

L'auteur conserve la propriété du droit d'auteur et des droits moraux qui protège cette thèse. $\mathrm{Ni}$ la thèse ni des extraits substantiels de celle-ci ne doivent être imprimés ou autrement reproduits sans son autorisation.
In compliance with the Canadian

Privacy Act some supporting forms may have been removed from this thesis.

While these forms may be included in the document page count, their removal does not represent any loss of content from the thesis.
Conformément à la loi canadienne sur la protection de la vie privée, quelques formulaires secondaires ont été enlevés de cette thèse.

Bien que ces formulaires aient inclus dans la pagination, il n'y aura aucun contenu manquant.

\section{Canada}




\begin{abstract}
Simple tools for the design application of smoke detectors in commercial spaces with high ceilings and/or complex geometries do not exist due to the complexity in accurately estimating smoke densities and smoke detector activation characteristics. The response of commercial smoke detectors to UL/ULC standard flaming acceptance test fires and non-standard test fires in large open spaces with ceiling heights varying from $3 \mathrm{~m}$ to $21 \mathrm{~m}$ with radial distances from the fires up to $11.4 \mathrm{~m}$ is measured. Two algebraic models intended for unconfined ceilings, the two-zone computer model CFAST and the computational fluid dynamics computer model FDS are compared against each other and the experimental results. The ability to predict obscuration levels and detection times for these fires is evaluated. Recommendations are made for using the various models in commercial applications.
\end{abstract}




\section{Table of Contents}

1 INTRODUCTION......................................................................

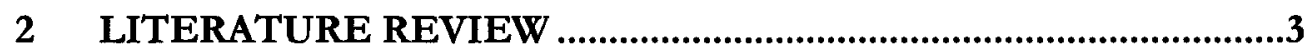

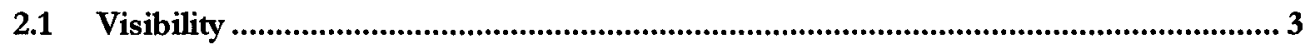

2.2 Smoke Density .................................................................................................................... 7

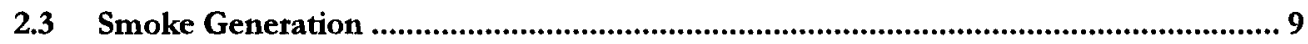

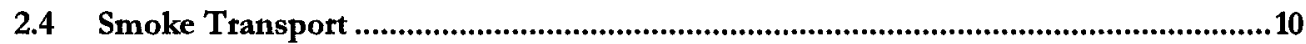

2.4.1 Plume ......................................................................................................................

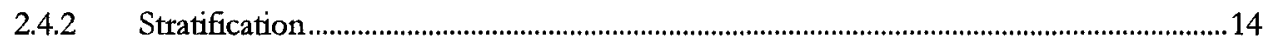

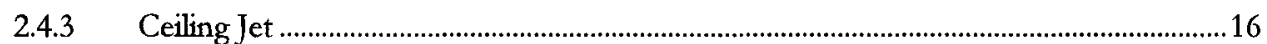

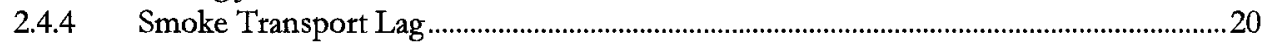

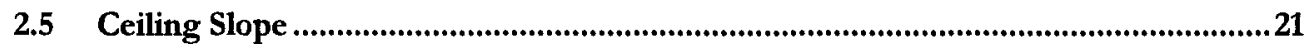

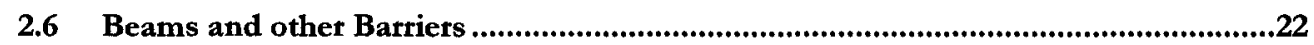

2.7 Ceiling Openings and Ventilation..............................................................................22

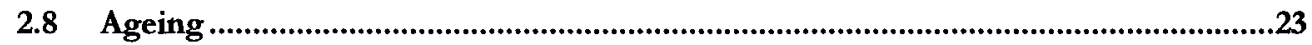

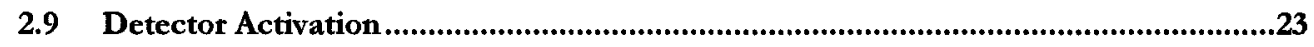

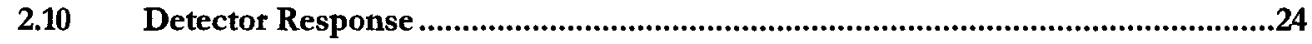

2.11 Detector Time Lag..............................................................................................26

2.12 Detection Algorithm ......................................................................................27

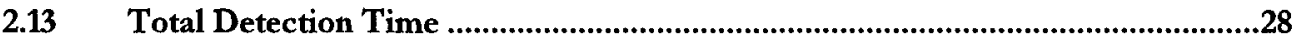

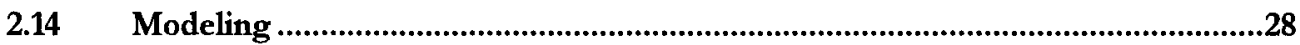

2.14.1 Algebraic modeling …………………………………………………………………....28

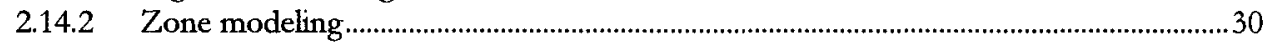

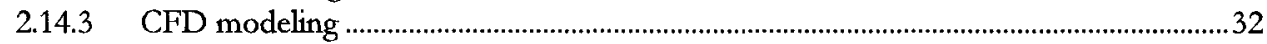

3 DESCRIPTION OF EXPERIMENTS ........................................34

$3.1 \quad$ Testing Facility ….............................................................................................................34

iii 
$3.2 \quad$ Experimental set up........................................................................................................

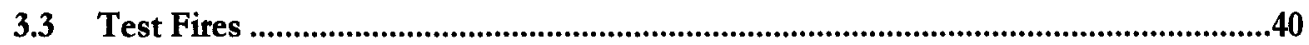

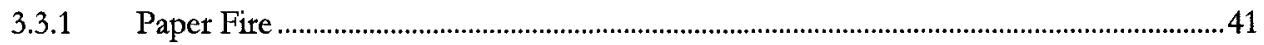

3.3.2 Flammable liquid fire .......................................................................................................4

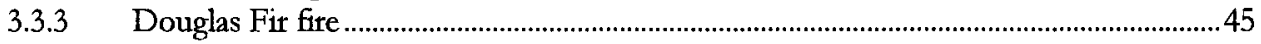

4 MODELING

4.1 Newspaper fire model …...............................................................................................48

4.2 Liquid fuel fire models .................................................................................................49

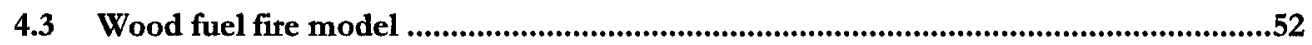

4.4 Algebraic Modeling .....................................................................................................53

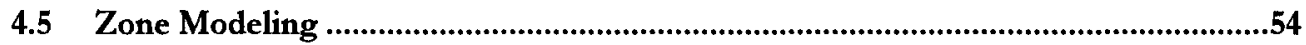

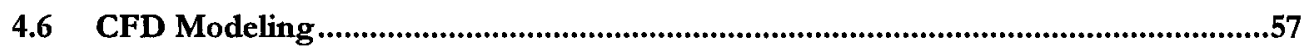

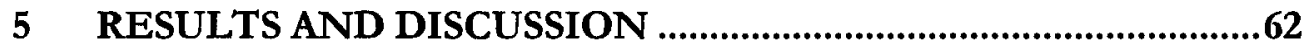

$5.1 \quad$ Experimental Results ...................................................................................................62

$5.2 \quad$ Algebraic Modeling Results ..........................................................................................64

5.3 Zone Modeling Results .......................................................................................................66

5.4 CFD Modeling Results..................................................................................................71

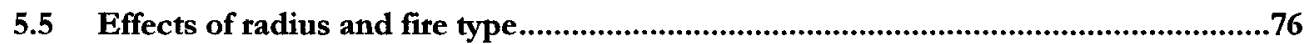

5.5.1 3-m Elevation ......................................................................................................................77

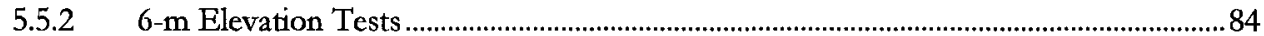

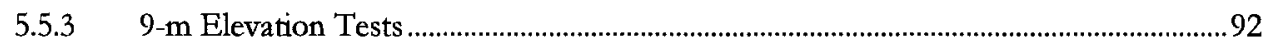

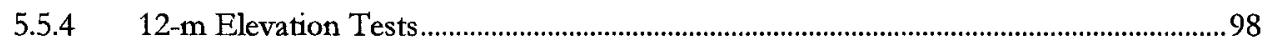

5.5.5 15-m Elevation Tests.......................................................................................................107

5.5.6 18-m Elevation Tests..............................................................................................118

5.5.7 21-m Elevation Tests...................................................................................................123

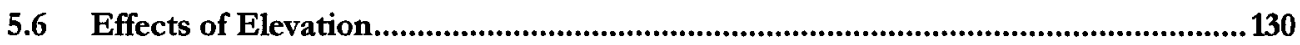

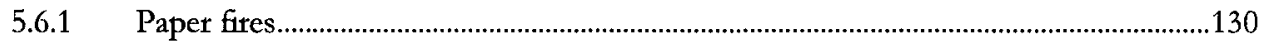

5.6.2 20-ml liquid fuel fires.......................................................................................................132

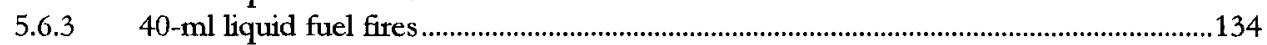

5.6.4 60-ml liquid fuel fires ..........................................................................................................135

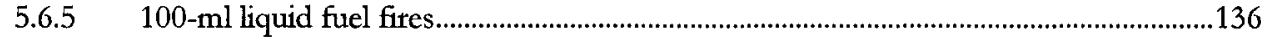

5.6.6 Wood crib fires ..................................................................................................................138 
5.7 Selected Results and Discussion ................................................................................. 139

6 CONCLUSIONS AND RECOMMENDATIONS ......................... 146

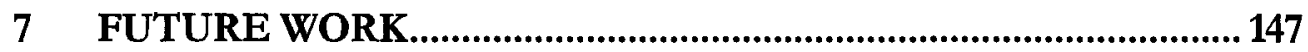

Appendix A - Fuel Properties

Appendix B - Test Parameters

Appendix C - Typical CFAST and FDS data entry files 


\section{List of figures}

FIGURE 1 - IDEALIZED FIRE PLUME

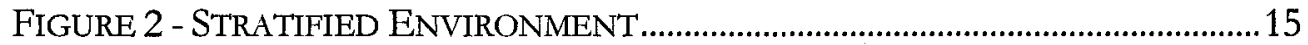

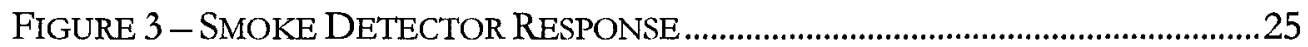

FIGURE 4 - VIEW OF PLATFORM BEING CONSTRUCTED FROM ONE OF THE VENT

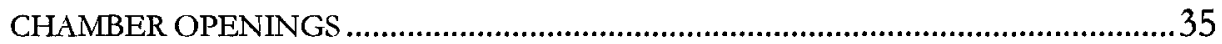

FIGURE 5 - SCHEMATIC LAYOUT OF TEST EQUIPMENT …....................................36

FIGURE 6 - SMOKE DETECTOR PULSE WIDTH NOMINAL SENSITIVITY CHART......39

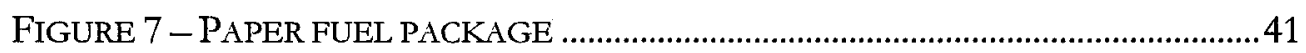

FIGURE 8 - NEWSPRINT FIRE EARLY SMOKE PRODUCTION ......................................42

FIGURE 9 - NEWSPRINT FIRE TRANSITION TO OPEN FLAME ..................................44

FIGURE 10 - NEWSPRINT FIRE THERMAL LIFT OF EARLY SMOKE PRODUCED .......43

FIGURE 11 - 20 ML LIQUID FUEL FIRE TEST WITH PLATFORM ELEVATION AT 3M 45

FIGURE 12 - WOOD CRIB FIRE TEST WITH PLATFORM ELEVATION AT 3M..............46

FIGURE 13 - SMOKE CHARACTERIZATION REPORT - NEWSPRINT HEAT RELEASE RATE

FIGURE 14-MODEL NEWSPAPER HEAT RELEASE RATE, 5 S MOVING AVERAGE..49

FIGURE 15 - 20-ML LIQUID FUEL FIRE MODEL HEAT RELEASE RATE, 5 S MOVING AVERAGE

FIGURE 16-40 ML LIQUID FUEL FIRE MODEL HEAT RELEASE RATE, 5 S MOVING AVERAGE

FIGURE 17 - 60 ML LIQUID FUEL FIRE MODEL HEAT RELEASE RATE, 5 S MOVING AVERAGE

FIGURE 18 - 100 ML LIQUID FUEL FIRE MODEL HEAT RELEASE RATE, $5 \mathrm{~S}$ MOVING AVERAGE

FIGURE 19 -SMOKE CHARACTERIZATION REPORT-DOUGLAS FIR HEAT

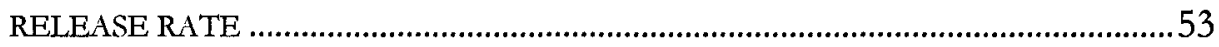

FIGURE 20 - DOUGLAS FIR HEAT RELEASE RATE...............................................53

FIGURE 21 - CFAST COMPARTMENT GEOMETRY ................................................5

FIGURE 22 - CFAST RENDERING OF THE 3-M ELEVATION TESTS.........................55

FIGURE 23 - CFAST FIRE MODEL FOR 20 ML LIQUID FUEL FIRE..............................56

FIGURE 24 - FDS MODEL FOR 21 M ELEVATION .....................................................58

FIGURE 25 - TEMPERATURE PROFILE, 21-M ELEVATIION, 100-ML LIQUID FUEL

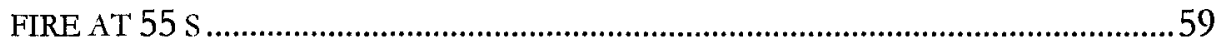

FIGURE 26-3D SMOKEVIEW, 21-M ELEVATION, 100-ML LIQUID FUEL FIRE AT $55 \mathrm{~s}$

FIgURE 27 - AvERAgE OBSCURATION VS. TIME FROM FDS, 100 ML LIQUID FUEL FIRE

FIGURE 28 - SMOKE MOVEMENT AROUND THE PLATFORM ..................................64

vi 
FIGURE 29 - CFAST OBSCURATION VS. TIME, PAPER FIRE MODEIS 67

FIGURE 30 - CFAST OBSCURATION VS. TIME, 20-ML LIQUID FUEL FIRE MODELS

.67

FIGURE 31 - CFAST OBSCURATION VS. TIME, 40-ML LIQUID FUEL FIRE MODELS

.68

FIGURE 32 - CFAST OBSCURATION VS. TIME, 60-ML LIQUID FUEL FIRE MODELS

FIGURE 33 - CFAST OBSCURATION VS. TIME, 100 ML LIQUID FUEL FIRE MODELS

FIGURE 34 - CFAST OBSCURATION VS. TIME RESULTS FOR WOOD FIRE MODELS

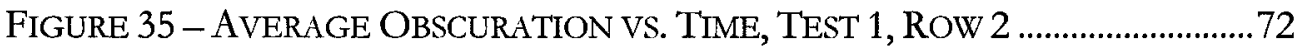

Figure 36 - AVERAGE OBSCURATION VS. TIME, 20 ML LIQUID FUEL FIRE, FDS 73

FIGURE 37-100 ML LIQUID FUEL FIRE MODEL HEAT RELEASE RATE, $5 \mathrm{~S}$ MOVING

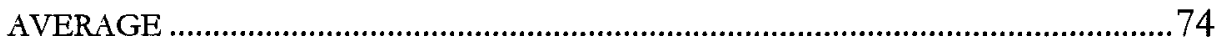

FIGURE 38 - HRR VS. TIME FOR FDS 100-ML LIQUID FUEL FIRE, 21-M ELEVATION

FIGURE 39-OBSCURATION VS. TIME - EXPERIMENTAL RESULTS FOR WOOD FIRE TEST NUMBER 25 AT 9-M ELEVATION, ROW 3 …….........................................75

FIGURE 40 - OBSCURATION VS. TIME - FDS SIMULATION FOR WOOD FIRE AT 9-M

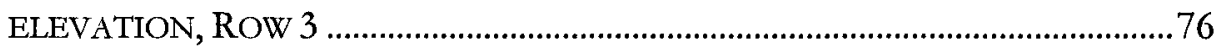

FIGURE 41 - MAXIMUM OBSCURATION VS. RADIUS FOR NEWSPRINT FIRE AT 3-M ELEVATION

FIGURE 42 - MAXIMUM OBSCURATION VS. RADIUS, 20 ML LIQUID FUEL FIRE AT 3-

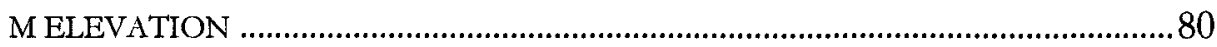

FIGURE 43 - MAXIMUM OBSCURATION VS. RADIUS FOR WOOD FIRE AT 3-M

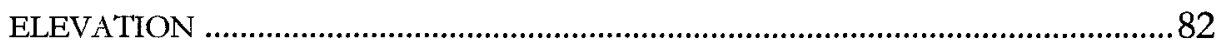

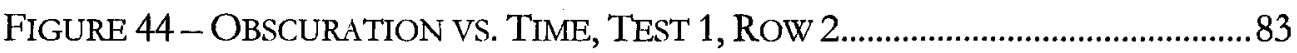

FIGURE 45-AVERAGE OBSCURATION VS. TIME, TEST 1......................................... 84

FIGURE 46 - MAXIMUM OBSCURATION VS. RADIUS FOR PAPER FIRE AT 6-M

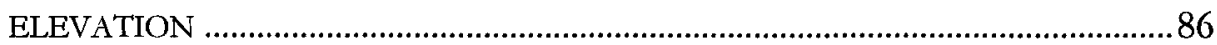

FIGURE 47 - MAXIMUM OBSCURATION VS. RADIUS FOR 20-ML LIQUID FUEL FIRES

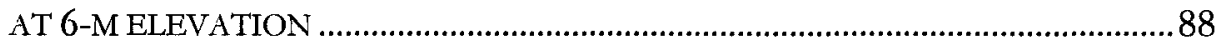

FIGURE 48 - MAXIMUM OBSCURATION VS. RADIUS FOR WOOD FIRE AT 6-M

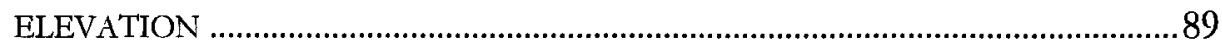

FIGURE 49 - OBSCURATION VS. TIME FOR ROW 3, TEST 13 ..................................91

Figure 50 - Averaged ObSCURATION vs. TIME FOR EACH Row, TEST 13 .......92

Figure 51 - MAXIMUM OBSCURATION VS. RADIUS, PAPER FIRE, 9-M ELEVATION . .94

FIGURE 52 - MAXIMUM OBSCURATION VS. RADIUS, 20-ML LIQUID FIRE, 9-M ELEVATION 
FIGURE 53 - MAXIMUM OBSCURATION VS. RADIUS, WOOD FIRE, 9-M ELEVATION

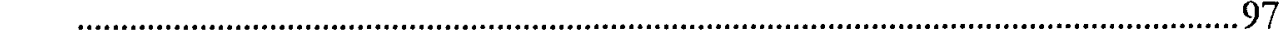

Figure 54-AVERAGE OBSCURATION VS. Time, TEST 25 …..............................98

Figure 55 - MAXIMUM OBSCURATION VS. RADIUS, PAPER FIRE, 12-M ELEVATION 101

FiguRE 56 - MAXIMUM OBSCURATION VS. RADIUS, 20-ML LIQUID FIRE, 12-M

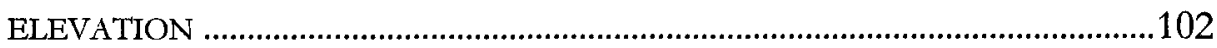

FIGURE 57 - MAXIMUM OBSCURATION VS. RADIUS, WOOD FIRE, 12-M ELEVATION 104

Figure 58 - OBSCURATION VS. TIME - TEST 33, ROW 1 105

Figure 59 - OBSCURATION Vs. TIME, FDS, PAPER FiRE, 12-M ELEVATION, ROW 1 106

Figure 60 - AVERAGE OBSCURATION VS. TIME - TEST 33....................................106

Figure 61 - MAXIMUM OBSCURATION VS. RADIUS, PAPER FIRE, 15-M ELEVATION 109

FIGURE 62 - MAXIMUM OBSCURATION VS. RADIUS, 20-ML LIQUID FIRE, 15-M ELEVATION

FIGURE 63 - MAXIMUM OBSCURATION VS. RADIUS, 40-ML LIQUID FIRE, 15-M ELEVATION

FIGURE 64 - MAXIMUM OBSCURATION VS. RADIUS, 100-ML LIQUID FIRE, 15-M

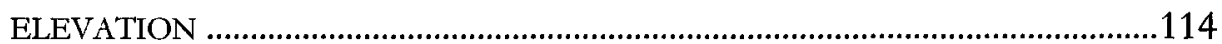

FIGURE 65 - MAXIMUM OBSCURATION VS. RADIUS, WOOD FIRE, 15-M ELEVATION

Figure 66 - ObSCURATION Vs. TIME, 20 ML LIQUID FUEL FIRE ROW 1, TEST 44, 15-M ELEVATION .116

Figure 67 - OBSCURATION VS. TIME, 40 ML LIQUID FUEL FIRE, ROW 1, TEST 51, 15-M ELEVATION.

FIGURE 68 - OBSCURATION vs. TIME, 100 ML LIQUID FUEL FIRE, ROW 1, TEST 49, 15-M ELEVATION

FIGURE 69 - MAXIMUM OBSCURATION VS. RADIUS, 40-ML LIQUID FIRE, 18-M ELEVATION 120

FIGURE 70 - MAXIMUM OBSCURATION VS. RADIUS, 60-ML LIQUID FIRE, 18-M ELEVATION

FIGURE 71 - AVERAGE OBSCURATION VS. TIME FOR ALL ROWS, TEST 54 .........122

FIGURE 72 - AVERAGE OBSCURATION VS. TIME FOR ALL ROWS, TEST 57 ...........122

FIGURE 73 - MAXIMUM OBSCURATION VS. RADIUS, 40-ML LIQUID FIRE, 21-M ELEVATION

FIGURE 74 - MAXIMUM OBSCURATION VS. RADIUS, 60-ML LIQUID FIRE, 21-M ELEVATION

FiguRE 75 - MAXIMUM OBSCURAT'ION VS. RADIUS, 100-ML LIQUID FIRE, 21-M ELEVATION 
Figure 76 - AVERAGE OBSCURATION VS TIME FOR EACH ROW OF DETECTORS,

TEST 62

Figure 77 - AVERAgE OBSCURATION VS TIME FOR EACH ROW OF DETECTORS,

TEST 65 129

FIgURE 78 - AVERAgE OBSCURATION VS TIME FOR EACH ROW OF DETECTORS,

TEST 68 130

Figure 79 - MAXIMUM AVERAgE OBSCURATION vS. HEIGHT, PAPER FIRES .....132

FIgURE 80 - MAXIMUM AVERAGE ObSCURATION VS. HEIGHT, 20-ML LIQUID

FUEL FIRES.

FIGURE 81 - MAXIMUM AVERAGE OBSCURATION VS. HEIGHT, 40-ML LIQUID

FUEL FIRES.

FIGURE 82 - MAXIMUM AVERAGE OBSCURATION VS. HEIGHT, 60-ML LIQUID FUEL FIRES

Figure 83 - MAXIMUM AVERAGE OBSCURATION VS. HEIGHT, 100-ML LIQUid

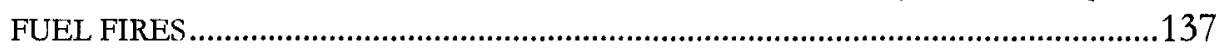

Figure 84 - MAXIMUM AVERAGE OBSCURATION vs. HeIGHT, WOOD CRIB FIRES

FIGURE 85 - MAXIMUM OBSCURATION COMPARISON, 20-ML LIQUID FUEL FIRE, 6M ELEVATION 140 


\section{List of Tables}

Number

TABLE 1 - DETECTOR SENSITIVITY VALUES 40

TABLE 2 - ALGEBRAIC MODEL RESULTS FOR 20-ML LIQUID FUEL FIRE, 3-M ELEVATION

TABLE 3 - TEST CONDITIONS AT 3-M ELEVATION.

TABLE 4 - PAPER FIRE MAXIMUM OBSCURATION RESULTS AT 3-M ELEVATION....78

TABLE 5-20-ML LIQUID FUEL MAXIMUM OBSCURATION RESULTS AT 3-M ELEVATION

TABLE 6 - WOOD FIRE MAXIMUM OBSCURATION RESULTS AT 3-M ELEVATION ...81

TABLE 7 - TEST CONDITIONS AT 6-M ELEVATION.

TABLE 8 - PAPER FIRE MAXIMUM OBSCURATION AT 6-M ELEVATION .86

TABLE 9 - LIQUID FUEL FIRE (20-ML) MAXIMUM OBSCURATION AT 6-M ELEVATION

TABLE 10 - WOOD FIRE MAXIMUM OBSCURATION RESULTS AT 6-M ELEVATION. 89

TABLE 11 - TEST CONDITIONS AT 9 M ELEVATION

TABLE 12 - PAPER FIRE MAXIMUM OBSCURATION RESULTS AT 9-M ELEVATION...93

TABLE 13 - LIQUID FUEL FIRE (20-ML) MAXIMUM OBSCURATION AT 9-M ELEVATION

TABLE 14 - WOOD FIRE MAXIMUM OBSCURATION RESULTS AT 9-M ELEVATION.. 97

TABLE 15 - TEST CONDITIONS AT 12 M ELEVATION.

TABLE 16 - PAPER FIRE MAXIMUM OBSCURATION RESULTS AT 12-M ELEVATION

TABLE 17 - LIQUID FUEL FIRE (20-ML) MAXIMUM OBSCURATION AT 12-M ELEVATION 102

TABLE 18 - WOOD FIRE MAXIMUM OBSCURATION RESULTS AT 12-M ELEVATION

TABLE 19 - TEST CONDITIONS AT 15 M ELEVATION 107

TABLE 20 - PAPER FIRE MAXIMUM OBSCURATION RESULTS AT 15-M ELEVATION

TABLE 21 - LIQUID FUEL FIRE (20 ML) MAXIMUM OBSCURATION RESULTS AT 15-M ELEVATION

TABLE 22 - LIQUID FUEL FIRE (40 ML) MAXIMUM OBSCURATION RESULTS AT 15-M ELEVATION

TABLE 23 - LIQUID FUEL FIRE (100 ML) MAXIMUM OBSCURATION RESULTS AT 15M ELEVATION 113

TABLE 24 - WOOD CRIB FIRE MAXIMUM OBSCURATION RESULTS AT 15-M ELEVATION

TABLE 25 - TEST CONDITIONS AT 18-M ELEVATION 
TABLE 26 - LIQUID FUEL (40-ML) MAXIMUM OBSCURATION RESULTS AT 18-M ELEVATION

TABLE 27 - LIQUID FUEL (60-ML) MAXIMUM OBSCURATION RESULTS AT 18-M ELEVATION

TABLE 28 - TEST CONDITIONS AT 21-M ELEVATION .............................................123

TABLE 29 - LIQUID FUEL (40-ML) MAXIMUM OBSCURATION RESULTS AT 21-M

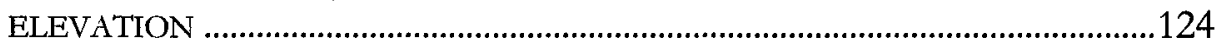

TABLE 30 - LIQUID FUEL (60-ML) MAXIMUM OBSCURATION RESULTS AT 21-M

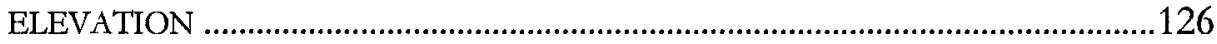

TABLE 31 - LIQUID FUEL (100-ML) MAXIMUM OBSCURATION RESULTS AT 21-M ELEVATION

TABLE 32 - MAXIMUM OBSCURATTION DEPENDENCE ON HEIGHT, PAPER FIRES

TABLE 33 - MAXIMUM OBSCURATION DEPENDENCE ON HEIGHT, 20-ML LIQUID FIRES.

TABle 34 - Maximum Obscuration Dependence ON HeIgHT, 40-ML LiQuid FIRES. 134

TABLE 35 - MAXIMUM OBSCURATION DEPENDENCE ON HEIGHT, 60-ML LIQUID FIRES

TABLE 36 - MAXIMUM OBSCURATION DEPENDENCE ON HEIGHT, 100-ML LIQUID FIRES 137

TABLE 37- MAXIMUM ObSCURATION DEPENDENCE ON HEIGHT, wOOD CRIB FIRES.

TABLE 38 -SELECTED OBSCURATION RESULTS .....................................................141 


\section{NOMENCLATURE}

\section{Symbols:}

\begin{tabular}{|l|l|}
\hline $\mathrm{b}$ & plume radius $[\mathrm{m}]$ \\
\hline $\mathrm{d}$ & particle diameter $[\mathrm{m}]$ \\
\hline $\mathrm{D}$ & diameter of fire $[\mathrm{m}]$ \\
\hline$\dot{m}$ & mass loss rate $[\mathrm{kg} / \mathrm{s}]$ \\
\hline$\dot{Q}$ & heat release rate $[\mathrm{kW}]$ \\
\hline $\mathrm{C}_{\mathrm{s}}$ & concentration of soot or smoke $\left[\mathrm{g} / \mathrm{m}^{3}\right]$ \\
\hline $\mathrm{H}$ & room height $[\mathrm{m}]$ \\
\hline $\mathrm{I}$ & intensity of light \\
\hline $\mathrm{k}$ & thermal conductivity $[\mathrm{W} / \mathrm{m} \cdot \mathrm{K}]$ \\
\hline $\mathrm{K}$ & proportionality constant \\
\hline $\mathrm{m}$ & mass $[\mathrm{kg}]$ \\
\hline $\mathrm{n}$ & number of particles \\
\hline $\mathrm{OD}$ & Optical density $\left[\mathrm{m}^{-1}\right]$ \\
\hline $\mathrm{P}$ & pressure $[\mathrm{Pa}]$ \\
\hline $\mathrm{r}$ & radius of interest from plume centreline $[\mathrm{m}]$ \\
\hline $\mathrm{S}$ & visibility $[\mathrm{m}]$ \\
\hline $\mathrm{SP}$ & scattering photoelectric detector output \\
\hline $\mathrm{t}$ & time $[\mathrm{s}]$ \\
\hline $\mathrm{T}$ & temperature $\left[{ }^{0} \mathrm{C}\right]$ \\
\hline $\mathrm{u}$ & velocity $[\mathrm{m} / \mathrm{s}]$ \\
\hline $\mathrm{V}$ & volume $\left[\mathrm{m}^{3}\right]$ \\
\hline $\mathrm{Y}$ & yield fraction of product of combustion $[\mathrm{g} / \mathrm{g}]$ \\
\hline$z$ & height of interest above fuel $[\mathrm{m}]$ \\
\hline$\Delta \mathrm{H}$ & heat of combustion $[\mathrm{k} / \mathrm{kg}]$ \\
\hline$\Delta \mathrm{MIC}$ & measuring ionization chamber output change \\
\hline$\alpha$ & extinction coefficient $\left[\mathrm{m}^{-1}\right]$ \\
\hline$\alpha_{\mathrm{m}}$ & mass specific extinction coefficient $\left[\mathrm{m}^{2} / \mathrm{g}\right]$ \\
\hline$\delta \mathrm{t}$ & dwell time $[\mathrm{s}]$ \\
\hline$\phi$ & mass specific absorption area $\left[\mathrm{m}^{2} / \mathrm{g}\right]$ \\
\hline$\sigma$ & plume radius for temperature drop to $1 / \mathrm{e}$ of centreline value $[\mathrm{m}]$ \\
\hline$\sigma_{\mathrm{m}}$ & mass specific extinction area $\left[\mathrm{m}^{2} / \mathrm{g}\right]$ \\
\hline$\lambda$ & per cent obscuration of light \\
\hline & \\
\hline & \\
\hline & \\
\hline
\end{tabular}




\begin{tabular}{|l|l|}
\hline$\rho$ & density $\left[\mathrm{kg} / \mathrm{m}^{3}\right]$ \\
\hline$\tau$ & mixing time $[\mathrm{s}]$ \\
\hline
\end{tabular}

\section{Constants:}

\begin{tabular}{|l|l|}
\hline $\mathrm{g}$ & gravitational acceleration $\left[9.81 \mathrm{~m} / \mathrm{s}^{2}\right]$ \\
\hline $\mathrm{R}$ & gas constant for air $[287 \mathrm{~J} / \mathrm{kg} \cdot \mathrm{K}]$ \\
\hline $\mathrm{c}_{\mathrm{p}}$ & specific heat of air at constant pressure $\left[1.004 \mathrm{~kJ} / \mathrm{kg}^{0} \mathrm{C}\right]$ \\
\hline$\lambda^{2}$ & gaussian width ratio $[1.157]$ \\
\hline
\end{tabular}

\section{Subscripts and Superscripts:}

\begin{tabular}{|l|l|}
\hline a & ambient \\
\hline c & convective \\
\hline ch & chemical \\
\hline cj & ceiling jet \\
\hline f & fire \\
\hline $\mathrm{g}$ & growth \\
\hline i & interface \\
\hline l & lower layer, target location \\
\hline $\mathrm{m}$ & maximum, mass specific \\
\hline o & origin \\
\hline $\mathrm{p}$ & plume \\
\hline $\mathrm{r}$ & radiative \\
\hline $\mathrm{s}$ & soot or smoke \\
\hline $\mathrm{u}$ & upper layer \\
\hline $\mathrm{x}$ & distance \\
\hline$*$ & non dimensional \\
\hline
\end{tabular}




\section{ACKNOWLEDGEMENTS}

Thanks go to the great folks at System Sensor for the monetary support, for the donation of equipment and assistance with the data gathering process.

Zenix Engineering provided monetary support, and assistance with preparing design drawings. Many thanks.

I would especially like to thank the group of employee volunteers from Zenix Engineering for taking time out of their personal lives on a Saturday to help with the construction of the platform at the test lab in Almonte. Thanks guys.

Thank you to the staff at the testing laboratory for their help and guidance.

To $\mathrm{Ba}$ for your help and to my supervisor George Hadjisophocleous for your guidance, thanks.

Of course I cannot begin to express proper gratitude for my wife Patricia and to my children, Harrison and Melissa for their loving patience throughout all of this. 


\section{Introduction}

Prediction of the time to activation of commercially available smoke detectors is not practical due to difficulties in modeling the movement of smoke in the early stages of fire growth when smoke detectors are expected to operate. There is a lack of correlations between optical density and detection time through either experimentation or manufacturer's available data [1]. As a result, guidelines for the placement of smoke detectors are limited to normal height ceiling applications [2,3]. The use and placement of smoke detectors in high ceiling/large room applications is not widely documented.

In the design of fire detection systems for the types of spaces in question, the designer must be able to answer the following two questions when considering the application of smoke detectors:

1. Is the use of smoke detectors appropriate for the space protected?

2. How should smoke detectors be placed to achieve the desired response?

These questions must be answered through a combination of experience and predictive measures taken by the designer. The following items should be considered when choosing smoke detectors as an early warning device in the design of a fire alarm system;

- Life Safety Criteria

- Smoke Generation and Transport

- Smoke Dilution and Ageing

- Detector Activation 
Several studies [4,5] have indicated that reducing spacing between smoke detectors may not significantly affect detection time.

A method for predicting smoke detector activation has been sought for some time [6,7]. Initially, a fuel dependent temperature change correlation was envisioned as an acceptable method by Heskestad and Delichatsios [4,7-10]. Other metrics like the Heskestad characteristic detector length [11] and later Davis and Cleary dwell and mixing time model [12,13] for predicting smoke detector activation time in the presence of a ceiling jet were introduced. A detector material response characteristic was envisioned by Bukowski and Averill [14]. A minimum ceiling jet velocity of $0.15 \mathrm{~m} / \mathrm{s}$ has been suggested as a detector sighting criteria [3]. Most recently, the Cleary method has been incorporated into the Fire Dynamics Simulator (FDS) model [15] to predict detector activation. Watanabe and Tanaka [16] developed maximum optical smoke density equations using buoyant plume theory and ceiling jet correlations. Davis and Reneke [17] developed similar correlations that predict smoke concentration in an unconfined ceiling jet. These methods do not incorporate findings that indicate different detector types respond to smoke in different ways [18] even though they are evaluated by the same criteria for listing purposes [19,20], nor do they incorporate the proprietary activation algorithms often included with modern smoke detectors by the equipment manufacturer in an attempt to compensate for false stimuli.

The aim of this research is to provide a correlation for fire plumes and ceiling jets to predict smoke detector activation in high ceiling applications. The test fires used are based on standard acceptance test fires used by Underwriters Laboratories in Canada [19] and the United States [20]. 


\section{Literature Review}

\subsection{Visibility}

It is considered common to encounter situations where the critical life safety design factor for exposure to smoke is visibility [21]. At optical densities low enough for effective movement of people in a smoke filled atmosphere, thermal and toxicity effects are often not severe enough to be a life safety concern. These three types of hazard have overlapping effects however. The disorientation caused by a lack of visibility requires increased amount of time for exiting, which in turn increases exposure to toxic gases and elevated temperatures.

Optical Density is the only criterion used to evaluate smoke detectors for listing purposes by testing laboratories [19,20]. Visibility through smoke depends on the optical density of smoke, which is characterized by the extinction coefficient $\alpha$ $\left(\mathrm{m}^{-1}\right)$. Through experimental work, Jin [22] provided the following relationship.

$$
S=\frac{K}{\alpha}
$$

Eq. 1

Where $S(m)$ is the visibility distance, $\alpha\left(\mathrm{m}^{-1}\right)$ is the extinction coefficient and $K$ is the proportionality constant. Jin offers values of $K=3$ for reflective signs and $\mathrm{K}=8$ for illuminated signs.

The extinction coefficient $\alpha$ is a measure of the transmission intensity of light over a distance, $l(\mathrm{~m})$ from the source to the target for a particular wavelength of light given by the expression of Bouguer's Law shown in Eq. 2 .

$$
\frac{I_{l}}{I_{0}}=e^{-\alpha l}
$$


Where $I$ is the intensity of light measured at the origin $\left(I_{0}\right)$ and target $\left(I_{\nu}\right.$.

An alternate measure of light obscuration is Optical Density per unit distance OD $\left(\mathrm{m}^{-1}\right)$.

$$
\frac{I_{l}}{I_{0}}=10^{-O D \cdot l}
$$

The relationship between optical density and the extinction coefficient can then be expressed as.

$$
O D=\frac{\alpha}{\ln (10)}=0.4343 \alpha
$$

The wavelength of light of common interest in research is that given by a $\mathrm{HeNe}$ laser, a value of $633 \mathrm{~nm}[23,24]$. The HeNe laser light source is commonly used to measure light extinction in smoke detection tests. The direct beam light source used for tests in this study is a near-infrared pulsed white light with a wavelength of $\approx 900 \mathrm{~nm}$. The light source has shown to provide more stable measurements with similar results than the HeNe source.[25,26]

Smoke detectors are evaluated by the ability to detect smoke within an optical density range measured in per cent obscuration per unit distance $\lambda\left(\mathrm{m}^{-1}\right)$. This value is related to the extinction coefficient and optical density through the various forms shown in Eq. 5 . 


$$
\begin{aligned}
\lambda & =100\left(1-\frac{I_{l}}{I_{0}}\right) \\
& =100\left(1-e^{-\alpha \cdot l}\right) \\
& =100\left(1-10^{-O D \cdot l}\right)
\end{aligned}
$$

We can show the visibility in terms of percent obscuration per unit distance by rearranging Eq. 5 to show the extinction coefficient in terms of the percent obscuration. This form is useful when making performance predictions.

$$
\alpha=\frac{-\ln \left(1-\frac{\lambda}{100}\right)}{l}
$$

Substituting the extinction coefficient into Eq. 1 we get visibility in terms of percent obscuration per unit distance.

$$
S=\frac{K l}{-\ln \left(1-\frac{\lambda}{100}\right)}
$$

The visibility can also be related to the percent obscuration per unit distance by substituting for $\alpha$ from Eq. 1 into Eq. 5.

$$
\lambda=100\left(1-e^{\frac{K l}{S}}\right)
$$

Eq. 8 
In order for a commercial smoke detector to be listed for use in Canada, it must pass both a smoke box test and room test [19]. In room tests, a paper fire with a maximum obscuration of $\lambda=29 \% / \mathrm{m}$, a liquid fuel fire with a maximum obscuration of $\lambda=35 \% / \mathrm{m}$ as well as a smouldering fire with an approximately uniform obscuration per meter of $\lambda=20 \% / \mathrm{m}$ are used to test smoke detectors. The flaming tests require response of the detector within 4 minutes, and the smouldering test requires smoke detector response prior to smoke obscuration per meter reaching $20 \% / \mathrm{m}$ within $15 \pm 3$ minutes.

These performance measurements translate to a visibility (S) for a reflective surface $(K=3)$ of between $7 \mathrm{~m}$ and $13.7 \mathrm{~m}$ and for an internally illuminated surface like an exit sign $(K=8)$ of between $18.6 \mathrm{~m}$ and $36.5 \mathrm{~m}$.

In the United States and in other countries that accept the UL test standard for commercial smoke detectors [20], the requirements are similar with the addition of a flaming fire wood crib test that exhibits a maximum obscuration of $\lambda=55.8$ $\% / \mathrm{m}$ and also requires detector activation within 4 minutes.

It follows then, that a specific minimum value for visibility is a logical performance metric for smoke detectors. The designer could select a distance within the range of smoke detectors deemed acceptable and relate the difference in visibility at the detector elevation to the visibility at the highest occupied elevation. Another option could be to select the minimum visibility required to be able to see an exit at the maximum allowable travel distance to an exit and relate the visibility from the highest occupied elevation to the visibility at the detector. Relating visibility to detector activation times is another matter entirely however, and musings of how to achieve this metric go on today [6]. 


\subsection{Smoke Density}

Visibility is not a value that can be modeled directly, nor is light extinction. Instead, researchers use values of mass yield of soot $\mathrm{Ys}(\mathrm{g} / \mathrm{g})$ and measure mass loss rates of fuels to determine the mass of smoke created. The value that can be modeled from these measurements is the mass concentration of soot in the hot gas layer in a fire $C_{s}\left(g / \mathrm{m}^{3}\right)$. The smoke concentration can be related to visibility through the mass specific extinction coefficient $\alpha_{\mathrm{m}}\left(\mathrm{m}^{2} / \mathrm{g}\right)$ for that fuel and method of combustion.

$$
\alpha=\alpha_{\mathrm{m}} \mathrm{C}_{\mathrm{s}}
$$

Mulholland and Croarkin [23] suggest that there is an almost universal value for mass specific extinction coefficient of $\alpha_{\mathrm{m}}=8.7 \mathrm{~m}^{2} / \mathrm{g}$ with an expanded uncertainty $\left(95 \%\right.$ confidence interval) of $1.1 \mathrm{~m}^{2} / \mathrm{g}$ for all fuels experiencing flaming combustion in over ventilated conditions. The theory supporting this is that soot from all flames is primarily carbon with a primary sphere size much smaller than the wavelength of light and a fractal dimension less than two. Under these conditions, the light absorption cross section is proportional to the soot mass concentration and is the dominant contributor to light extinction [23]. Other values have been suggested for flaming combustion of woods and plastics $\alpha_{\mathrm{m}}=7.6 \mathrm{~m}^{2} / \mathrm{g}$ and for smouldering of woods and plastics of $\alpha_{\mathrm{m}}=4.4 \mathrm{~m}^{2} / \mathrm{g}$ by Seader and Einhorn [27]. Mulholland and Croarkin offer a range of between 4 and $5 \mathrm{~m}^{2} / \mathrm{g}$ for mass specific extinction coefficient of smouldering combustion [23]. The value has shown to be more variable for smouldering combustion than flaming combustion. A partial reason for the difference is the transition from light scattering during smouldering combustion to light absorption during flaming combustion as the major contributor to light extinction [23]. 
Another measure of smoke density commonly used in the literature is termed the extinction area $\sigma\left(\mathrm{m}^{2}\right)$. The extinction area is also referred to as the absorption section area or just smoke. The extinction area in a volume of air denotes optical density.

$$
O D=\frac{\sigma}{V}
$$

The mass specific extinction area $\sigma_{\mathrm{m}}\left(\mathrm{m}^{2} / \mathrm{g}\right)$ is a measure of the total smoke produced per unit mass consumed in a fire. The value has been related to the mass specific extinction coefficient $[17,18]$ to produce a value for smoke yield.

$$
Y_{\text {smoke }}=\frac{\sigma_{m}}{\alpha_{m}}
$$

The mass specific extinction area is measurable by experiment through the burning of a known mass of fuel in a known volume to obtain the mass concentration of smoke and measuring optical density or through cone calorimeter measurement of optical density, flow rate and overall mass loss of fuel as described in ASTM E1354 [28].

Watanabe and Tanaka [16] describe mass specific absorption section area $\phi$ $\left(\mathrm{m}^{2} / \mathrm{g}\right)$ as the absorption section area of smoke in a unit mass of gas and relate gas mass density to optical density.

$$
O D=\rho \phi
$$

The common theme here is that smoke density in flaming fires can be described in terms of its tendency to absorb light as a cross sectional area within a volume. 


\subsection{Smoke Generation}

Smoke generation can be expressed as a mass generation rate $\dot{m}_{s}(\mathrm{~g} / \mathrm{s})$ or a light extinction area generation rate $\dot{S}\left(\mathrm{~m}^{2} / \mathrm{s}\right)$.

Smoke mass generation rate is a function of fuel mass burning rate $\dot{m}_{f}(\mathrm{~g} / \mathrm{s})$ and can be quantified when the fuel source is identified in a fire scenario. The soot yield fraction of a fuel $Y_{s}(g / g)$ is an expression of mass of soot created per unit mass of fuel burned. Assuming that soot is the only species generated that creates visible smoke, the mass generation rate of smoke is determined by:

$$
\dot{m}_{s}=Y_{s} \dot{m}_{f}
$$

This value can be translated into a mass concentration generation rate of smoke $\dot{C}_{s}\left(\mathrm{~g} / \mathrm{s}^{\cdot} \mathrm{m}^{3}\right)$ knowing the volume of the space contaminated $\mathrm{V}\left(\mathrm{m}^{3}\right)$

$$
\dot{C}_{s}=\frac{\dot{m}_{s}}{V}
$$

Another method of expressing smoke production is the smoke release rate $\dot{S}\left(\mathrm{~m}^{2} / \mathrm{s}\right)$. This value can be more directly measured using light extinction measurements as in a cone calorimeter according to the procedures described in ASTM E1354 [28]. The smoke release rate is obtained by measuring the optical density and volumetric flow rate.

$$
\dot{S}=\dot{V} \cdot O D
$$

When the mass loss over the entire test $(\mathrm{m})$ is measured, a mass specific extinction area value $\sigma_{\mathrm{m}}\left(\mathrm{m}^{2} / \mathrm{g}\right)$ is obtained. 


$$
\sigma_{m}=\frac{\int_{0}^{t} \dot{S} \cdot d t}{m}
$$

With the value of specific extinction area, we can express smoke production in terms of the mass loss rate of a steady state fire.

$$
\dot{S}=\sigma_{m} \dot{m}_{f}
$$

\subsection{Smoke Transport}

Enclosure fires can be modeled from an order of magnitude approach using algebraic equations from buoyant plume theory $[29,30]$ where the fire is modeled as a point source, with a region of persistent flame directly above the source, a region of intermittent flame above that, and an axisymmetric buoyant plume region reaching to the ceiling of the enclosure where a ceiling jet develops. This theory can be used to predict the height smoke will rise above a fire, the temperature and velocity above a fire and at radial distances from its centre. Systems of algebraic equations are available $[31,32]$ to model this phenomena but not smoke concentration. Two zone models like CFAST [33,34] provide optical density predictions for the upper layer, but don't account for phenomena like entrainment of air in the ceiling jet or agglomeration of smoke particles that can occur over time. Field models like FDS $[35,36]$ that are provided with turbulence or large eddy simulation models can predict obscuration $(\lambda)$ directly. This section of the report deals only with the order of magnitude approach, intended to provide the designer with a method to evaluate whether to proceed with more sophisticated computer modeling (discussed later).

\subsubsection{Plume}

Smoke transport depends on the buoyant properties of the fire plume. The correlations of Heskestad [30], McAffrey [37] or others can be used to determine 
the change in temperature $\Delta T(K)$, upward velocity $u(m / s)$ at the centreline of a fire plume and the plume radius $\mathrm{b}(\mathrm{m})$ at any height $\mathrm{z}(\mathrm{m})$ above the flame height l(m) [38]. The Heskestad plume equations are presented here. Refer to the idealized fire plume schematic presented in Figure 1.

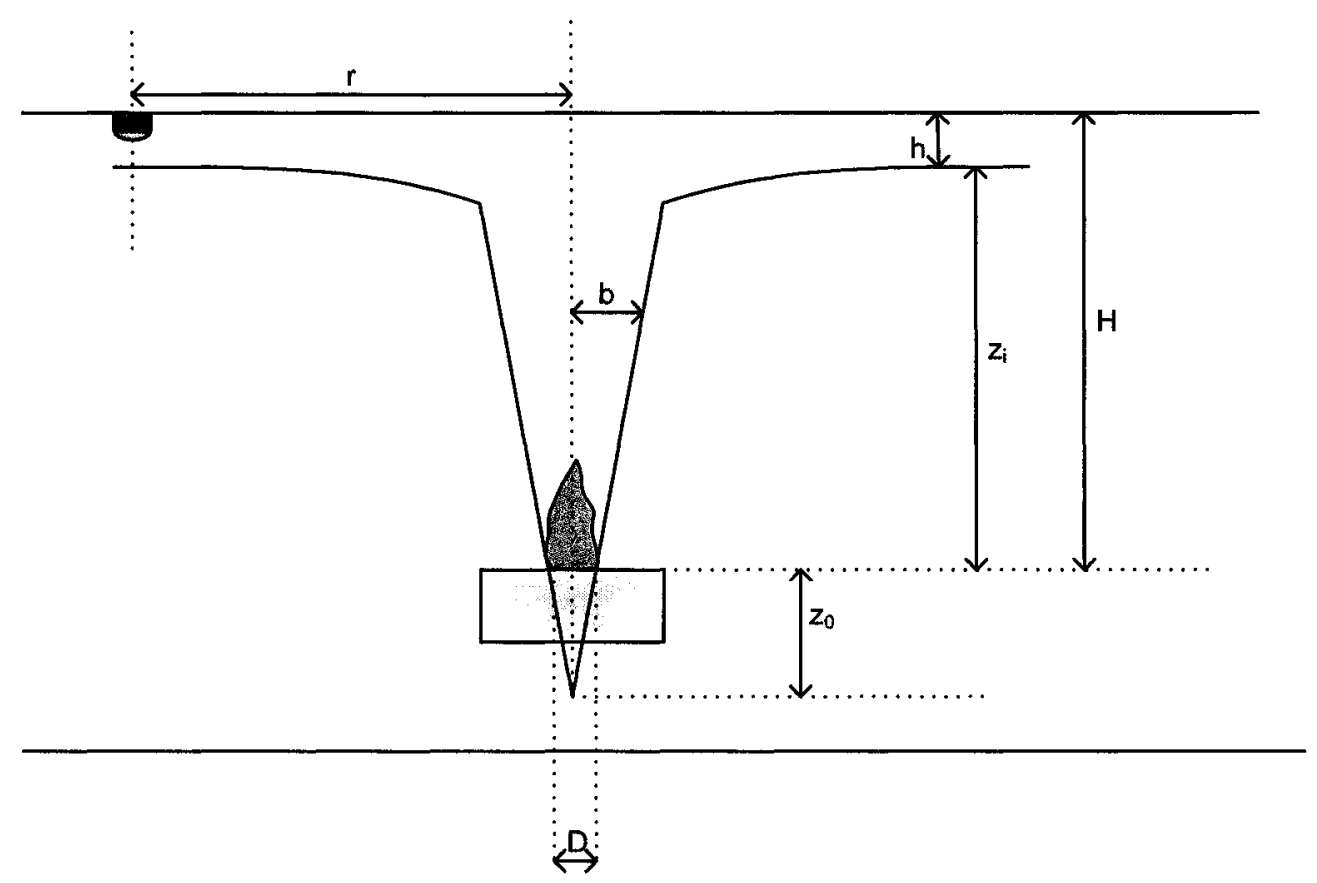

Figure 1 - Idealized fire plume

The flame height $1(\mathrm{~m})$ and virtual origin $z_{0}(\mathrm{~m})$ equations, when the fire is modeled as a point source are.

$$
\begin{gathered}
l=0.235 \dot{Q}^{2 / 5}-1.02 D \\
z_{0}=0.083 \dot{Q}^{2 / 5}-1.02 D
\end{gathered}
$$

Where $\dot{Q}(\mathrm{~kW})$ is the heat release rate and $\mathrm{D}(\mathrm{m})$ is the diameter at the base of the fire. These equations make use of the overall heat release rate whereas the remainder of the plume correlation equations make use of the convective portion 
of the heat release rate $\dot{Q}_{c}(\mathrm{~kW})$. The difference between the two values depends on the radiative fraction of the flame $\chi_{\mathrm{r}}$ as expressed below.

$$
\dot{Q}_{c}=\dot{Q}\left(1-\chi_{r}\right)
$$

The maximum axial temperature change $\Delta \mathrm{T}_{\mathrm{m}}(\mathrm{K})$ above the flame height is.

$$
\Delta T_{m}=9.1\left(\frac{T_{0}}{g c_{p}^{2} \rho_{0}^{2}}\right)^{1 / 3} \dot{Q}_{c}^{2 / 3}\left(z-z_{0}\right)^{-5 / 3}
$$

Where $\Delta T_{m}=T-T_{0}, T(K)$ is the temperature at the height of interest, $T_{0}(K)$ is the ambient temperature, $g$ is gravitational acceleration $\left(9.81 \mathrm{~m} / \mathrm{s}^{2}\right), \mathrm{c}_{\mathrm{p}}$ is the specific heat of air $(1.004 \mathrm{~kJ} / \mathrm{kg} . \mathrm{K}), \rho_{0}$ is the ambient density of air $\left(\mathrm{kg} / \mathrm{m}^{3}\right)$, and $\mathrm{z}$ is the height of interest.

The maximum upward axial velocity $u_{m}(\mathrm{~m} / \mathrm{s})$ above the flame height is.

$$
u_{m}=3.4\left(\frac{g}{c_{p} T_{0} \rho_{0}} \frac{\dot{Q}_{c}}{\left(z-z_{0}\right)}\right)^{1 / 3}
$$

The radius of the plume $\mathrm{b}(\mathrm{m})$ not far above the flame where the temperature is half of its centreline value is.

$$
b(z)=0.12\left[\frac{T(z)}{T_{0}}\right]^{1 / 2}\left(z-z_{0}\right)
$$


Davis and Reneke [17] used the Heskestad plume equations to determine the smoke concentration $\mathrm{C}_{\mathrm{sp}}(\mathrm{z})\left(\mathrm{kg} / \mathrm{m}^{3}\right)$ within the plume up to the interface height $\left(z_{i}\right)$. They assumed a Gaussian shape of the temperature, velocity and smoke profiles in the radial direction. The essence of their derivation is shown below, with the result given as Eq. 28. The smoke mass flux at an elevation $\mathrm{z}(\mathrm{m})$ can be expressed in terms of smoke concentration and velocity.

$$
\dot{m}_{s}(z)=\int C_{s p}(r, z) u_{z}(r, z) 2 \pi r \cdot d r
$$

Where the mass concentration of smoke and the velocity of the plume are assumed to have Gaussian profiles.

$$
\begin{gathered}
C_{s p}(r, z)=C_{s p 0}(z) e^{-\left(r^{2} / \lambda^{2} \sigma^{2}\right)} \\
u(r, z)=u_{z m} e^{-\left(r^{2} / \sigma^{2}\right)}
\end{gathered}
$$

By substituting into Eq. 24 and integrating they arrived at the centreline smoke concentration within an axisymmetrical plume Eq. 27.

$$
C_{s}(z)=\frac{\dot{m}_{s}(z)\left[\frac{\lambda^{2}+1}{\lambda^{2}}\right]}{u(z) \pi \sigma^{2}}
$$

Where $\dot{m}_{s}(z)$ is the smoke mass flux at the height of interest; $\lambda$ is the Gaussian width ratio for the velocity and temperature profiles $\lambda^{2}=1.157$ and $\sigma=1.201 \mathrm{~b}$ is the plume radius where the temperature drops to $1 / \mathrm{e}$ of the centreline value. Substituting the Heskestad equations for velocity $u$, and plume radius b, Eq. 27 becomes. 


$$
C_{s}(z)=\frac{8.403 \dot{m}_{s}}{\left(\frac{g}{c_{p} T_{0} \rho_{0}}\right)^{1 / 3} \dot{Q}_{c}^{1 / 3} \frac{T(z)}{T_{0}}\left(z-z_{0}\right)^{5 / 3}}
$$

Smoke mass concentration can be expressed in terms of heat release rate instead of smoke generation rate by substituting the smoke yield $\left(\mathrm{Y}_{\mathrm{s}}\right)$ and heat of combustion $\left(\Delta \mathrm{H}_{\mathrm{ch}}\right)$ into Eq. 28 using the relationship

$$
\dot{m}_{s}=\frac{Y_{s} \dot{Q}}{\Delta H_{c h}}
$$

\subsubsection{Stratification}

Stratification occurs when unmixed air within an enclosure is separated into thermal layers as may result in high open spaces, where thermal gradients are large, with certain HVAC arrangements, in glass atria, etc. When fire gases cool due to the entrainment of ambient air as the plume rises, there is a point eventually reached where there is no temperature difference between the temperature of the plume and the ambient temperature at a particular height. As a result, the smoke looses buoyancy and forms a layer with a maximum height below that of the ceiling (depicted in Figure 2). Since smoke detection obviously relies on smoke reaching the detector, stratification is an important factor to consider when determining the effectiveness of smoke detectors and their placement within an enclosure. 


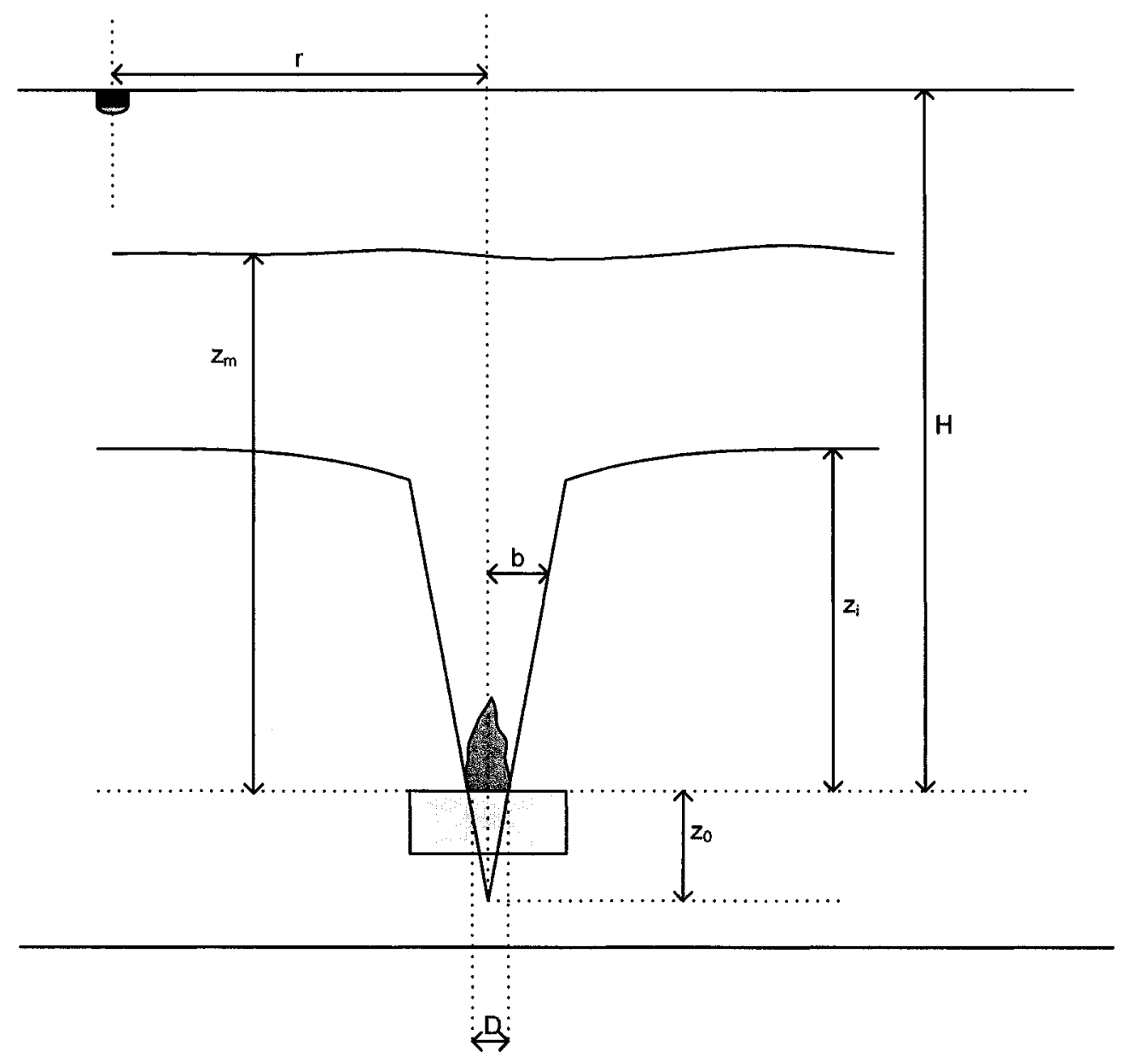

Figure 2 - Stratified Environment

This phenomenon can be predicted by knowing the temperature gradients within an enclosure and the heat release rate of a given design fire. The maximum height $z_{m}(\mathrm{~m})$ that smoke is expected to rise above a fire is given by Eq. 30 [30] where the ambient temperature gradient is given by $d T_{0} / d q$ :

$$
z_{m}=3.79\left[\frac{T_{0}}{g\left(\rho_{0} c_{p}\right)^{2}}\right]^{1 / 8} \dot{Q}_{c}^{1 / 4}\left(\frac{d T_{0}}{d z}\right)^{-3 / 8}
$$


Where the average gradient is linear at standard temperature and pressure, the maximum height smoke will rise above the fire surface is given by Eq.31 [3,39].

$$
z_{m}=5.54 \dot{Q}_{c}^{1 / 4}\left(\frac{\Delta T_{0}}{H-z_{0}}\right)^{-3 / 8}
$$

Where $\Delta T_{0}(K)$ is the difference between the ambient temperature at the ceiling smoke detector and the ambient temperature at the fire surface.

\subsubsection{CeilingJet}

If a fire is large enough that the plume reaches the ceiling, a ceiling jet will form above the fire and will propagate radially under the ceiling from the centreline of the fire unless affected by obstructions, ceiling height variations or forced airflows. The work of Alpert [40] Heskestad and Delichatsios [41] as well as others provides temperature and velocity correlations for ceiling jet flows. These correlations are for rooms without an appreciable smoke layer. It has been assumed that smoke mass moves like any other mass fraction, driven by temperature induced pressure differences caused by the fire $[16,17,42]$.

Alpert [43] offers a mix of the Heskestad correlations for excess temperature as well as the Alpert correlations for the velocity as the recommended set of equations for ceiling jets.

where $\mathrm{r} / \mathrm{H} \leq 0.2 \quad \Delta T=\frac{6.3 T_{0}^{1 / 3} \dot{Q}_{c}^{2 / 3}}{\left(\rho_{0}^{2} c_{p}^{2} g\right)^{1 / 3}\left(H-z_{0}\right)^{5 / 3}}$ 
where $0.2 \leq \mathrm{r} / \mathrm{H}<4.0$

$$
\Delta T=\frac{T_{0}^{1 / 3} \dot{Q}_{c}^{2 / 3}}{\left(\rho_{0}^{2} c_{p}^{2} g\right)^{1 / 3}\left(H-z_{0}\right)^{5 / 3}\left(0.225+0.27 \frac{r}{H}\right)^{4 / 3}}
$$

where $\mathrm{r} / \mathrm{H} \leq 0.17 \quad u=\frac{3.61}{\left(\frac{\rho_{0} c_{p} T_{0}}{g}\right)^{1 / 3}}\left(\frac{\dot{Q}_{c}}{H-z_{0}}\right)^{1 / 3}$

where $0.17 \leq \mathrm{r} / \mathrm{H}<4.0$

$$
u=\frac{1.06}{\left(\frac{\rho_{0} c_{p} T_{0}}{g}\right)^{1 / 3}}\left(\frac{\dot{Q}_{c}}{H-z_{0}}\right)^{1 / 3}\left(\frac{H-z_{0}}{r}\right)^{0.69}
$$

Davis and Reneke [17] also developed a ceiling jet correlation for smoke concentration $C_{s}(r)\left(\mathrm{kg} / \mathrm{m}^{3}\right)$ using Alpert's original temperature correlation where $r>0.18 \mathrm{H}$. That correlation is slightly modified here to incorporate the currently recommended correlation by Alpert from Eq. 35 .

where $0.17 \leq \mathrm{r} / \mathrm{H}<4.0$

$$
C_{s}(r)=0.216\left(\frac{H}{r}\right)^{0.71} C_{s}(H)
$$

Eq. 36

Where $C_{s}(r)\left(\mathrm{kg} / \mathrm{m}^{3}\right)$ is the maximum mass concentration of smoke at a distance $r$ from the fire plume centreline within the ceiling jet. With the value of mass specific extinction coefficient $\left(\alpha_{\mathrm{m}}\right)$ either known or assumed, the smoke concentration can be related to the extinction coefficient using Eq. 9.

$-17-$ 
Watanabe and Tanaka [16] developed equations to predict smoke concentration in a ceiling jet in the presence of a smoke layer in the form of extinction area per unit mass. They made the same assumption as Davis and Reneke that the smoke profile and heat profile are the same and apply a conservation equation to the average absorption section area. The difference between the correlations is that this one requires information about smoke production section area $\dot{S}$ rather that mass of soot production $\dot{m}_{s}$. Watanabe and Tanaka offer the value of maximum mass specific absorption section area in the ceiling jet prior to the development of a smoke layer of.

$$
\phi_{m}(r, H)=\left(\frac{\dot{S} c_{p}}{\dot{Q}_{c}}\right) \Delta T(r, H)
$$

When $\sigma_{\mathrm{m}}$ is known, Eq. 37 can be expressed as

$$
\phi_{m}(r, H)=\left(\frac{\sigma_{m} c_{p}}{\Delta H_{c}}\right) \Delta T(r, H)
$$

Since these smoke production values are available for the types of fires used in this study from the smoke characterization project [18] and values for specific extinction area $\sigma_{\mathrm{m}}\left(\mathrm{m}^{2} / \mathrm{g}\right)$ are provided we are able to use the Watanabe and Tanaka equations to compare predicted values of percent obscuration against the Davis and Reneke method.

When heat release rate, temperature rise, velocity and smoke concentration are cast in the form of normalized non-dimensional equations, the comparison with other correlations is made easier. The non-dimensional forms of the equations are indicated by the asterisk *. They rely on the following definitions provided by Yamauchi et al and Alpert $[42,43]$. 


$$
\begin{gathered}
\dot{Q}^{*}=\frac{\dot{Q}}{\rho_{0} c_{p} T_{0} \sqrt{g}\left(H-z_{0}\right)^{5 / 2}} \\
T^{*}=\frac{\Delta T / T_{0}}{\left(Q^{*}\right)^{2 / 3}} \\
u^{*}=\frac{u / \sqrt{g\left(H-z_{0}\right)}}{\left(Q^{*}\right)^{1 / 3}} \\
C_{s}^{*}=\frac{C_{s}}{\dot{m}_{s}} \frac{\dot{Q}}{\rho_{0} c_{p} T_{0}\left(\dot{Q}^{*}\right)^{2 / 3}}
\end{gathered}
$$

Alpert's recommended ceiling jet correlation equations when cast in nondimensional form are [43]

$$
\begin{array}{lc}
\text { for } 0.2 \leq \mathrm{r} / \mathrm{H}<4.0 & \Delta T^{*}=\left(0.225+0.27 \frac{r}{H}\right)^{-4 / 3} \\
\text { for } \mathrm{r} / \mathrm{H} \leq 0.2 & \Delta T^{*}=6.3 \\
\text { for } 0.17 \leq \mathrm{r} / \mathrm{H}<4.0 & u^{*}=1.06\left(\frac{r}{H}\right)^{-0.69} \\
\mathrm{r} / \mathrm{H} \leq 0.17 & u^{*}=3.61
\end{array}
$$

When expressed in non-dimensional form, the Davis and Reneke smoke concentrations are:

$-19-$ 
for $\mathrm{r} / \mathrm{H} \leq 0.2$

$$
C_{s}^{*}=8.403 \frac{T_{0}}{T_{H}}
$$

$$
\text { for } 0.2 \leq \mathrm{r} / \mathrm{H}<4.0 \quad C_{s}^{*}=2.398\left(\frac{H}{r}\right)^{0.71} \frac{T_{0}}{T_{H}}
$$

\subsubsection{Smoke Transport Lag}

Once it has been determined that a fire is likely to reach a detector under the ceiling, plume theory and ceiling jet correlations can be used to determine the plume time lags. The time lag for transport of the fire plume to reach the ceiling and follow a ceiling jet until it reaches a detector has at least two components. The time lag for smoke to enter a detector chamber and be detected as well as the time from detection to activation of alarm signals are further factors to consider. Mowrer [44] developed plume and ceiling jet transport time lag equations for quasi steady state fires and growing fires.

For quasi steady state fires the following apply.

For the plume

$$
t_{p}=0.67 \frac{H^{\frac{4}{3}}}{\dot{Q}^{\frac{1}{3}}}
$$

where $t_{p}(s)$ is the transport time of fire plume, $H(m)$ is the height of ceiling above the top of the fuel, and $\dot{Q}(\mathrm{~kW})$ is the heat release rate of the fire. 
For the ceiling jet

$$
t_{c j}=0.833 \frac{r^{\frac{11}{6}}}{\dot{Q}^{\frac{1}{3}} H^{\frac{1}{2}}}
$$

where $t_{c i}(s)$ is the transport time of the ceiling jet, and $r(m)$ is the radial distance from the fire centre line to the detector.

While Mowrer developed equations for growing fires also, for most fires, and specifically the ones under consideration here, the use of a computer model is the practical way to make such estimates. It should be noted that the values estimated by the methods presented here would not be conservative. They will return the shortest possible lag time from the fires studied rather than the longest.

\subsection{Ceiling Slope}

Ceiling slope affects the movement of smoke differently in the upward slope direction and the downward slope direction and these differences are magnified by the slope of the ceiling [10]. Sugawa et. al [45] developed correlations related to the work of Alpert as well as Heskestad and Delichatsios that account for the slope of a smooth ceiling for temperature and velocity in the ceiling jet.

$$
\begin{array}{crc}
\Delta T^{*}=(0.41+0.4 y \operatorname{Cos} \theta / H)^{-4 / 3} & \text { for } 0<\theta<90^{\circ} & \text { Eq. } 51 \\
u=\alpha \frac{H}{H+2 r \cdot \operatorname{Cos} \theta} \sqrt{\Delta T / T_{0} \cdot g H} & \text { where } \alpha \sim 3 / 4 \text { to } 7 / 8 & \text { Eq. } 52
\end{array}
$$

Ceiling obstruction experiments for sprinkler activation conducted by Vettori [46] also showed temperature and activation times are indirectly proportional to ceiling slope. 


\subsection{Beams and other Barriers}

Sufficiently deep beams on level ceilings affect the movement of smoke by slowing the velocity of smoke perpendicular to beam channels, allowing for increased temperatures to exist [10]. Beams on sloped ceilings magnify the affect of the slope when they are parallel to the slope and redirect the flow laterally when they are perpendicular to the ceiling slope [10]. In high bay spaces such as aircraft hangars with ceiling heights up to $20 \mathrm{~m}$, it has been shown that beam depths of $0.25 \mathrm{~m}$ have no effect on the actuation of spot type fire detectors [5]. It has been shown that ceiling pockets slow smoke spread, but increases in temperature, velocity and density of smoke in the areas of the underside of beams tend to offset this for the detection of smoke so that it is almost the same as on smooth ceilings [47]. Some findings for corridor experiments were validated by a later study [48] but concerns were raised that performance criteria for smoke detectors should be established to include fire size, fuel type and detection time metrics. Ceiling obstruction experiments for sprinkler activation conducted by Vettori [46,49] also showed temperature and activation times are increased where beams are installed compared to smooth ceilings.

\subsection{Ceiling Openings and Ventilation}

Ceiling openings can be modeled using Cooper's model [50], which takes into account both pressure driven forces and gravitational forces affecting smoke movement through vertical openings. While the Cooper model provides an estimate of the flow rate through a vent, it does not predict the effect of this flow on the ceiling jet in the vicinity of the vent. It is clear however that the effect of flow through horizontal ceiling vents is the reduction in smoke concentration downstream within the ceiling jet proportional to the distance from the opening(s). 
Forced ventilation through return air grilles and ducts or plenum spaces has a similar effect as a ceiling opening, but the effect can be increased due to the ventilation scheme used. Forced ventilation can also direct air away from the ceiling or towards it, which has the effect of mixing air in a space and increasing the entrainment of fresh air significantly. Forced ventilation can also change flow patterns in a horizontal plane, forcing the air to become faster, more turbulent etc.

There are no practical methods for estimating the effect in the vicinity of openings or for forced ventilation scenarios for hand calculations that can be an accurate predictor. Modeling of these phenomena is limited to computer methods. From a practical perspective, the placement of smoke detectors where air currents are unpredictable and should be avoided.

\subsection{Ageing}

As smoke ages it tends to agglomerate forming relatively larger, yet fewer particles. In one experiment [23], collecting smoke from burning crude oil in a 1 $\mathrm{m}^{3}$ chamber and measuring the specific extinction as a function of time over a period of about $1 \mathrm{~h}$ showed that the average cluster size grew form about 200 to about 4000 primary spheres with a change in specific extinction of about $\sigma_{\mathrm{m}}=$ $0.33 \mathrm{~m}^{2} / \mathrm{g}$. This effect is relatively small compared to the affect that combustion type has on particle size, with smouldering combustion fires yielding values in the range of 4 to $5 \mathrm{~m}^{2} / \mathrm{g}$ [23].

\subsection{Detector Activation}

The purpose of this project is not to predict activation times of detectors but rather to predict the relative difference in time detectors activate at varying ceiling heights. An understanding of detector activation in general is necessary however to be able to make these relative predictions. 


\subsection{Detector Response}

An extensive study of smoke detector performance [18] determined that smoke detectors are sensitive to the number of particles and the mean particle diameter, but revealed differences in the relative sensitivity of detector outputs depending on the detection technology.

Ionization smoke detectors outputs $(\Delta \mathrm{MIC})$ were found to be linearly proportional to both the particles size and number (Eq. 53). Light scattering photoelectric detector outputs (SP) were linearly sensitive to the number of particle count, but the particle size had a second order effect on the detector output (Eq. 54). Direct optical density measurement detector outputs (OD/1) were linearly sensitive to particle count but the particle size had third order effects on the detector outputs (Eq. 55).

$$
\begin{array}{ll}
\Delta M I C \propto \overline{d n} & \text { Eq. } 53 \\
S P \propto \sum n_{i} d_{i}^{2} & \text { Eq. } 54 \\
\frac{O D}{l} \alpha \sum n_{i} d_{i}^{3} & \text { Eq. } 55
\end{array}
$$

Where $d$ and $n$ represent the mean values of collections of diameter and particle count data while $n_{i}$ and $d_{i}$ represent individual particle number and diameter counts.

It can be inferred by this data that detectors remote from fires, especially small fires, where particle numbers are reduced and diameters are increased by the time it reaches a detector, will be more sensitive to changes in the environment in the order of ionization, photo scattering and then direct photo detectors. 


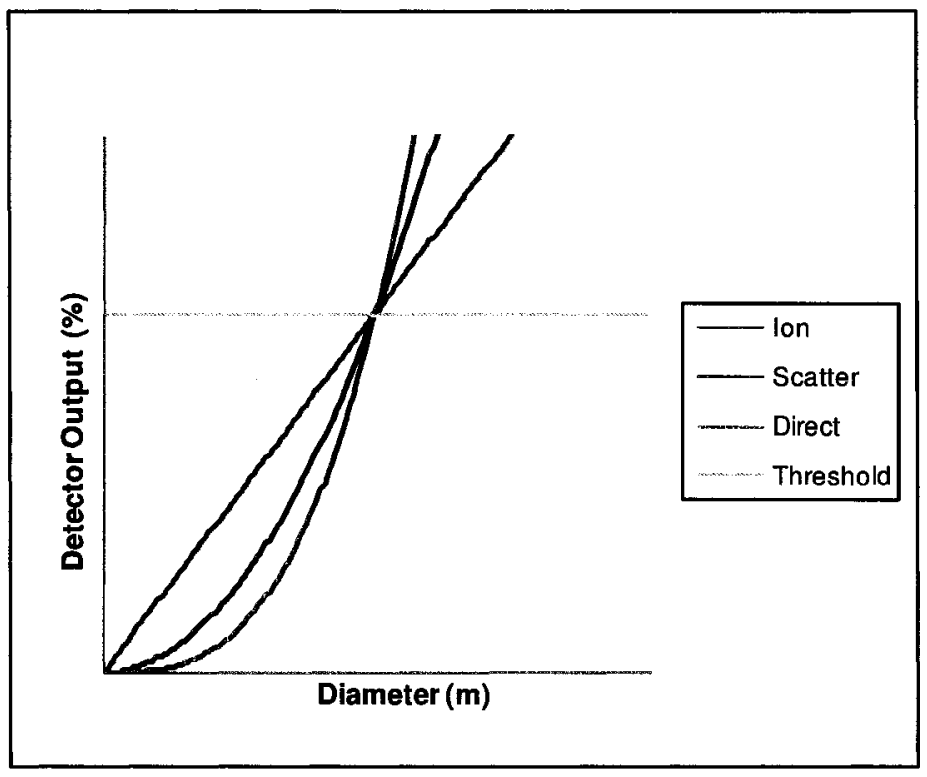

Figure 3 - Smoke Detector Response

The findings of the study indicated that flaming combustion produced smaller particle sizes and fewer particles than does non-flaming combustion. Ionization type detectors acted faster than photoelectric detectors in flaming fire situations and visa versa for non-flaming fires.

Figure 3 shows a plot of the response of smoke detectors types based on equations $53-55$. The figure shows that, for a given sensitivity, each type of detector could arrive at the same alarm threshold at the same time, but with different approaches. Differences in the way a detector reacts to these phenomena could be used to prepare more sophisticated detection decision algorithms. Predicting the particle count and size distribution of smoke in the vicinity of a smoke detector could lead to more accurate predictions of activation time. 


\subsection{Detector Time Lag}

Physical characteristics of smoke detectors introduce a detector activation delay represented by the difference in smoke density outside the detector and the smoke density inside the detector. These characteristics have been studied by Heskestad [51], who proposed a detector characteristic length for smoke detectors that accounts for entry delay. Cleary et al [13] proposed a more detailed model involving a dwell time $\delta \mathrm{t}(\mathrm{s})$ and mixing time $\tau(\mathrm{s})$. The times are governed by the velocity of the ceiling jet $u$ and the physical characteristics of the detector to resist entry to and then mix within the detection chamber represented by constants a and b respectively in Eq. 56 and Eq. 57. The exponents $\mathrm{c}$ and $\mathrm{c}^{\prime}$ are not necessarily the same.

$$
\begin{aligned}
& \delta t=a u^{-c} \\
& \tau=b u^{-c^{\prime}}
\end{aligned}
$$

The values for the four constants can be experimentally determined for any given detector using the fire emulator/detector evaluator (FE/DE) developed by NIST [52] through measurement of detector outputs and optical density at various flow rates. For higher velocities, the mixing time can be ignored and the dwell time can be estimated as a constant value. For a particular photoelectric detector, Cleary et al [13] found that at air velocities greater than $0.5 \mathrm{~m} / \mathrm{s}$ the dwell time was below $10 \mathrm{~s}$ and the mixing time was essentially zero. For this detector they found $\mathrm{a}=1.8, \mathrm{~b}=0.97, \mathrm{c}=1$ and $\mathrm{c}^{\prime}=0.76$.

One study has suggested the minimum velocity of smoke past a detector of 0.15 $\mathrm{m} / \mathrm{s}$ as performance criteria [53]. Brozovski also suggested a time lag of less than 10 seconds for ceiling jets of velocities greater than $0.15 \mathrm{~m} / \mathrm{s}$. The best fit to Brozovsky's experimental data was a form of equation similar to that of 
Heskestad. [ $\Delta \mathrm{t}=0.8 /(\mathrm{u}-0.075)]$. Keski-Rahkonen [54] used Brozovsky's data to try to explain the relationship between ceiling jet velocity and smoke detector lag time but could not. Keski-Rahkonen attempted to account for a 'non Newtonian' fluid flow characteristics assertion through smoke detectors by suggesting that the charged particles are affected in some way as they enter the detector.

In order for smoke detectors to become listed by ULC [19], the smoke entry resistance is measured to ensure that the detector will operate within a flow field of 0.15 to $0.18 \mathrm{~m} / \mathrm{s}$ of smoke with an obscuration of 1.6 to $13.1 \% / \mathrm{m}$.

\subsection{Detection Algorithm}

A commercial smoke detector is often equipped with more than one sensing element to improve its performance in detecting combustion particles while reducing its response to false stimuli. The particle distribution of smoke has a lower and an upper limit that make detectors more susceptible to reaction from false stimuli [55]. The environment of a detector affects its sensitivity over time due to the accumulation of deposits on the sending or receiving elements of a device. Electromagnetic and radio frequency interference are transient effects that can change the way a device operates or how it communicates with a control panel. Environmental extremes of temperature and humidity also affect the way a detector operates. In an attempt to overcome some of these environmental variables, manufacturers of smoke detectors have designed devices with microprocessor electronics that constantly measure the characteristics within the sensing chamber and compare the data over time against known false stimuli like the transient rise in light obscuration resulting from a disturbance of dust or puff of cigarette smoke. 
Conversely, if the detector were to sense an increasing rise in light obscuration with a higher rate over a longer period of time, the theory is that it could determine that is was sensing a fire even before the required maximum value reached for listing of the device and initiate an alarm signal. A time lag $t_{\text {alg }}$ associated with the trend processing of the smoke would theoretically have a negative number, thereby reducing the time for detection in the presence of recognized fire stimuli.

\subsection{Total Detection Time}

Detector activation in the presence of a ceiling jet with a smoke concentration at least high enough to set the detector off can be predicted by summing all of the detection time lags together from equations Eq. 49, Eq. 50, Eq. 56, and Eq. 57 as well as the algorithm time lag.

$$
\mathrm{t}_{\mathrm{Det}}=\mathrm{t}_{\mathrm{p}}+\mathrm{t}_{\mathrm{cj}}+\delta \mathrm{t}+\tau+\mathrm{t}_{\mathrm{alg}}
$$

\subsection{Modeling}

Modeling smoke detector performance is the basis for being able to predict activation times. Modeling can take the form of algebraic equations developed through empirical data, making use of buoyant plume theory and ceiling jet correlations [31]. It could take the form of computer zone models such as CFAST $[33,34]$ that use numerical methods to solve a system of ordinary differential equations governing heat and mass transfer. Modeling can be in the form of computational fluid dynamics using more sophisticated computational techniques such as FDS $[35,36]$. All three forms of modeling are used here to provide a relative comparison among methods.

\subsubsection{Algebraic modeling}

An algebraic model titled the 'Fire Dynamics Tools' (FDT) is available from the U.S. Nuclear Regulatory Commission (NRC) [31]. Section 11.5 of the tool set 
provides 3 methods to determine the activation time of a smoke detector. The Alpert, Mowrer and Milke methods are presented that assume a steady state fire without forced ventilation or significant obstructions and detectors at or near the ceiling. FDT and another algebraic model FIVE-Rev1 [56] were validated by the U.S. NRC and the Electrical Power Research Institute (EPRI) along with zone models and computational fluid dynamics models [57,58]. Neither smoke concentration, nor visibility predictions were performed using the algebraic models.

Davis and Reneke [17] used Alpert's work [40] and Yamauchi's work [59] to develop algebraic equations for maximum smoke concentration in the fire plume (Eq. 28) and ceiling jet (Eq. 36) prior to a smoke layer developing.

Watanabe and Tanaka [16] developed a similar algebraic equation that predicts maximum mass specific absorption section area in the ceiling jet prior to the development of smoke layer (Eq. 38).

An algebraic model is offered here that predicts smoke concentration, velocity time lag and activation times for flaming steady state fires in well-ventilated conditions prior to the development of a smoke layer.

1. The first step is to determine whether smoke will reach the ceiling and form a ceiling jet or if stratification will occur using Eq. 30 .

2. If the maximum predicted height of the plume is at least that of the enclosure then determine the maximum smoke concentration at the maximum detector distance from the fire location using Eq. 28 and Eq. 36 as appropriate. Alternately, predict the maximum mass specific absorption section area using Eq. 38 . 
3. Convert the predicted values to equivalent minimum obscuration values using Eq. 5, Eq. 9 and Eq. 12 to compare against the maximum obscuration levels specified.

4. Next, predict the time to activation of the smoke detector using Eq. 58 and compare with the predicted detection time of a baseline detector $(\mathrm{H}=3, \mathrm{r}=4.9)$ for the same fire and its time limit for detection based on standard acceptance criteria. (240 seconds for flaming fires).

If all of the conditions outlined indicate smoke detector activation within an acceptable time frame then the smoke detector spacing is recommended for use.

If the method outlined does not fit the scenario being evaluated due to conditions of geometry, ventilation, fire growth type, fuel etc., or if predicted values are outside safety margins then zone or computational fluid dynamics modeling methods are recommended to evaluate the scenario.

\subsubsection{Zone modeling}

CFAST $[33,34]$ is a commonly used zone modelling software developed by the National Institute of Standards and Technology (NIST). The software solves the coupled time dependent ordinary differential equations for mass and energy conservation in a two-zone mode. The model includes a ceiling jet sub-model to resolve heat transfer to the ceiling. Sub models for the direct prediction of smoke detector activation are not yet available in CFAST, so additional calculations are required to predict detector activation time for smoke detectors within the ceiling jet.

Early modelling of smoke detector activation that used zone models such as CFAST, FPEtool and LAVENT [60], relied on temperature predictions by the models and then temperature correlation equations were used to predict smoke 
detector activation [61]. Comparison of these models with experiments in a Hangar with 15-m ceilings (Barbers Point, Hawaii) showed that smoke detectors operated at temperature increases lower than default values of the software and varied for different size of fires. Also noted was the fact that these models did not account for transport time in the predictions.

The U.S. NRC and EPRI conducted validation tests of CFAST (ver 6.0.5) and MAGIC (ver 4.1.1b) zone models [57,58]. Validation results using CFAST resulted in $50 \%$ difference or more between the measured smoke concentrations and those predicted using the model. The differences were attributed to the measurement errors in light extinction, path length, soot yield predictions, and mass specific extinction coefficients used. MAGIC results indicated $30 \%$ difference or more between measured smoke and those predicted by the model. Both models over-predicted smoke concentration in these tests.

Davis, et al [12] developed algebraic equations for maximum smoke concentration at the plume centreline, within the turning region and ceiling jet in the presence of a smoke layer. Watanabe and Tanaka [16] developed equations for optical smoke density in a ceiling jet in the presence of a smoke layer.

Yamauchi et al [42] developed equations for the prediction of smoke concentration in a ceiling jet in the presence of a smoke layer intended for use with any two-zone computer model. The method is used to determine ceiling jet correlations and equivalent source strength values for temperature, velocity and smoke concentration.

CFAST version 6 offers a ceiling jet sub-model based on the work of Cooper [62] in addition to the McAffrey [63] plume. The model tracks soot generation based on the model input ratio of carbon to carbon-dioxide yield ratio. The model also tracks soot transport and concentration in the upper layer. CFAST reports OD 
in the upper layer as a conversion from the soot mass concentration it tracks. The value of $\mathrm{OD}$ is obtained by multiplying the soot mass concentration $\mathrm{C}_{\mathrm{s}}$ by $3817 \mathrm{~m}^{2} / \mathrm{kg}$. The authors of the CFAST user guide [34] indicate the value is taken from Mulholland and Croarkin [23].

There is a slight discrepancy between the multiplier used to provide the optical density and my calculations however. The reported value for mass specific extinction coefficient of $\alpha_{\mathrm{m}}=8.7 \mathrm{~m}^{2} / \mathrm{g}$ is provided by Mulholland and Croarkin. Using the relationship between OD and $\alpha$ from Eq. 4 as well as the relationship between $\alpha$ and $\mathrm{C}_{\mathrm{s}}$ from Eq. 9 we can see that OD can be shown as in Eq. 59.

$$
O D=\frac{\alpha_{m} C_{s}}{\ln (10)}=3778 C_{s}
$$

Eq. 59

Since there is only a $1 \%$ difference in the multiplier, we will use the reported value of 3817 from reference 34 .

\subsubsection{CFD modeling}

A literature review of one-zone and two-zone models and CFD models conducted by Bounagui and Bénichou [64] heralds CFD over zone models, but recommends more flexibility, heat release validation and parallel processing for FDS field models.

Ierardi and Barnett [65] have recommended that improvements in CFD codes be implemented that include;

- An aerosol dynamics sub-model which includes agglomeration, sedimentation and deposition, 
- Additional variables for particle size and number concentration,

- Characterization of detection hazards as a source of energy and mass which is compatible with the aerosol dynamics sub-model, and

- Characterization of sensor modulation related to combustion byproducts.

In 2004 Gobeau and Zhou [66] used the CFD model CFX, which made use of a $\mathrm{k}-\varepsilon$ turbulence model to evaluate 3 spaces (an underground station, an offshore accommodation module, and a building under construction). They felt that large eddy simulation (LES) was too computationally expensive for practical use.

High bay hangar tests have been modelled for temperature distribution [4] using HARWELL-FLOW3D CFD [67] program. A NASA high bay lab was modeled, with FLOW3D using temperature correlation and mass optical density estimates to predict smoke concentration [9].

The U.S. NRC and EPRI conducted validation tests of the FDS (ver 4) CFD model $[57,58]$. Validation results showed a $30 \%$ difference or more between the measured smoke concentrations and those predicted using the model, with the model consistently over-predicting smoke concentration.

FDS [35] uses LES [68] to predict movement of smoke. The algorithm used for predicting the percent obscuration per unit length of smoke in a detector sensing chamber was developed by Roby et al [15]. They found that, while exact numerical solutions were possible, a numerical solution to the ordinary differential equations yielded accurate results. FDS reports obscuration directly using equation 60 . 


$$
\lambda=100\left(1-e^{-\sigma_{m} \rho Y_{c} l}\right)
$$

Where $\rho$ is the density of the surrounding gas, $Y_{c}(t)$ is the predicted mass fraction of smoke in the detection chamber, $l$ is the preferred unit of length ( $1 \mathrm{~m}$ or $1 \mathrm{ft})$. FDS suggests the use of the Mullholland and Croarkin [23] specific extinction coefficient for flaming fires of $\sigma_{\mathrm{m}}=8.7 \pm 1.1 \mathrm{~m}^{2} / \mathrm{g}$ at wavelength of $633 \mathrm{~nm}$. The model provided in FDS allows for use of the Cleary parameters [13] or the Heskestad [51] characteristic length model as discussed in section 2.11 of this report to estimate detector activation time lag.

\section{Description of Experiments}

\subsection{Testing Facility}

The tests were conducted in the 10 story atrium of the Carleton University fire research facilities. The atrium has an approximately $20 \mathrm{~m} \times 20 \mathrm{~m}$ floor area and a height of $22 \mathrm{~m}$. The vent chamber of the atrium is suspended from the roof above and has six openings to the atrium space below for ventilation approximately $2 \mathrm{~m} \times 2 \mathrm{~m}$ in size. The vent chamber is connected to the smoke exhaust plenum, which is served by the variable speed smoke exhaust fans.

\subsection{Experimental set up}

The validation experiments used to test model theories were designed to mimic the ULC room tests, yet allow for the variance of ceiling height and eliminate the walls. The purpose for the open platform was to simulate a large open room with much larger dimensions than the standard test room. The atrium section of the Carleton University fire test lab was used for this reason. A $9.75 \mathrm{~m}$ by 10.97 $\mathrm{m}$ platform was constructed of engineered wood beams with a subsurface of oriented strand board. The platform was hoisted above the floor using steel cables suspended from the openings in the vent chamber floor of the atrium. A 
view of the platform during construction from one of the atrium vent chamber floor openings is shown in Figure 4. The test conditions are summarized in Appendix B for all of the tests conducted.

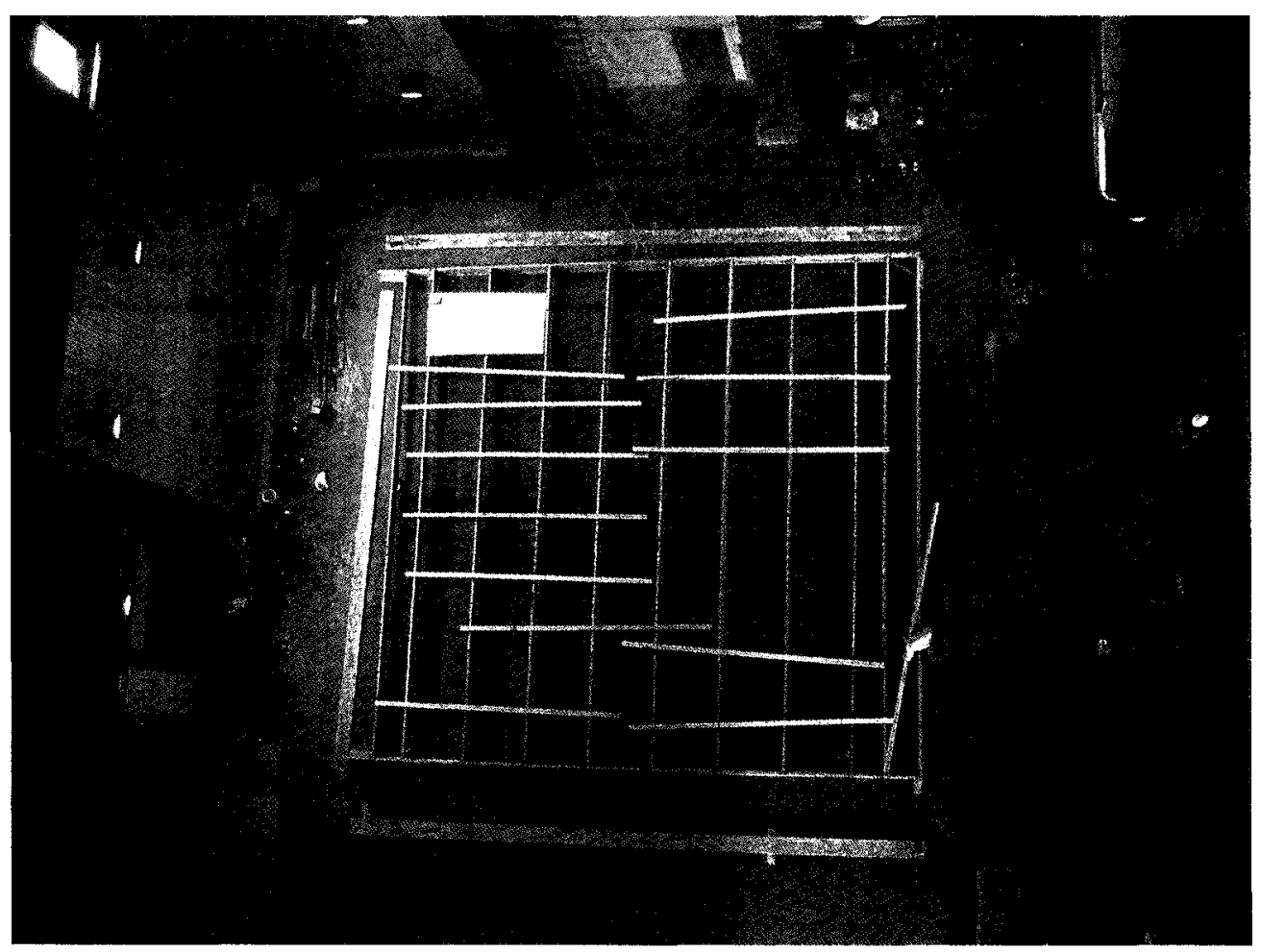

Figure 4 - View of platform being constructed from one of the vent chamber openings

The equipment layout and fire location were designed to coincide with the test set up described in part 7.9 of ULC 529 [19]. The equipment layout is shown in Figure 5. Additional detectors were placed at $1.63 \mathrm{~m}$ intervals with 8 rows of 3 detectors. The furthest detector was placed at a radial distance of $11.41 \mathrm{~m}$ from the fire source. Tests were conducted at $3-\mathrm{m}$ intervals from $3 \mathrm{~m}$ to $21 \mathrm{~m}$ above the atrium floor. 


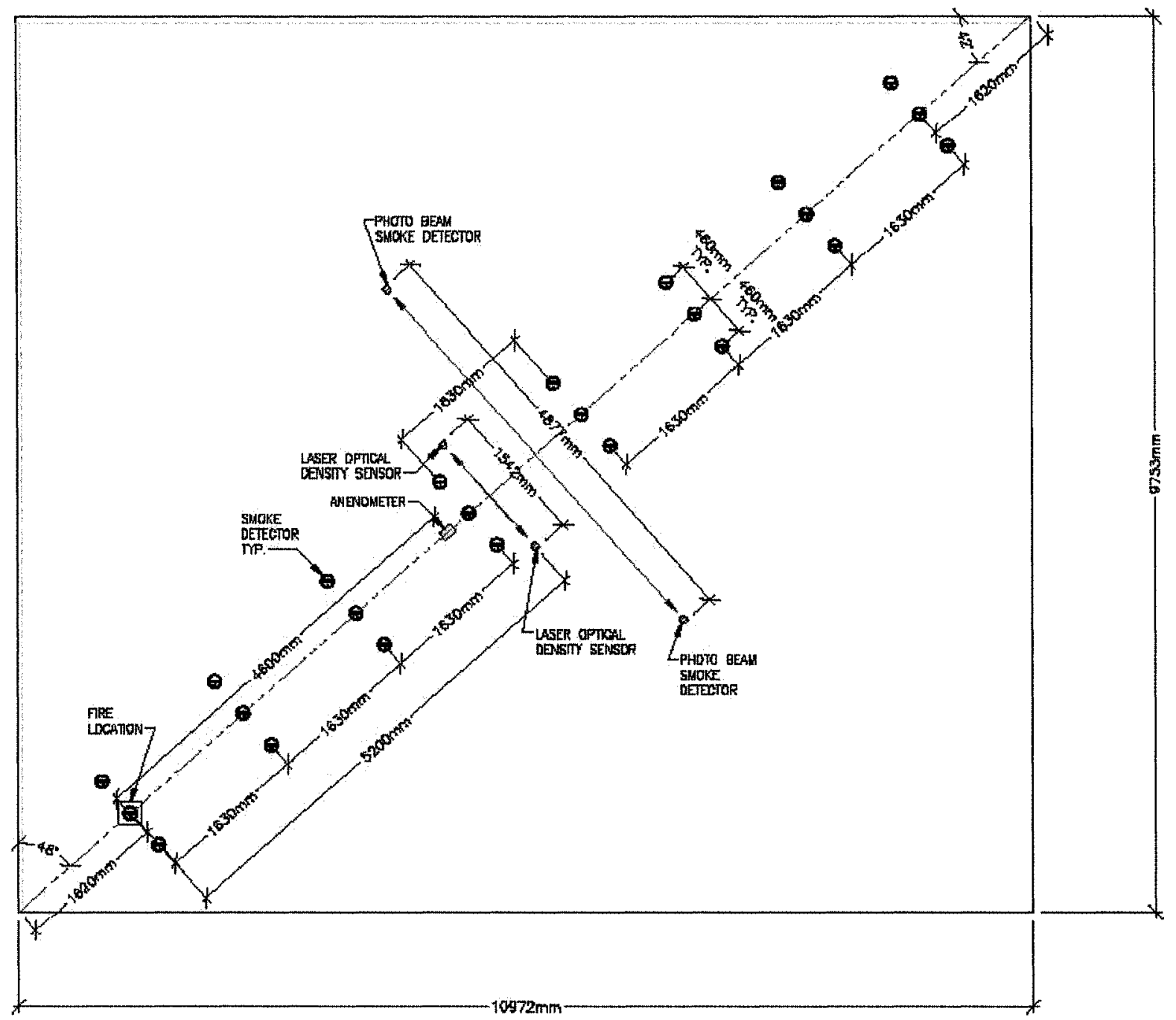

Figure 5 - Schematic layout of test equipment

A thermocouple tree consisting of 14 type-K thermocouples spaced $1 \mathrm{~m}$ apart was positioned above the flame for temperature measurements for tests conducted at platform elevations of 15-m and above. A thermal imaging infrared camera was placed on the floor of the atrium, focused on the underside of the platform to measure surface temperatures of the ceiling. A colour video camera 
was also placed on the atrium floor focused on the underside of the platform to provide visual images during testing.

A white light optical density measurement instrument was provided by the National Research Council of Canada (NRCC) to measure light extinction at a radial distance of $5.2 \mathrm{~m}$ from the fire source. The unit was constructed by NRCC staff and is called the Pulsed 940 smoke density meter. The equipment consists of a white light diode transmitter and receiver pairs. The equipment was set up with the receiver and transmitter $620 \mathrm{~mm}$ apart and $202 \mathrm{~mm}$ from the underside of the platform. The equipment was set up and calibrated according to the work instruction document for the device [25].

The 24 smoke detectors and the linear beam smoke detector provided by System Sensor were placed as shown in Figure 5 on the underside of the platform and connected to the data acquisition device provided by System Sensor (endcal). The spot type smoke detectors provided are Notifier model FSP-851 plug in type addressable photoelectric detectors that operate on the light scattering principle. The spot type detectors were installed according to their installation and maintenance instructions [69] using the B501 detector base according to its installation and maintenance instructions [70]. The linear beam smoke detector used is a System Sensor model FSB-200 single ended reflected type projected beam smoke detector. It was installed under the platform such that the receiver and transmitter were located $4870 \mathrm{~mm}$ apart with the top of the unit $150 \mathrm{~mm}$ below the ceiling, making the transmitting and receiving lenses 205 and $260 \mathrm{~mm}$ below the ceiling. The detectors were wired in parallel and connected to the endcal data acquisition device using 2-conductor, 18-awg, twisted, shielded, stranded cable. The linear beam smoke detector was installed and calibrated according to its installation and maintenance instructions [71]. 
The endcal data acquisition device provides a parallel port output to a $\mathrm{pc}$ computer running a Labview virtual instrument program written by System Sensor to gather, display and output data from each detector on the loop. Once the cables are connected between the pc and endcal and between the endcal and the power/data loop for the addressable detectors, the endcal device is powered up and the Labview program is initiated. The Labview software communicates with each detector to determine the device address and measures the device output at the time steps set in the initialization of the software. All of the data for each device is then saved to a tab delimited text file for analysis using a spreadsheet program. The equipment measures the time required by each detector to draw current from the endcal power supply through a pulse width modulated signal set up. The duration is reported in microseconds varying from 850 to $3185 \mu \mathrm{s}$. There is a linear relationship between the pulse width and detector sensitivity provided by the manufacturer. A chart of the sensitivity is provided in Figure 6. The detector alarm point is set to a pulse width of $2400 \mu \mathrm{s}$ and sensitivity numbers are the pulse width values recorded at this level. The sensitivity data reported by the manufacturer are for response to grey smoke from the standard tests $[19,20]$ and are shown in Table 1. 


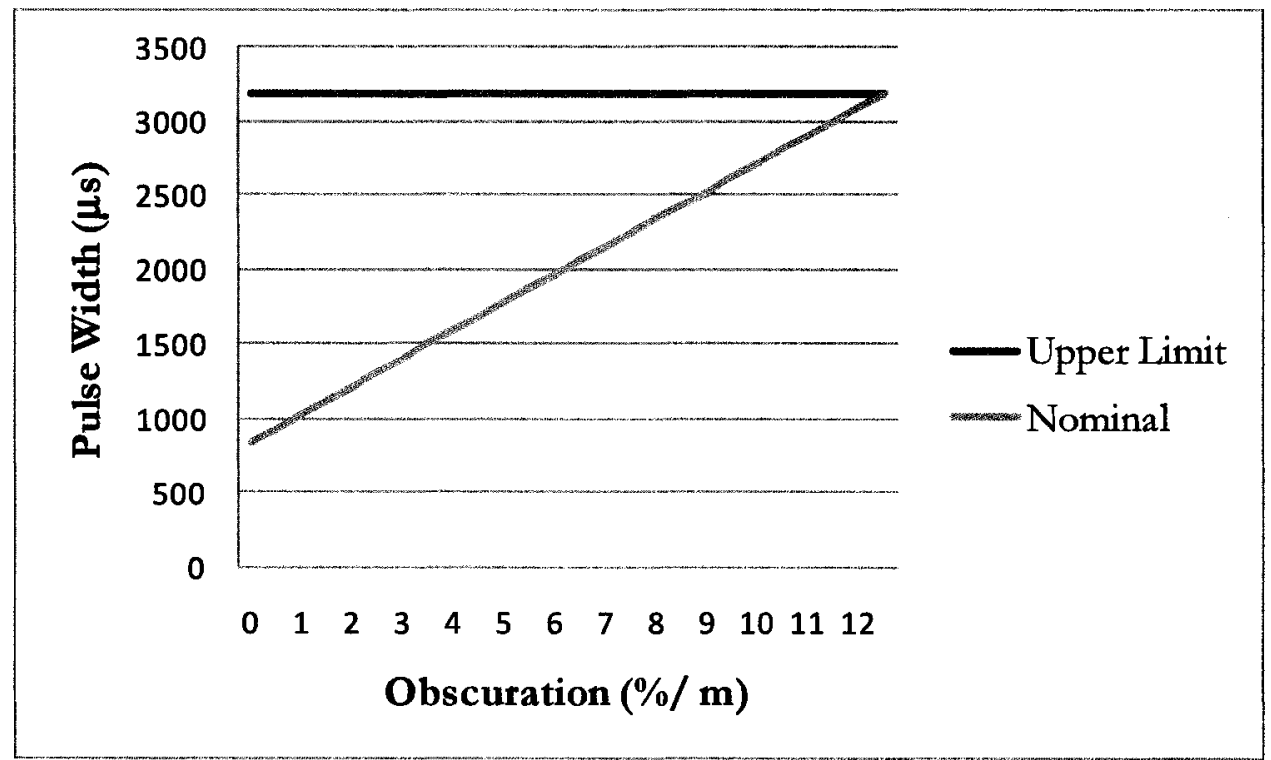

Figure 6-Smoke Detector pulse width nominal sensitivity chart.

$-39-$

Reproduced with permission of the copyright owner. Further reproduction prohibited without permission. 
Table 1 - Detector Sensitivity Values

\begin{tabular}{|c|c|c|}
\hline $\begin{array}{l}\text { Detector } \\
\text { Number }\end{array}$ & $\begin{array}{l}\text { Clear } \\
\text { Air } \\
\text { Pulse } \\
\text { Width } \\
(\square s)\end{array}$ & $\begin{array}{c}\text { Obscuration at } \\
\text { Pulse Width of } \\
2400 \square \mathrm{s} \\
(\% / \mathrm{m})\end{array}$ \\
\hline 1 & 846 & 6.40 \\
\hline 2 & 821 & 6.07 \\
\hline 3 & 850 & 6.23 \\
\hline 4 & 880 & 6.07 \\
\hline 5 & 865 & 6.40 \\
\hline 6 & 852 & 6.89 \\
\hline 7 & 850 & 7.05 \\
\hline 8 & 850 & 6.23 \\
\hline 9 & 835 & 7.05 \\
\hline 10 & 830 & 7.22 \\
\hline 11 & 851 & 7.55 \\
\hline 12 & 853 & 7.05 \\
\hline 13 & 850 & 6.56 \\
\hline 14 & 875 & 7.05 \\
\hline 15 & 834 & 7.38 \\
\hline 16 & 853 & 7.05 \\
\hline 17 & 847 & 7.22 \\
\hline 18 & 879 & 6.23 \\
\hline 19 & 850 & 6.56 \\
\hline 20 & 868 & 6.89 \\
\hline 21 & 850 & 6.56 \\
\hline 22 & 850 & 7.05 \\
\hline 23 & 830 & 6.89 \\
\hline 24 & 850 & 7.05 \\
\hline 25 & 830 & 7.05 \\
\hline 26 & 845 & 6.56 \\
\hline 27 & 860 & 6.23 \\
\hline 28 & 845 & 6.23 \\
\hline 29 & 830 & 6.40 \\
\hline 30 & 844 & 6.23 \\
\hline
\end{tabular}

\subsection{Test Fires}

Three fuels were chosen to match ULC 529 flaming test fires: paper and Heptane/Toluene mix [19] as well as the UL 217 flaming fire test involving Douglas Fir [20]. Given the ceiling heights that were under test here, smouldering tests were not considered. During the course of testing, alternate 
fire scenarios were used to evaluate detector response at elevations above those considered practical for the original design fires chosen.

\subsubsection{Paper Fire}

In accordance with the ULC 529 paper fire test procedures [19], approximately $28 \mathrm{~g}$ of black and white newsprint was cut into strips approximately $6 \mathrm{~mm}$ wide by $100 \mathrm{~mm}$ long and packed into a steel container to a height of $115 \mathrm{~mm}$ with a $25 \mathrm{~mm}$ hole in the centre. The container is a $100 \mathrm{~mm}$ diameter cylinder by 175 $\mathrm{mm}$ high made of $6 \mathrm{~mm}$ thick steel pipe (Figure 7). The cylinder is supported in a vertical position by wire mesh screen. The assembly was placed on a pedestal $900 \mathrm{~mm}$ off the floor of the atrium and ignited by an open flame placed at the bottom centre through the wire screen.

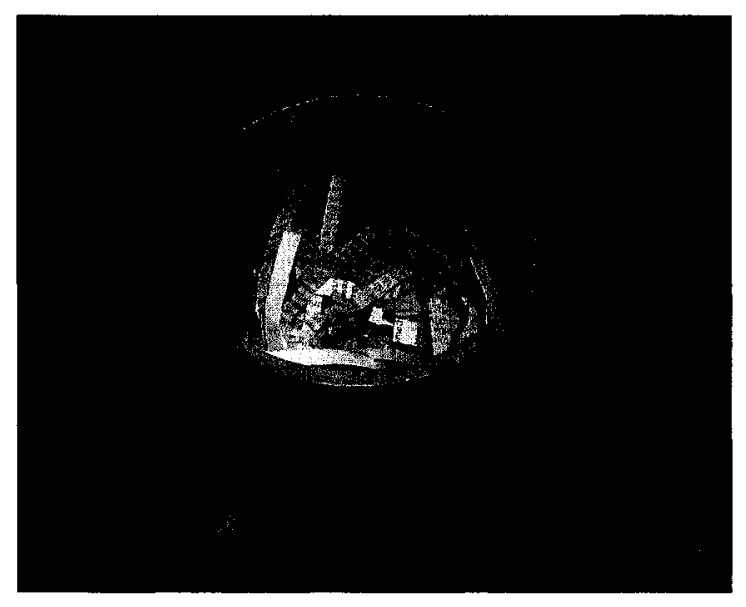

Figure 7 - Paper fuel package

The various combinations of fuel and elevation tests are listed in Appendix B. Measurements of smoke detector obscuration over time were taken for each test.

The paper fire tests tended to smoulder for a period of time, producing a significant amount of smoke, without being driven by a significant amount of 
thermal lift. This period was followed by a flaming period that had the effect of driving the earlier generated smoke toward the ceiling along with that generated during the flaming period. The following three figures are taken from a video recording of Test 15 (6-m elevation).

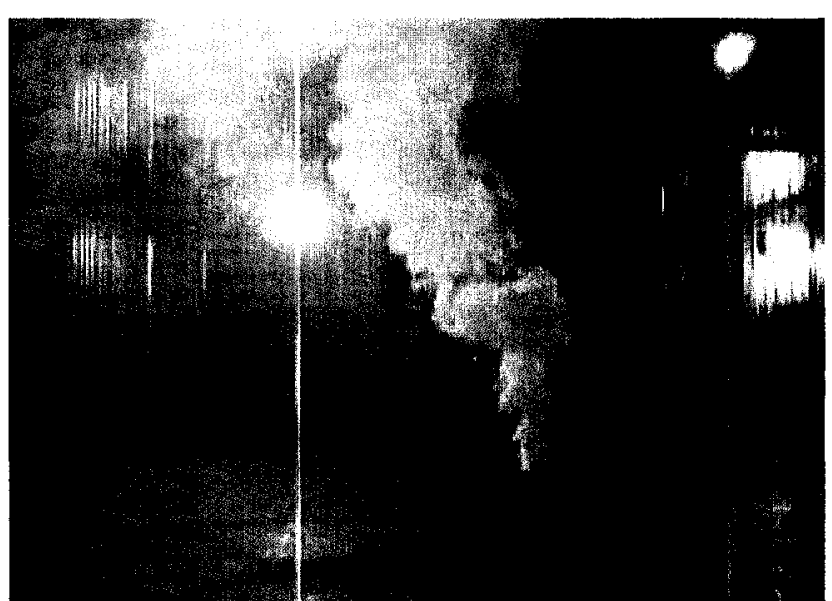

Figure 8-Newsprint fire early smoke production

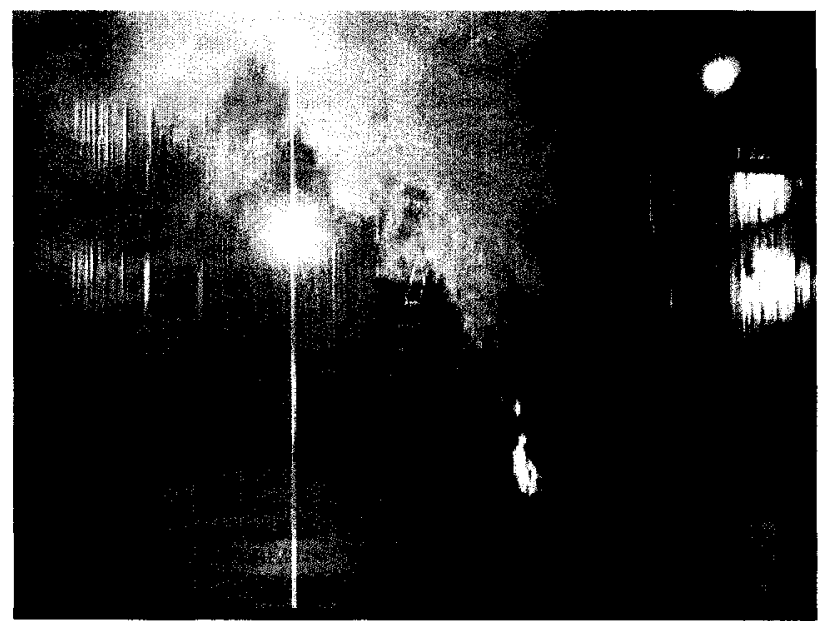

Figure 9-Newsprint fire transition to open flame 


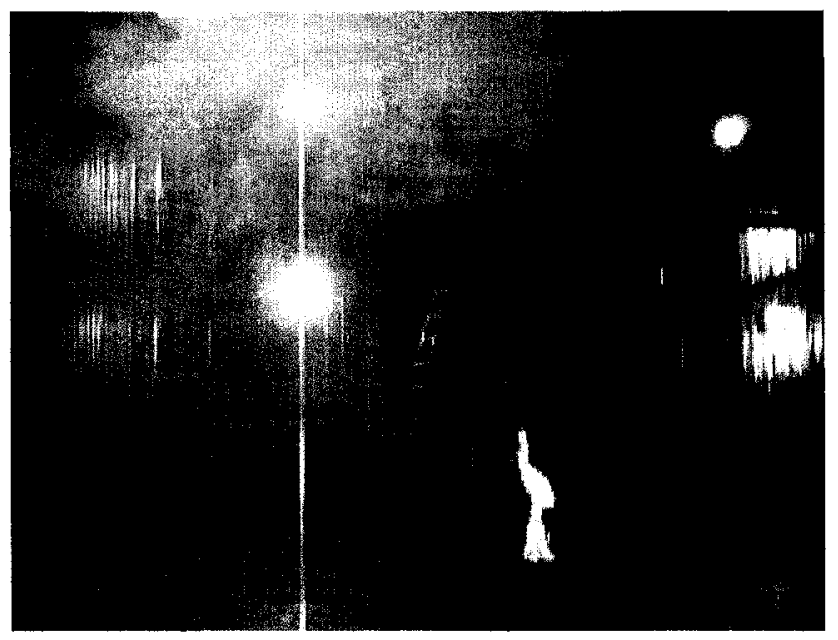

Figure $10-$ Newsprint fire thermal lift of early smoke produced

Early on during the test, the smoke produced exhibits a minimal amount of lift resulting in a concentrated amount of smoke just above the fuel source as shown in Figure 8. After approximately 20 seconds of smouldering, the fire transitions into open flame as shown in Figure 9. The next image was taken a few seconds later, shown in Figure 10. The figure shows the new thermal lift moving the smoke directly above the flame towards the platform ceiling.

\subsubsection{Flammable liquid fire}

A mixture of $25 \%$ toluene and $75 \%$ heptane was poured into a steel container. The assembly was placed on a pedestal at an elevation of $900 \mathrm{~mm}$ above the floor and ignited by an open flame. 42 tests were done using five different size containers. The $20-\mathrm{ml}$ fire container was a $32 \mathrm{~mm}$ high $\times 158 \mathrm{~mm}$ diameter steel container on a flat bottom steel base, corresponding with the ULC S529 requirements [19]. The $40-\mathrm{ml}$ fire container was a $184 \mathrm{~mm}$ x $184 \mathrm{~mm}$ square pan. The $60-\mathrm{ml}$ fire container was a $168 \mathrm{~mm}$ x $267 \mathrm{~mm}$ rectangular pan. The $100-\mathrm{ml}$ fire container was a $254 \mathrm{~mm}$ x $381 \mathrm{~mm}$ pan and the $200-\mathrm{ml}$ fire consisted 
of two $100 \mathrm{ml}$ containers placed side by side. Fuel quantities and containers used were estimated based on area comparisons between the standard fire area and the increased areas for the larger fires, with the intention of achieving a similar burning period of approximately 60 seconds.

Observations and results indicated that the test fires did not cause significant changes in obscuration within detectors to warrant continuation of the tests with the original fuel packages above the $15-\mathrm{m}$ platform elevation. Above this height, only the liquid fuel experiments were conducted. Larger fuel containers with more heptane/toluene mixtures were used for the remainder of the tests. Refer to section 5.5 .5 for further discussion.

A preliminary evaluation of the heat release rate was done to determine the approximate pan size for the larger fires using Eq. 61[29].

$$
\dot{Q}_{c}=\Delta H_{c h} \cdot \dot{m}^{\prime \prime} A
$$

It was assumed that the specific mass loss rate and chemical heat of combustion were constant through the various fuel surface areas evaluated. This results in an increase in heat release rate directly proportional to the surface area of the fuel.

A thermocouple tree was added to the experimental set-up directly above the fire for experiments starting with the $15-\mathrm{m}$ elevation tests. The thermocouple tree consisted of 14 thermocouples spaced $1 \mathrm{~m}$ apart with the lower thermocouple at an elevation of $2-\mathrm{m}$ (1.1 $\mathrm{m}$ above the base of the fire). For the higher elevations, the lower thermocouple remained at an elevation of $2 \mathrm{~m}$.

The various combinations of fuel quantity, elevations used in the testing are listed in Appendix B. Readings of light obscuration measurements taken by the detectors were recorded for all of these tests. Temperature readings were taken 
for all of the tests at elevations of $15 \mathrm{~m}$ and above. A set of three tests was conducted at the end of the test program (tests 70-72) to measure temperatures of the $20 \mathrm{ml}$ liquid fuel fire for modeling purposes. Temperature readings were not taken for the initial series of tests because the intention was that heat release values would be obtained from the tests results of the Smoke Characterization Project [18].

Liquid fuel fire tests produced flame instantly when ignited. The tests produced relatively steady amounts of smoke and a consistent flame. One of theses tests are shown in Figure 11

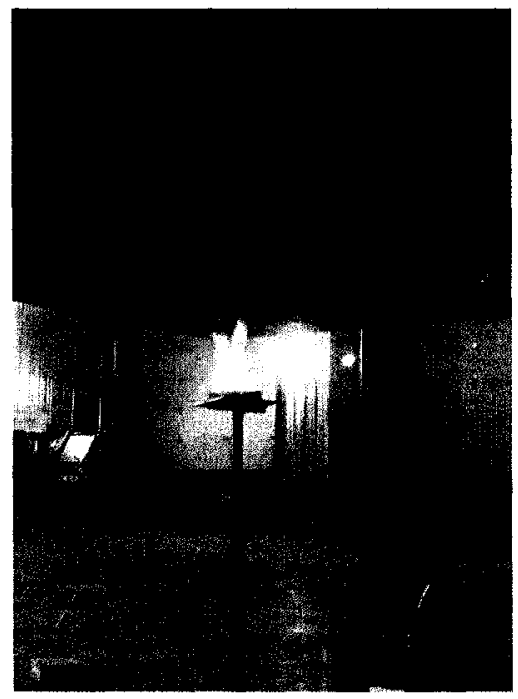

Figure $11-20 \mathrm{ml}$ liquid fuel fire test with platform elevation at $3 \mathrm{~m}$

\subsubsection{Douglas Fir fire}

Wood cribs consisting of kiln dried Douglas Fir strips with a $19 \mathrm{~mm}$ square cross section $152 \mathrm{~mm}$ long made up another of the fuel packages. The cribs were constructed to conform to the UL268 Test B requirements [20]. The cribs were constructed using eighteen strips with three layers of six strips in each layer with altering layers glued at right angles to form a crib with dimensions of $152 \mathrm{x} 152 \mathrm{x}$ 
$64 \mathrm{~mm}$. Ignition of the crib was achieved by using $4 \mathrm{ml}$ of alcohol in a dish below the crib. The various combinations of fuel and elevation tests are listed in Appendix B. Light obscuration readings provided by the smoke detectors were recorded for each test case.

Wood fire tests produced minor amounts of flame, mostly on the underside of the sample. The smoke produced appeared to be created from smouldering of the wood. The amount of smoke generated appeared to increase steadily through the test period. Wood crib fires did not consume a significant amount of the available fuel, and the fuel packages needed to be extinguished at the end of a test. One example is shown in Figure 12.

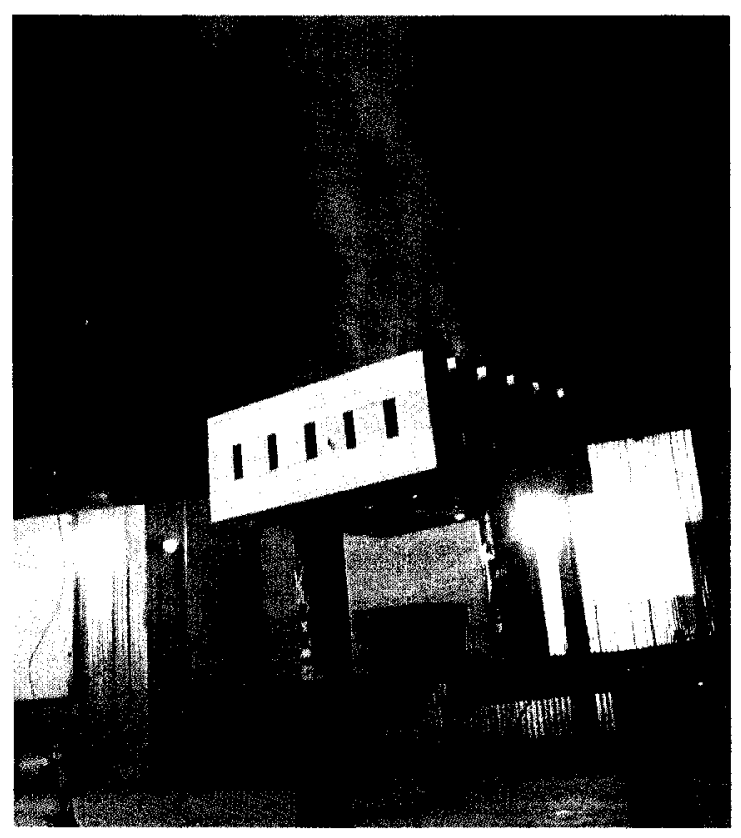

Figure 12 - Wood crib fire test with platform elevation at $3 \mathrm{~m}$ 


\section{Modeling}

Three types of modeling approaches were used to predict obscuration levels and smoke detector response to fires; algebraic models, zone models and computational fluid dynamics models. The algebraic models included correlation equations developed by Davis and Reneke [17] and altemative equations developed by Watanabe and Tanaka [16]. The zone model used was from the computer program CFAST $[33,34]$. The computational fluid dynamics model used was FDS [35]

Material properties used for modeling activities were taken from values obtained through either the smoke characterization project [18] or the SFPE Handbook of Fire Protection Engineering $3^{\text {rd }}$ Edition [72] and are reported in Appendix A of this report.

Environmental values of atmospheric pressure, humidity and temperature were used in the models that matched as close as possible with the actual conditions at the time of the experimental tests.

The three types of test fires used were based on ULC 529 [19] and UL 268 [20] standard tests for commercial smoke detectors. Each of these fires was part of the Smoke Characterization Study [18] conducted by the Fire Protection Research Foundation. The heat release rates from that study were used as model inputs for the paper and wood fire tests. Liquid fuel fire test heat release estimates from the experiments were used for modeling. The heat release rate inputs were used to predict the maximum smoke concentration in the ceiling jet or plume as the case may be. These predictions were used to assess the likelihood of smoke detectors activating and values obtained were compared against experiments conducted. 
For the algebraic model, only the peak heat release rate values are used, but for the other two methods, data was reduced to a 5 second moving average. This gives a small enough sampling so that the data can be used with the zone model.

\subsection{Newspaper fire model}

The newspaper fuel used consisted of strips of newspaper described in section 3.3.1. The heat release rates reported by the Smoke Characterization Project [18] were used as model inputs. The test data selected was Test 2 from the tests conducted using an intermediate scale cone calorimeter that was set up with ignition parameters to match the standardized tests $[19,20]$. The peak heat release rate was reported as $6 \mathrm{~kW}\left(764 \mathrm{~kW} / \mathrm{m}^{2}\right)$ with a peak smoke release rate of $1.04 \mathrm{~m}^{2} / \mathrm{s}$ and a total smoke development of $39 \mathrm{~m}^{2}$. The reported values are shown in Figure 13. The data was reduced using a five second moving average for use in the models as shown in Figure 14.

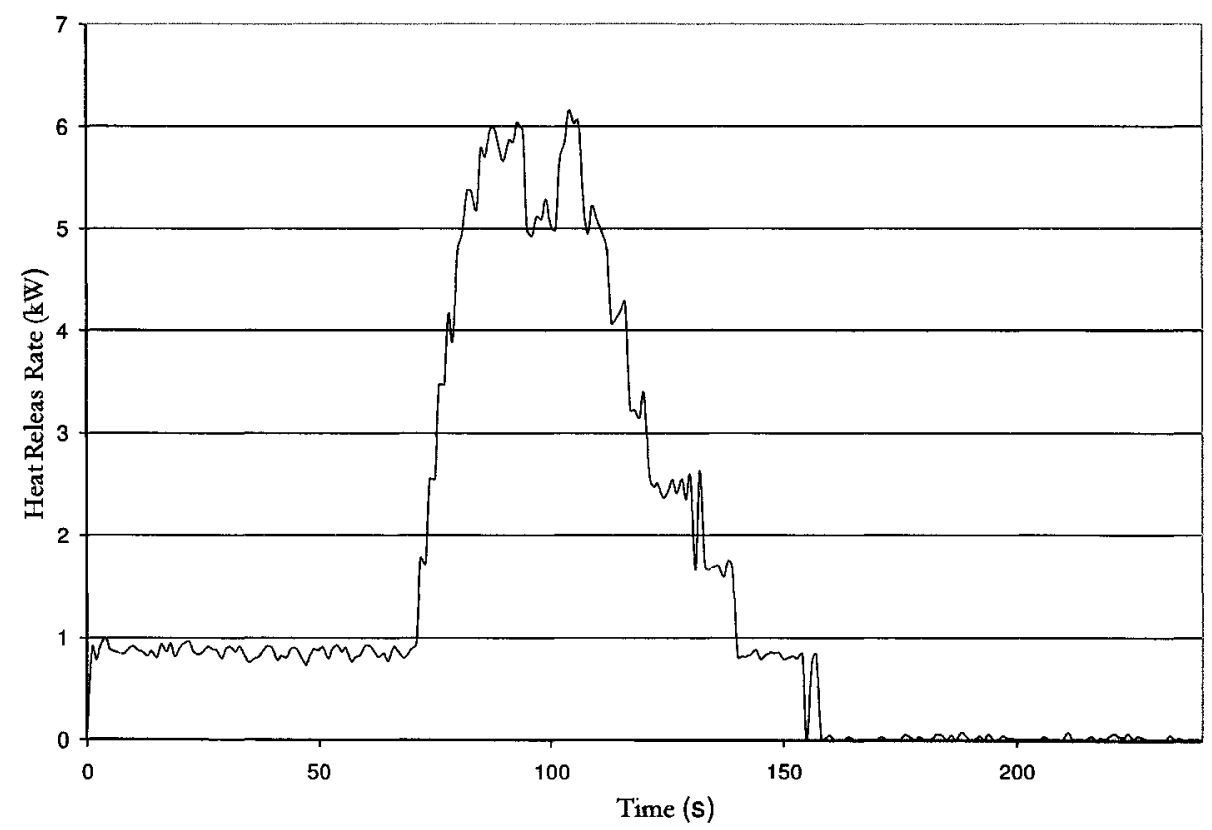

Figure 13 - Smoke Characterization Report - newsprint heat release rate $-48-$ 


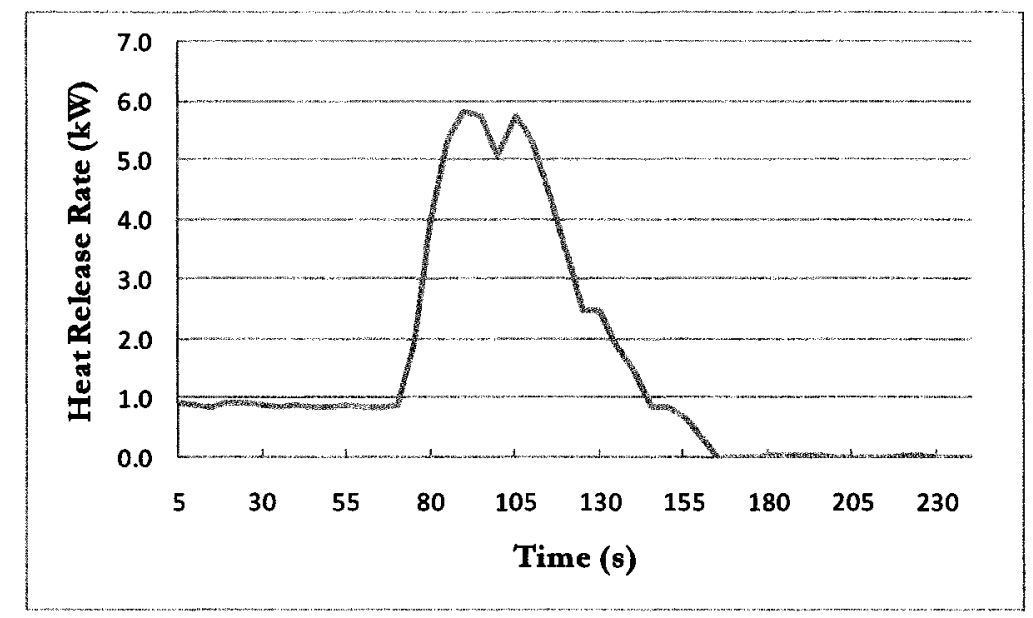

Figure 14 - Model newspaper heat release rate, $5 \mathrm{~s}$ moving average

\subsection{Liquid fuel fire models}

The liquid fuel used consisted of a mixture of heptane and toluene described in section 3.3.2.

For modeling purposes, the original intention was to use heat release data from reference 18. Due to the need for larger sized fires and also due to a discrepancy in the fuel quantity used for acceptance testing between the ULC tests [19] and the Smoke Characterization Project tests [18], heat release rates used for modeling liquid fuel fires were estimated from temperature measurements made above the fire centreline.

For these fires, the heat release rate was estimated from thermocouple tree temperature measurements made during testing. Time/temperature measurements were taken and used to estimate the heat release rate values used 
for modeling. A modified version of Eq. 21 was used to estimate heat total release rate from the measured temperatures (Eq. 62). The virtual origin value of $\mathrm{z}_{0}$ was neglected for this exercise.

$$
\dot{Q}=\left(\frac{1}{1-\chi_{r}}\right)\left(\frac{\Delta T(z)^{5 / 3}}{9.1\left(\frac{T_{0}}{g c_{p}^{2} \rho_{0}^{2}}\right)^{1 / 3}}\right)^{3 / 2}
$$

This data was then filtered using a five second moving average and used to model the fire. The data used in the $20-\mathrm{ml}$ liquid fuel fire models was taken from Test 71 and is shown in Figure 15. The 40-ml liquid fuel heat release rate was taken from Test 52 and is shown in Figure 16. The $60-\mathrm{ml}$ liquid fuel heat release rate was taken from Test 58 and is shown in Figure 17. The 100-ml liquid fuel heat release rate was taken from Test 67 and is shown in Figure 18. Each of the plots includes the standard error for these calculations.

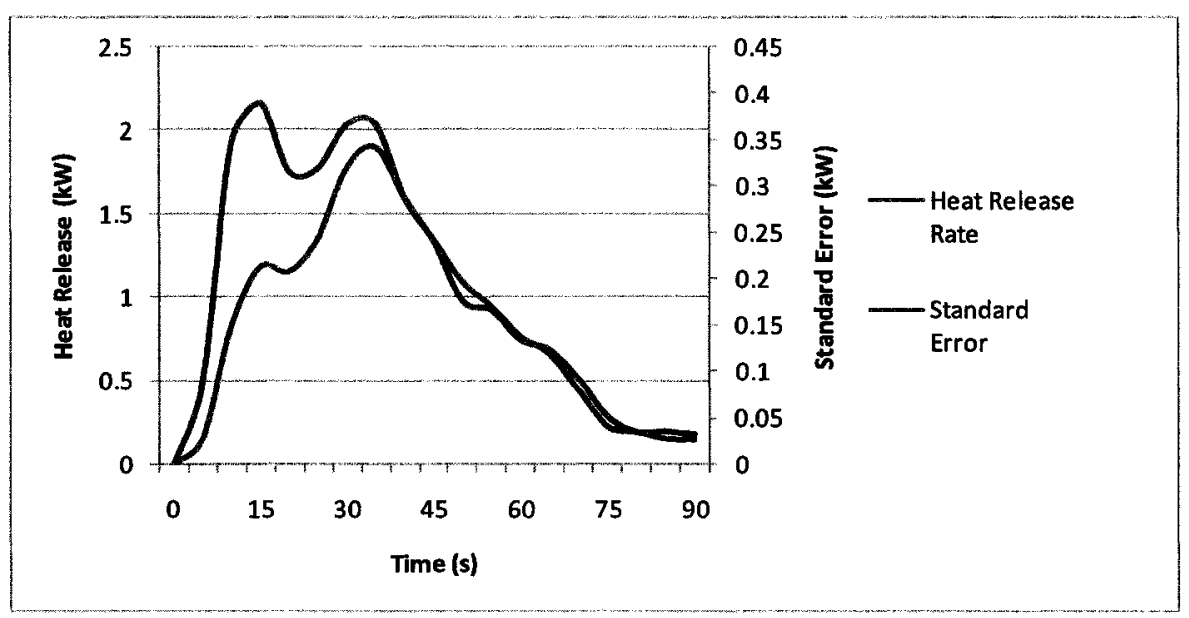

Figure $15-20-\mathrm{ml}$ liquid fuel fire model heat release rate, $5 \mathrm{~s}$ moving average 


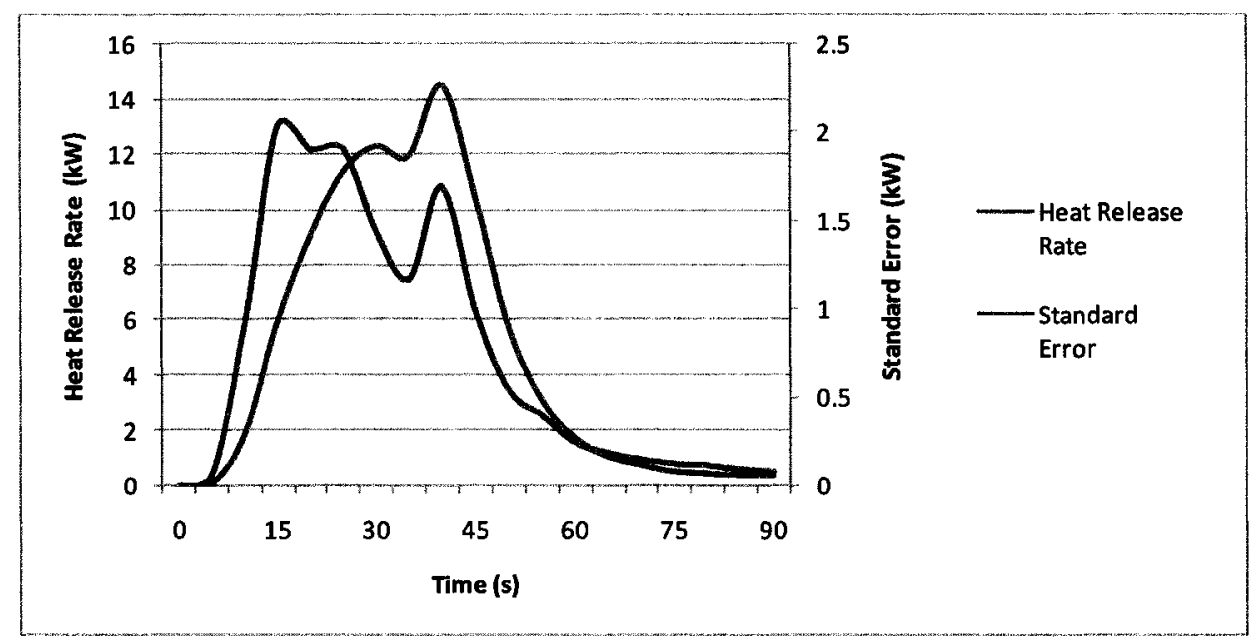

Figure $16-40 \mathrm{ml}$ liquid fuel fire model heat release rate, $5 \mathrm{~s}$ moving average

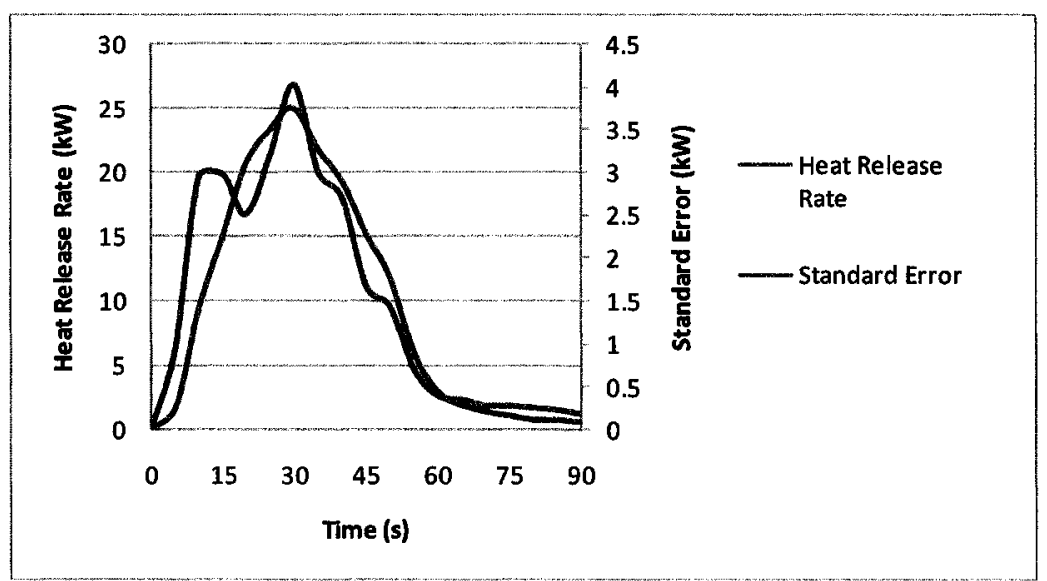

Figure $17-60 \mathrm{ml}$ liquid fuel fire model heat release rate, $5 \mathrm{~s}$ moving average 


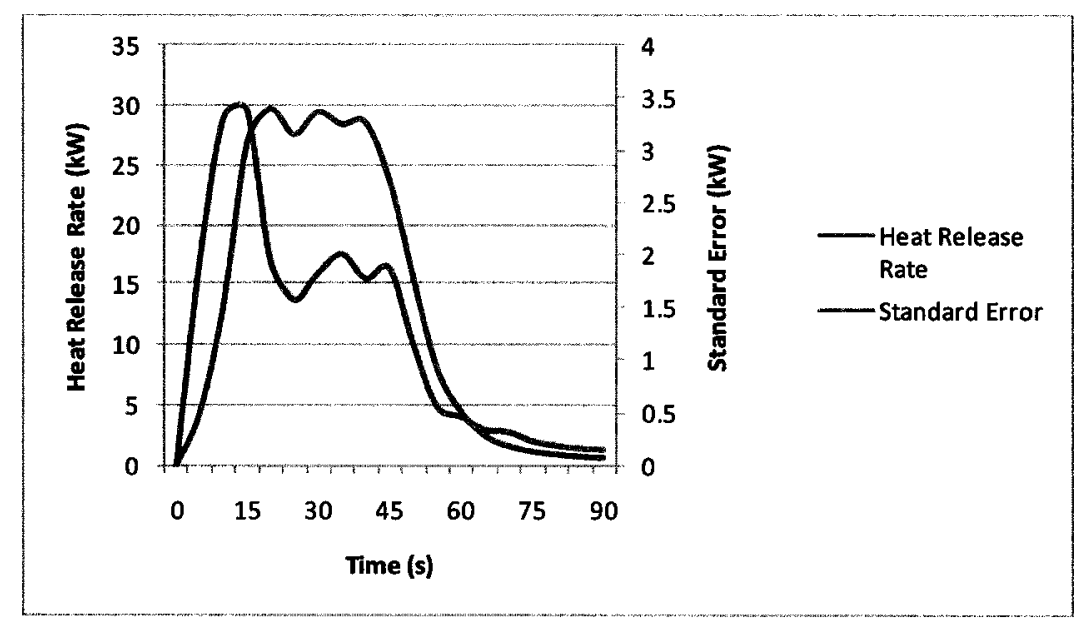

Figure $18-100 \mathrm{ml}$ liquid fuel fire model heat release rate, $5 \mathrm{~s}$ moving average

\subsection{Wood fuel fire model}

The Douglas fir fuel used consisted of a wood crib described in section 3.3.3. The heat release rates reported by the Smoke Characterization Project [18] shown in Figure 19 were used to create model inputs. The test data selected was Test 2 from the tests conducted using an intermediate scale cone calorimeter that was set up with ignition parameters to match the standardized tests $[19,20]$. The peak heat release rate was reported as $10 \mathrm{~kW}$ with a peak smoke release rate of 0.24 $\mathrm{m}^{2} / \mathrm{s}$ and a total smoke development of $11 \mathrm{~m}^{2}$. For the algebraic model, only the peak values are used, but for the other two methods, a five second moving average approximation of the heat release rate was used as shown in Figure 20. 


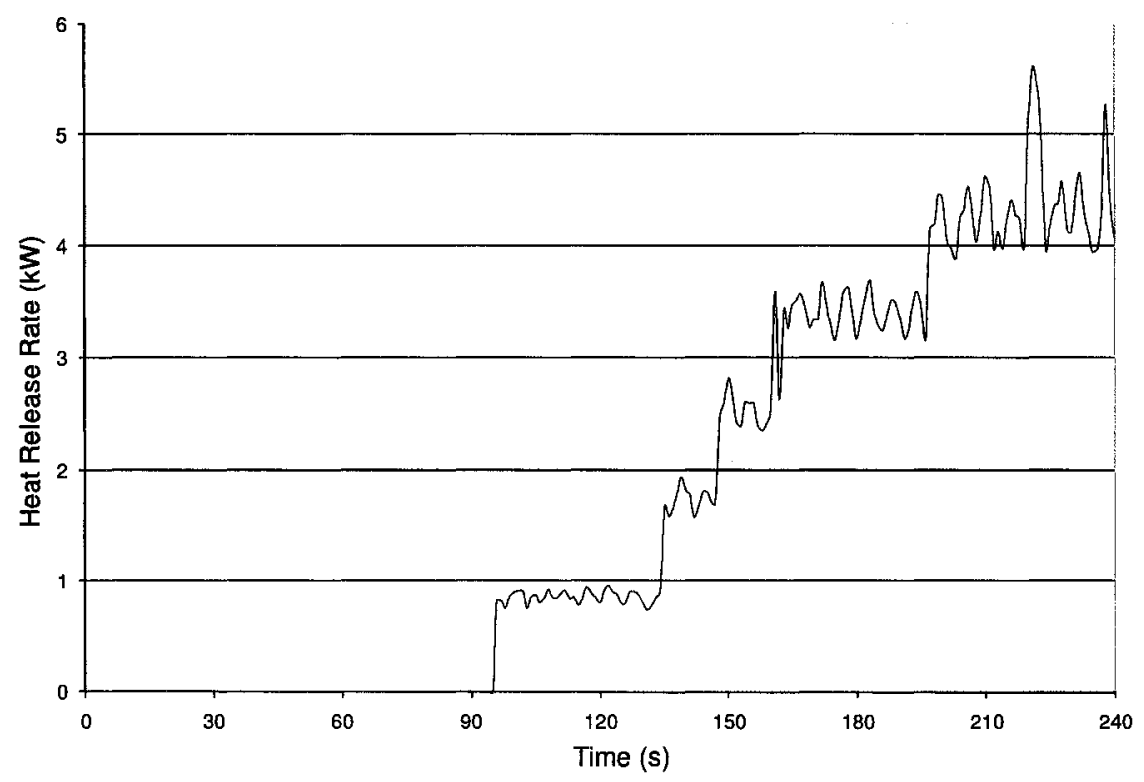

Figure 19 - Smoke Characterization Report - Douglas Fir heat release rate

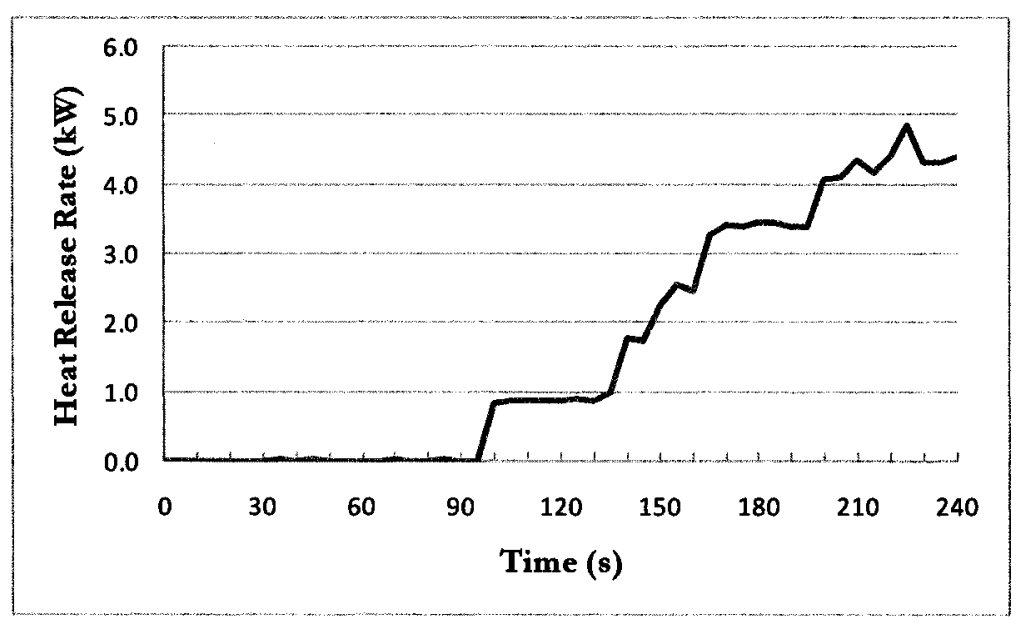

Figure 20 - Douglas Fir Heat Release Rate

\subsection{Algebraic Modeling}

The algebraic equations presented in section 2.14 .1 of this report were used along with the environmental conditions and maximum fire size for each modeling

$-53-$ 
scenario. An excel spreadsheet was set-up to calculate the algebraic predictions (and compare against the measured data as well as other model predictions).

\subsection{Zone Modeling}

The two-zone model CFAST - Consolidated Model of Fire Growth and Smoke Transport, Version $6[33,34]$ was used for zone modeling. Each simulation made use of the same physical model (Figure 21). The compartment, called Atrium is a $10.97 \times 9.75 \times \mathrm{H}$ rectilinear shape. The $\mathrm{x}$ and $\mathrm{y}$ dimensions were set to match the size of the platform and $\mathrm{H}$ was set to the height of the platform for each model run. All sides of the Atrium were set as open vents to the outside in the model. One target was set to match the location of the detector at the centre of row 4 , which coincides with the ULC detector location set during acceptance testing for ULC 529 listing [19]. This target is in addition to the default target set by the fire definition. The atmospheric conditions recorded at the time of the tests were used in the model. 


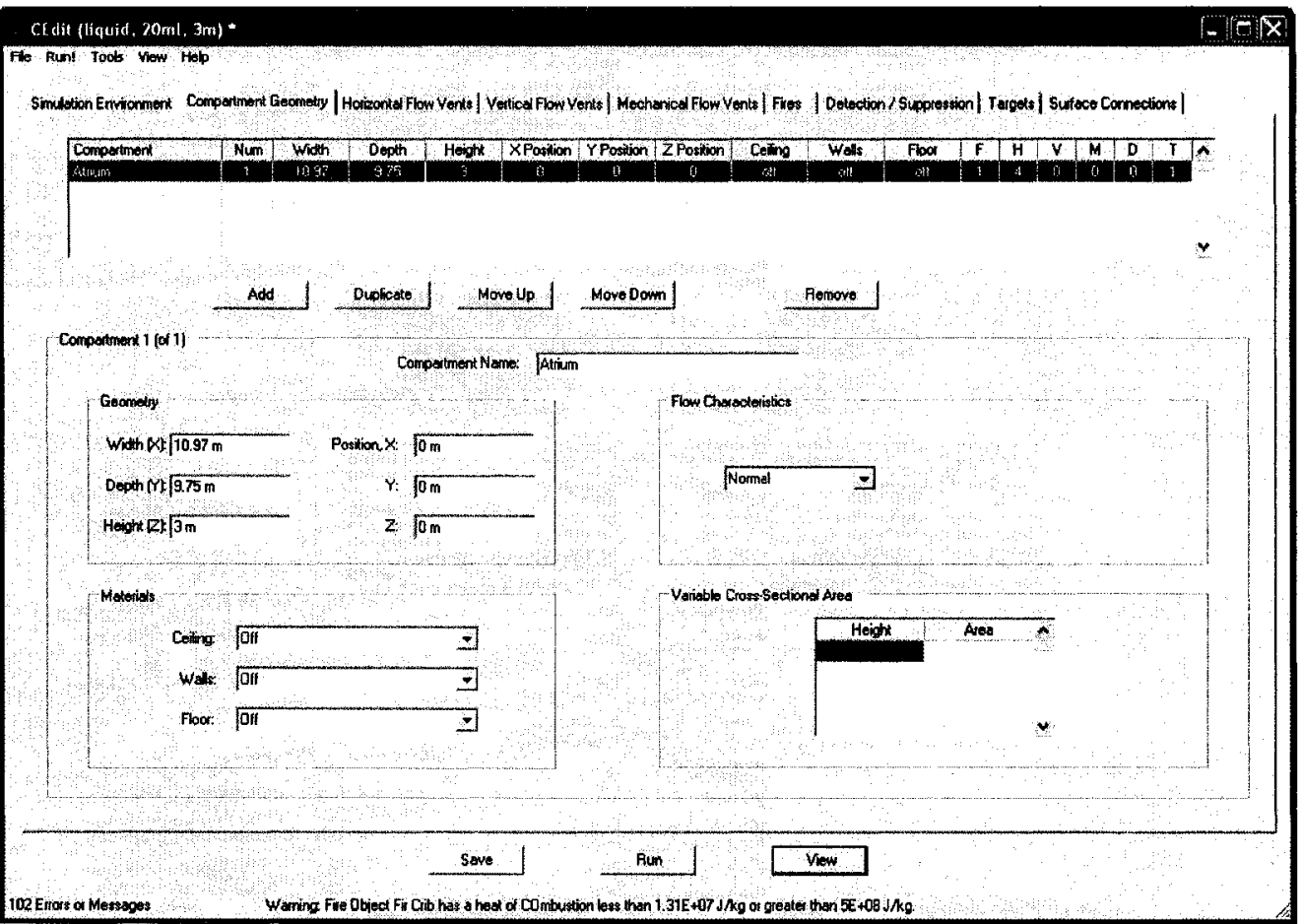

Figure 21 - CFAST compartment geometry

Smakeview $5.22-$ Jul 182008

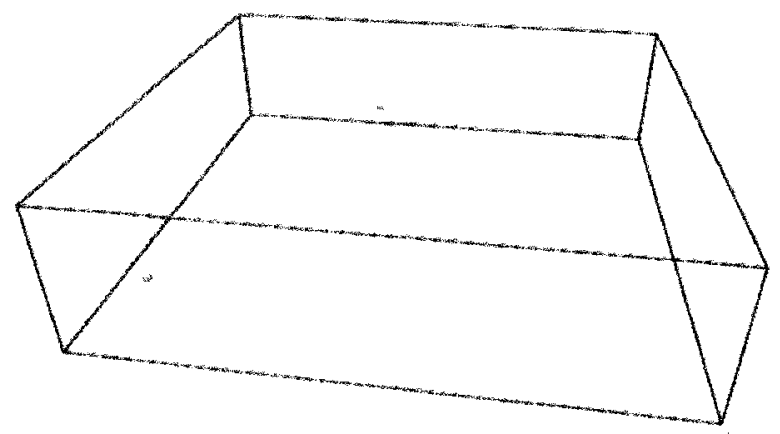

Figure $22-$ CFAST rendering of the 3-m elevation tests 


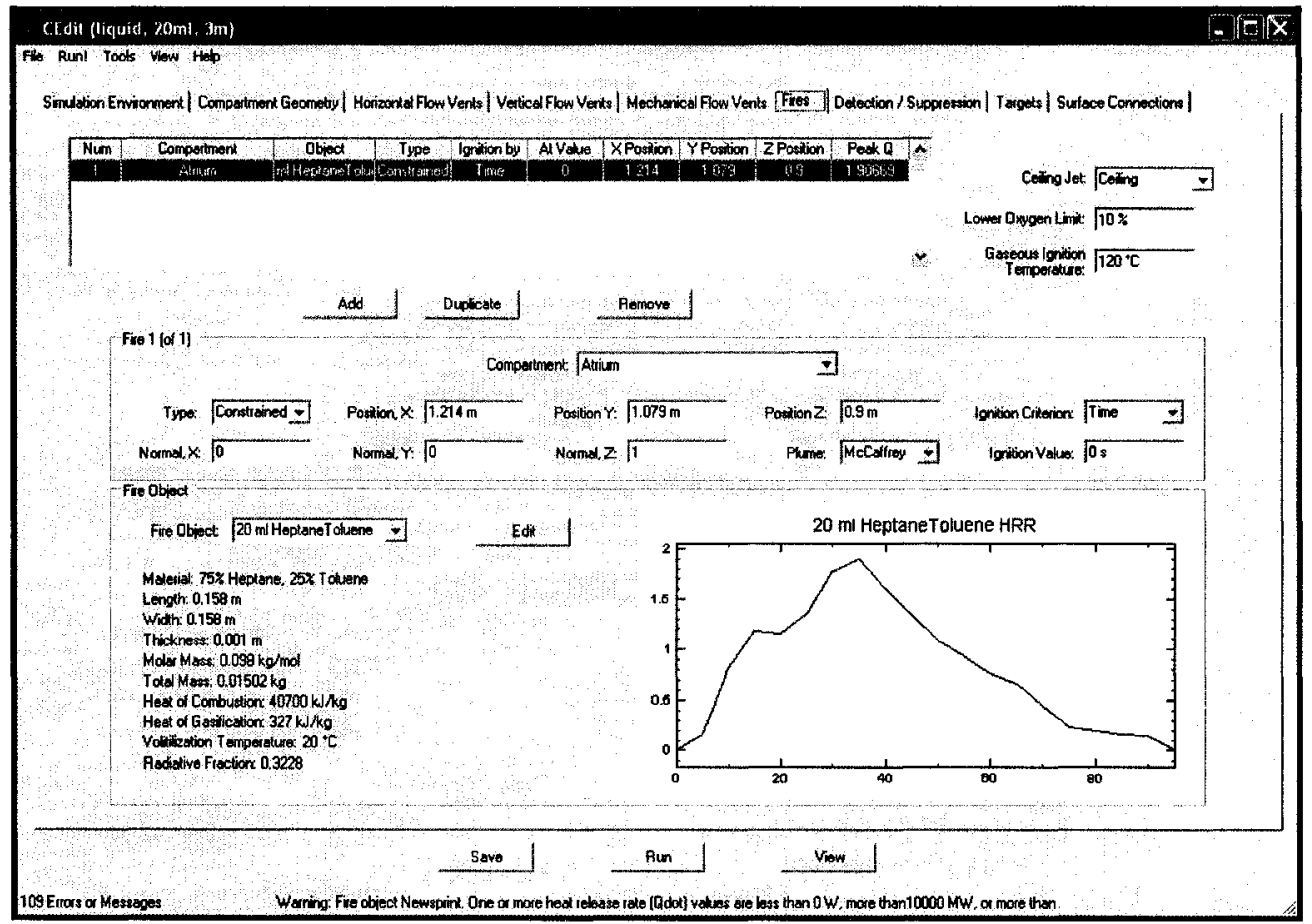

Figure 23 - CFAST fire model for $20 \mathrm{ml}$ liquid fuel fire

A typical fire model screen shot is shown in Figure 23. The simulated fire object was provided with values of material, density, heat of combustion, radiative fraction, ratios of $\mathrm{CO} / \mathrm{CO}_{2}$ and $\mathrm{C} / \mathrm{CO}$ taken from Appendix A. A typical set of input values are provided in Appendix C.

Since CFAST only reports the upper layer values without adding a ceiling jet correlation for radial distance from the source, the algebraic ceiling jet correlations could be used to report these values for comparison. Instead, the CFAST maximum obscuration is reported directly. Charts shown in the results section of this report show the single value reported by the model at each radial distance for visibility purposes only, not to infer that the model predicts that radius has any effect on the reported value. 


\subsection{CFD Modeling}

The CFD modeling was performed using the Fire Dynamics Simulator Version 5.2.0 [36] from NIST. A typical input file is provided in Appendix C. Between 7 and 13 mesh grids were included in the model starting with 7 for the lowest elevation and adding a $10 \mathrm{~cm}$ grid for each $3 \mathrm{~m}$ increment in elevation of the platform. The regions surrounding the fires were modeled using a $2 \mathrm{~cm}$ grid. Each simulation was run for a 4 minute time period. Each simulation was set up with the ambient temperature, pressure and humidity data recorded for the group of tests simulated. Reaction data and material properties were included as discussed at the beginning of this chapter. Obstructions for the concrete floor, the smoke detector platform and the ceiling of the atrium were included as well as the steel pedestal that held the fuel packages. Fire obstruction statements varied depending on the size of the pan for liquid fuels and to match the wood crib and newsprint container. All of the sides of the meshes were set to be open, with only the upper boundary set as a solid inert surface. Each detector, along with their specific sensitivity was included in the model. The Cleary Photoelectric P2 parameters were chosen for smoke detectors since there was no Fire Emulator/Detector Evaluator [52] test data available to predict dwell and mixing time constant values for the equipment tested. Each fire was modeled using a heat release rate per unit area and a ramp function in the model as discussed earlier.

A sample Smokeview rendering of a model of the 21-m elevation case is shown in Figure 24. The figure shows the fire at the bottom and four of the large grids outlined in black, the platform with the detectors near the top of the figure and the inert upper boundary at the top. 


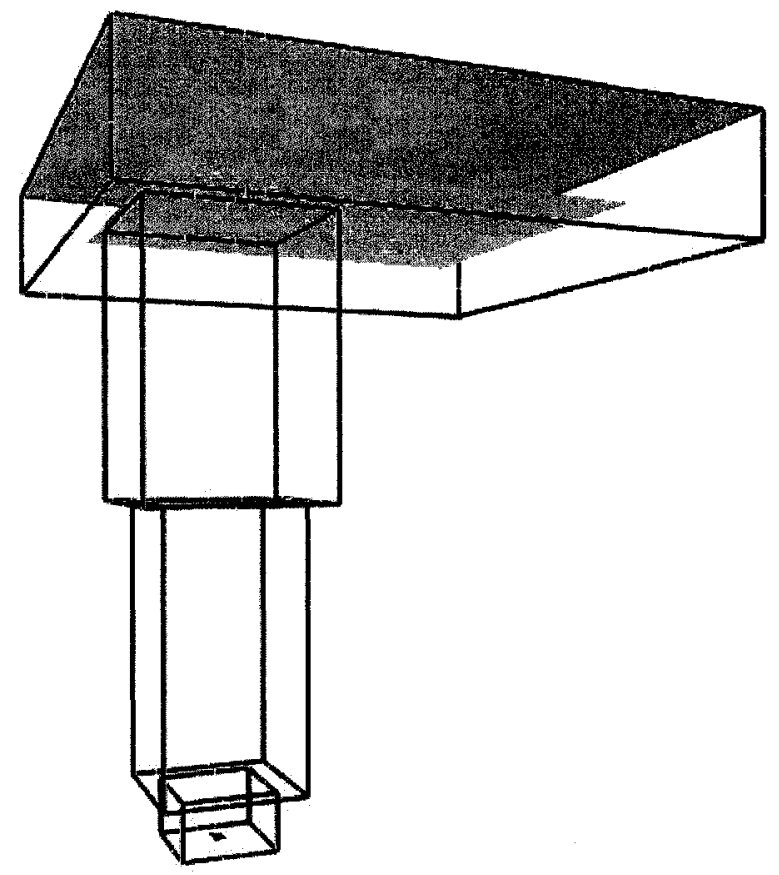

mesh: 1

Figure 24 - FDS model for 21 m elevation

Models were run on one of three pc computers running either Windows $\mathrm{XP} \circledast$ or Windows Vista ${ }^{\circledR}$ operating systems with varying amounts of memory and processor speed. Simulation time ran for between 12 and 19 hours depending on the model mesh detail size and the computer used. A sample temperature slice file image is shown in Figure 25 with a matching 3D Smokeview image shown in Figure 26.

$-58-$ 


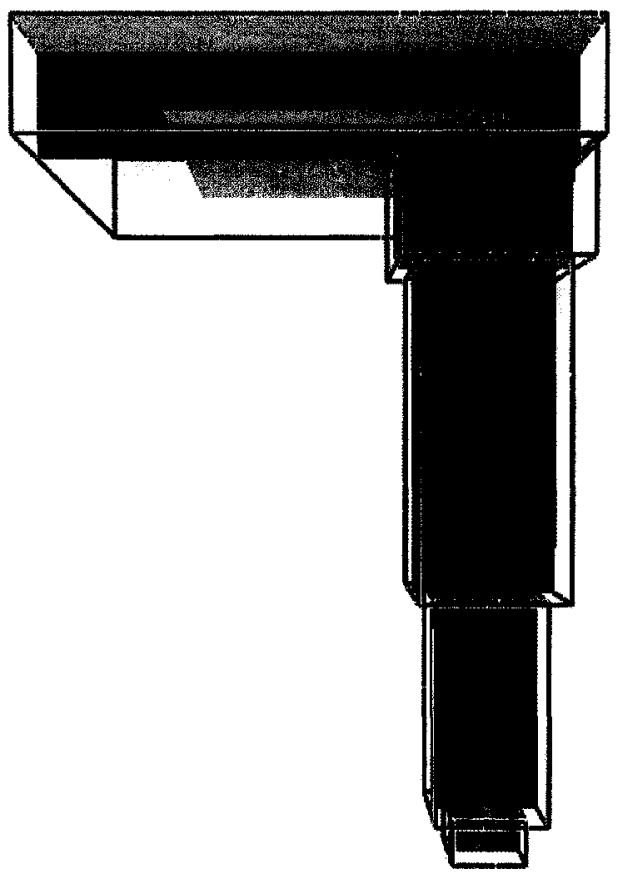

Figure 25 - Temperature profile, 21-m elevation, 100-ml liquid fuel fire at $55 \mathrm{~s}$ 


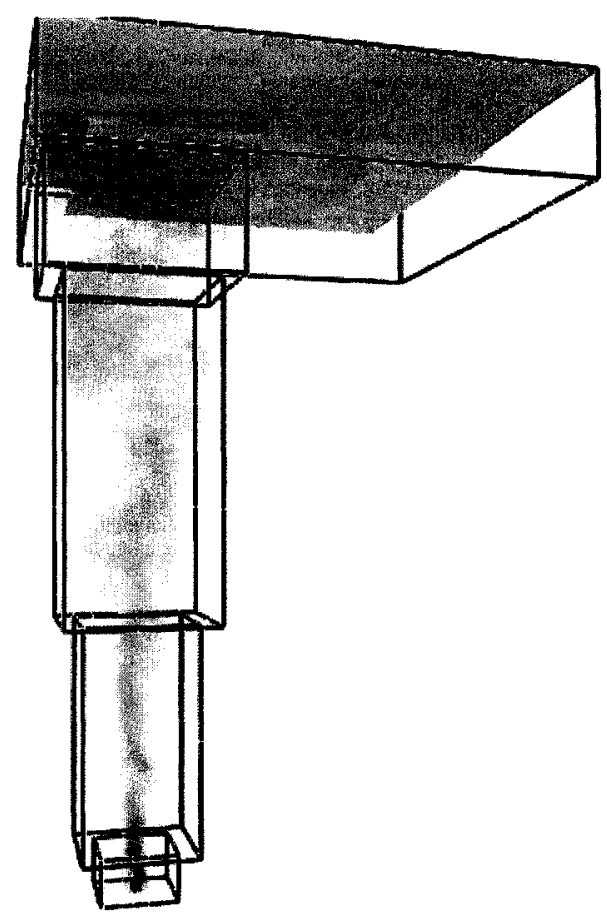

Figure 26-3D Smokeview, 21-m elevation, 100-ml liquid fuel fire at $55 \mathrm{~s}$

The obscuration values predicted by FDS for the first row of detectors from this simulation are plotted in Figure 27. When comparing the $3 \mathrm{D}$ image with the data plot, it can be seen that at the simulation time of 55.2 seconds, the obscuration is at or near its peak value for this model.

$-60-$ 


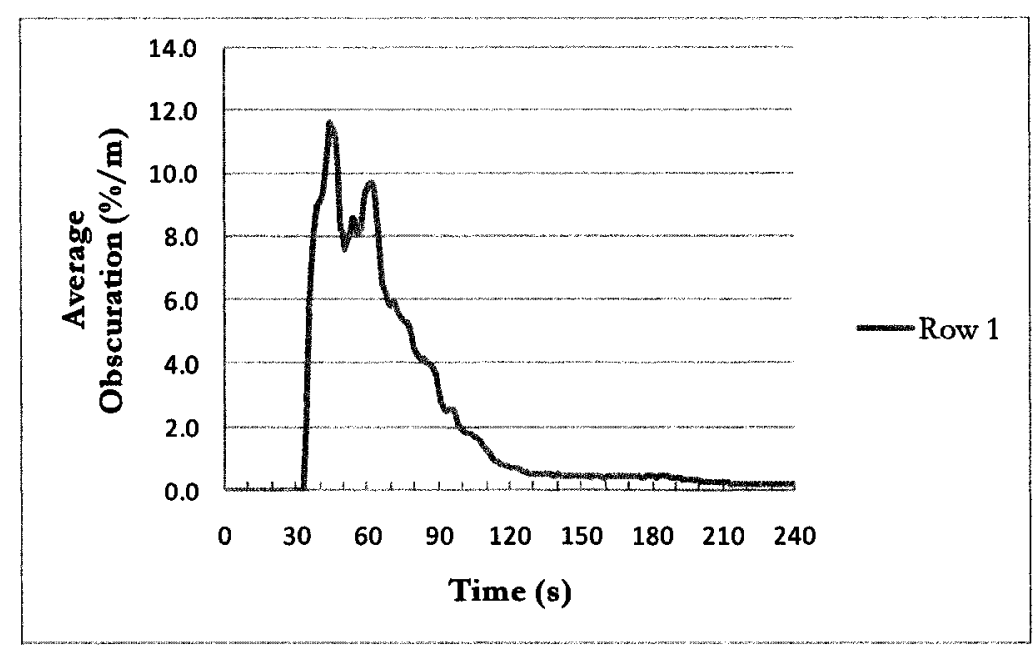

Figure 27 - Average Obscuration vs. Time from FDS, $100 \mathrm{ml}$ liquid fuel fire

$-61-$

Reproduced with permission of the copyright owner. Further reproduction prohibited without permission. 


\section{Results and Discussion}

Experimental results are presented along with modeling results in this chapter. The modeling activities necessarily followed the experimental activities for this project because some of the test fires were designed during the experimental phase in response to environmental factors and experimental findings. The results of experiments and simulations are presented together for comparison purposes. Results are evaluated by elevation to get a sense of the effects of radius on the obscuration results and predictions for each fire type at a particular elevation. Then the effects of elevation on results and predictions are presented and finally some selected comparisons are made in the last section of the chapter.

A discussion of how well the flow field is resolved by FDS is contained in this chapter but the bulk of the discussion is on the maximum obscuration measured or predicted. Since commercial smoke detectors produce latching alarm signals, this type of discussion is appropriate because only a comparison of the maximum value predicted against the alarm threshold of the detector is necessary.

\subsection{Experimental Results}

In all, 72 burn tests were conducted over a period of four months from May to September 2008. Testing was conducted with three different fuels in seven different fuel packages and seven different elevations. Each fire type consisted of a fuel type and fuel quantity. At each elevation there were a number of fire types tested. Each fire type and elevation combination test was generally repeated three times. Records were taken of temperature and detector response to smoke for all of the tests.

A record of the testing conditions for all tests was prepared and is included in Appendix B. The record includes test number, fuel type and quantity as well as the platform elevation during the test. The record also includes ambient values of 
temperature, pressure and humidity. The pressure and humidity values were taken from the Environment Canada web site www.weatheroffice.gc.ca while the temperature values were the average of the recorded thermocouple tree values prior to beginning the tests. The data from these records were used as model inputs.

Detector outputs are limited to approximately $150 \%$ of their alarm value (around $10 \%$ obscuration per metre). Any optical density values reached above this limit are not reflected in the alarm output data. When any of the detectors reached its alarm limit, no further inference from the data was made.

The proximity of the fire to the edge of the platform resulted in a significant amount of smoke missing the platform altogether as indicated in Figure 28. This observation was expected since there were no walls constructed for these tests. The purpose for the open platform was to simulate a large open room with much larger dimensions than the standard test room. 


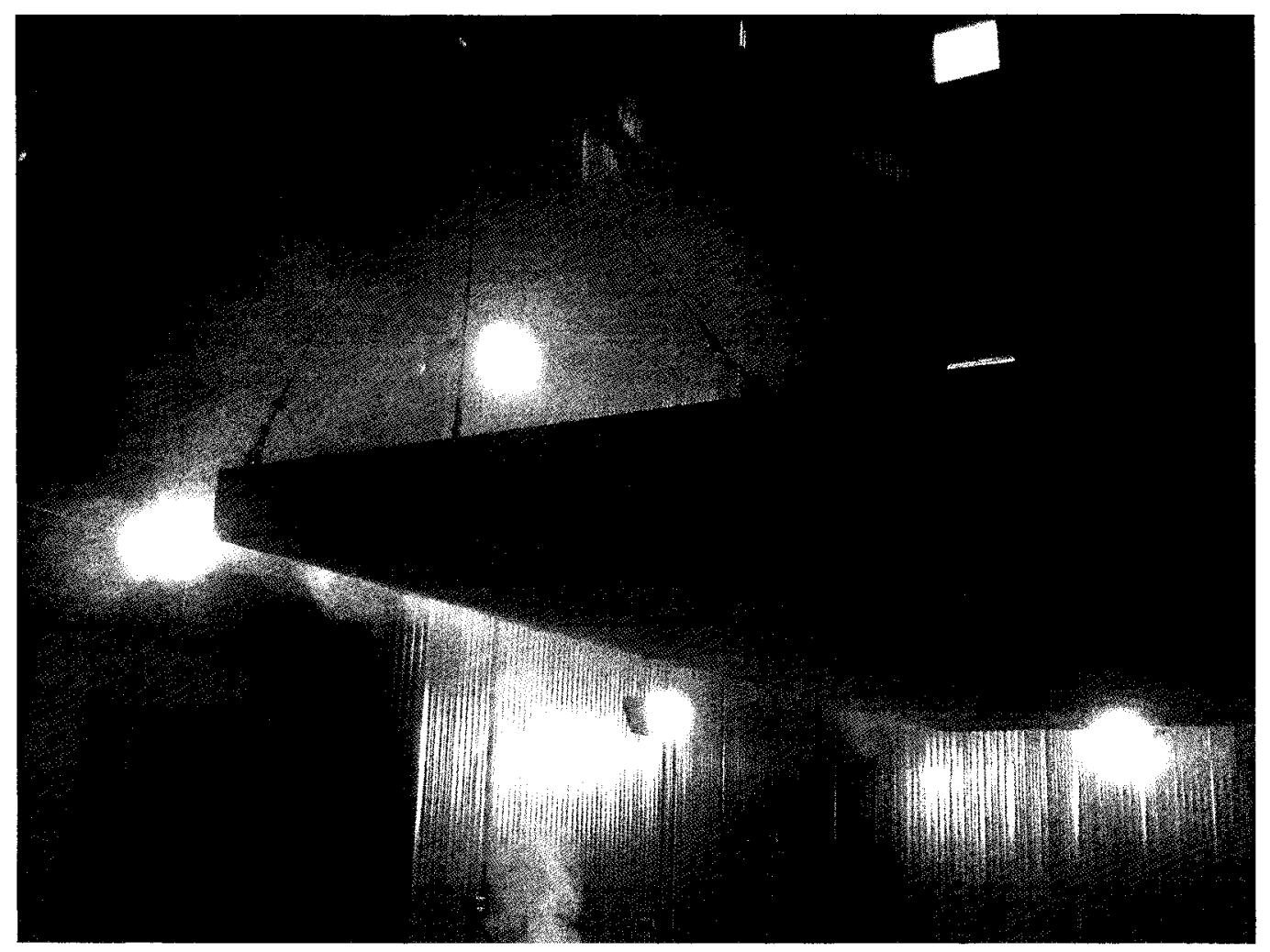

Figure 28 - Smoke movement around the platform

\subsection{Algebraic Modeling Results}

The model steps discussed in section 2.14.1 were followed to predict maximum obscuration at the smoke detector location using maximum heat release rates of the experimental fires.

All fires modeled were determined to have enough lift to reach the ceiling and create a ceiling jet using Eq. 30 although the maximum difference recorded from the lowest thermocouple to the highest prior to a test fire was not more than a few tenths of a degree in total, a value of $\mathrm{dT} / \mathrm{dz}$ of as high as $0.25{ }^{\circ} \mathrm{C} / \mathrm{m}$ still 
results in a $z_{m}$ of $50 \mathrm{~m}$ even for the smallest fire modeled. Stratification was not considered a factor.

Typical results from the algebraic models are shown in Table 2. The table gives results of the $20-\mathrm{ml}$ liquid fuel fire modeled with a ceiling elevation of $3 \mathrm{~m}$. The Watanabe and Tanaka [16] predictions are shown in the column labelled W+T and the Davis and Reneke [17] predictions are shown in the column labelled $D+R$. The results show that the two algebraic models compare well.

Table 2 - Algebraic model results for 20-ml liquid fuel fire, 3-m elevation

\begin{tabular}{cccc}
\hline & & \multicolumn{2}{c}{$\begin{array}{c}\text { Maximum } \\
\text { Obscuration }\end{array}$} \\
\hline Row & Radius & W+T & D+R \\
\hline & $(\mathrm{m})$ & $(\% / \mathrm{m})$ & $(\% / \mathrm{m})$ \\
\hline 1 & 0 & 12.31 & 12.80 \\
2 & 1.63 & 5.16 & 7.82 \\
3 & 3.26 & 3.51 & 5.09 \\
4 & 4.89 & 2.79 & 3.68 \\
5 & 6.52 & 2.38 & 2.83 \\
6 & 8.15 & 2.10 & 2.28 \\
7 & 9.78 & 1.89 & 1.89 \\
8 & 11.41 & 1.73 & 1.60 \\
\hline
\end{tabular}

None of the predicted times were close to the maximum allowable time from the standard acceptance tests, however it is acknowledged that the calculation formula are for steady state fires which would return faster than expected detection times. Since the observations of detection times from experiments also shows that detection time is not a factor in the acceptance tests, the topic is not pursued further. 
The algebraic model results are discussed in more detail in the following sections, where they are compared with the results from the other models and the experimental data.

\subsection{Zone Modeling Results}

The zone model CFAST was used to simulate the experimental tests. As CFAST predictions do not take into account a ceiling jet factor, the reported obscuration values should be compared against only the maximum measured obscuration value for a given test regardless of the radial distance of the measurement from the fire source.

The fire heat release rates were modeled as described in chapter 4 of this report. All six fire types were modeled at all seven elevations of the platform for a total of 22 CFAST models. Four liquid fuel fires with 20, 40,60 and $100 \mathrm{ml}$ of heptane/toluene as well as one paper and one wood fire were modeled. At elevations $3 \mathrm{~m}$ through $12 \mathrm{~m}$, one model was run for each of the $20 \mathrm{ml}$ liquid, paper and wood fires. At the $15-\mathrm{m}$ elevation the $20 \mathrm{ml}, 40 \mathrm{ml}$ and $100 \mathrm{ml}$ liquid fire simulations as well as the wood and paper simulations were run. For the 18 $\mathrm{m}$ elevation the $40 \mathrm{ml}$ and $60 \mathrm{ml}$ liquid models were run. For the $21 \mathrm{~m}$ elevation the $60 \mathrm{ml}$ and $100 \mathrm{ml}$ liquid fire simulations were run.

Obscuration vs. time plots of the CFAST outputs are provided here, one for each fuel package with a plot line for each elevation. Figure 29 shows the CFAST model results for the five paper fire models at elevations from $3 \mathrm{~m}$ to $15 \mathrm{~m}$. The $3 \mathrm{~m}$ elevation reaches a maximum obscuration of $1.27 \% / \mathrm{m}$ at approximately two minutes into the model simulation, while the $6 \mathrm{~m}$ model doesn't reach a maximum value of $1.15 \% / \mathrm{m}$ until the end of the simulation. The remaining elevations quickly reach a maximum of $0.13 \% / \mathrm{m}$ and remain at that value for the rest of the simulation (the lines overlap in the plot). 


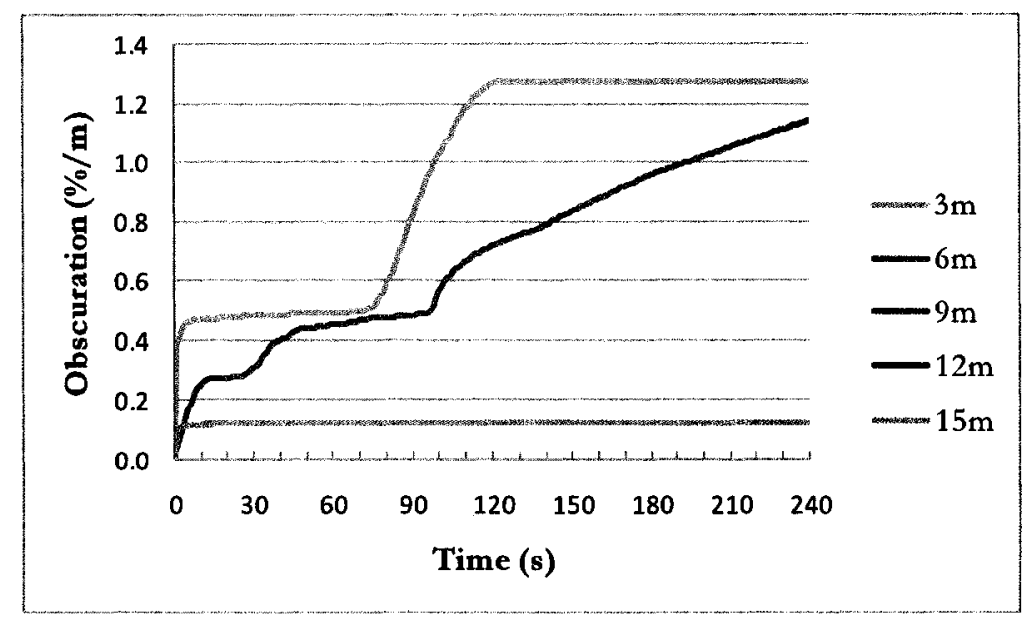

Figure 29 - CFAST Obscuration vs. Time, paper fire models

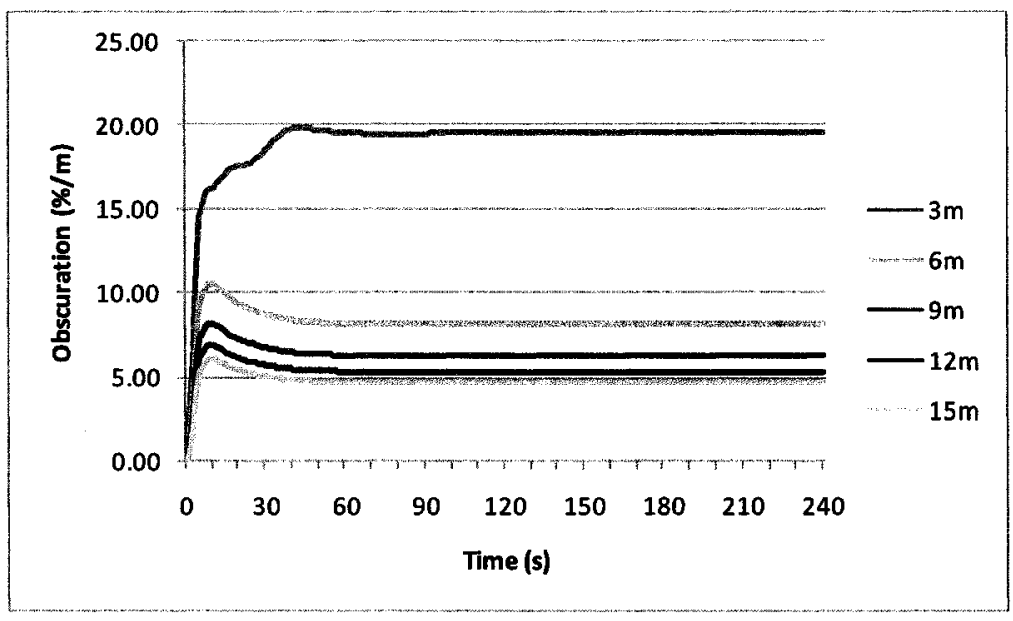

Figure 30 - CFAST Obscuration vs. Time, 20-ml liquid fuel fire models

Figure 30 shows the CFAST results for the 20-ml liquid fuel fire models. Simulations were run for elevations from $3 \mathrm{~m}$ to $15 \mathrm{~m}$. In this case maximum values for the 3-m model produced a maximum obscuration result later in the simulation than the simulations with higher platform elevations. The $3-\mathrm{m}$ simulation reached a maximum obscuration value of $19.79 \% / \mathrm{m}$ at around $50 \mathrm{~s}$. The peak for the other simulations was reached before the $20 \mathrm{~s}$ mark. The 
maximum obscuration values were $10.58 \% / \mathrm{m}$ for the $6-\mathrm{m}$ elevation, $8.18 \% / \mathrm{m}$ for the $9-\mathrm{m}$ elevation, $6.92 \% / \mathrm{m}$ for the $12-\mathrm{m}$ elevation, and $6.07 \% / \mathrm{m}$ for the 15-m elevation. Figure 31 shows the CFAST results for the three 40-ml liquid fuel fire models. The maximum values appear affected by some model instability occurring at approximately 150 seconds into the model run. This instability affects the $15-\mathrm{m}$ and $18-\mathrm{m}$ elevations more than the $21-\mathrm{m}$ elevation. The maximum value was taken at the time of the first peak for these simulations at around $11 \mathrm{~s}$ time period. The peak for the $15-\mathrm{m}$ elevation was taken as 6.11 $\% / \mathrm{m}$, the $18-\mathrm{m}$ elevation peak was taken as $5.99 \% / \mathrm{m}$ and the $21-\mathrm{m}$ elevation peak was taken as $5.09 \% / \mathrm{m}$ for comparison with other model results for this fuel.

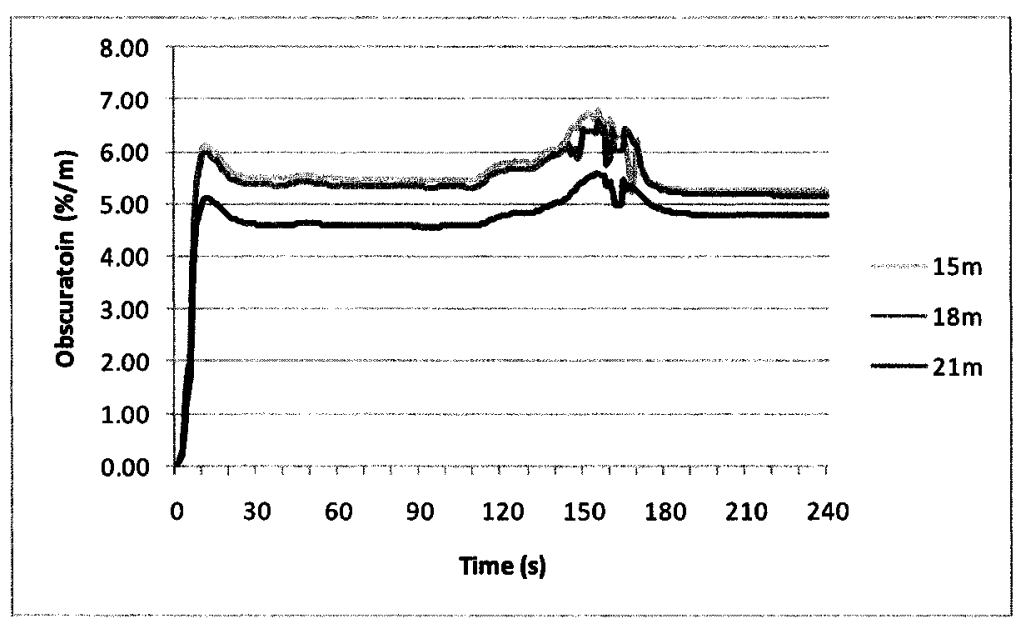

Figure 31 - CFAST Obscuration vs. Time, 40-ml liquid fuel fire models 


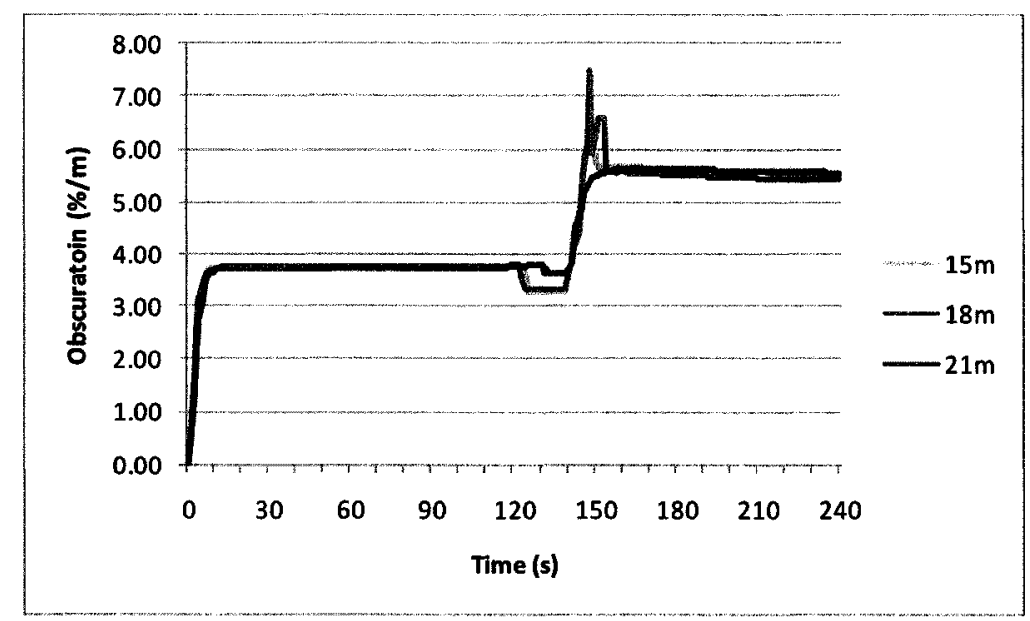

Figure 32 - CFAST Obscuration vs. Time, 60-ml liquid fuel fire models

A similar instability occurred for the $60-\mathrm{ml}$ liquid fuel fire models shown in Figure 32. The affect is more dramatic for the $60-\mathrm{ml}$ fires than the $40-\mathrm{ml}$ liquid fuel fires and occurs sooner. The steady maximum value after the instability is higher than those listed before the instability. For this reason, the maximum value used for comparison with other models for the $60-\mathrm{ml}$ liquid fuel fire is the value simulated around the $180 \mathrm{~s}$ mark. For the $15-\mathrm{m}$ elevation the value is $6.11 \% / \mathrm{m}$, for the $18-\mathrm{m}$ elevation the value is $5.99 \% / \mathrm{m}$ and for the $21-\mathrm{m}$ elevation simulated value of $5.09 \% / \mathrm{m}$ is used. The obscuration values attained from the two $100-\mathrm{ml}$ liquid fuel fire models are more shaped like the values form the $40-\mathrm{ml}$ simulation as shown in Figure 33. The maximum values used for comparison for the $100-\mathrm{ml}$ fires are $19.31 \% / \mathrm{m}$ for the $15-\mathrm{m}$ simulation and $15.95 \% / \mathrm{m}$ for the 21-m simulation. 


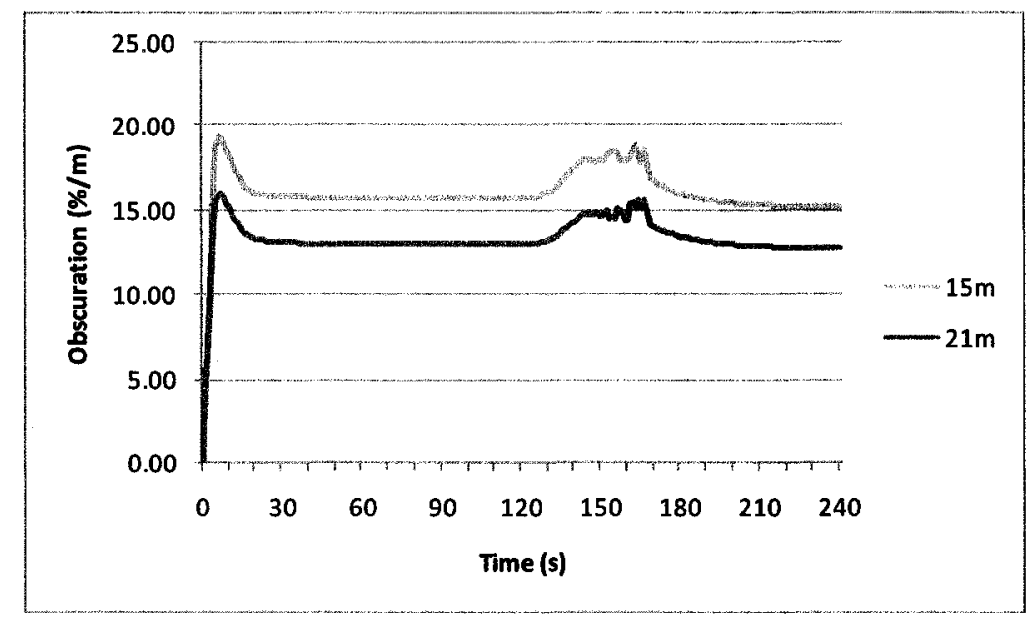

Figure 33 - CFAST Obscuration vs. Time, $100 \mathrm{ml}$ liquid fuel fire models

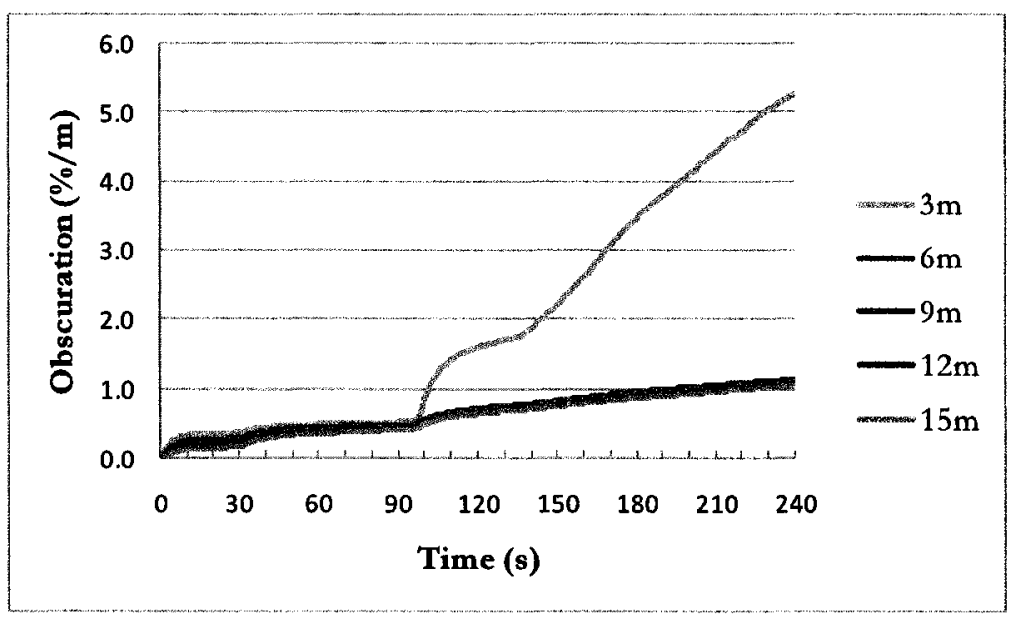

Figure 34 - CFAST Obscuration vs. Time results for wood fire models

The wood fire CFAST model results are shown in Figure 34. The 3-m elevation model reaches a maximum obscuration of $5.28 \% / \mathrm{m}$ at the end of the simulation. The model results for the other elevations are very close together, growing for the entire duration of the model, returning maximum obscuration values of the end of the simulation of $1.16 \% / \mathrm{m}$ for the $6-\mathrm{m}$ elevation, $1.10 \% / \mathrm{m}$ for the $9-\mathrm{m}$ elevation, and $1.05 \% / \mathrm{m}$ for the $12-\mathrm{m}$ and $15-\mathrm{m}$ elevations. The wood fire is the 
only fire type that does not achieve a level of steady state obscuration because the fire continues to grow throughout the simulation period. Fire growth data was provided to the model only up to the $240 \mathrm{~s}$ mark of the test, which marks the end of the test.

\subsection{CFD Modeling Results}

A simulation using FDS was conducted for each fuel type and elevation combination used in the tests. Six fires were modeled, spread out over the seven elevations of the platform for a total of 22 runs. Four liquid fuel fires with 20, 40, 60 and $100 \mathrm{ml}$ of heptane/toluene as well as one paper and one wood fire were modeled. At elevations from $3 \mathrm{~m}$ through $12 \mathrm{~m}$, one model was run for each of the $20 \mathrm{ml}$ liquid, paper and wood fires. At the $15 \mathrm{~m}$ elevation, the $20 \mathrm{ml}, 40 \mathrm{ml}$ and $100 \mathrm{ml}$ liquid fire simulations as well as the wood and paper simulations were run. For the $18 \mathrm{~m}$ elevation the $40 \mathrm{ml}$ and $60 \mathrm{ml}$ liquid models were run. For the $21 \mathrm{~m}$ elevation the $40 \mathrm{ml}, 60 \mathrm{ml}$ and $100 \mathrm{ml}$ liquid fire simulations were run.

One of the questions that is commonly asked when evaluating FDS modeling is, how well did the simulation resolve the flow field? In order to assess this question we can look at the plot of average obscuration measured from one of the test shown in Figure 35 and compare it to the same data returned from FDS shown in Figure 36. 


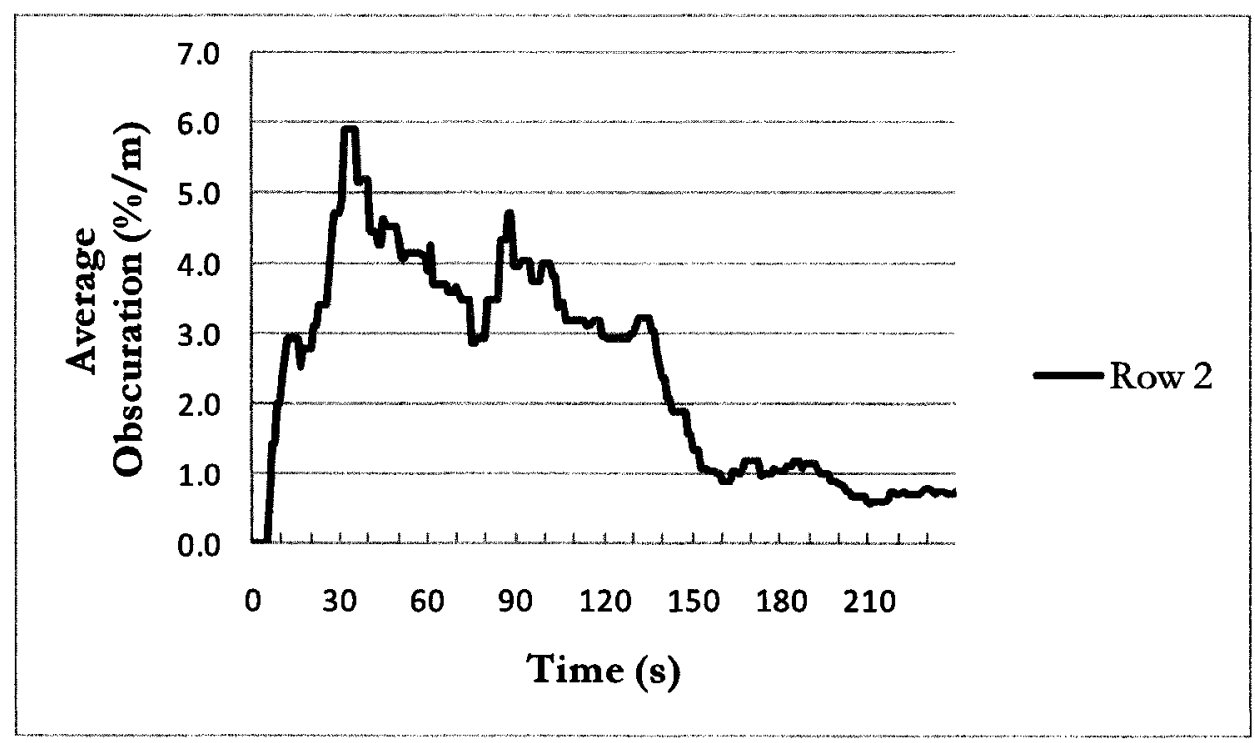

Figure 35 - Average Obscuration vs. Time, Test 1, Row 2

The average values from Row 2 of Test 1 show that obscuration begins to increase sooner (less than 10 seconds for the test and around 20 seconds for the FDS model) but has slower growth in obscuration with a lower peak $(6 \% / \mathrm{m}$ for the test and $9 \% / \mathrm{m}$ for the FDS model) but the peaks occur at roughly the same time (around 30 to 40 seconds). The decay in obscuration levels is also quicker for the FDS model versus measured values. 


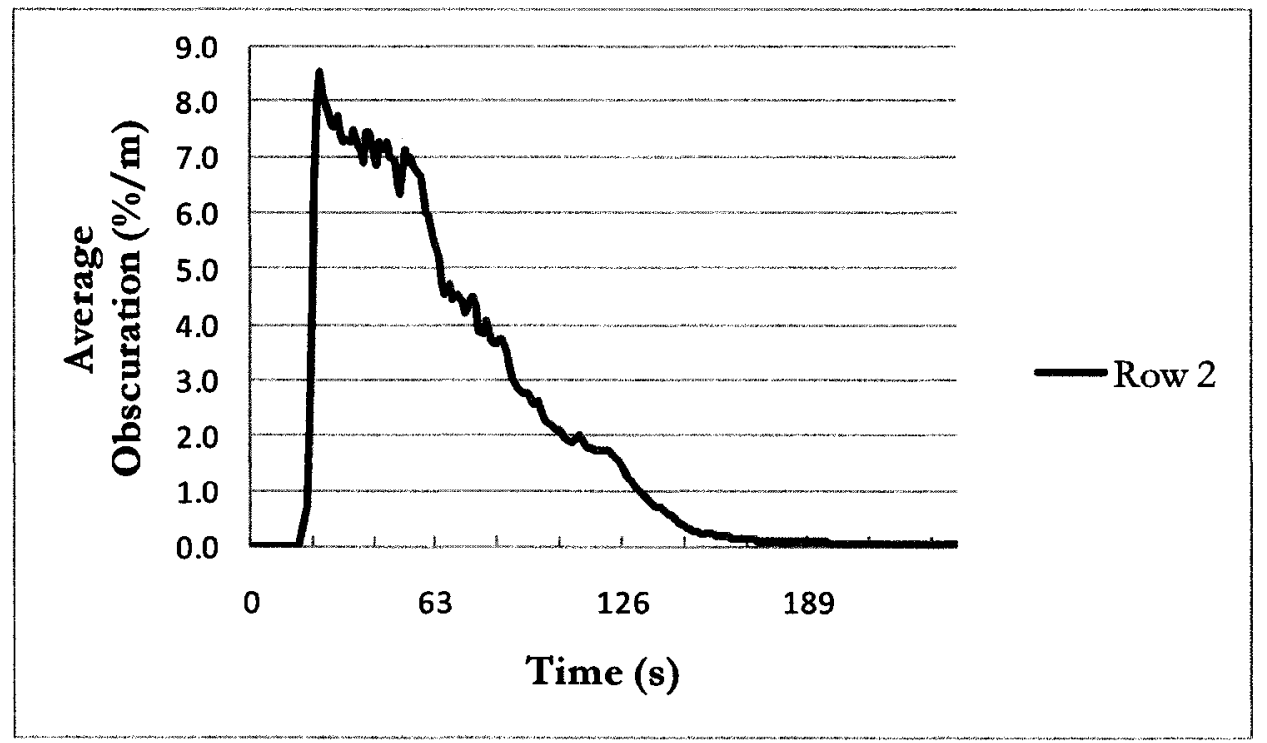

Figure 36 - Average Obscuration vs. Time, $20 \mathrm{ml}$ liquid fuel fire, FDS

Another test of how well the model resolves the flow field is to compare the heat release data input with the heat release data output from the model. The expectation here is that they will be nearly identical. Since the model inputs were derived from temperature data taken directly from the experiments, a good comparison is with this data. The heat release data for the $100-\mathrm{ml}$ liquid fuel fire shown in Figure 37 was used as the model input. This data was derived from Test 67 , so a comparison of this information with the heat release output from $100-\mathrm{ml}$ liquid fuel simulation at the same height $(21 \mathrm{~m})$ shown in Figure 38 is useful. 


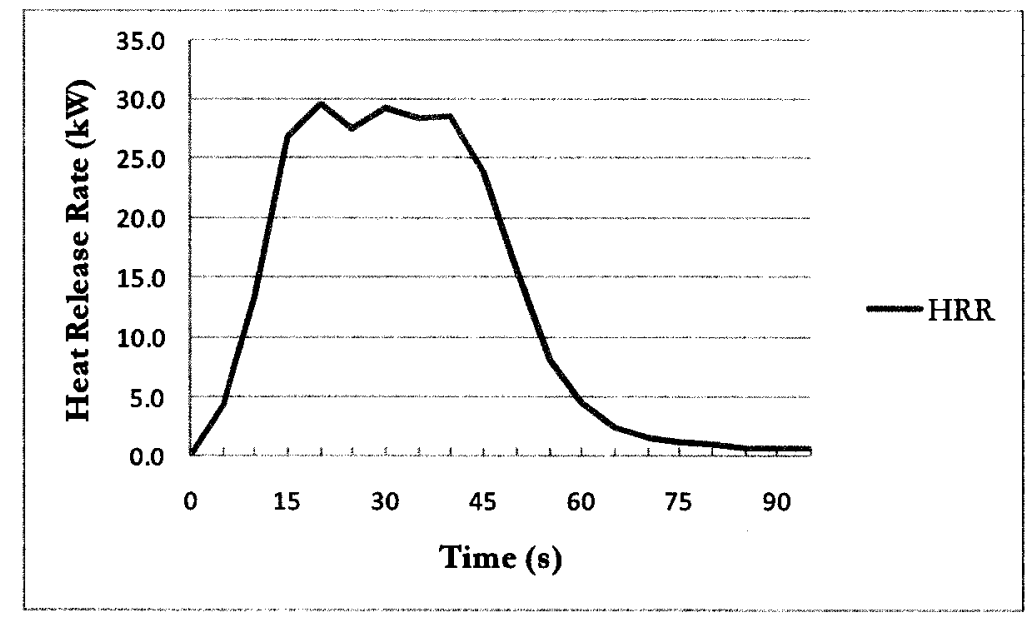

Figure $37-100 \mathrm{ml}$ liquid fuel fire model heat release rate, $5 \mathrm{~s}$ moving average

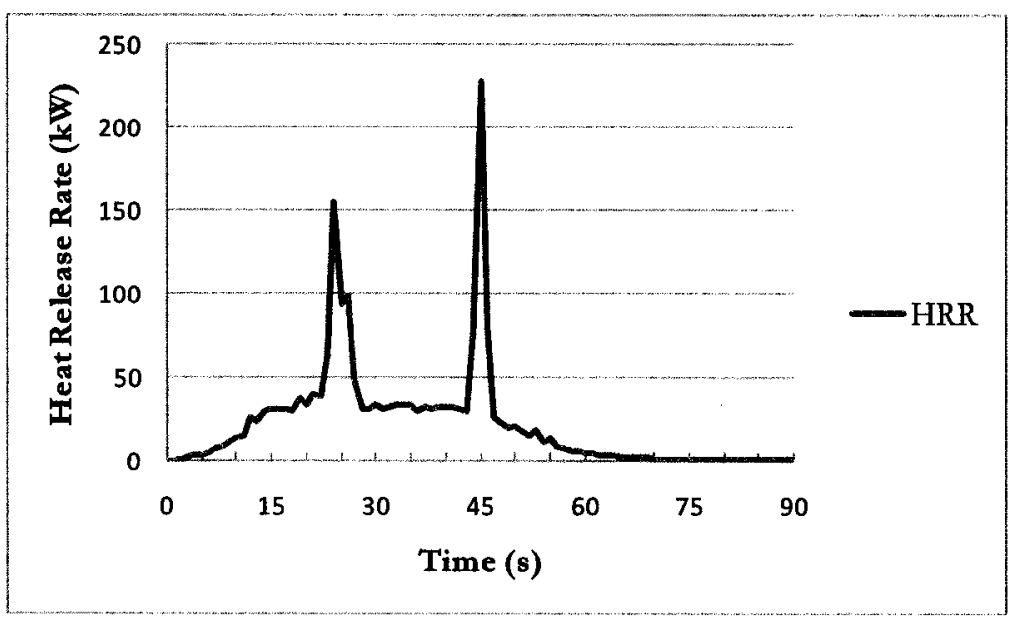

Figure 38 - HRR vs. Time for FDS 100-ml liquid fuel fire, 21-m elevation

The FDS output shows instability at the leading and trailing edge of the heat release peak, producing very high heat release values. Otherwise, the FDS output shows a similar top hat output with the same maximum value of around $20 \mathrm{~kW}$ at the same time as the input data. The instability could be explained by the sudden change in heat release rate of change input into the model (Figure 18) at the two time periods and the peaks shown could be related to the differences in slope of 
the heat release input chart. The spreadsheet output chart indicates that the instability last for approximately $3 \mathrm{~s}$ on both the leading and trailing edges and does not appear to create a similar instability in the obscuration vs. time data for the same simulation.

A typical obscuration vs. time plot from the experimental testing is shown in Figure 39. The figure shows the wood fire test results for the third row of detectors for Test 25 . There are two initial peaks in the obscuration values recorded. The first peak at approximately 120 seconds and the second at approximately 160 seconds into the test.

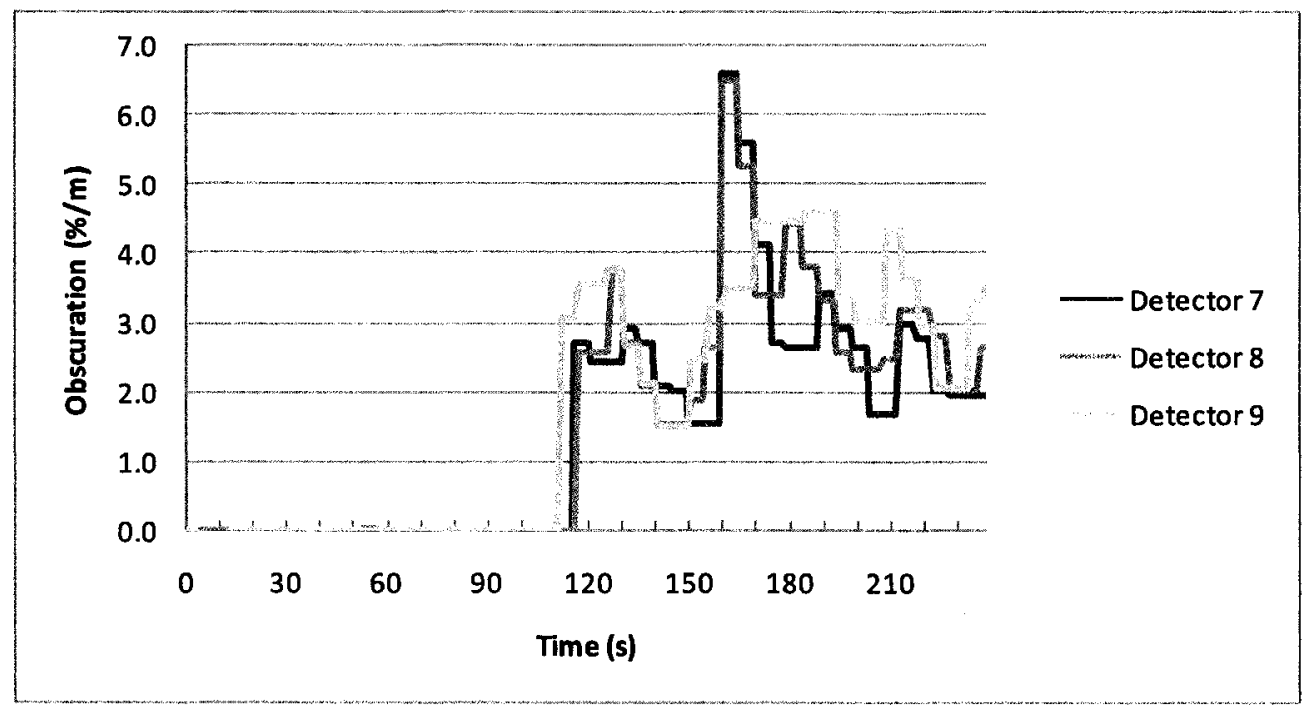

Figure 39 - Obscuration vs. Time - Experimental results for wood fire test number 25 at $9-\mathrm{m}$ elevation, Row 3 


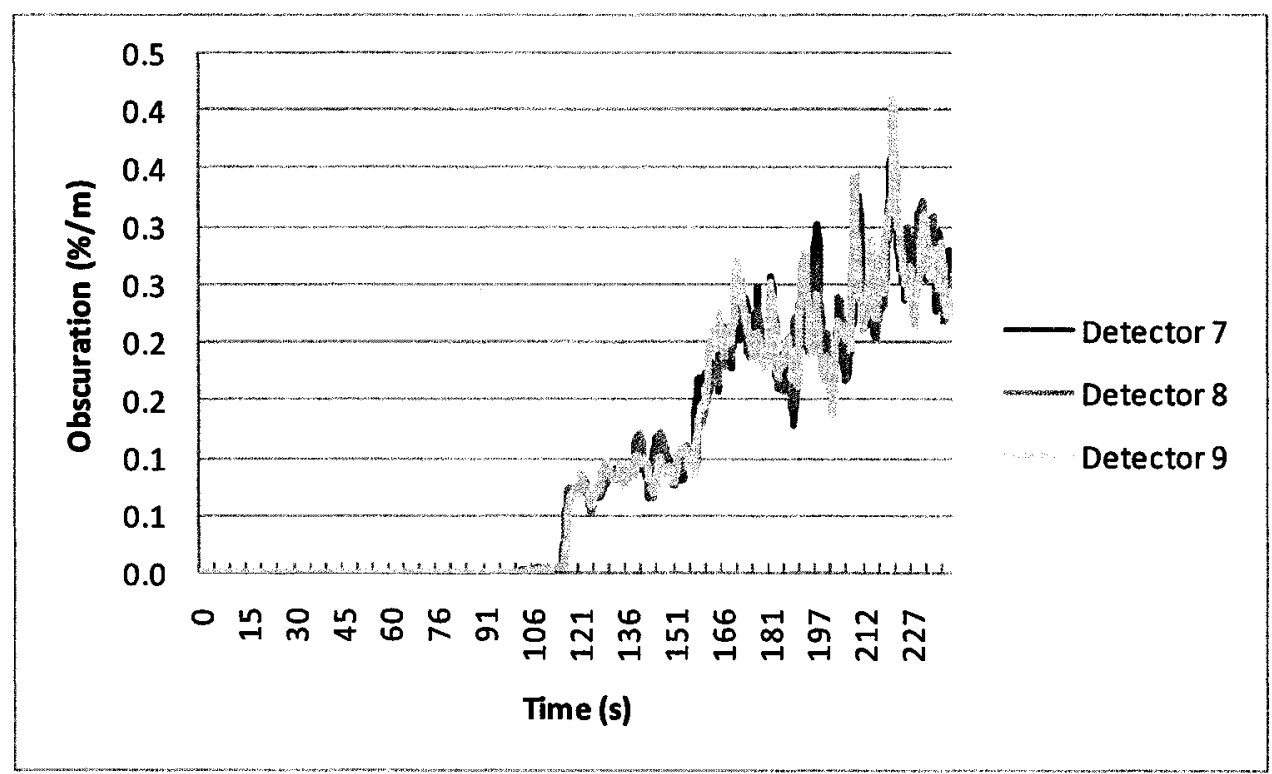

Figure 40 - Obscuration vs. Time - FDS simulation for wood fire at 9-m elevation, Row 3

In comparison with the recorded obscuration values for Test 25, the FDS results shown in Figure 40 indicate that the predicted first indication of smoke occurs roughly at the same time as Test 25 but the peak value is much lower than that recorded and it climbs steadily through the simulation as opposed to the peak value followed by a decline in obscuration recorded during the test.

\subsection{Effects of radius and fire type}

This section of the report shows experimental results along with model results together for comparison purposes. The values compared are the maximum obscuration values averaged for the three detectors in a row obtained from either experimental or FDS modeling. Only a single result is obtained for each row for the algebraic models and only a single result for the entire upper layer is obtained from CFAST. Charts in this section show the single value reported by the 
CFAST model at each radial distance for visibility purposes only, not to infer that the model predicts that radius has an effect on the reported value.

The test conditions are summarized in Appendix B for all of the tests conducted.

\subsubsection{3-m Elevation}

Nine tests were conducted with the platform at an elevation of $3 \mathrm{~m}$ on May 20 , 2008 (Tests 1-9). Three fuel packages were used; $20-\mathrm{ml}$ heptane/toluene mixture, newsprint, and wood crib. Each fuel package was tested 3 times. Test data was gathered for 240 seconds following ignition for each test. Ambient temperature, pressure and humidity data were recorded for each test and are shown in Table 3. The environmental values were used as model inputs.

Table 3 - Test conditions at 3-m elevation

\begin{tabular}{cccccc}
\hline Test & Fuel & Fuel & & $\mathrm{RH}$ & \\
No. & Type & Qty & $\mathrm{P}_{0}$ & 0 & $\mathrm{~T}_{0}$ \\
\hline & & $\mathrm{ml}$ & $\mathrm{kPa}$ & $\%$ & $\mathrm{C}$ \\
\hline 1 & Liquid & 20 & 99.6 & 44 & 14.32 \\
2 & Liquid & 20 & 99.6 & 44 & 14.39 \\
3 & Liquid & 20 & 99.6 & 44 & 14.64 \\
4 & Paper & & 99.53 & 48 & 14.72 \\
5 & Paper & & 99.53 & 48 & 14.74 \\
6 & Paper & & 99.48 & 48 & 14.29 \\
7 & Wood & & 99.48 & 48 & 14.68 \\
8 & Wood & & 99.48 & 48 & 14.54 \\
9 & Wood & & 99.45 & 48 & 14.77 \\
\hline
\end{tabular}

Table 4 lists maximum averaged obscuration values for the three detectors in each row of the platform for tests 4 and 5, averaged values in each row reported 
from the FDS model simulation, algebraic results for the Watanabe and Tanaka $(\mathrm{W}+\mathrm{T})$ as well as the Davis and Reneke $(\mathrm{D}+\mathrm{R})$ model for the paper fire at this elevation. The data is plotted in Figure 41.

Table 4 - Paper fire maximum obscuration results at 3-m elevation

\begin{tabular}{cccrrrrr}
\hline & \multicolumn{3}{c}{ Alarm } & \multicolumn{5}{c}{ Maximum Obscuration } \\
\hline Row & Radius & Threshold & Test 4 & Test 5 & FDS & W+T & D+R \\
\hline & $(\mathrm{m})$ & $(\% / \mathrm{m})$ & $(\% / \mathrm{m})$ & $(\% / \mathrm{m})$ & $(\% / \mathrm{m})$ & $(\% / \mathrm{m})$ & $(\% / \mathrm{m})$ \\
\hline 1 & 0 & 6.23 & 5.80 & 3.03 & 0.59 & 1.26 & 1.12 \\
2 & 1.63 & 6.45 & 1.54 & 1.02 & 0.27 & 0.75 & 0.45 \\
3 & 3.26 & 6.78 & 0.32 & 0.32 & 0.18 & 0.48 & 0.31 \\
4 & 4.89 & 7.27 & 0.02 & 0.21 & 0.14 & 0.35 & 0.24 \\
5 & 6.52 & 7.00 & 0.04 & 0.09 & 0.11 & 0.27 & 0.21 \\
6 & 8.15 & 6.84 & 0.02 & 0.09 & 0.08 & 0.21 & 0.18 \\
7 & 9.78 & 6.67 & 0.05 & 0.11 & 0.07 & 0.18 & 0.16 \\
8 & 11.41 & 7.00 & 0.05 & 0.07 & 0.06 & 0.15 & 0.15 \\
\hline
\end{tabular}

The maximum obscuration obtained from CFAST for this fuel and elevation was $1.27 \% / \mathrm{m}$. None of the average obscuration values recorded had values high enough to produce an alarm response for the paper fire tests. The obscuration levels measured decrease in value with radial distance from the source. All of the models under predicted measured results above the fire, but tended towards over prediction as radial distance increased. FDS significantly under predicted measured results for this fire in the first two rows. This may be due to the high influence from environmental conditions on the smoke plume, which for this fire had very weak buoyancy. 


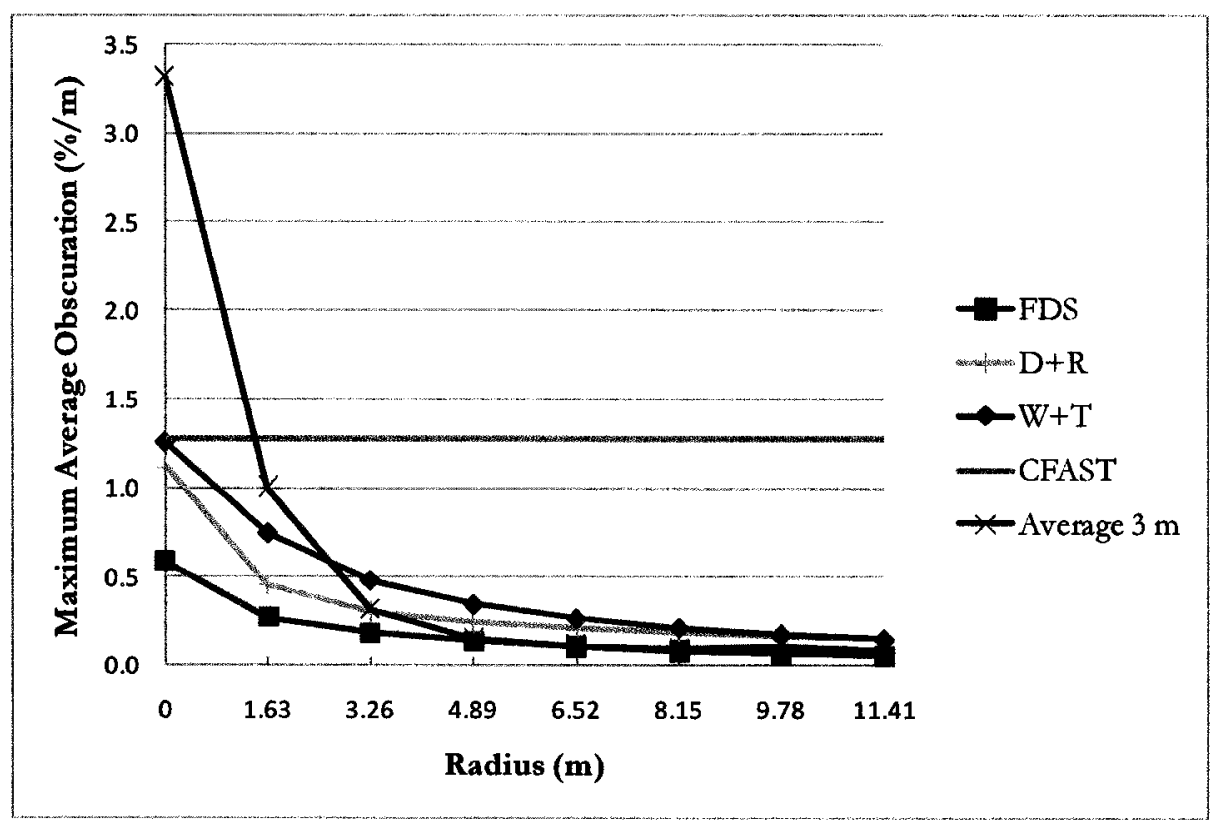

Figure 41 - Maximum Obscuration vs. Radius for newsprint fire at 3-m elevation

Table 5 lists data for the $20-\mathrm{ml}$ liquid fuel fire at this elevation. The maximum obscuration value obtained from CFAST was $19.79 \% / \mathrm{m}$. The data is plotted in Figure 42. Detectors in the first row reached the alarm threshold level for the three liquid fuel tests conducted. Detectors in the second row of Test 3 also produced alarm level obscuration values. The obscuration values followed the same trend as the paper fuel fire with levels decreasing with radius. Since the detectors in the first row reached their saturation limit, comparison of test values to modeled values don't produce any practical inferences. Except for the D+R prediction in the second row of detectors, all of the model predictions are higher than values measured. The fact that the first row of detectors reached saturation also explains the over prediction by the models in this case. 
Table $5-20-\mathrm{ml}$ liquid fuel maximum obscuration results at 3-m elevation

\begin{tabular}{ccccccccc}
\hline & \multicolumn{9}{c}{ Alarm } & \multicolumn{7}{c}{ Maximum Obscuration } \\
\hline Row & Radius & Threshold & Test 1 & Test 2 & Test 3 & FDS & W+T & D+R \\
\hline & $(\mathrm{m})$ & $(\% / \mathrm{m})$ & $(\% / \mathrm{m})$ & $(\% / \mathrm{m})$ & $(\% / \mathrm{m})$ & $(\% / \mathrm{m})$ & $(\% / \mathrm{m})$ & $(\% / \mathrm{m})$ \\
\hline 1 & 0 & 6.23 & 9.52 & 9.54 & 9.57 & 20.12 & 12.31 & 12.80 \\
2 & 1.63 & 6.45 & 5.91 & 4.59 & 8.04 & 8.52 & 5.16 & 7.82 \\
3 & 3.26 & 6.78 & 2.33 & 1.70 & 3.20 & 5.25 & 3.51 & 5.09 \\
4 & 4.89 & 7.27 & 0.96 & 0.81 & 1.64 & 3.90 & 2.79 & 3.68 \\
5 & 6.52 & 7.00 & 1.01 & 0.90 & 1.78 & 2.86 & 2.38 & 2.83 \\
6 & 8.15 & 6.84 & 0.51 & 0.42 & 1.06 & 2.19 & 2.10 & 2.28 \\
7 & 9.78 & 6.67 & 0.07 & 0.13 & 0.63 & 1.76 & 1.89 & 1.89 \\
8 & 11.41 & 7.00 & 0.03 & 0.04 & 0.36 & 1.36 & 1.73 & 1.60 \\
\hline
\end{tabular}

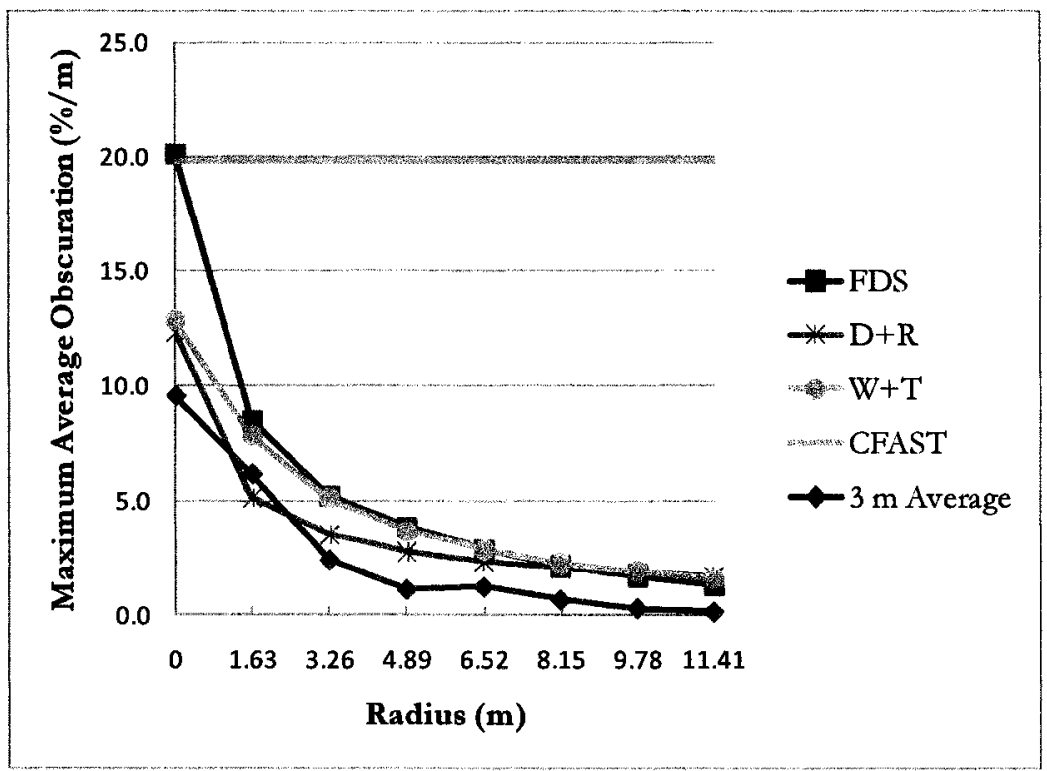

Figure 42 - Maximum Obscuration vs. Radius, $20 \mathrm{ml}$ liquid fuel fire at 3-m elevation

Table 6 data for the wood fire at this elevation. The maximum obscuration value from CFAST is $5.28 \% / \mathrm{m}$. The data is plotted in Figure 43 .

$-80-$ 
Table 6 - Wood fire maximum obscuration results at 3-m elevation

\begin{tabular}{cccrrrrrr}
\hline & \multicolumn{7}{c}{ Alarm } & \multicolumn{7}{c}{ Maximum Obscuration } \\
\hline & & & & & FDS & W+T & D+R \\
Row & Radius & Threshold & Test 7 & Test 8 & Test 9 & & & \\
\hline & $(\mathrm{m})$ & $(\% / \mathrm{m})$ & $(\% / \mathrm{m})$ & $(\% / \mathrm{m})$ & $(\% / \mathrm{m})$ & $(\% / \mathrm{m})$ & $(\% / \mathrm{m})$ & $(\% / \mathrm{m})$ \\
\hline 1 & 0 & 6.23 & 9.58 & 9.66 & 9.72 & 2.24 & 4.38 & 4.10 \\
2 & 1.63 & 6.45 & 9.89 & 9.87 & 9.94 & 1.18 & 2.63 & 1.68 \\
3 & 3.26 & 6.78 & 5.29 & 10.32 & 10.38 & 0.83 & 1.69 & 1.13 \\
4 & 4.89 & 7.27 & 0.41 & 6.84 & 9.03 & 0.64 & 1.22 & 0.90 \\
5 & 6.52 & 7.00 & 0.07 & 5.91 & 7.52 & 0.50 & 0.93 & 0.76 \\
6 & 8.15 & 6.84 & 0.05 & 5.54 & 2.38 & 0.41 & 0.75 & 0.67 \\
7 & 9.78 & 6.67 & 0.05 & 3.44 & 0.31 & 0.33 & 0.62 & 0.61 \\
8 & 11.41 & 7.00 & 0.11 & 1.55 & 0.20 & 0.28 & 0.53 & 0.56 \\
\hline
\end{tabular}

The wood fire produced alarm level obscuration values in all tests in multiple rows, with test 9 producing alarms in the first 5 rows. Obscuration values did not start to diminish below detector saturation levels until the fifth row of detectors for Test 9. The obscuration values reduced with radial distance from the source in general. All the models significantly under predicted measured results. There is a wide range of values reported from the three tests conducted outside the second row of detectors. 


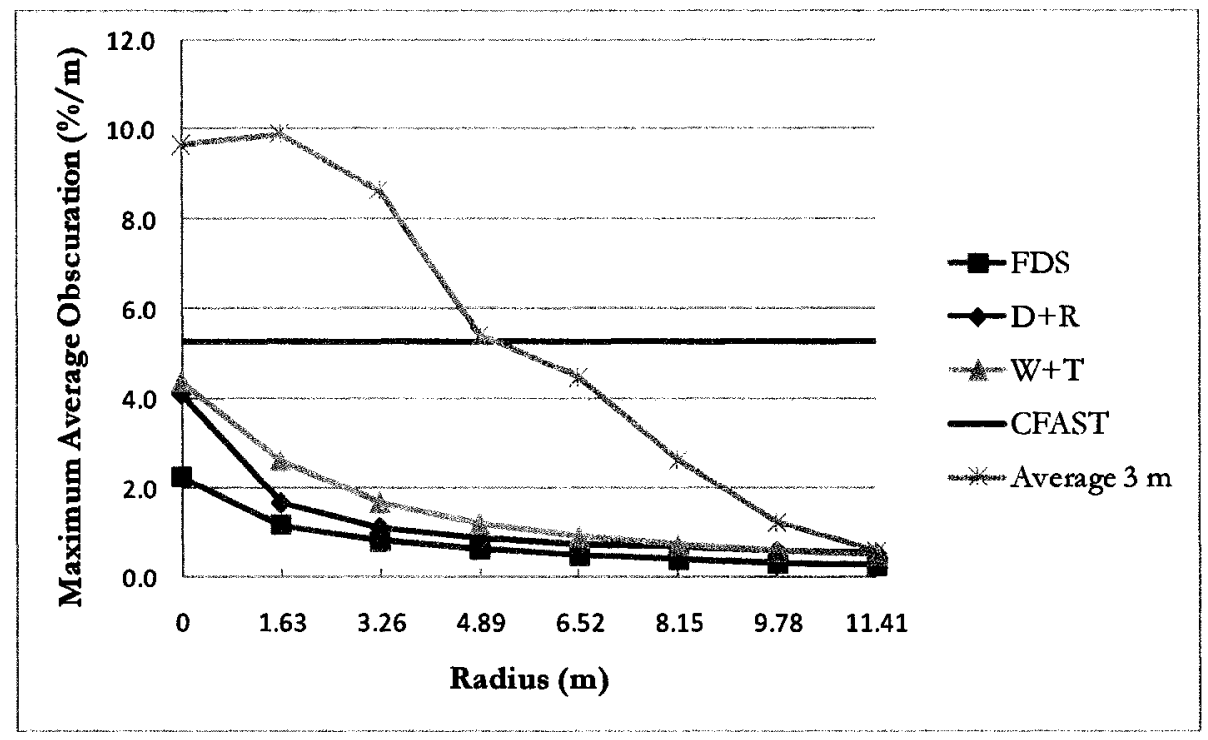

Figure 43 - Maximum Obscuration vs. Radius for wood fire at 3-m elevation

A typical obscuration vs. time plot is shown in Figure 44. The three detectors in row 2 (Detector 4, 5, and 6) are shown. The graph indicates that the three detectors followed essentially the same time trend with the peak value of detector 6 on the outside of the row reaching an alarm level just past 30 seconds into the test. Detector 6 reaches an alarm level obscuration at approximately 30 seconds into the test, but the other two do not record values as high. 


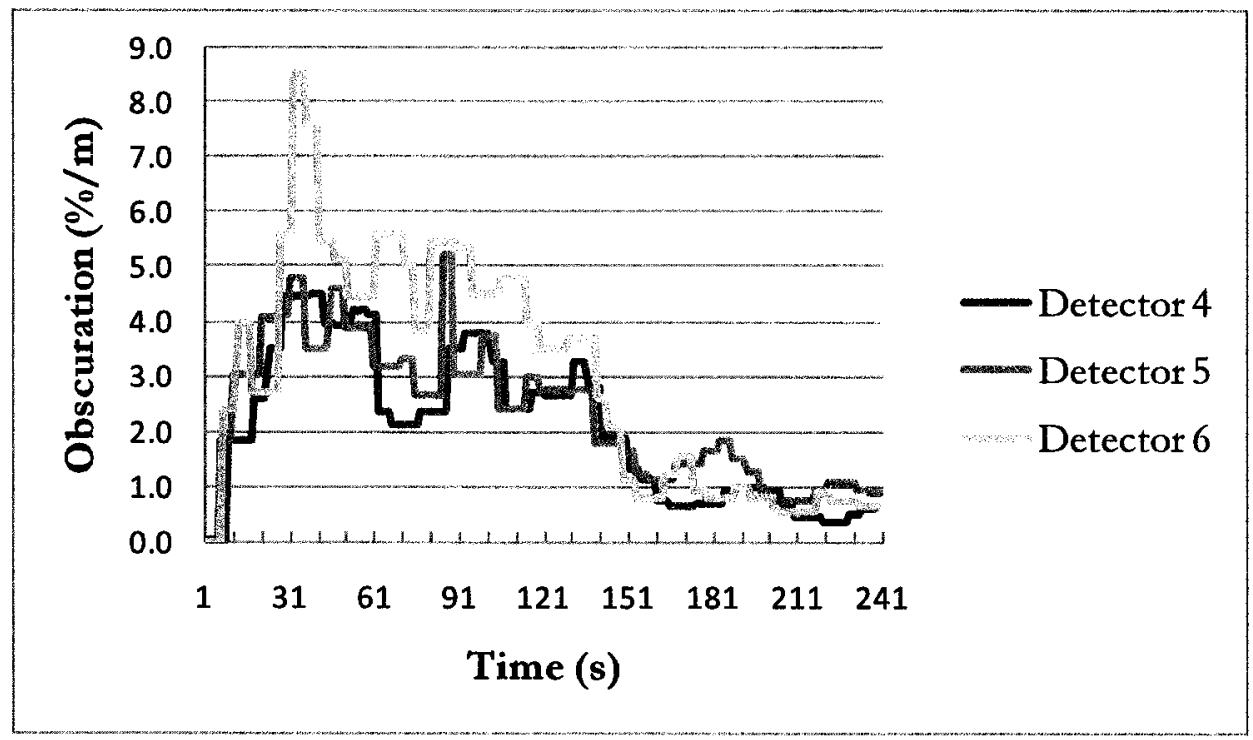

Figure 44 - Obscuration vs. Time, Test 1 , Row 2

Figure 45 shows the average obscuration values recorded for each row of detectors. The $1^{\text {st }}$ row records alarm level obscuration for this test from approximately 10 seconds until approximately 140 seconds. The first three rows of detectors show discernable levels of obscuration from this test and follow the same top hat shaped obscuration results. The remainder of the rows of detectors show only small changes in obscuration levels, with the first indication of any readings occurring progressively later as the radial distance from the source increases. 


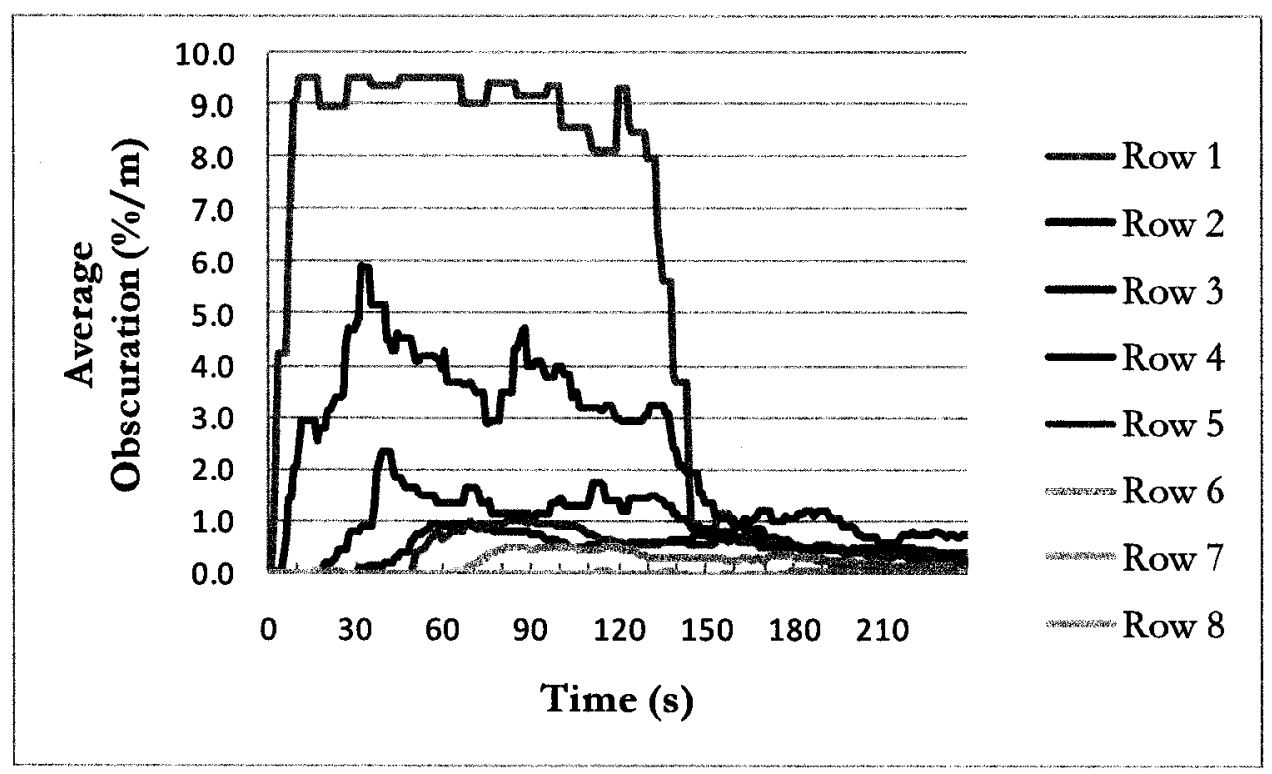

Figure 45 - Average Obscuration vs. Time, Test 1

\subsubsection{6-m Elevation Tests}

Nine tests were conducted with the platform at an elevation of $6 \mathrm{~m}$ on May 21, 2008 (Tests 10-18). Three fuel packages were used; 20-ml heptane/toluene mixture, newsprint, and wood crib. Each fuel package was tested 3 times. Test data was gathered for 240 seconds following ignition for each test. Ambient temperature, pressure and humidity data was recorded for each test and are listed in Table 7.

Table 7 - Test conditions at $6-\mathrm{m}$ elevation

\begin{tabular}{rlrrrr}
$\begin{array}{l}\text { Test } \\
\text { No. }\end{array}$ & $\begin{array}{c}\text { Fuel } \\
\text { Type }\end{array}$ & Qty & \multicolumn{1}{c}{$\mathrm{P}_{0}$} & $\mathrm{RH}_{0}$ & \multicolumn{1}{c}{$\mathrm{T}_{0}$} \\
\hline & & $\mathrm{ml}$ & $\mathrm{kPa}$ & $\%$ & \multicolumn{1}{c}{$\mathrm{C}$} \\
\hline 10 & Liquid & 20 & 99.38 & 76 & 12.77 \\
11 & Liquid & 20 & 99.4 & 71 & 12.06 \\
12 & Liquid & 20 & 99.4 & 71 & 12.06 \\
\hline
\end{tabular}




\begin{tabular}{cccccc}
\hline & & & & & \\
Test & Fuel & & & & \\
No. & Type & Qty & $\mathrm{P}_{0}$ & $\mathrm{RH}_{0}$ & $\mathrm{~T}_{0}$ \\
\hline & & $\mathrm{ml}$ & $\mathrm{kPa}$ & $\%$ & $\mathrm{C}$ \\
\hline 13 & Paper & & 99.4 & 71 & 12.13 \\
14 & Paper & 99.4 & 71 & 11.96 \\
15 & Paper & 99.42 & 62 & 11.83 \\
16 & Wood & 99.42 & 62 & 11.93 \\
17 & Wood & 99.42 & 62 & 11.79 \\
18 & Wood & 99.42 & 62 & 11.59 \\
\hline
\end{tabular}

Table 8 lists maximum averaged obscuration values for the three detectors in each row of the platform, averaged values in each row reported from the FDS model simulation, algebraic results for the Watanabe and Tanaka (W+T) as well as the Davis and Reneke $(D+R)$ model for the paper fire at this elevation. The data is plotted in Figure 46. The paper fires produced alarm level obscuration in the first three rows during test 13 and in the first row during test 15. The highest recorded obscuration value for this test series was in the second row during Test 13. In Contrast, the maximum obscuration value was only $1.23 \% / \mathrm{m}$ in the first row during Test 14 . The lower recorded maximum averaged obscuration values during Test 14 are partially attributable to the environmental conditions at the time of the test. Observations made during this test indicate that a significant amount of the plume missed the elevated platform entirely. The CFAST model returned a maximum obscuration of $1.15 \% / \mathrm{m}$ for this simulation. The $\mathrm{W}+\mathrm{T}$, $\mathrm{D}+\mathrm{R}$ and the FDS models predicted similar results, but all significantly under predicted measured results for these tests. The models even under predicted the results from Test 14 for the first six rows of detectors. 
Table 8 - Paper fire maximum obscuration at 6-m elevation

\begin{tabular}{ccccccccrr}
\hline & \multicolumn{7}{c}{ Alarm } & \multicolumn{7}{c}{ Maximum Obscuration } \\
\hline & & & Test & Test & Test & & W+T & D+R \\
Row & Radius & Threshold & 13 & 14 & 15 & FDS & & \\
\hline & $(\mathbf{m})$ & $(\% / \mathrm{m})$ & $(\% / \mathrm{m})$ & $(\% / \mathrm{m})$ & $(\% / \mathrm{m})$ & $(\% / \mathrm{m})$ & $(\% / \mathrm{m})$ & $(\% / \mathrm{m})$ \\
\hline 1 & 0 & 6.23 & 6.48 & 1.01 & 8.53 & 0.27 & 0.40 & 0.36 \\
2 & 1.63 & 6.45 & 9.91 & 0.60 & 4.79 & 0.16 & 0.32 & 0.21 \\
3 & 3.26 & 6.78 & 8.27 & 0.66 & 3.01 & 0.11 & 0.24 & 0.14 \\
4 & 4.89 & 7.27 & 4.21 & 0.16 & 1.05 & 0.09 & 0.19 & 0.11 \\
5 & 6.52 & 7.00 & 2.61 & 0.25 & 0.67 & 0.08 & 0.15 & 0.10 \\
6 & 8.15 & 6.84 & 2.30 & 0.18 & 0.00 & 0.06 & 0.13 & 0.09 \\
7 & 9.78 & 6.67 & 1.30 & 0.06 & 0.07 & 0.05 & 0.11 & 0.08 \\
8 & 11.41 & 7.00 & 1.15 & 0.09 & 0.07 & 0.04 & 0.10 & 0.07 \\
\hline
\end{tabular}

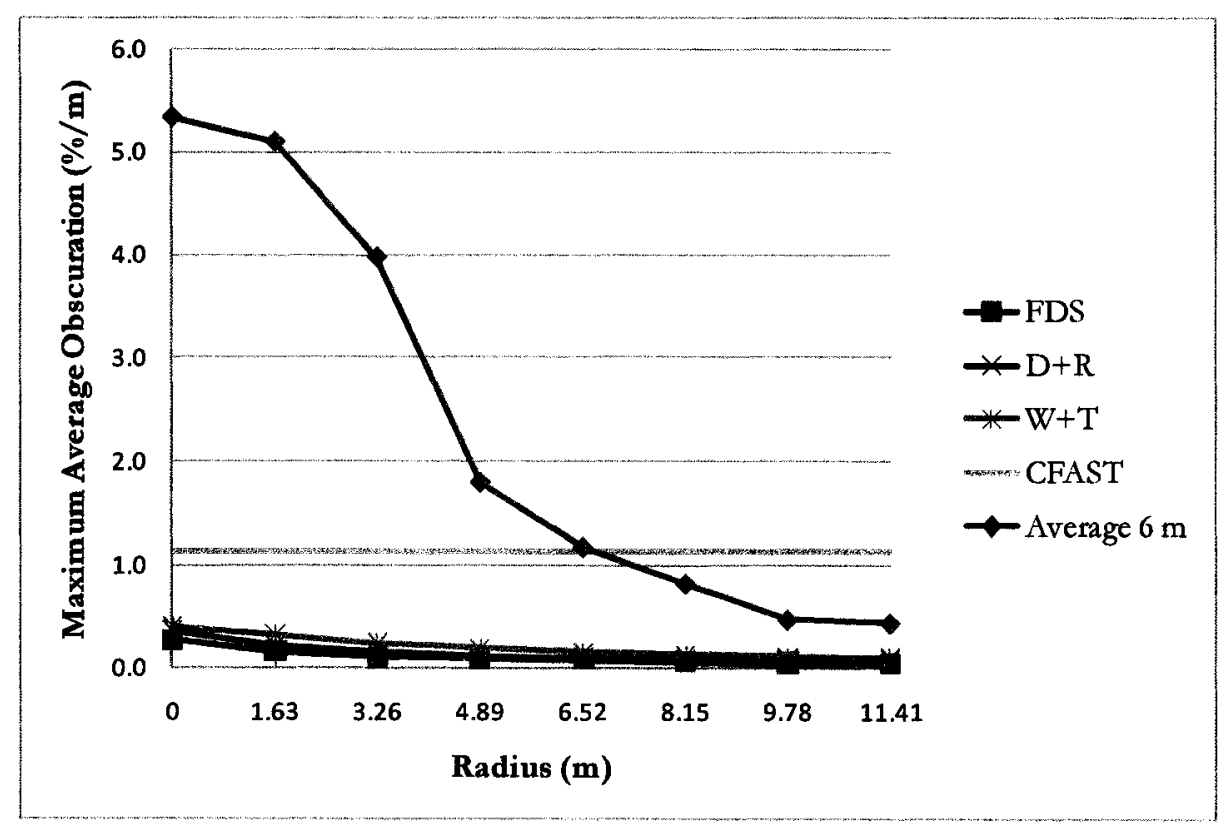

Figure 46 - Maximum Obscuration vs. Radius for paper fire at 6-m elevation

As shown in Table 8, the second, rather than the first row of Test 13 produced the highest obscuration values $(9.91 \% / \mathrm{m}$ vs. $6.48 \% / \mathrm{m})$. The values recorded during Test 14 show a higher obscuration level in the third row than the second 
row $(0.66 \% / \mathrm{m}$ vs. $0.60 \% / \mathrm{m})$. The higher obscuration values recorded at higher radii indicate the level of weakness of the fire plume and the nature of the smoke production. Test results for this series actually produced higher maximum obscuration values than the tests held with the platform elevation of $3 \mathrm{~m}$. The higher obscuration values recorded at higher platform elevations can only be explained by differences in the nature of the fires. Observations of the tests indicate that the fire tests at lower elevations produced open flames sooner with almost no period of smouldering prior to the open flaming period. This difference is the result of the ignition process. Ignition of fires at lower elevations made use of open flame as with all tests, but the period of application of the flame was longer than during tests at higher elevations.

Table 9 lists data for the $20-\mathrm{ml}$ liquid fuel fire at this elevation.

Table 9 - Liquid fuel fire (20-ml) maximum obscuration at 6-m elevation

\begin{tabular}{|c|c|c|c|c|c|c|c|c|}
\hline \multirow[b]{2}{*}{ Row } & \multirow[b]{2}{*}{ Radius } & \multirow{2}{*}{$\begin{array}{c}\text { Alarm } \\
\text { Threshold }\end{array}$} & \multicolumn{6}{|c|}{ Maximum Obscuration } \\
\hline & & & $\begin{array}{c}\text { Test } \\
10\end{array}$ & $\begin{array}{c}\text { Test } \\
11\end{array}$ & $\begin{array}{c}\text { Test } \\
12\end{array}$ & FDS & $\mathrm{W}+\mathrm{T}$ & $\mathrm{D}+\mathrm{R}$ \\
\hline & $(\mathrm{m})$ & $(\% / \mathrm{m})$ & $(\% / \mathrm{m})$ & $(\% / \mathrm{m})$ & $(\% / \mathrm{m})$ & $(\% / \mathrm{m})$ & $(\% / \mathrm{m})$ & $(\% / \mathrm{m})$ \\
\hline 1 & 0 & 6.23 & 7.06 & 4.30 & 3.41 & 11.92 & 4.31 & 4.14 \\
\hline 2 & 1.63 & 6.45 & 4.86 & 2.71 & 2.51 & 5.64 & 3.45 & 2.50 \\
\hline 3 & 3.26 & 6.78 & 2.74 & 0.96 & 1.27 & 3.78 & 2.59 & 1.69 \\
\hline 4 & 4.89 & 7.27 & 1.37 & 0.68 & 0.55 & 2.87 & 2.04 & 1.35 \\
\hline 5 & 6.52 & 7.00 & 0.92 & 0.36 & 0.45 & 2.31 & 1.67 & 1.14 \\
\hline 6 & 8.15 & 6.84 & 0.77 & 0.22 & 0.22 & 1.95 & 1.40 & 1.01 \\
\hline 7 & 9.78 & 6.67 & 0.61 & 0.11 & 0.09 & 1.56 & 1.20 & 0.91 \\
\hline 8 & 11.41 & 7.00 & 0.37 & 0.04 & 0.09 & 1.24 & 1.04 & 0.83 \\
\hline
\end{tabular}

The average maximum obscuration for the three tests is plotted along with the other data from the table as well as the maximum value reported by the CFAST model of $10.58 \% / \mathrm{m}$ in Figure 47. 


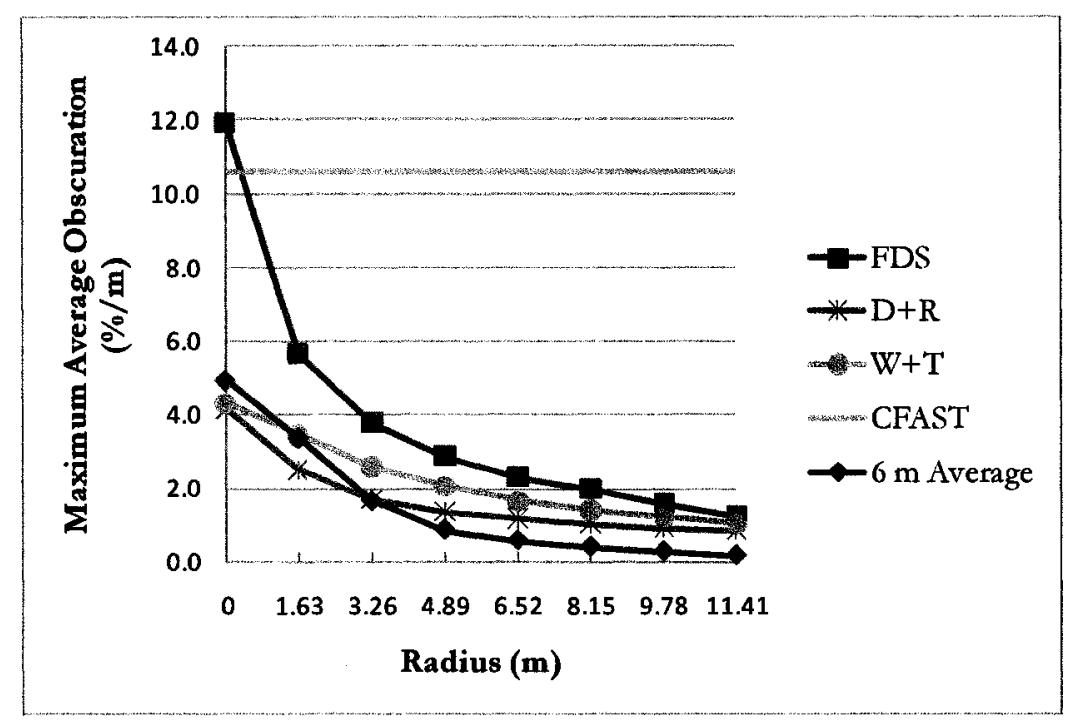

Figure 47 - Maximum Obscuration vs. Radius for 20-ml liquid fuel fires at 6-m elevation

From the table it can been seen that the first row in test 10 reached the alarm threshold level but no other test produced alarm level obscuration values. The obscuration levels decrease with radial distance from the source as with the previous series of tests with the highest values recorded in the first row of detectors. The three models follow a similar pattern. The radial decay in obscuration value is approximately exponential for all of the data in the table. In this case FDS and CFAST over predicted obscuration results measured. The algebraic models produced the closest to measured results. They under predicted measured values near the source, but over predicted measured results at locations further than the second row of detectors. Tests 11 and 12 returned similar maximum values with slightly higher values recorded in Test 10 . The obscuration values recorded for tests at this elevation were lower than those recorded for the tests at the 3-m elevation as expected. 
Table 10 lists data for the wood fire at this elevation. The maximum obscuration value from CFAST is $1.15 \% / \mathrm{m}$. The data is shown plotted in Figure 48

Table 10 - Wood fire maximum obscuration results at 6-m elevation

\begin{tabular}{cccccccc}
\hline & & Alarm & \multicolumn{5}{c}{ Maximum Obscuration } \\
\hline Row & Radius & Threshold & $\begin{array}{c}\text { Test } \\
17\end{array}$ & $\begin{array}{c}\text { Test } \\
18\end{array}$ & FDS & W+T & D+R \\
\hline & $(\mathbf{m})$ & $(\% / \mathrm{m})$ & $(\% / \mathrm{m})$ & $(\% / \mathrm{m})$ & $(\% / \mathrm{m})$ & $(\% / \mathrm{m})$ & $(\% / \mathrm{m})$ \\
\hline 1 & 0 & 6.23 & 2.57 & 8.63 & 1.22 & 1.43 & 1.34 \\
2 & 1.63 & 6.45 & 4.01 & 7.37 & 0.71 & 1.14 & 0.80 \\
3 & 3.26 & 6.78 & 5.93 & 7.22 & 0.52 & 0.85 & 0.54 \\
4 & 4.89 & 7.27 & 4.10 & 1.53 & 0.40 & 0.67 & 0.43 \\
5 & 6.52 & 7.00 & 3.00 & 0.50 & 0.33 & 0.55 & 0.37 \\
6 & 8.15 & 6.84 & 2.10 & 0.02 & 0.26 & 0.46 & 0.32 \\
7 & 9.78 & 6.67 & 1.49 & 0.04 & 0.21 & 0.39 & 0.29 \\
8 & 11.41 & 7.00 & 0.69 & 0.02 & 0.19 & 0.34 & 0.27 \\
\hline
\end{tabular}

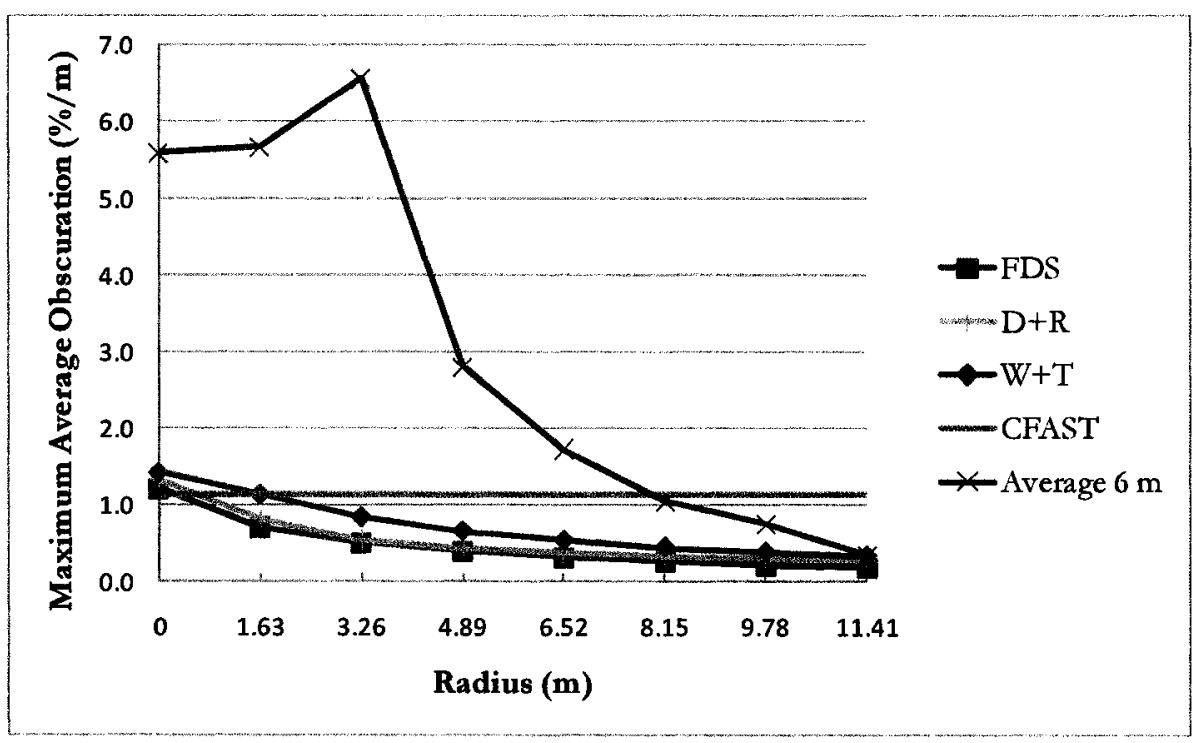

Figure 48 - Maximum Obscuration vs. Radius for wood fire at 6-m elevation $-89-$ 
As shown in Table 10, the wood fire produced alarm level obscuration values in the first three rows during Test 18 . The maximum obscuration values actually rose from the first to third rows during test 17 but did not produce alarm level obscuration readings. These results are attributed to the weakness of the plume and the environmental conditions at the time of the test. By the time in the test when there was significant enough heat release to produce enough thermal lift to raise smoke levels to the platform, the plume had spread out to the further radial distances from the fire source. All of the models under predicted results for this test series as well. Generally speaking, the values recorded started to decrease with radius values higher than $3.26 \mathrm{~m}$. The radial dependence of obscuration values tended to be linear for Test 17 at radii further that $3.26 \mathrm{~m}$ and tended to be exponential for Test 18 at radii further than $4.89 \mathrm{~m}$. The results for tests at this elevation are lower than the values recorded at the 3-m elevation as expected.

All three standard fire types produced obscuration levels within smoke detectors high enough to trigger an alarm response at this elevation. No alarm level obscuration values were measured at the standard radius of $4.89 \mathrm{~m}$, but rather they were confined to the first three rows. In comparison to the 3-m elevation, only the wood test produced alarm level obscuration results in the fourth row of detectors. This suggests that the overall test results produce lower obscuration values than the standard test in the standard room and that smoke detectors can be effective at elevations up to at least $6 \mathrm{~m}$, albeit with reduced coverage than at 3 m.

A typical obscuration vs. time plot is shown in Figure 49. The figure shows the paper fire test results for test 13 . The test obscuration values rose sharply at approximately $90 \mathrm{~s}$ into the test, with alarm levels being reached for two of the three detectors in row $3(\mathrm{r}=3.26 \mathrm{~m})$. The average obscuration level of the three rows is $8.27 \% / \mathrm{m}$ from Table 8 . The measured obscuration values quickly 
reduced again to below alarm levels. When this data is compared with the heat release data used for model inputs shown in Figure 14, the shape of the curve is similar but has a narrower peak, indicating a more concentrated smoke production and transport period than that modeled. This data is attributed to the nature of the smoke produced with a significant amount of early developing smoke density suddenly driven by thermal lift from open flames some time into the fire test.

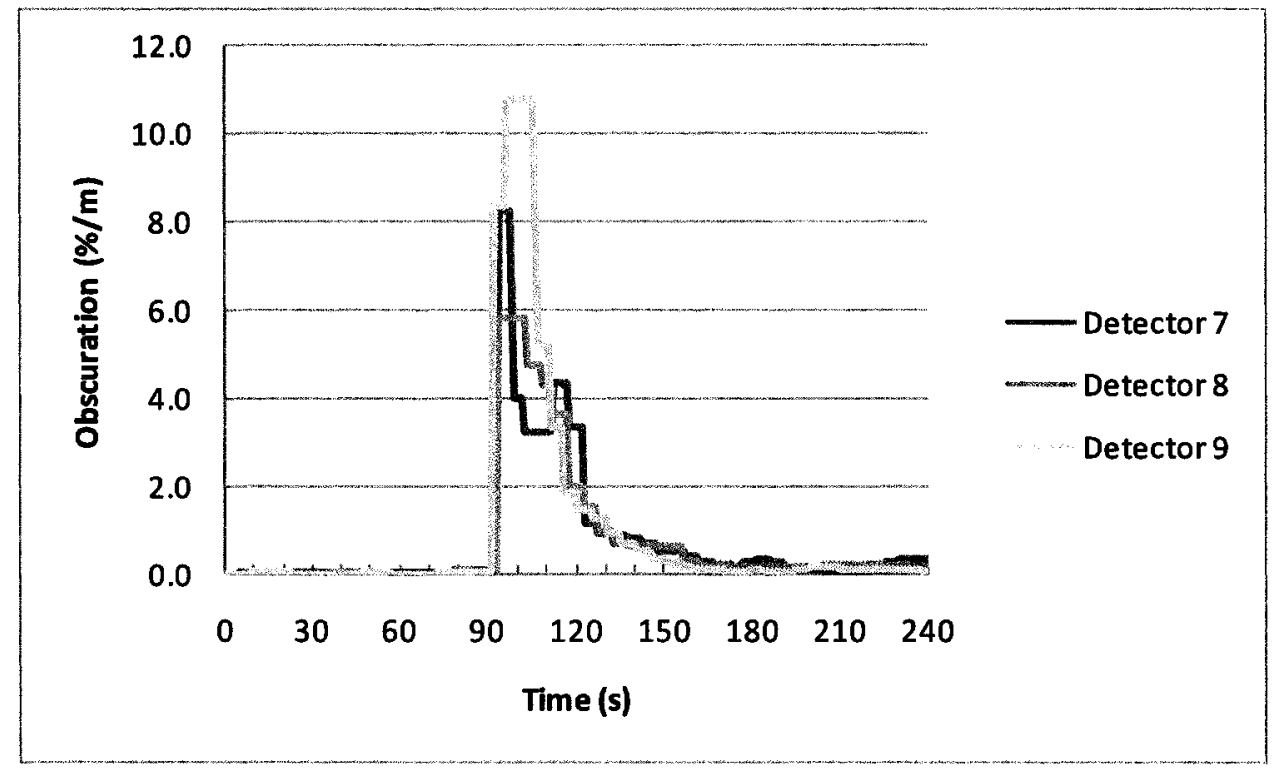

Figure 49 - Obscuration vs. Time for Row 3, Test 13

The averaged obscuration values versus time are plotted for each row during Test 13 in Figure 50. The figure shows that both the first and second rows of detectors indicate the presence of smoke at virtually the same time during the test. The figure also shows that the closer to the source each detector row is, the sharper the rise and fall in obscuration values are. This suggests that smoke moved quickly due to the heat of the flames and developed a relatively strong but short lived ceiling jet. The original volume of smoke was what caused the alarms 
in this case, becoming less and less dense as it spread out due to more and more fresh air being entrained into it the further it traveled from the source.

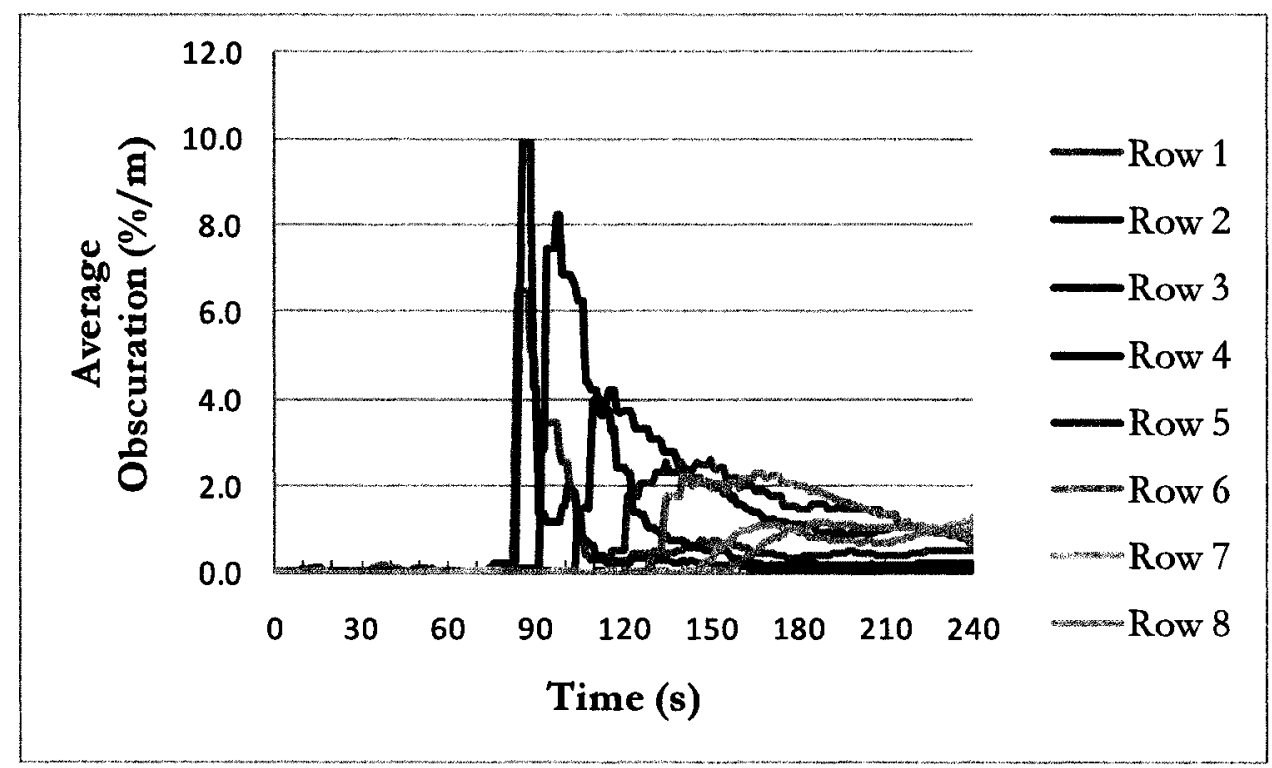

Figure 50 - Averaged Obscuration vs. Time for each Row, Test 13

\subsubsection{9-m Elevation Tests}

Nine tests were conducted with the platform at an elevation of $9 \mathrm{~m}$ on May 21, 2008 (Tests 19-27). Three fuel packages were used; 20-ml Heptane/Toluene mixture, newsprint, and wood crib. Each fuel package was tested 3 times. Test data was gathered for 240 seconds from ignition for each test. Ambient temperature, pressure and humidity data was recorded for each test and listed in Table 11. 
Table 11 - Test conditions at $9 \mathrm{~m}$ elevation

\begin{tabular}{clcccc}
\hline $\begin{array}{c}\text { Test } \\
\text { No. }\end{array}$ & $\begin{array}{l}\text { Fuel } \\
\text { Type }\end{array}$ & $\begin{array}{c}\text { Qty } \\
\mathrm{ml}\end{array}$ & $\begin{array}{c}\mathrm{P}_{0} \\
\mathrm{kPa}\end{array}$ & $\begin{array}{c}\mathrm{RH}_{0} \\
\%\end{array}$ & $\begin{array}{c}\mathrm{T}_{0} \\
\mathrm{C}\end{array}$ \\
\hline 19 & Liquid & 20 & 99.48 & 81 & $\mathrm{~N} / \mathrm{A}$ \\
20 & Liquid & 20 & 99.48 & 81 & 11.83 \\
21 & Liquid & 20 & 99.48 & 81 & 11.93 \\
22 & Paper & & 99.56 & 93 & 11.97 \\
23 & Paper & & 99.56 & 93 & 11.4 \\
24 & Paper & & 99.56 & 93 & 11.02 \\
25 & Wood & & 99.56 & 93 & 11.32 \\
26 & Wood & & 99.6 & 81 & 11.35 \\
27 & Wood & & 99.6 & 81 & 11.37 \\
\hline
\end{tabular}

Table 12 lists maximum averaged obscuration values for the three detectors in each row of the platform, averaged values in each row reported from the FDS model simulation, algebraic results for the Watanabe and Tanaka $(\mathrm{W}+\mathrm{T})$ as well as the Davis and Reneke (D+R) model for the paper fire at this elevation.

Table 12 - Paper fire maximum obscuration results at 9-m elevation

\begin{tabular}{cccccccc}
\hline & & Alarm & \multicolumn{5}{c}{ Maximum Obscuration } \\
\hline Row & Radius & Threshold & $\begin{array}{c}\text { Test } \\
23\end{array}$ & $\begin{array}{c}\text { Test } \\
24\end{array}$ & FDS & W+T & D+R \\
\hline & $(\mathrm{m})$ & $(\% / \mathrm{m})$ & $(\% / \mathrm{m})$ & $(\% / \mathrm{m})$ & $(\% / \mathrm{m})$ & $(\% / \mathrm{m})$ & $(\% / \mathrm{m})$ \\
\hline 1 & 0 & 6.23 & 9.64 & 6.71 & 0.12 & 0.20 & 0.18 \\
2 & 1.63 & 6.45 & 9.90 & 7.25 & 0.10 & 0.18 & 0.14 \\
3 & 3.26 & 6.78 & 9.13 & 4.94 & 0.07 & 0.15 & 0.09 \\
4 & 4.89 & 7.27 & 4.85 & 2.27 & 0.06 & 0.12 & 0.07 \\
5 & 6.52 & 7.00 & 1.99 & 0.42 & 0.05 & 0.10 & 0.06 \\
6 & 8.15 & 6.84 & 1.29 & 0.11 & 0.04 & 0.09 & 0.05 \\
7 & 9.78 & 6.67 & 0.97 & 0.23 & 0.03 & 0.08 & 0.05 \\
8 & 11.41 & 7.00 & 0.82 & 0.21 & 0.03 & 0.07 & 0.05 \\
\hline
\end{tabular}

$-93-$ 


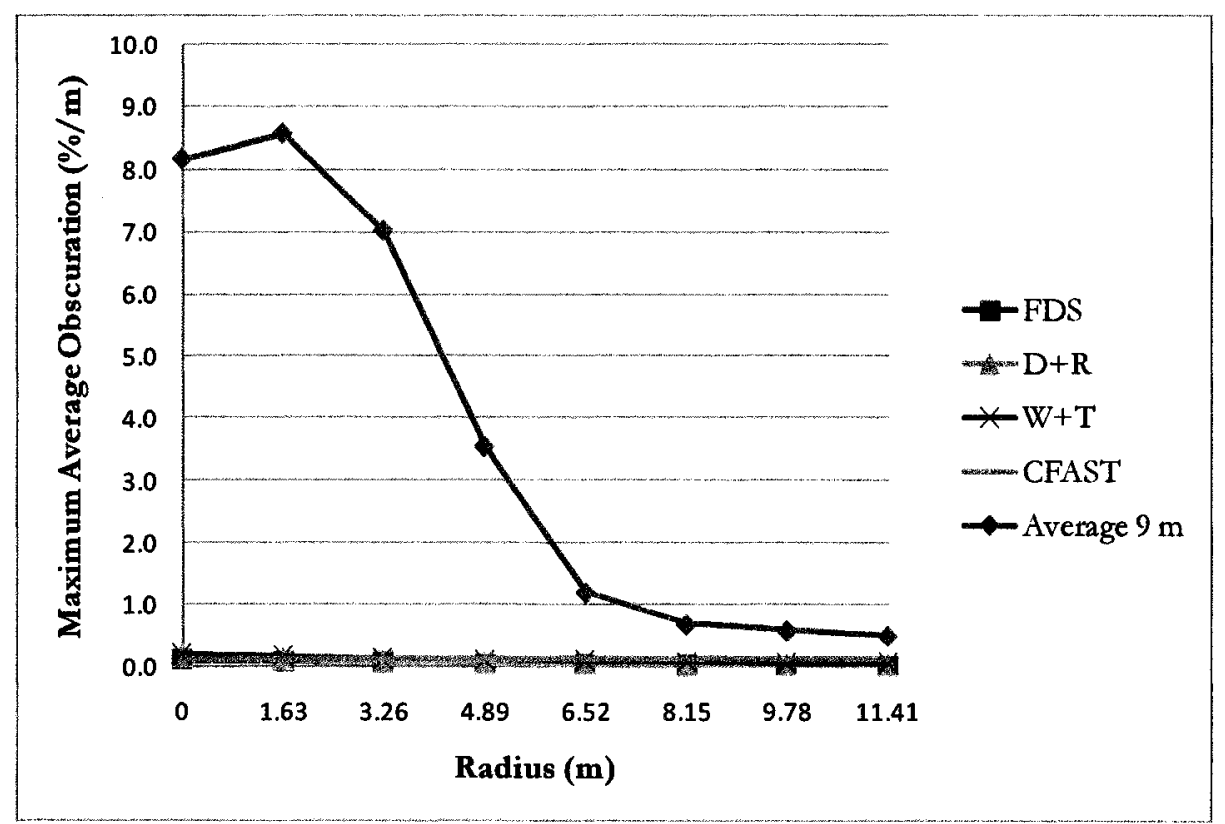

Figure 51 - Maximum Obscuration vs. Radius, paper fire, 9-m elevation

The overall average maximum of the tests is plotted along with the other data from Table 12 as well as the maximum value reported by the CFAST model of $0.13 \% / \mathrm{m}$ in Figure 51. From Table 12, it can be seen that alarm level obscuration values were recorded in the first three rows for test 23 and the first two rows for test 24 . In contrast, model predictions were significantly lower. Both tests produced higher values of obscuration in the second row than the first row. This is the only test series at this elevation to produce alarm level responses from the smoke detectors.

Table 13 lists data for the $20-\mathrm{ml}$ liquid fuel fire at the 9-m elevation. The average maximum obscuration of the test is plotted along with the other data from the table as well as the maximum value reported by the CFAST model of $8.18 \% / \mathrm{m}$ in Figure 52. 
Two of the three tests did not produce results due to recording errors, so the only test listed is Test 19 . Test 19 produced obscuration values that reduced with increasing radial distance from the source. All of the model results are higher than the measured values. All of the data exhibits a similar radial decay pattern. Alarm producing levels were neither predicted nor measured for this test series. The obscuration values measured as well at those predicted by the models were lower at this elevation than for either the 6-m or the 3-m elevation fires of this type. In this case the model results that most closely matched the test data is from the $D+R$ model. The two computer models predicted a higher maximum obscuration above the fire than the algebraic models.

Table 13 - Liquid fuel fire $(20-\mathrm{ml})$ maximum obscuration at 9-m elevation

\begin{tabular}{ccccccc}
\hline & & Alarm & \multicolumn{5}{c}{ Maximum Obscuration } \\
\hline Row & Radius & Threshold & $\begin{array}{c}\text { Test } \\
19\end{array}$ & FDS & W+T & D+R \\
\hline & $(\mathrm{m})$ & $(\% / \mathrm{m})$ & $(\% / \mathrm{m})$ & $(\% / \mathrm{m})$ & $(\% / \mathrm{m})$ & $(\% / \mathrm{m})$ \\
\hline 1 & 0 & 6.23 & 1.44 & 5.14 & 2.23 & 2.14 \\
2 & 1.63 & 6.45 & 1.15 & 3.50 & 1.99 & 1.62 \\
3 & 3.26 & 6.78 & 0.97 & 2.63 & 1.61 & 1.09 \\
4 & 4.89 & 7.27 & 0.47 & 2.12 & 1.33 & 0.87 \\
5 & 6.52 & 7.00 & 0.48 & 1.66 & 1.13 & 0.74 \\
6 & 8.15 & 6.84 & 0.26 & 1.29 & 0.98 & 0.65 \\
7 & 9.78 & 6.67 & 0.17 & 1.01 & 0.86 & 0.59 \\
8 & 11.41 & 7.00 & 0.14 & 0.85 & 0.76 & 0.54 \\
\hline
\end{tabular}




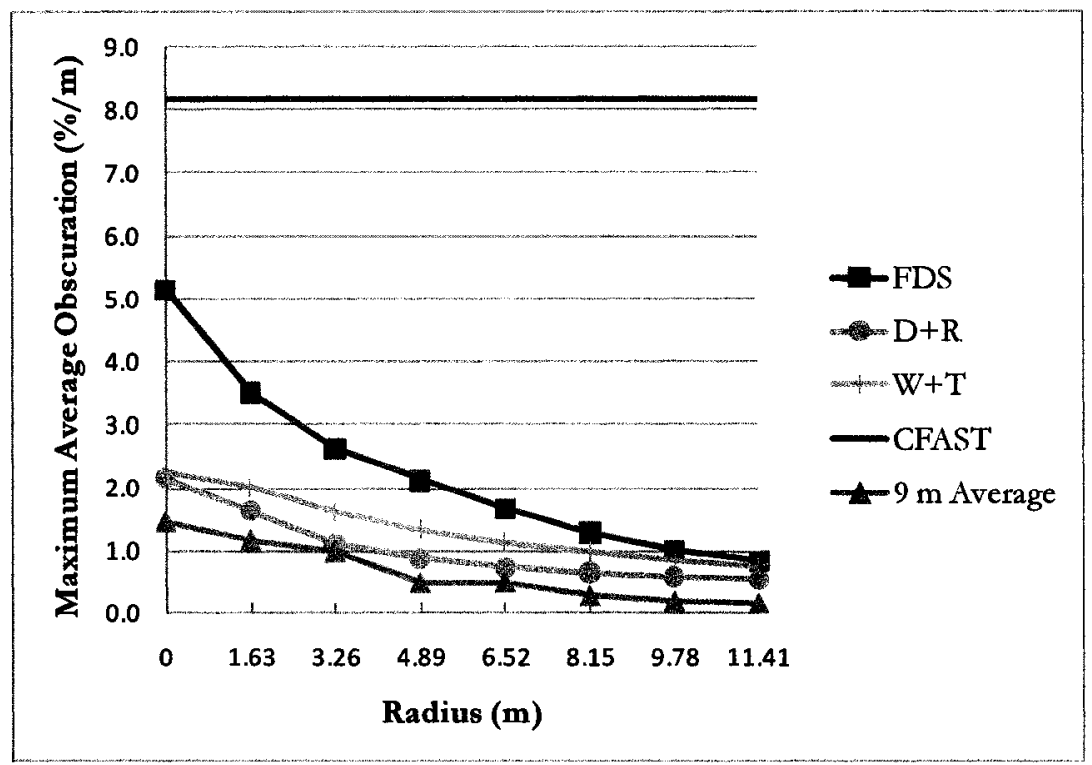

Figure 52 - Maximum Obscuration vs. Radius, 20-ml liquid fire, 9-m elevation

Table 14 lists data for the wood fire at the 9-m elevation. The average maximum obscuration between the three tests is plotted along with the other data from the table as well as the maximum value reported by the CFAST model of $1.05 \% / \mathrm{m}$ in Figure 53.

The highest obscuration values for this series were measured in the third row of detectors for test 25 from Table 14. Again, obscuration values went up for the first three rows in one test (Test 25) in this series. In Test 26 the first three rows of detectors recorded similar maximum values. The second row in Test 27 recorded higher obscuration values than the first row. The remainder of the values in this series indicated the typical result of reduced obscuration values with increased radial distance from the source. Model predictions were lower than measured values for the first six rows, but higher for the last two rows. The actual values recorded by detectors in the last few rows appear only as noise when 
reviewing the time/obscuration charts for these tests. Here we have FDS, W+T and $\mathrm{D}+\mathrm{R}$ models predicting similar results.

Table 14 - Wood fire maximum obscuration results at 9-m elevation

\begin{tabular}{ccccccccc}
\hline & \multicolumn{7}{c}{ Alarm } & \multicolumn{7}{c}{ Maximum Obscuration } \\
\hline & & & Test & Test & Test & & W+T & D+R \\
Row & Radius & Threshold & 25 & 26 & 27 & FDS & & \\
\hline & $(\mathrm{m})$ & $(\% / \mathrm{m})$ & $(\% / \mathrm{m})$ & $(\% / \mathrm{m})$ & $(\% / \mathrm{m})$ & $(\% / \mathrm{m})$ & $(\% / \mathrm{m})$ & $(\% / \mathrm{m})$ \\
\hline 1 & 0 & 6.23 & 3.26 & 3.18 & 0.45 & 0.78 & 0.73 & 0.69 \\
2 & 1.63 & 6.45 & 4.69 & 2.25 & 1.25 & 0.51 & 0.66 & 0.52 \\
3 & 3.26 & 6.78 & 5.52 & 3.18 & 0.17 & 0.37 & 0.53 & 0.35 \\
4 & 4.89 & 7.27 & 3.97 & 1.07 & 0.03 & 0.27 & 0.44 & 0.28 \\
5 & 6.52 & 7.00 & 3.30 & 0.03 & 0.03 & 0.22 & 0.37 & 0.24 \\
6 & 8.15 & 6.84 & 0.99 & 0.00 & 0.06 & 0.19 & 0.32 & 0.21 \\
7 & 9.78 & 6.67 & 0.07 & 0.02 & 0.13 & 0.16 & 0.28 & 0.19 \\
8 & 11.41 & 7.00 & 0.05 & 0.07 & 0.05 & 0.16 & 0.25 & 0.17 \\
\hline
\end{tabular}

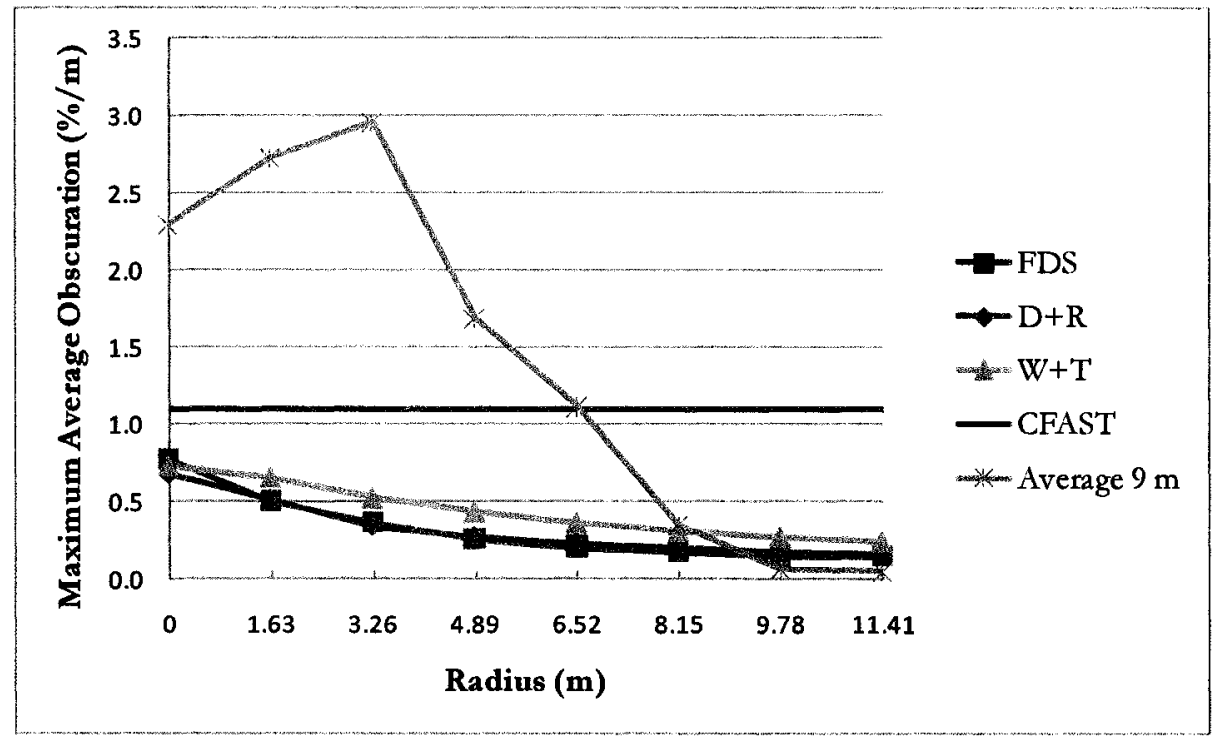

Figure 53 - Maximum Obscuration vs. Radius, wood fire, 9-m elevation

The averaged obscuration values for each row in Test 25 are shown, plotted against time in Figure 54. The figure shows that the first rows to record data 
were the second and third rows almost simultaneously, followed by the fourth, then first followed by the fifth and then the sixth rows. The peak values are higher for those rows that begin to report values first. There were essentially no results recorded for the last two rows during this test.

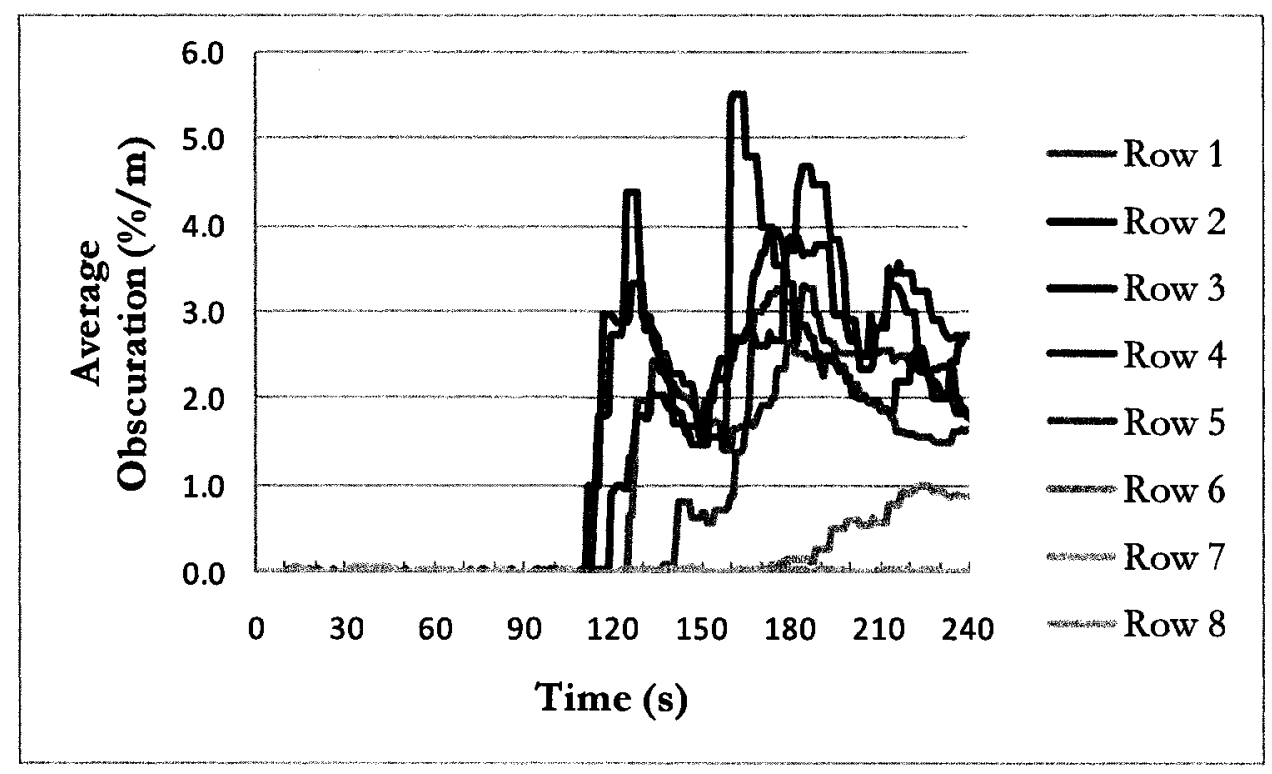

Figure 54 - Average Obscuration vs. Time, Test 25

\subsubsection{2-m Elevation Tests}

Nine tests were conducted with the platform at an elevation of $12 \mathrm{~m}$ on May 22, 2008 (Tests 28-36). Three fuel packages were used; 20-ml heptane/toluene mixture, newsprint, and wood crib. Each fuel package was tested 3 times. Test data was gathered for 240 seconds from ignition for each test. Ambient temperature, pressure and humidity data was recorded for each test and listed in Table 15. 
Table 15 - Test conditions at $12 \mathrm{~m}$ elevation

\begin{tabular}{cccccc}
\hline $\begin{array}{c}\text { Test } \\
\text { No. }\end{array}$ & $\begin{array}{c}\text { Fuel } \\
\text { Type }\end{array}$ & $\begin{array}{c}\text { Qty } \\
\mathrm{ml}\end{array}$ & $\begin{array}{c}\mathrm{P}_{0} \\
\mathrm{kPa}\end{array}$ & $\begin{array}{c}\mathrm{RH}_{0} \\
\%\end{array}$ & $\mathrm{C}$ \\
\hline 28 & Liquid & 20 & 99.99 & 87 & 11.45 \\
29 & Liquid & 20 & 99.99 & 87 & 10.71 \\
30 & Liquid & 20 & 99.99 & 87 & 10.69 \\
31 & Paper & & 100.02 & 82 & 11.53 \\
32 & Paper & & 100.02 & 82 & 11.16 \\
33 & Paper & & 100.02 & 82 & 10.63 \\
34 & Wood & & 100.02 & 82 & 10.66 \\
35 & Wood & & 100.03 & 82 & 10.05 \\
36 & Wood & & 100.03 & 82 & 10.07 \\
\hline
\end{tabular}

Table 16 lists maximum average obscuration values for the three detectors in each row of the platform, average values in each row reported from the FDS model simulation, algebraic results for the Watanabe and Tanaka $(\mathrm{W}+\mathrm{T})$ as well as the Davis and Reneke $(D+R)$ model for the paper fire at this elevation. The average maximum obscuration between the three tests is plotted along with the other data from the table as well as the maximum value reported by the CFAST model of $0.13 \% / \mathrm{m}$ in Figure 55.

In this test series, there is a large variance in the measurements recorded. The maximum average obscuration recorded was in Row 3 during Test 33, with a value of $10.36 \% / \mathrm{m}$. Test 31 produced the next highest values with a peak of $4.14 \% / \mathrm{m}$ in row 4 , followed by Test 32 with a peak of $0.30 \% / \mathrm{m}$ also in row 4 . In comparison, the CFAST model predicted $0.13 \% / \mathrm{m}$, the FDS model produced a peak value of $0.08 \% / \mathrm{m}$ in row 1 , while the algebraic models produce similar peak values of $0.11 \% / \mathrm{m}$ for $\mathrm{D}+\mathrm{R}$ and $0.13 \% / \mathrm{m}$ for $\mathrm{W}+\mathrm{T}$ in row 1 . 
Again, a significant overall under prediction of the measured result has occurred, likely as a result of the early smoke development not accounted for in the models. The peak values in this series were recorded in the third or fourth rows rather than the first row, indicating that the plume is weak. The ceiling height for this test does not appear to be much of a factor so far in this test series when it comes to producing maximum obscuration values as alarm level obscuration values have been recorded at $3-\mathrm{m}, 9-\mathrm{m}$ and $12-\mathrm{m}$ elevations. As with the 9-m elevation test series, the paper fuel fire is the only one to produce alarm level responses in the smoke detectors at this elevation.

Table 16 - Paper fire maximum obscuration results at 12-m elevation

\begin{tabular}{ccccccccc}
\hline & & Alarm & \multicolumn{7}{c}{ Maximum Obscuration } \\
\hline & & & Test & Test & Test & & W+T & D+R \\
Row & Radius & Threshold & 31 & \multicolumn{1}{c}{32} & \multicolumn{1}{c}{33} & FDS & & \\
\hline & $(\mathrm{m})$ & $(\% / \mathrm{m})$ & $(\% / \mathrm{m})$ & $(\% / \mathrm{m})$ & $(\% / \mathrm{m})$ & $(\% / \mathrm{m})$ & $(\% / \mathrm{m})$ & $(\% / \mathrm{m})$ \\
\hline 1 & 0 & 6.23 & 2.48 & 0.42 & 9.65 & 0.08 & 0.13 & 0.11 \\
2 & 1.63 & 6.45 & 1.61 & 0.17 & 9.90 & 0.07 & 0.13 & 0.11 \\
3 & 3.26 & 6.78 & 3.71 & 0.18 & 10.36 & 0.05 & 0.10 & 0.07 \\
4 & 4.89 & 7.27 & 4.17 & 0.30 & 8.49 & 0.04 & 0.09 & 0.05 \\
5 & 6.52 & 7.00 & 2.26 & 0.14 & 4.20 & 0.03 & 0.07 & 0.05 \\
6 & 8.15 & 6.84 & 0.94 & 0.14 & 2.61 & 0.03 & 0.07 & 0.04 \\
7 & 9.78 & 6.67 & 0.41 & 0.13 & 0.58 & 0.03 & 0.06 & 0.04 \\
8 & 11.41 & 7.00 & 0.18 & 0.07 & 0.07 & 0.02 & 0.05 & 0.03 \\
\hline
\end{tabular}




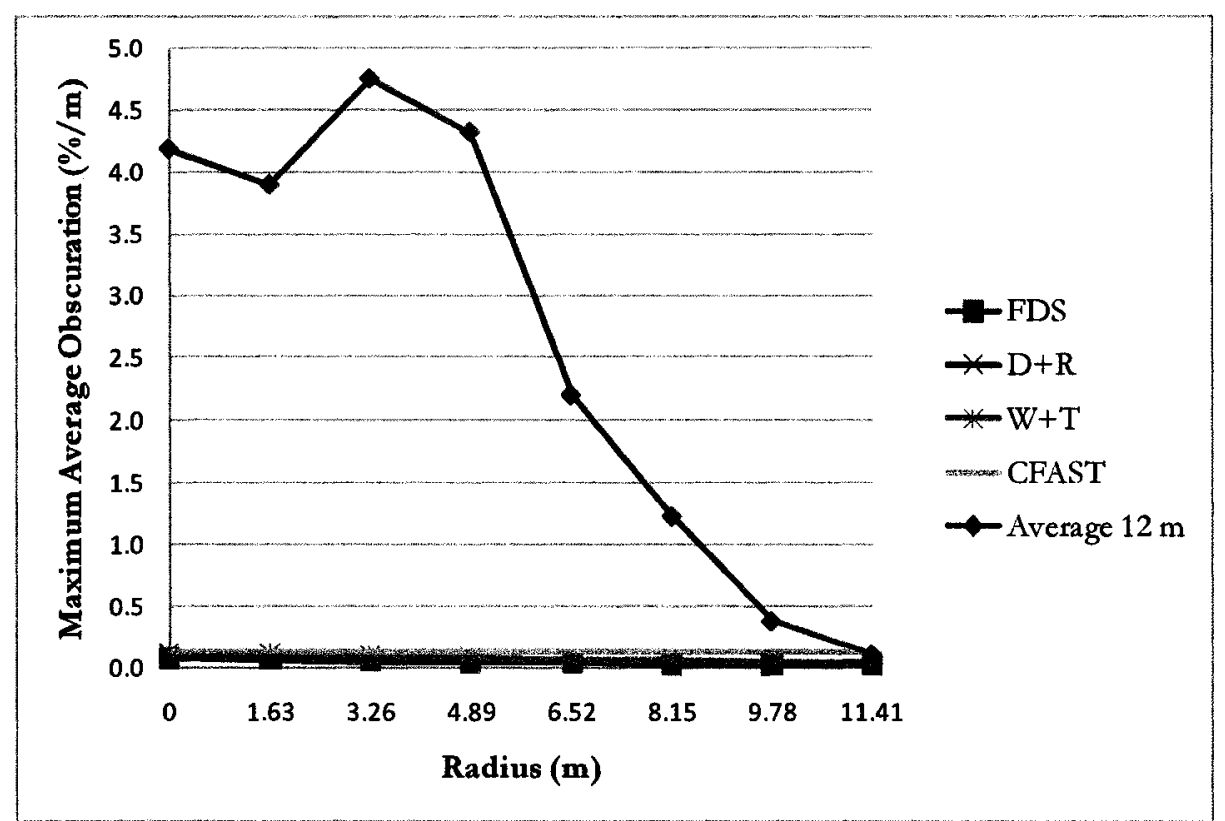

Figure 55 - Maximum Obscuration vs. Radius, paper fire, 12-m elevation

When average results are considered, alarm level obscuration is neither predicted nor measured in this series of tests.

Table 17 lists for the $20-\mathrm{ml}$ liquid fuel fire at the $12-\mathrm{m}$ elevation. The average maximum obscuration between the three tests is plotted along with the other data from the table in Figure 56. The maximum value reported by the CFAST model which is not shown was $6.92 \% / \mathrm{m}$.

Each test in this series had maximum average obscuration values that tended to reduce with radial distance from the fire. The trend exhibited to the data in this series was closer to a linear relationship with radius rather than an exponential one that has been the general trend up to this height. As with the test at all of the lower elevations, FDS over predicted results from this test series. 
Table 17 - Liquid fuel fire $(20-\mathrm{ml})$ maximum obscuration at $12-\mathrm{m}$ elevation

\begin{tabular}{ccccccccc}
\hline & & Alarm & \multicolumn{7}{c}{ Maximum Obscuration } \\
\hline & & & Test & Test & Test & & W+T & D+R \\
Row & Radius & Threshold & 28 & 29 & 30 & FDS & & \\
\hline & $(\mathrm{m})$ & $(\% / \mathrm{m})$ & $(\% / \mathrm{m})$ & $(\% / \mathrm{m})$ & $(\% / \mathrm{m})$ & $(\% / \mathrm{m})$ & $(\% / \mathrm{m})$ & $(\% / \mathrm{m})$ \\
\hline 1 & 0 & 6.23 & 1.17 & 1.49 & 1.35 & 2.35 & 1.39 & 1.34 \\
2 & 1.63 & 6.45 & 0.93 & 1.37 & 1.38 & 2.60 & 1.39 & 1.34 \\
3 & 3.26 & 6.78 & 0.88 & 1.14 & 1.31 & 1.96 & 1.11 & 0.80 \\
4 & 4.89 & 7.27 & 0.82 & 1.18 & 0.95 & 1.39 & 0.95 & 0.64 \\
5 & 6.52 & 7.00 & 0.61 & 0.76 & 1.16 & 1.13 & 0.83 & 0.54 \\
6 & 8.15 & 6.84 & 0.32 & 0.40 & 0.78 & 0.78 & 0.73 & 0.48 \\
7 & 9.78 & 6.67 & 0.24 & 0.24 & 0.69 & 0.61 & 0.65 & 0.43 \\
8 & 11.41 & 7.00 & 0.09 & 0.14 & 0.21 & 0.55 & 0.59 & 0.39 \\
\hline
\end{tabular}

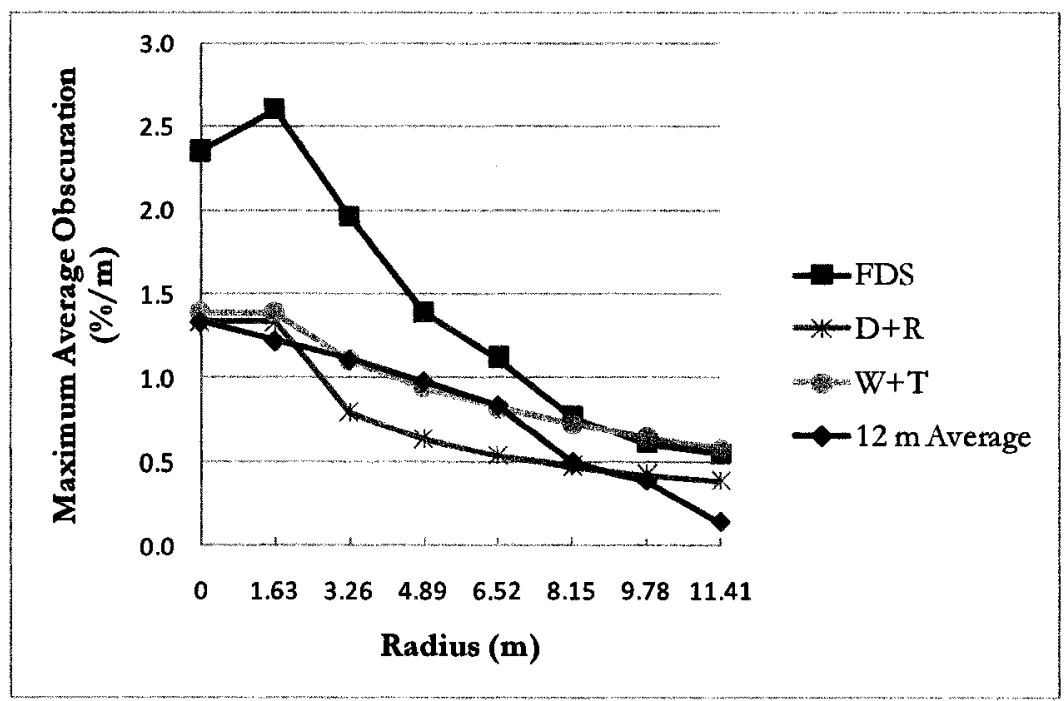

Figure 56 - Maximum Obscuration vs. Radius, 20-ml liquid fire, 12-m elevation

Table 18 lists for the wood fire at the 12-m elevation. The average maximum obscuration between the three tests is plotted along with the other data from the table as well as the maximum value reported by the CFAST model of $1.05 \% / \mathrm{m}$ in Figure 57. 
The highest obscuration values for this series were measured in the second row of detectors for test 36 . Test 36 exhibited a sharp decrease from the peak value of $2.73 \% / \mathrm{m}$ in the second row to $0.05 \% / \mathrm{m}$ in the fourth row. As with the three previous elevations, FDS under predicted measured results for this fire type. Not only did FDS under predict obscuration values for this test series, the results from the model predicted no obscuration results would be found. While the $\mathrm{W}+\mathrm{T}$ and $\mathrm{D}+\mathrm{R}$ algebraic models also under predicted the measured results, the predictions were closer than by FDS. In this case CFAST returned the highest results among the models. From the third row outwards, the algebraic models over predicted measured results.

Table 18 - Wood fire maximum obscuration results at 12-m elevation

\begin{tabular}{ccccccccc}
\hline & & Alarm & \multicolumn{7}{c}{ Maximum Obscuration } \\
\hline & & & Test & Test & Test & & W+T & D+R \\
Row & Radius & Threshold & 34 & 35 & 36 & FDS & & \\
\hline & $(\mathrm{m})$ & $(\% / \mathrm{m})$ & $(\% / \mathrm{m})$ & $(\% / \mathrm{m})$ & $(\% / \mathrm{m})$ & $(\% / \mathrm{m})$ & $(\% / \mathrm{m})$ & $(\% / \mathrm{m})$ \\
\hline 1 & 0 & 6.23 & 0.09 & 1.77 & 2.43 & 0.01 & 0.46 & 0.43 \\
2 & 1.63 & 6.45 & 0.03 & 1.37 & 2.73 & 0.00 & 0.46 & 0.43 \\
3 & 3.26 & 6.78 & 0.00 & 0.35 & 1.74 & 0.00 & 0.36 & 0.26 \\
4 & 4.89 & 7.27 & 0.07 & 0.30 & 0.05 & 0.00 & 0.31 & 0.20 \\
5 & 6.52 & 7.00 & 0.12 & 0.12 & 0.09 & 0.00 & 0.27 & 0.17 \\
6 & 8.15 & 6.84 & 0.00 & 0.08 & 0.07 & 0.00 & 0.24 & 0.15 \\
7 & 9.78 & 6.67 & 0.02 & 0.05 & 0.11 & 0.00 & 0.21 & 0.14 \\
8 & 11.41 & 7.00 & 0.07 & 0.02 & 0.09 & 0.00 & 0.19 & 0.13 \\
\hline
\end{tabular}




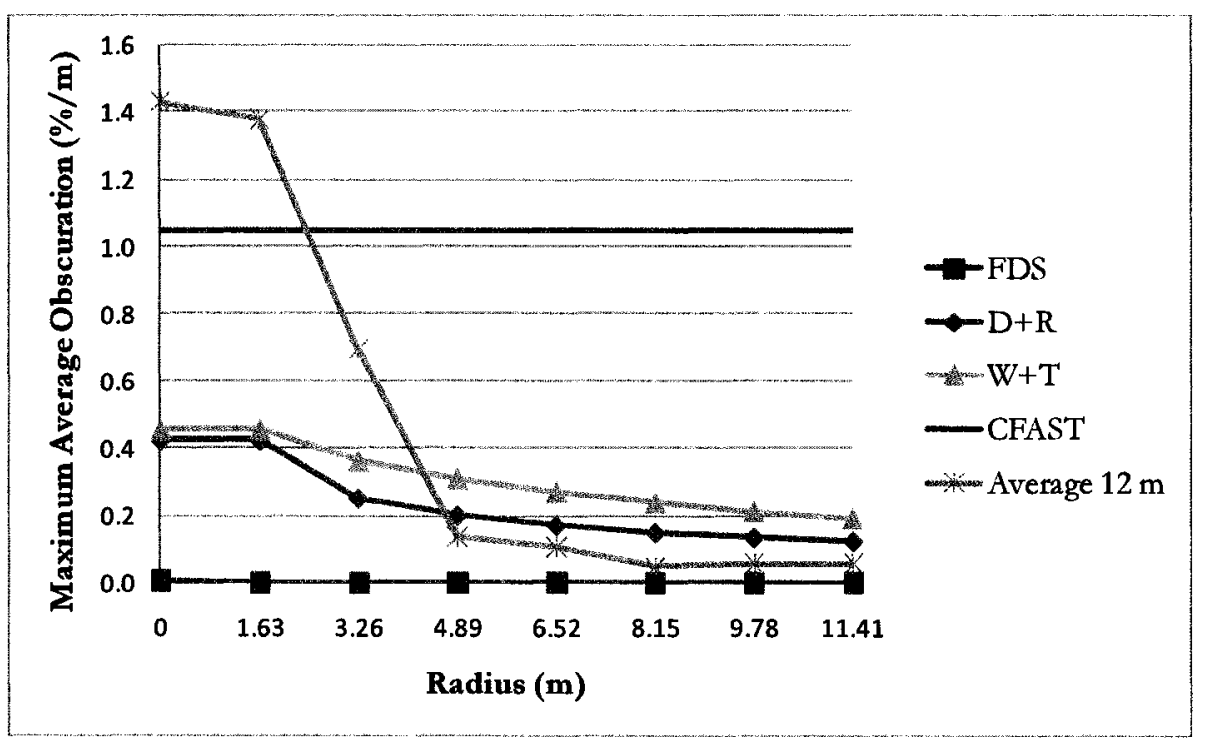

Figure 57 - Maximum Obscuration vs. Radius, wood fire, 12-m elevation

An Obscuration/time plot for the detectors in the first row of test 33 is shown in Figure 58. The plot indicates that there was no response from the detectors for the first 175 seconds, followed by an instantaneous rise in obscuration to maximum levels within the detector. The actual obscuration data recorded shows an obscuration level of $0 \% / \mathrm{m}$ at time $\mathrm{t}=174 \mathrm{~s}$ and a level of $10.18 \% / \mathrm{m}$ at time $\mathrm{t}=175 \mathrm{~s}$. 


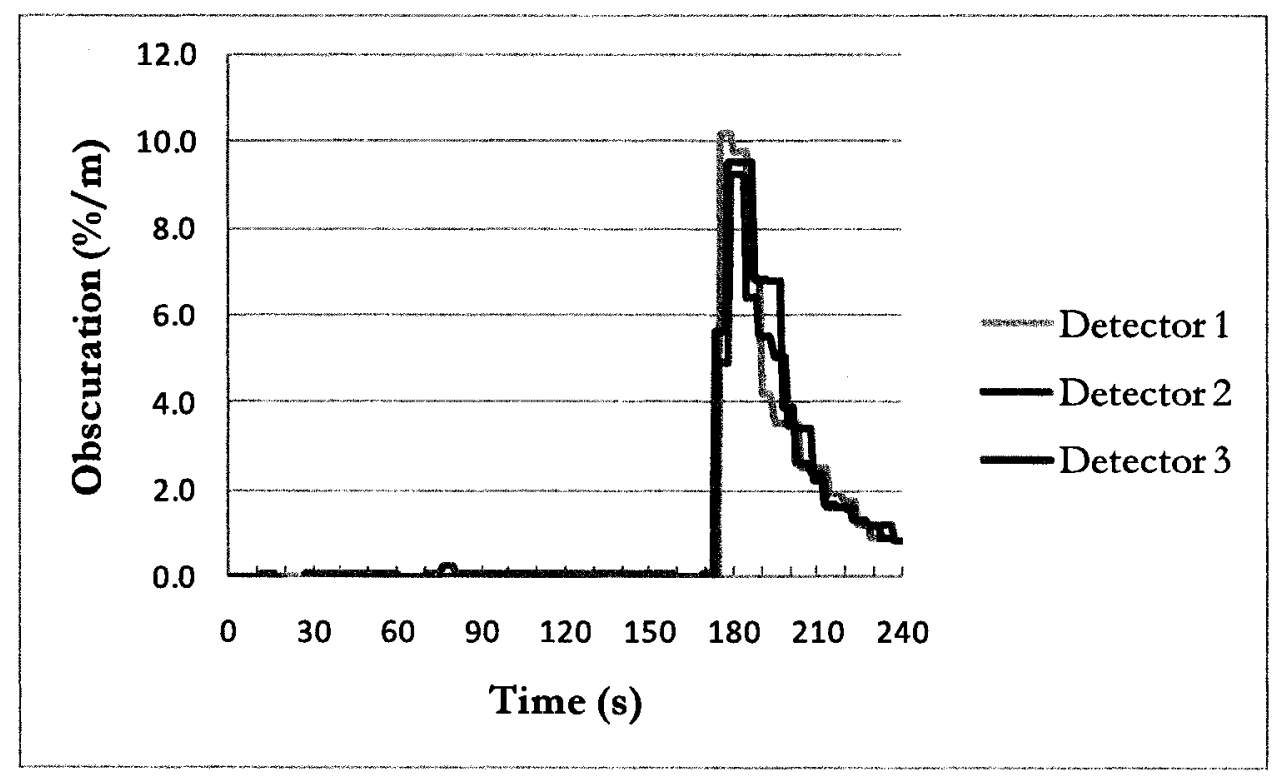

Figure 58 - Obscuration vs. Time - Test 33, Row 1

The FDS model for this fire shown in Figure 59 predicts much lower maximum obscuration levels, but also predicts the results will occur sooner than the measured values shown in Figure 58.

Figure 60 is a plot of the average obscuration values in each tow versus time. The plots indicates that a similar rise in obscuration was seen for the first four rows of devices, and it isn't until row five that there is much delay or reduction in the level of obscuration reached. The peak levels are sustained for 10 to $15 \mathrm{~s}$ and then quickly start to drop again. These types of measurements are indicative of a concentrated quantity of smoke being lifted to the detector all at once from its original stagnant position above the flame. 


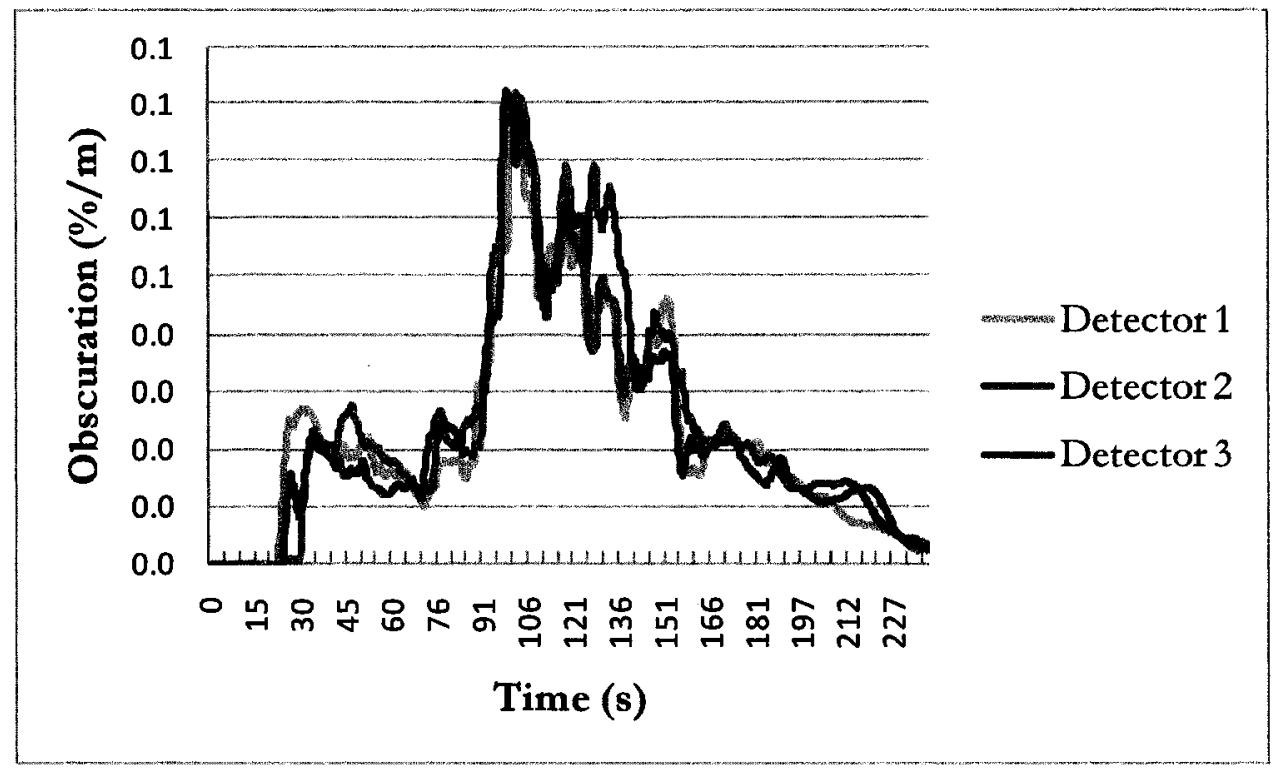

Figure 59 - Obscuration vs. Time, FDS, Paper Fire, 12-m elevation, Row 1

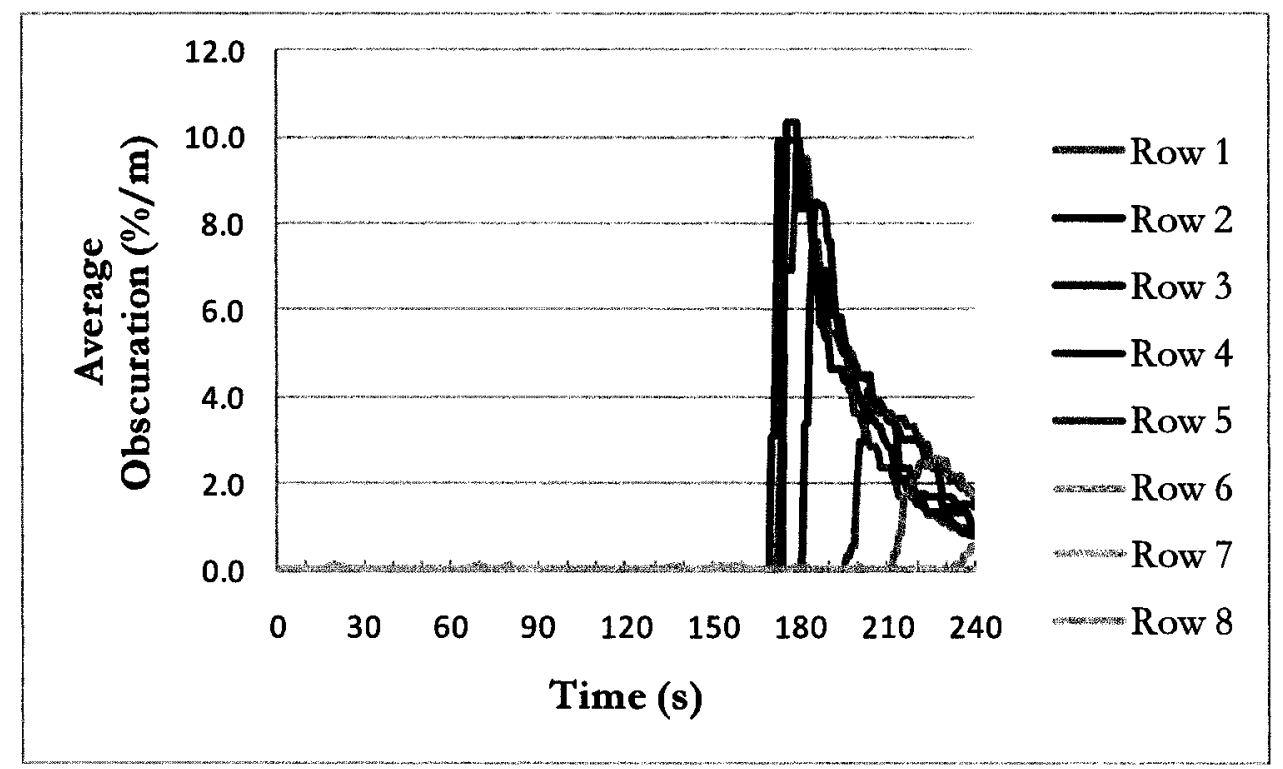

Figure 60 - Average Obscuration vs. Time - Test 33

$$
-106-
$$




\subsubsection{5-m Elevation Tests}

Seventeen tests were conducted with the platform at an elevation of $15 \mathrm{~m}$ (Tests 37-53). The tests were conducted over three dates. May 22, 2008, June 6, 2008 and July 17, 2008. Six fuel packages were used; $20 \mathrm{ml}, 40 \mathrm{ml}, 100 \mathrm{ml}$, and $200 \mathrm{ml}$ Heptane/Toluene mixture, newsprint, and wood crib. Except for the largest test fire, each fuel package was tested 3 times. Test data was gathered for 240 seconds from ignition for each test. Ambient temperature, pressure and humidity data was recorded for each test and listed in Table 19

Table $19-$ Test conditions at $15 \mathrm{~m}$ elevation

\begin{tabular}{rlrrrr}
\hline Test & Fuel & Qty & $\mathrm{P}_{0}$ & $\mathrm{RH}_{0}$ & \multicolumn{1}{c}{$\mathrm{T}_{0}$} \\
No. & Type & & & \multicolumn{1}{c}{$\mathrm{kPa}$} & \multicolumn{1}{c}{$\%$} \\
& & $\mathrm{ml}$ & \multicolumn{1}{c}{$\mathrm{c}$} \\
37 & Wood & & 100.03 & \multicolumn{1}{c}{77} & \multicolumn{1}{c}{12.89} \\
38 & Wood & & 100.03 & 77 & 12.02 \\
39 & Wood & & 100.6 & 82 & 11.49 \\
40 & Paper & & 100.6 & 82 & 11.49 \\
41 & Paper & & 100.6 & 82 & 11.57 \\
42 & Paper & & 100.6 & 82 & 11.76 \\
43 & Liquid & 20 & 100.1 & 77 & 11.7 \\
44 & Liquid & 20 & 100.1 & 77 & 11.77 \\
45 & Liquid & 20 & 100.1 & 77 & 12.2 \\
46 & Liquid & 100 & 101.52 & 100 & 18.89 \\
47 & Liquid & 200 & 101.52 & 100 & 19.15 \\
48 & Liquid & 100 & 101.56 & 100 & 19.3 \\
49 & Liquid & 100 & 101.56 & 100 & 19.35 \\
50 & Liquid & 40 & 102.06 & 69 & 22.74 \\
51 & Liquid & 40 & 102.05 & 65 & 22.95 \\
52 & Liquid & 40 & 102.05 & 65 & 23.12 \\
53 & Liquid & 40 & 102.05 & 65 & 23.32 \\
\hline & & & & &
\end{tabular}

$-107-$ 
It was during this test series that the limit of the ability for the smoke detectors to produce results from the standard test fires was shown. In order to further the experiments, larger fire sizes were considered (discussed in section 3.3 .2 of this report). Since the liquid fuel test is the most consistent of the three in that it consistently produces flaming combustion, only the liquid fuel fire tests were continued. Fire sizes with varying pans and fuel quantities from $40 \mathrm{ml}$ to $200 \mathrm{ml}$ were tested at this elevation. Based on the results of these tests, the $40 \mathrm{ml}, 60 \mathrm{ml}$ and $100 \mathrm{ml}$ fuel packages were carried forward to the higher elevations as they were expected to cause detector activation.

Table 20 lists maximum averaged obscuration values for the three detectors in each row of the platform, averaged values in each row reported from the FDS model simulation, algebraic results for the Watanabe and Tanaka (W+T) as well as the Davis and Reneke $(D+R)$ model for the paper fire at this elevation. The average maximum obscuration between the three tests is plotted along with the other data from the table as well as the maximum value reported by the CFAST model of $0.13 \% / \mathrm{m}$ in Figure 61.

Table 20 - Paper fire maximum obscuration results at 15-m elevation

\begin{tabular}{ccccccccc}
\hline & & Alarm & \multicolumn{7}{c}{ Maximum Obscuration } \\
\hline & & & Test & Test & Test & FDS & W+T & D+R \\
Row & Radius & Threshold & 40 & 41 & 42 & & & \\
\hline & $(\mathrm{m})$ & $(\% / \mathrm{m})$ & $(\% / \mathrm{m})$ & $(\% / \mathrm{m})$ & $(\% / \mathrm{m})$ & $(\% / \mathrm{m})$ & $(\% / \mathrm{m})$ & $(\% / \mathrm{m})$ \\
\hline 1 & 0 & 6.23 & 9.43 & 1.42 & 1.57 & 0.05 & 0.09 & 0.08 \\
2 & 1.63 & 6.45 & 8.83 & 0.85 & 2.80 & 0.04 & 0.09 & 0.08 \\
3 & 3.26 & 6.78 & 4.72 & 0.51 & 1.78 & 0.04 & 0.07 & 0.05 \\
4 & 4.89 & 7.27 & 1.95 & 0.35 & 0.52 & 0.03 & 0.06 & 0.04 \\
5 & $\mathbf{6 . 5 2}$ & 7.00 & 1.67 & 0.30 & 0.07 & 0.02 & 0.06 & 0.04 \\
6 & 8.15 & 6.84 & 1.13 & 0.24 & 0.00 & 0.02 & 0.05 & 0.03 \\
7 & 9.78 & 6.67 & 0.00 & 0.13 & 0.04 & 0.02 & 0.05 & 0.03 \\
8 & 11.41 & 7.00 & 0.05 & 0.12 & 0.05 & 0.02 & 0.04 & 0.03 \\
\hline
\end{tabular}




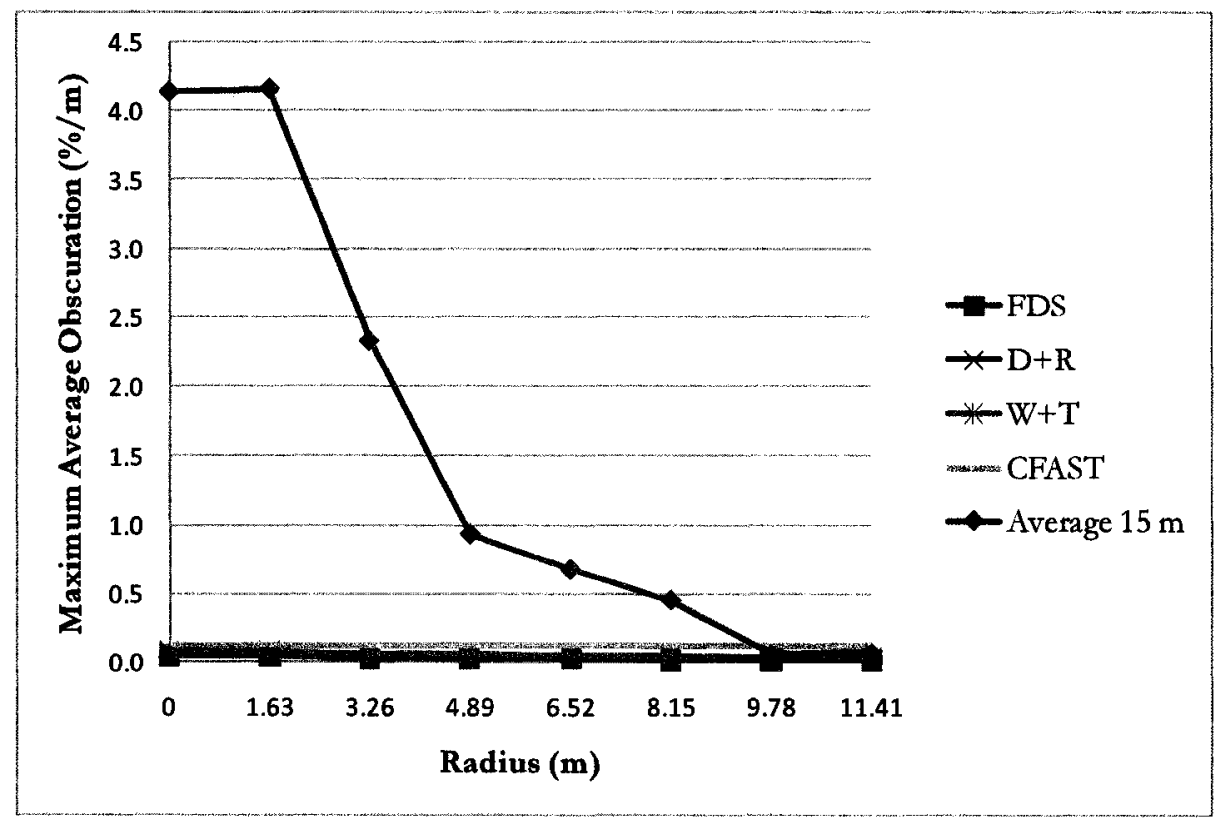

Figure 61 - Maximum Obscuration vs. Radius, paper fire, 15-m elevation

In Test 40, the first two rows of detectors returned alarm level obscuration readings at around 150 seconds into the test. The other two tests in the series reached maximum obscuration values of $1.42 \% / \mathrm{m}$ in row 1 of Test 41 and 2.8 $\% / \mathrm{m}$ in row 2 of Test 42 . Maximum obscuration values are lower at increased radial distance from the fire for Test 40 although no pattern is discernable from the data measured. Test 41 obscuration values also reduce with increased radius. Test 42 returned a higher maximum in row 2 than row 1 but lower values for the rest of the rows. The models predicted much lower results than that measured for the most part. Again, as with the 9-m and 12-m series of tests this was the only standard test fire to produce alarm level responses within smoke detectors at this elevation.

Table 21 lists data for the $20-\mathrm{ml}$ liquid fuel fire at the $15-\mathrm{m}$ elevation. The average maximum obscuration between the four tests is plotted along with the 
other data from the table in Figure 62 . The maximum value reported by the CFAST model is $6.07 \% / \mathrm{m}$ is not shown.

All of the tests in this series produced very similar results, with maximum obscuration values between about $1 \% / \mathrm{m}$ and $2 \% / \mathrm{m}$ and all in the first row. All three tests had a reduction in maximum obscuration with increased radial distances from the source. The reduction in maximum obscuration values followed an exponential pattern. The CFD and algebraic model results were a relatively close match to the data in this case. FDS slightly over predicted results, while the algebraic models slightly under predicted results near the fire source. All of the models tended towards over prediction at outside the fifth row.

Table 21 - Liquid fuel fire $(20 \mathrm{ml})$ maximum obscuration results at $15-\mathrm{m}$ elevation

\begin{tabular}{cccccccccr}
\hline & \multicolumn{7}{c}{ Alarm } & \multicolumn{7}{c}{ Maximum Obscuration } \\
\hline Row & Radius & Threshold & Test & Test & Test & FDS & W+T & D+R \\
\hline & $(\mathrm{m})$ & $(\% / \mathrm{m})$ & $(\% / \mathrm{m})$ & $(\% / \mathrm{m})$ & $(\% / \mathrm{m})$ & $(\% / \mathrm{m})$ & $(\% / \mathrm{m})$ & $(\% / \mathrm{m})$ \\
\hline 1 & 0 & 6.23 & 1.56 & 2.05 & 1.07 & 1.71 & 0.96 & 0.93 \\
2 & 1.63 & 6.45 & 1.32 & 1.69 & 0.93 & 1.76 & 0.96 & 0.93 \\
3 & 3.26 & 6.78 & 0.77 & 1.40 & 0.64 & 1.36 & 0.82 & 0.63 \\
4 & 4.89 & 7.27 & 0.52 & 0.76 & 0.63 & 1.02 & 0.72 & 0.50 \\
5 & 6.52 & 7.00 & 0.40 & 0.60 & 0.43 & 0.70 & 0.64 & 0.43 \\
6 & 8.15 & 6.84 & 0.30 & 0.36 & 0.19 & 0.56 & 0.57 & 0.37 \\
7 & 9.78 & 6.67 & 0.15 & 0.24 & 0.11 & 0.44 & 0.52 & 0.34 \\
8 & 11.41 & 7.00 & 0.04 & 0.04 & 0.07 & 0.30 & 0.47 & 0.31 \\
\hline
\end{tabular}




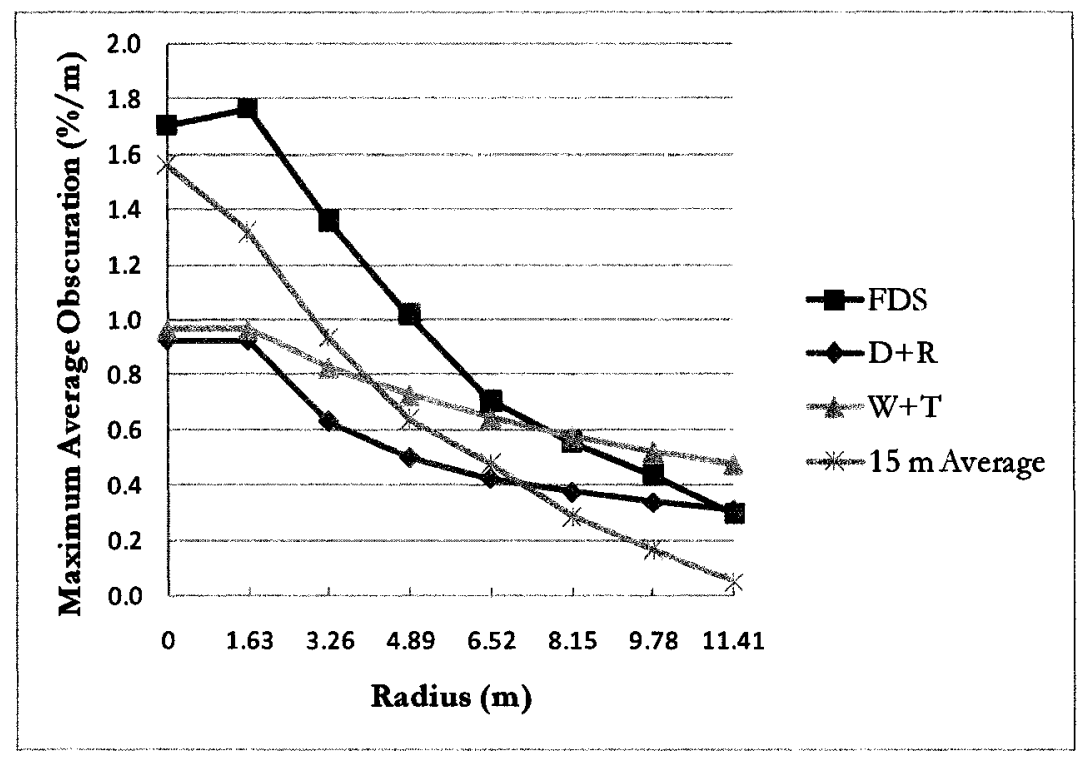

Figure 62 - Maximum Obscuration vs. Radius, 20-ml liquid fire, 15-m elevation

Table 22 lists data for the $40-\mathrm{ml}$ liquid fuel fire at this elevation. The average maximum obscuration between the three tests is plotted along with the other data from the table and the maximum value reported by the CFAST model of 6.11 $\% / \mathrm{m}$ in Figure 63.

There were four tests conducted in this series. Each test produced the highest maximum obscuration levels in the first row, ranging from $3.87 \% / \mathrm{m}$ to 5.55 $\% / \mathrm{m}$ in value. All of the tests produced the highest maximum value in the first row and lower values in subsequent rows. FDS over predicted all of the results of this test, with the maximum obscuration value of $6.72 \% / \mathrm{m}$ returned by the model in row 2 versus the maximum averaged obscuration value of $4.54 \% / \mathrm{m}$ in row 1 for experimental tests. The algebraic models under predicted the average maximum obscuration for the first two rows. The $\mathrm{W}+\mathrm{T}$ model began over predicting outside the third row, while the $D+R$ model continued under predicting results until outside the fifth row. 
Table 22 - Liquid fuel fire $(40 \mathrm{ml})$ maximum obscuration results at $15-\mathrm{m}$ elevation

\begin{tabular}{cccccccccc}
\hline & & Alarm & \multicolumn{7}{c}{ Maximum Obscuration } \\
\hline & & & Test & Test & Test & Test & FDS & & \\
Row & Radius & Threshold & 50 & 51 & 52 & 53 & & W+T & D+R \\
\hline & $(\mathbf{m})$ & $(\% / \mathrm{m})$ & $(\% / \mathrm{m})$ & $(\% / \mathrm{m})$ & $(\% / \mathrm{m})$ & $(\% / \mathrm{m})$ & $(\% / \mathrm{m})$ & $(\% / \mathrm{m})$ & $(\% / \mathrm{m})$ \\
\hline $\mathbf{1}$ & 0 & $\mathbf{6 . 2 3}$ & 4.47 & 5.55 & 3.87 & 4.27 & 6.28 & 3.73 & 3.58 \\
2 & 1.63 & $\mathbf{6 . 4 5}$ & 3.65 & 5.13 & 3.19 & 4.21 & 6.72 & 3.73 & 3.58 \\
3 & 3.26 & $\mathbf{6 . 7 8}$ & 3.37 & 2.85 & 2.34 & 3.08 & 6.08 & 3.19 & 2.45 \\
4 & 4.89 & 7.27 & 2.03 & 2.10 & 1.55 & 2.58 & 4.48 & 2.80 & 1.95 \\
5 & $\mathbf{6 . 5 2}$ & 7.00 & 1.51 & 1.49 & 0.98 & 1.92 & 3.77 & 2.49 & 1.66 \\
$\mathbf{6}$ & $\mathbf{8 . 1 5}$ & $\mathbf{6 . 8 4}$ & 1.46 & 0.85 & 0.80 & 1.55 & 3.10 & 2.23 & 1.46 \\
7 & $\mathbf{9 . 7 8}$ & $\mathbf{6 . 6 7}$ & 0.81 & 0.47 & 0.45 & 0.95 & 2.70 & 2.02 & 1.32 \\
$\mathbf{8}$ & $\mathbf{1 1 . 4 1}$ & 7.00 & 0.47 & 0.25 & 0.21 & 0.30 & 2.41 & 1.84 & 1.21 \\
\hline
\end{tabular}

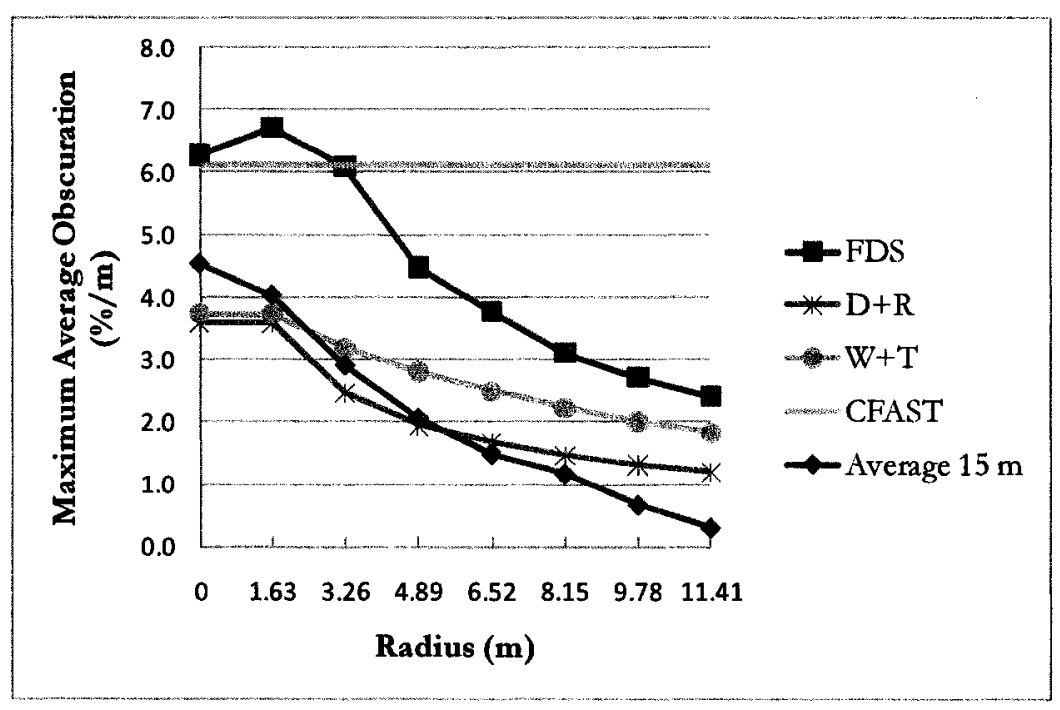

Figure 63 - Maximum Obscuration vs. Radius, 40-ml liquid fire, 15-m elevation

Table 23 lists data for the $100-\mathrm{ml}$ liquid fuel fire at the $15-\mathrm{m}$ elevation. The average maximum obscuration between the three tests is plotted along with the other data from the table and the maximum value reported by the CFAST model of $19.3 \% / \mathrm{m}$ in Figure 64 .

$-112$ 
Tests 46 and 48 produced alarm level obscuration results in the first row. Test 46 also produced alarm level obscuration results in the second row of detectors. Obscuration results were highest in the first row for this test series and were lower for each successive row with an approximately exponential reduction in obscuration with radial distance from the source.

Table 23 - Liquid fuel fire $(100 \mathrm{ml})$ maximum obscuration results at 15-m elevation

\begin{tabular}{ccccccccr}
\hline & \multicolumn{7}{c}{ Alarm } & \multicolumn{7}{c}{ Maximum Obscuration } \\
\hline Row & Radius & Threshold & $\begin{array}{c}\text { Test } \\
46\end{array}$ & $\begin{array}{c}\text { Test } \\
48\end{array}$ & $\begin{array}{c}\text { Test } \\
49\end{array}$ & FDS & W+T & D+R \\
\hline & $(\mathrm{m})$ & $(\% / \mathrm{m})$ & $(\% / \mathrm{m})$ & $(\% / \mathrm{m})$ & $(\% / \mathrm{m})$ & $(\% / \mathrm{m})$ & $(\% / \mathrm{m})$ & $(\% / \mathrm{m})$ \\
\hline 1 & 0 & 6.23 & 7.91 & 6.19 & 8.12 & 22.21 & 5.86 & 5.62 \\
2 & 1.63 & 6.45 & 6.78 & 5.83 & 6.04 & 21.93 & 5.86 & 5.62 \\
3 & 3.26 & 6.78 & 4.00 & 3.66 & 3.77 & 18.42 & 5.01 & 3.86 \\
4 & 4.89 & 7.27 & 3.94 & 3.63 & 3.36 & 14.68 & 4.41 & 3.08 \\
5 & 6.52 & 7.00 & 3.35 & 2.52 & 1.96 & 12.73 & 3.92 & 2.62 \\
6 & 8.15 & 6.84 & 2.53 & 2.28 & 1.63 & 9.64 & 3.52 & 2.31 \\
7 & 9.78 & 6.67 & 1.64 & 1.31 & 1.07 & 7.22 & 3.19 & 2.08 \\
8 & 11.41 & 7.00 & 1.86 & 1.15 & 1.16 & 6.73 & 2.91 & 1.91 \\
\hline
\end{tabular}




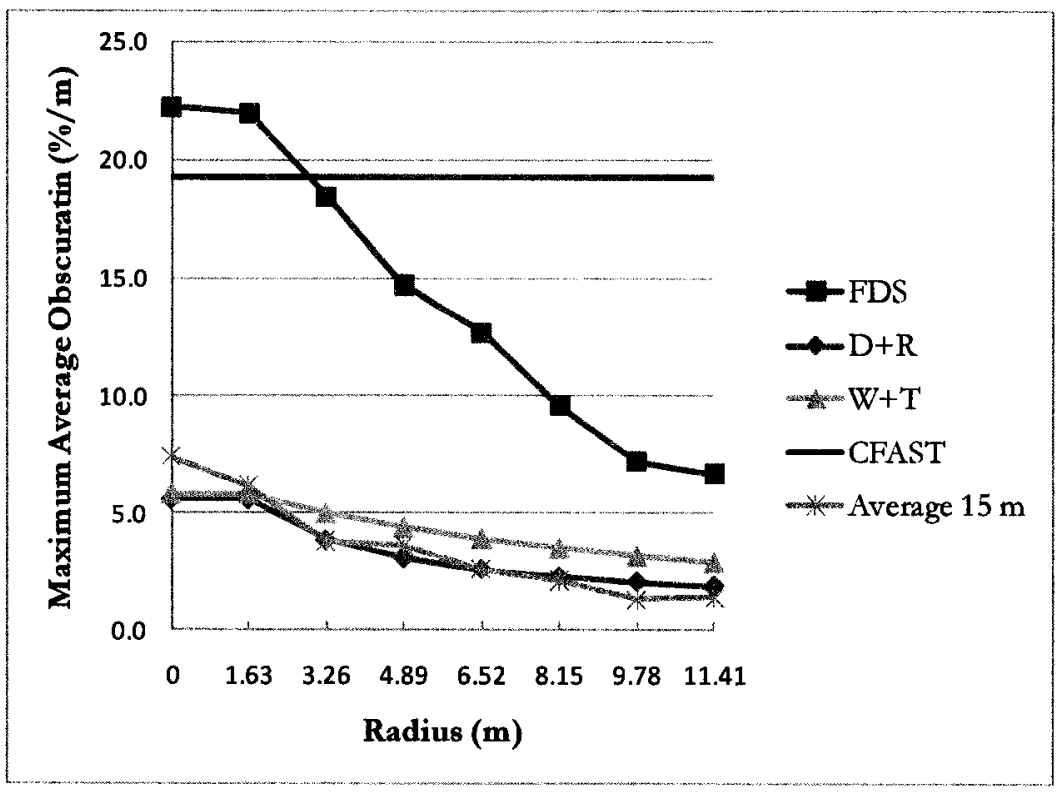

Figure 64 - Maximum Obscuration vs. Radius, 100-ml liquid fire, 15-m elevation

FDS and CFAST over predicted the measured results significantly for this series with the maximum value more than double the highest measured obscuration value. The algebraic models predicted roughly equal maximum values above the flame, but still lower than the corresponding test result. The algebraic models trended towards over prediction of results as the radius increased. The $D+R$ model most closely matched the measured results.

Table 24 and Figure 65 show data for the wood liquid fuel fire at the 15-m elevation. The maximum value reported by the CFAST model is $1.05 \% / \mathrm{m}$ (not shown).

The obscuration levels achieved at this elevation were negligible. Only two rows in Test 38 reached obscuration levels above $0.1 \%$ (row 1 and row 5). Only two 
rows in Test 39 reached obscuration levels above $0.1 \%$ (row 5 and row 8). All of the rest of the obscuration results are below $0.1 \%$.

Table $24-$ Wood crib fire maximum obscuration results at 15-m elevation

\begin{tabular}{ccccccccr}
\hline & \multicolumn{7}{c}{ Alarm } & \multicolumn{7}{c}{ Maximum Obscuration } \\
\hline & & & Test & Test & Test & FDS & W+T & D+R \\
Row & Radius & Threshold & 37 & 38 & 39 & & & \\
\hline & $(\mathrm{m})$ & $(\% / \mathrm{m})$ & $(\% / \mathrm{m})$ & $(\% / \mathrm{m})$ & $(\% / \mathrm{m})$ & $(\% / \mathrm{m})$ & $(\% / \mathrm{m})$ & $(\% / \mathrm{m})$ \\
\hline 1 & 0 & 6.23 & 0.09 & 0.11 & 0.06 & 0.20 & 0.31 & 0.29 \\
2 & 1.63 & 6.45 & 0.04 & 0.05 & 0.07 & 0.19 & 0.31 & 0.29 \\
3 & 3.26 & 6.78 & 0.04 & 0.02 & 0.08 & 0.16 & 0.27 & 0.20 \\
4 & 4.89 & 7.27 & 0.07 & 0.05 & 0.00 & 0.15 & 0.24 & 0.16 \\
5 & 6.52 & 7.00 & 0.00 & 0.21 & 0.16 & 0.13 & 0.21 & 0.13 \\
6 & 8.15 & 6.84 & 0.09 & 0.07 & 0.04 & 0.11 & 0.19 & 0.12 \\
7 & 9.78 & 6.67 & 0.04 & 0.04 & 0.08 & 0.08 & 0.17 & 0.11 \\
8 & 11.41 & 7.00 & 0.07 & 0.09 & 0.16 & 0.06 & 0.15 & 0.10 \\
\hline
\end{tabular}

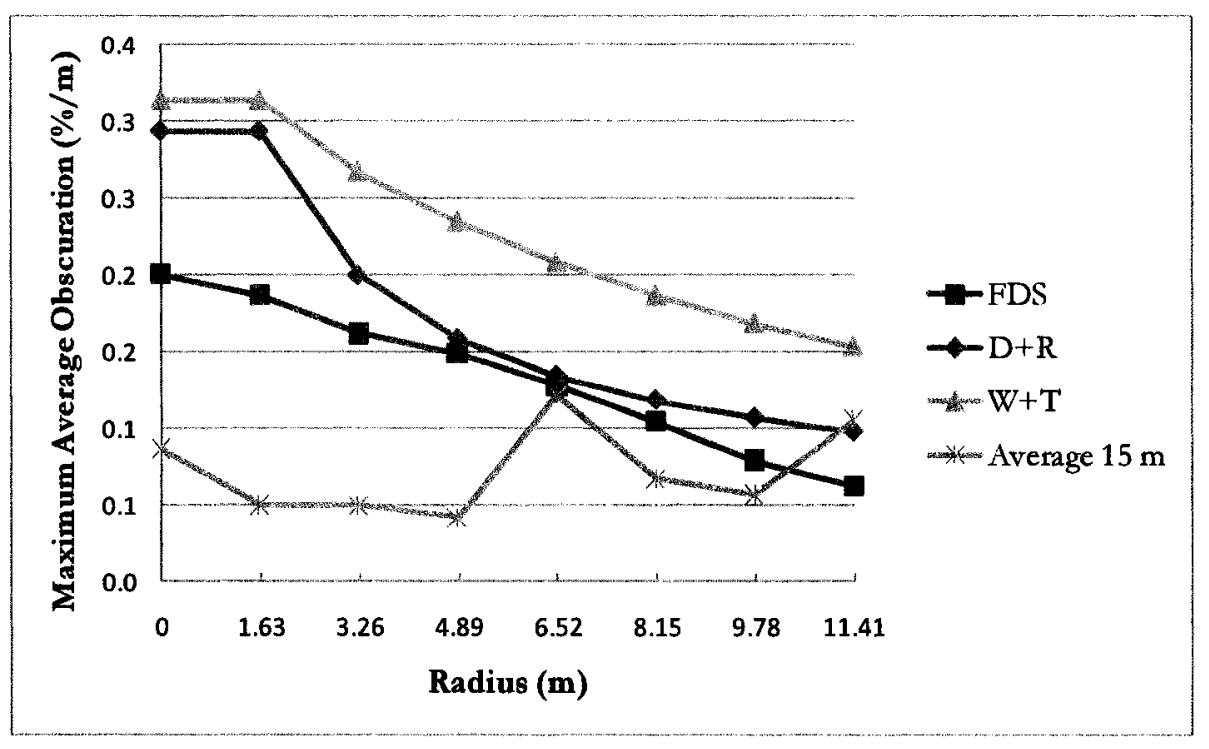

Figure 65 - Maximum Obscuration vs. Radius, wood fire, 15-m elevation 
In this case FDS predicted levels that were only slightly higher than the maximum levels for the most part. Slightly higher results were obtained from the algebraic models, while CFAST produced the highest predicted results.

The maximum obscuration results for the liquid fuel fire test series were obtained in the first row of detectors. Figure 66, Figure 67, and Figure 68, show the results for the first row of the fire that produced the highest maximum obscuration results for each series of liquid fuel fire tests at this elevation. It can be seen by comparison that each fire produced obscuration results starting at approximately 30 seconds into the test and the first rise was an almost instantaneous jump from zero to near the maximum value attained during the test. The actual peak was reached sometime later, but always between 30 and 90 seconds into the test. Each successive increase in fuel quantity and fire size produced higher maximum values of obscuration.

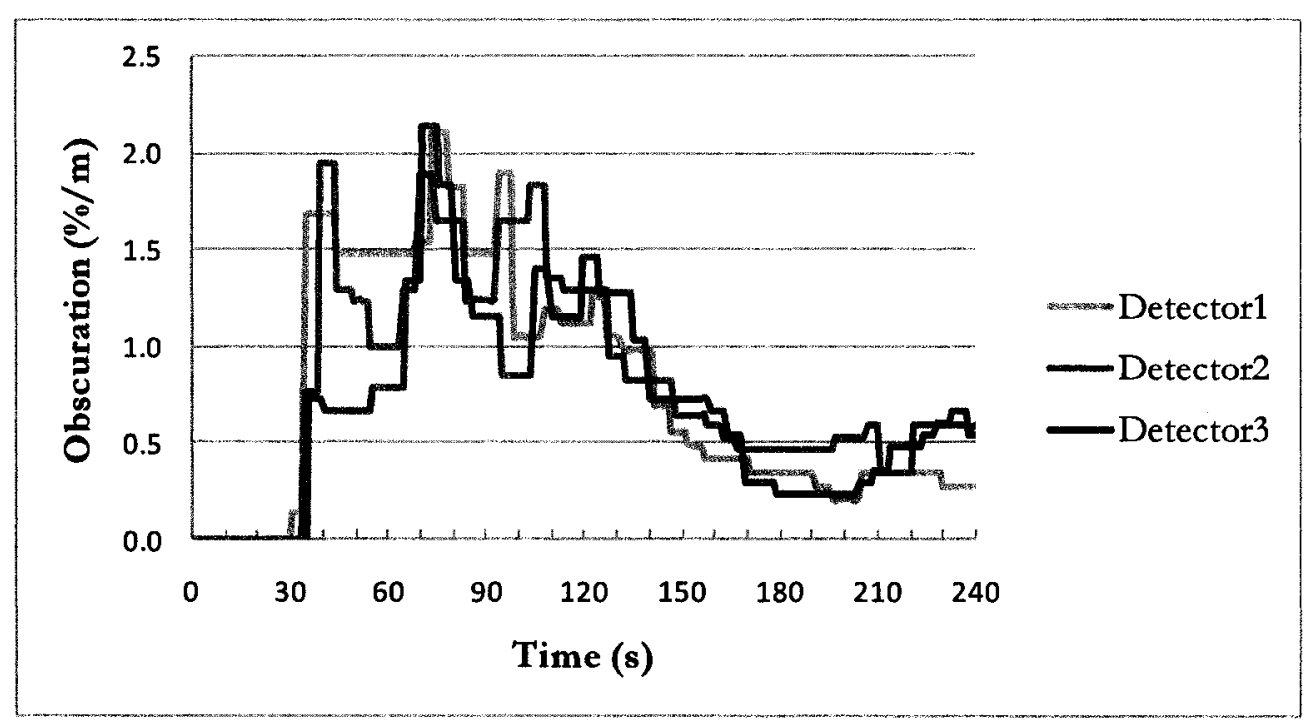

Figure 66 - Obscuration vs. Time, $20 \mathrm{ml}$ liquid fuel fire row 1, Test 44, 15-m elevation 


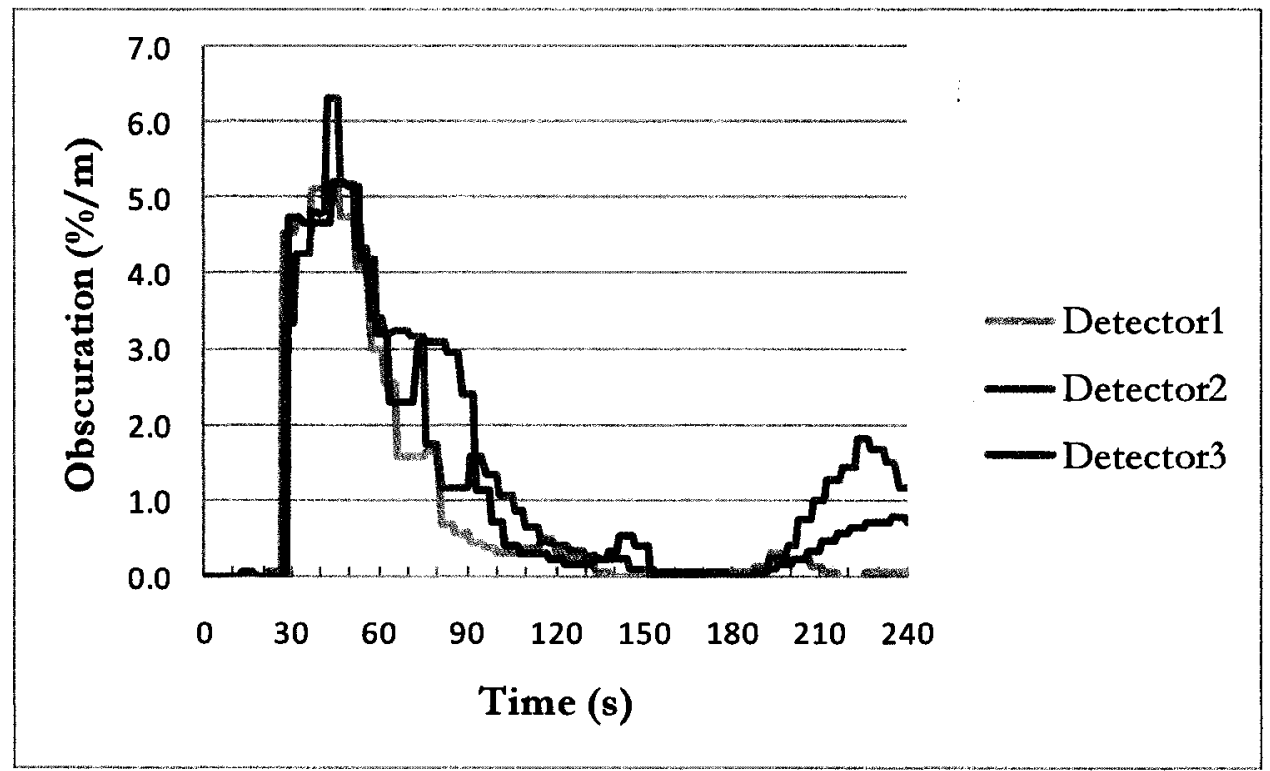

Figure 67 - Obscuration vs. Time, $40 \mathrm{ml}$ liquid fuel fire, row 1, Test 51, 15-m elevation

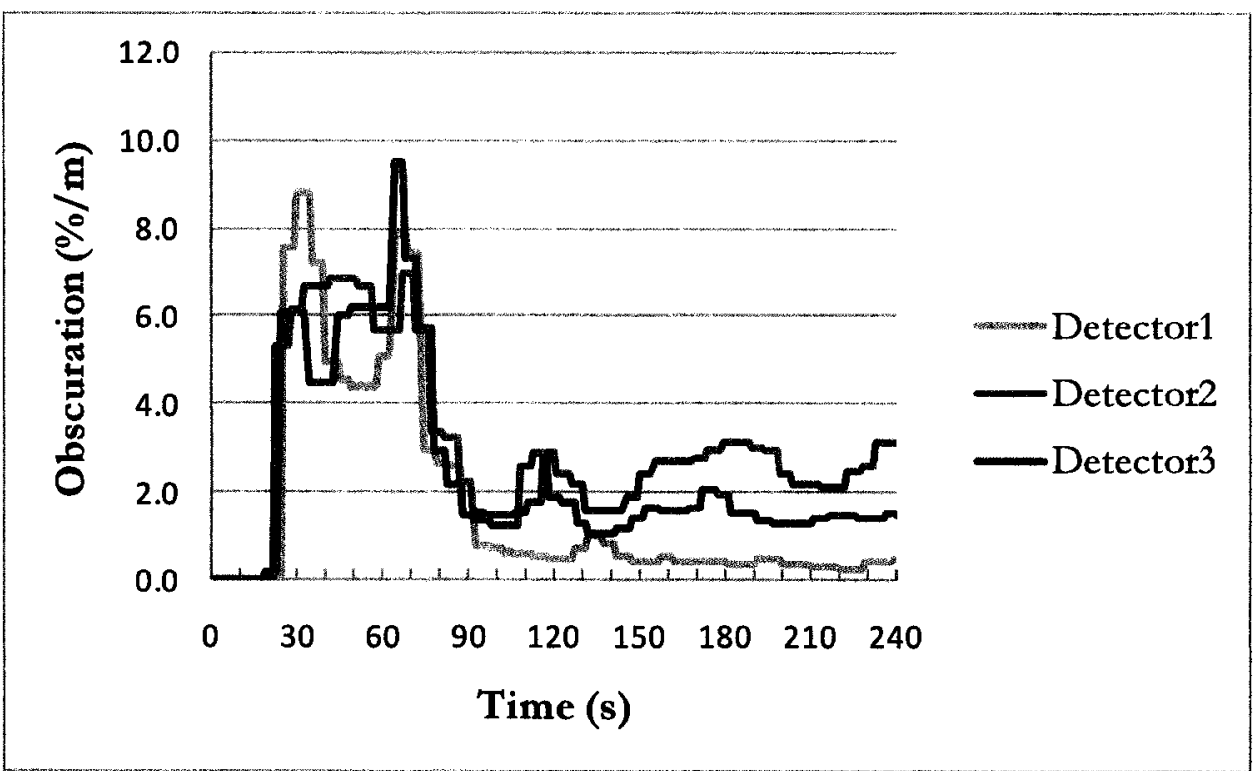

Figure 68 - Obscuration vs. Time, $100 \mathrm{ml}$ liquid fuel fire, row 1, Test 49, 15-m elevation 


\subsubsection{8-m Elevation Tests}

Six tests were conducted with the platform at an elevation of $18 \mathrm{~m}$ on July 17 , 2008 (Tests 54-59). Two fuel packages were used; 40-ml, and 60-ml heptane/toluene mixtures. Each fuel package was tested in a different size container; $339 \mathrm{~cm}^{2}$, and $449 \mathrm{~cm}^{2}$. Each fuel package was tested three times. Test data was gathered for 240 seconds from ignition for each test. Ambient temperature, pressure and humidity data was recorded for each test and listed in Table 25.

Table 25 - Test conditions at $18-\mathrm{m}$ elevation

\begin{tabular}{llcccc}
\hline Test & Fuel & Qty & $\mathrm{P}_{0}$ & $\mathrm{RH}$ & $\mathrm{T}_{0}$ \\
No. & Type & & & 0 & \\
& & $\mathrm{ml}$ & $\mathrm{kPa}$ & $\%$ & $\mathrm{C}$ \\
54 & Liquid & 40 & 101.99 & 61 & 25.02 \\
55 & Liquid & 40 & 101.99 & 61 & 25.71 \\
56 & Liquid & 40 & 101.97 & 54 & 25.71 \\
57 & Liquid & 60 & 101.97 & 54 & 26.4 \\
58 & Liquid & 60 & 101.97 & 54 & 26.16 \\
59 & Liquid & 60 & 101.97 & 54 & 26.45 \\
\hline
\end{tabular}

Table 26 lists maximum average obscuration values for the three detectors in each row of the platform, average values in each row reported from the FDS model simulation, algebraic results for the Watanabe and Tanaka (W+T) as well as the Davis and Reneke $(D+R)$ model for the $40-\mathrm{ml}$ liquid fuel fire at this elevation. Figure 69 plots the average maximum obscuration between the three tests along with the other data from the table and the maximum value reported by the CFAST model of $5.99 \% / \mathrm{m}$.

$-118-$ 
None of the detectors reported alarm level obscuration for this test series, nor was such a level predicted by any of the models. The FDS model over predicting the results at all of the locations for this series of tests. The Algebraic models were closer predictors of the results, shifting from under prediction near the fire to over prediction around the second row. CFAST provided the highest predicted result.

Table 26 - Liquid fuel $(40-\mathrm{ml})$ maximum obscuration results at $18-\mathrm{m}$ elevation

\begin{tabular}{ccccccccr}
\hline & \multicolumn{7}{c}{ Alarm } & \multicolumn{7}{c}{ Maximum Obscuration } \\
\hline & & & Test & Test & Test & FDS & W+T & D+R \\
Row & Radius & Threshold & 54 & 55 & 56 & & & \\
\hline & $(\mathrm{m})$ & $(\% / \mathrm{m})$ & $(\% / \mathrm{m})$ & $(\% / \mathrm{m})$ & $(\% / \mathrm{m})$ & $(\% / \mathrm{m})$ & $(\% / \mathrm{m})$ & $(\% / \mathrm{m})$ \\
\hline 1 & 0 & 6.23 & 3.74 & 2.42 & 2.82 & 3.88 & 2.76 & 2.65 \\
2 & 1.63 & 6.45 & 2.96 & 2.25 & 2.58 & 4.74 & 2.76 & 2.65 \\
3 & 3.26 & 6.78 & 1.61 & 1.98 & 1.71 & 3.70 & 2.47 & 2.01 \\
4 & 4.89 & 7.27 & 1.01 & 1.50 & 1.29 & 3.24 & 2.21 & 1.60 \\
5 & 6.52 & 7.00 & 0.85 & 1.52 & 0.77 & 2.73 & 1.99 & 1.36 \\
6 & 8.15 & 6.84 & 0.26 & 0.82 & 0.38 & 2.43 & 1.81 & 1.20 \\
7 & 9.78 & 6.67 & 0.17 & 0.39 & 0.07 & 2.13 & 1.65 & 1.08 \\
8 & 11.41 & 7.00 & 3.74 & 0.09 & 0.07 & 2.29 & 1.52 & 0.99 \\
\hline
\end{tabular}

$-119-$ 


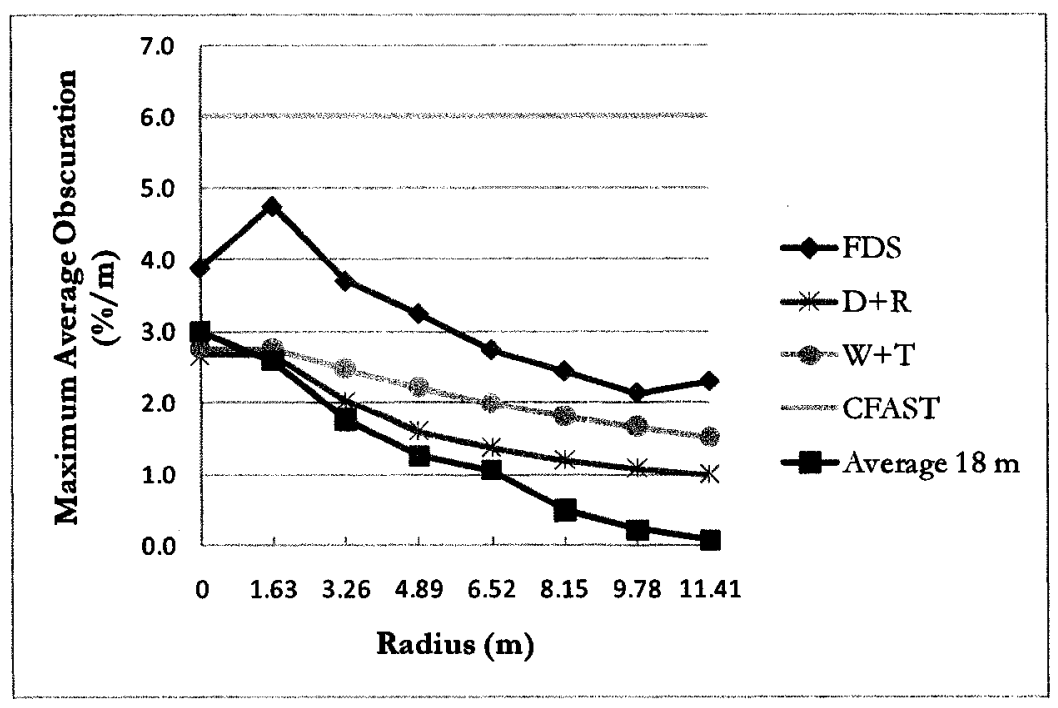

Figure 69 - Maximum Obscuration vs. Radius, 40-ml liquid fire, 18-m elevation

Table 27 lists data for the $60-\mathrm{ml}$ liquid fuel fire at the $18-\mathrm{m}$ elevation. The average maximum obscuration between the three tests is plotted along with the other data from the table and the maximum value reported by the CFAST model of $5.51 \% / \mathrm{m}$ in Figure 70 .

Table 27 - Liquid fuel $(60-\mathrm{ml})$ maximum obscuration results at $18-\mathrm{m}$ elevation

\begin{tabular}{ccccccccr}
\hline & \multicolumn{7}{c}{ Alarm } & \multicolumn{7}{c}{ Maximum Obscuration } \\
\hline & & & Test & Test & Test & FDS & W+T & D+R \\
Row & Radius & Threshold & 57 & 58 & 59 & & & \\
\hline & $(\mathrm{m})$ & $(\% / \mathrm{m})$ & $(\% / \mathrm{m})$ & $(\% / \mathrm{m})$ & $(\% / \mathrm{m})$ & $(\% / \mathrm{m})$ & $(\% / \mathrm{m})$ & $(\% / \mathrm{m})$ \\
\hline 1 & 0 & 6.23 & 3.52 & 3.85 & 3.22 & 7.61 & 3.96 & 3.80 \\
2 & 1.63 & 6.45 & 3.16 & 4.11 & 2.66 & 7.45 & 3.96 & 3.80 \\
3 & 3.26 & 6.78 & 3.05 & 2.54 & 1.72 & 7.31 & 3.54 & 2.88 \\
4 & 4.89 & 7.27 & 2.38 & 2.81 & 1.03 & 6.03 & 3.17 & 2.30 \\
5 & 6.52 & 7.00 & 1.66 & 1.89 & 0.67 & 4.41 & 2.86 & 1.95 \\
6 & 8.15 & 6.84 & 1.36 & 1.26 & 0.40 & 3.96 & 2.59 & 1.72 \\
7 & 9.78 & 6.67 & 0.41 & 0.81 & 0.10 & 3.63 & 2.37 & 1.55 \\
8 & 11.41 & 7.00 & 0.25 & 0.48 & 0.16 & 2.87 & 2.18 & 1.42 \\
\hline
\end{tabular}

$-120-$ 
No alarm level obscuration results were measured this test series although these levels were predicted by FDS for the first three rows of detectors. In this case, while the models predicted higher obscuration values for the larger fire at this elevation, the test results were close to the values recorded from the $40-\mathrm{ml}$ liquid fuel fire tests. The models and the test results show the maximum obscuration levels reduce with radial distance from source for this series. The algebraic models do not switch from under to over prediction of results as the radius from the source increases as with previous comparisons with test. In this case they over predict results for all radial distances.

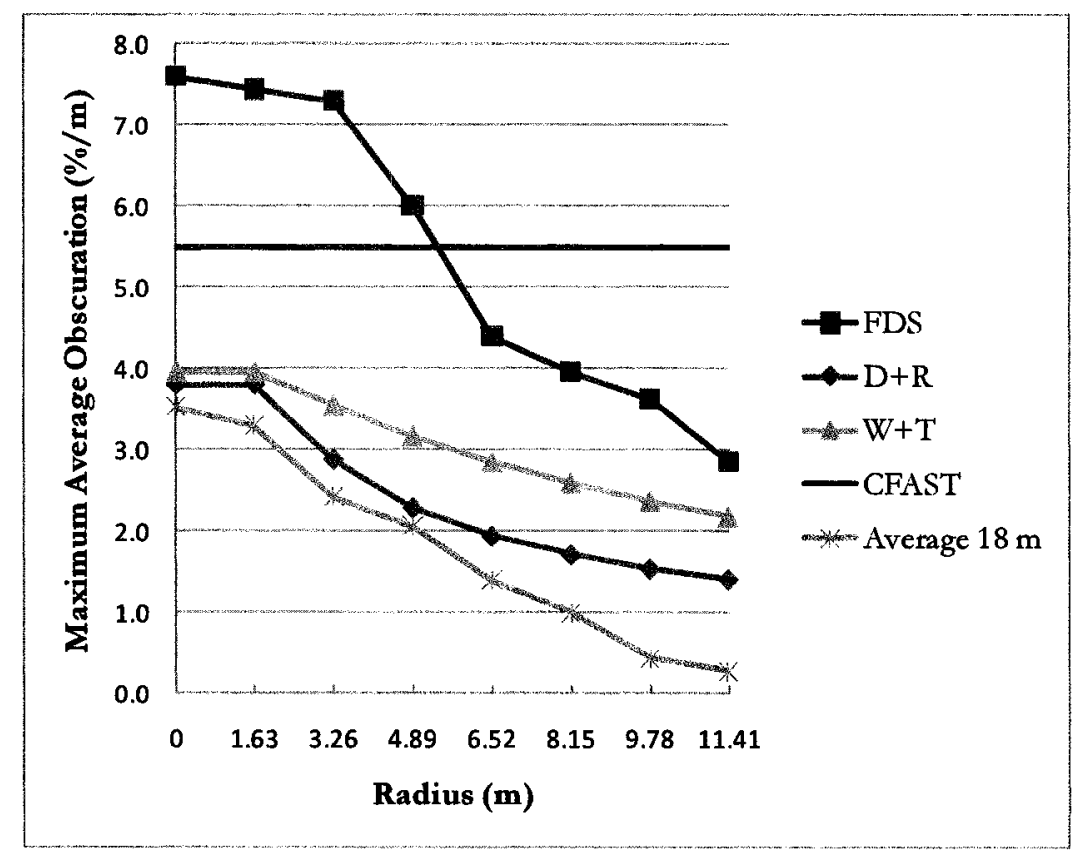

Figure 70 - Maximum Obscuration vs. Radius, 60-ml liquid fire, 18-m elevation 


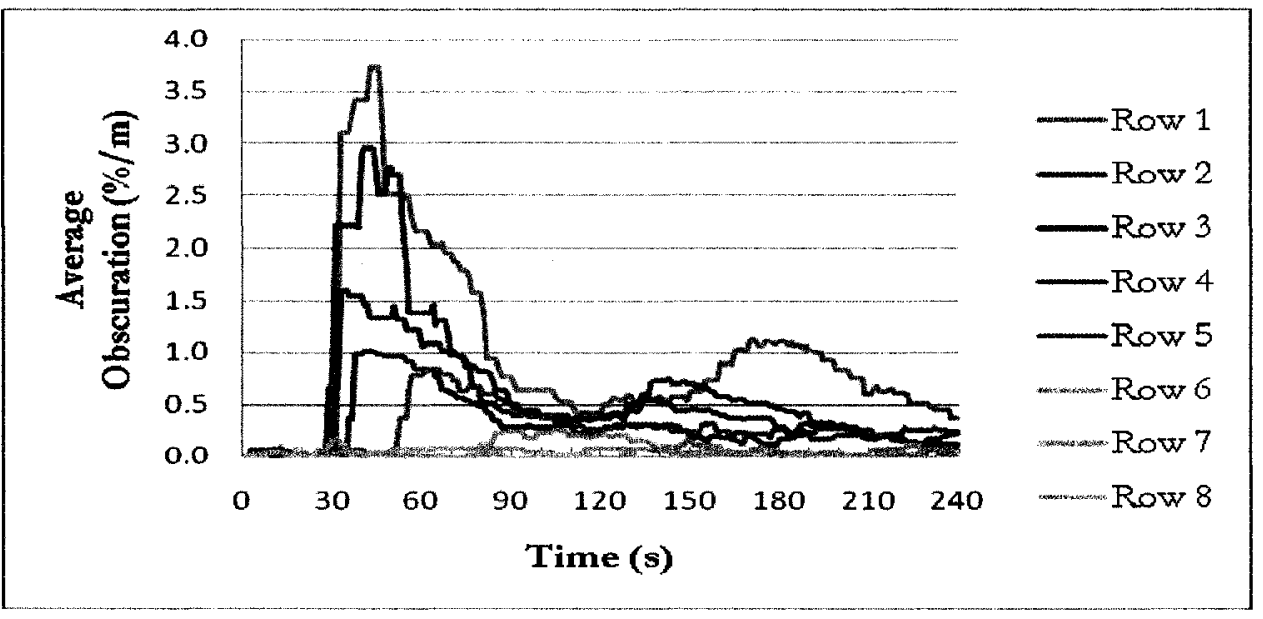

Figure 71 - Average Obscuration vs. Time for all rows, Test 54

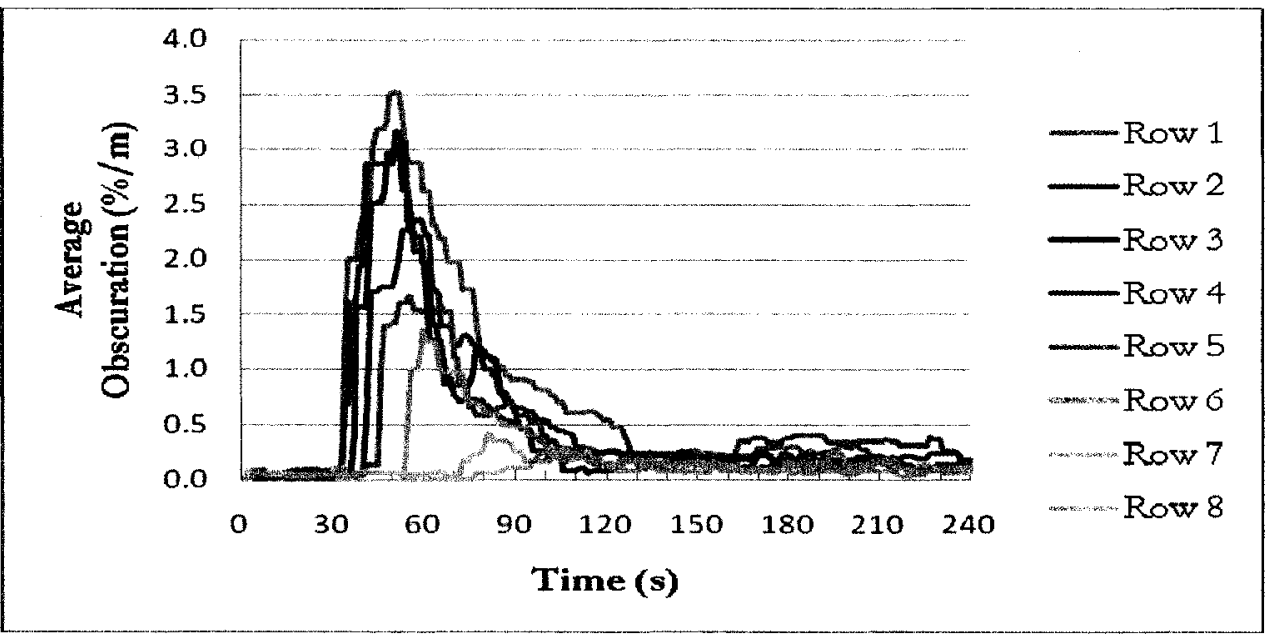

Figure 72 - Average Obscuration vs. Time for all rows, Test 57

Figure 71 shows the average obscuration for each tow in the 40-ml Test 54 while Figure 72 shows the average obscuration for each row in the $60-\mathrm{ml}$ Test 57. When the two sets of data are compared, the sharp rise in obscuration in the first three rows almost simultaneously can be seen for both of the tests, and this rise begins at approximately 30 seconds into the test. This suggests the radius of the plume is in the range of 3-5 $\mathrm{m}$ for both tests. The peak value in these first rows 
occurs at approximately the same time as well, between 30 and 60 seconds into the test. The peak value for both tests is very close, which is surprising given the difference in fire size. However, the $60-\mathrm{ml}$ fire produced a higher response from detectors further away from the fire than did the $40-\mathrm{ml}$ fire. This is an indication that the smoke was distributed more widely for the larger fire.

\subsubsection{1-m Elevation Tests}

Ten tests were conducted with the platform at an elevation of $21 \mathrm{~m}$ on July 18 , 2008 (Tests 60-69). Three fuel packages were used; 40-ml, 60-ml, and 100-ml Heptane/Toluene mixtures. Test data was gathered for 240 seconds from ignition for each test. Ambient temperature, pressure and humidity data was recorded for each test and listed in Table 28.

Table 28 - Test conditions at 21-m elevation

\begin{tabular}{llcccc}
\hline Test & $\begin{array}{l}\text { Fuel } \\
\text { No. }\end{array}$ & Qype & $\mathrm{P}_{0}$ & $\mathrm{RH}$ & $\mathrm{T}_{0}$ \\
& & $\mathrm{ml}$ & $\mathrm{kPa}$ & $\begin{array}{c}0 \\
\%\end{array}$ & $\mathrm{C}$ \\
60 & Liquid & 40 & 101.48 & 88 & 22.92 \\
61 & Liquid & 40 & 101.48 & 88 & 22.25 \\
62 & Liquid & 40 & 101.48 & 88 & 22.23 \\
63 & Liquid & 40 & 101.48 & 88 & 23.33 \\
64 & Liquid & 60 & 101.48 & 88 & 22.55 \\
65 & Liquid & 60 & 101.44 & 88 & 22.72 \\
66 & Liquid & 60 & 101.44 & 88 & 23.14 \\
67 & Liquid & 100 & 101.44 & 88 & 23.37 \\
68 & Liquid & 100 & 101.44 & 88 & 23.37 \\
69 & Liquid & 100 & 101.44 & 88 & 23.41 \\
\hline
\end{tabular}

Table 29 lists maximum average obscuration values for the three detectors in each row of the platform, average values in each row reported from the FDS model simulation, algebraic results for the Watanabe and Tanaka (W+T) as well as the Davis and Reneke (D+R) model for the $40-\mathrm{ml}$ liquid fuel fire at this 
elevation. The average maximum obscuration between the three tests is plotted along with the other data from the table and the maximum value reported by the CFAST model of $5.09 \% / \mathrm{m}$ in Figure 73 .

Test $61 \mathrm{had}$ to be repeated for this test due to a data gathering error. The three tests and the model results returned similar maximum obscuration values for this series. The FDS model slightly over predicted the results, while the algebraic models predicted the results closely. The maximum obscuration values were highest for Test 62 , which returned a maximum obscuration value in the second row that was higher than the first row. The other tests produced lower obscuration results at increased radial distance from the fire source.

Table 29 - Liquid fuel (40-m) maximum obscuration results at 21-m elevation

\begin{tabular}{ccccccccr}
\hline & \multicolumn{7}{c}{ Alarm } & \multicolumn{7}{c}{ Maximum Obscuration } \\
\hline Row & Radius & Threshold & $\begin{array}{c}\text { Test } \\
60\end{array}$ & $\begin{array}{c}\text { Test } \\
62\end{array}$ & $\begin{array}{c}\text { Test } \\
63\end{array}$ & FDS & W+T & D+R \\
\hline & $(\mathrm{m})$ & $(\% / \mathrm{m})$ & $(\% / \mathrm{m})$ & $(\% / \mathrm{m})$ & $(\% / \mathrm{m})$ & $(\% / \mathrm{m})$ & $(\% / \mathrm{m})$ & $(\% / \mathrm{m})$ \\
\hline 1 & 0 & 6.23 & 2.47 & 3.85 & 2.63 & 3.57 & 2.14 & 2.05 \\
2 & 1.63 & 6.45 & 2.34 & 4.11 & 2.35 & 3.95 & 2.14 & 2.05 \\
3 & 3.26 & 6.78 & 1.95 & 2.54 & 2.02 & 3.91 & 2.14 & 2.05 \\
4 & 4.89 & 7.27 & 1.37 & 2.81 & 1.82 & 3.53 & 1.79 & 1.35 \\
5 & 6.52 & 7.00 & 0.96 & 1.89 & 1.38 & 2.69 & 1.63 & 1.15 \\
6 & 8.15 & 6.84 & 0.53 & 1.26 & 0.89 & 1.74 & 1.50 & 1.01 \\
7 & 9.78 & 6.67 & 0.33 & 0.81 & 0.64 & 1.58 & 1.38 & 0.91 \\
8 & 11.41 & 7.00 & 0.14 & 0.48 & 0.46 & 1.35 & 1.28 & 0.83 \\
\hline
\end{tabular}




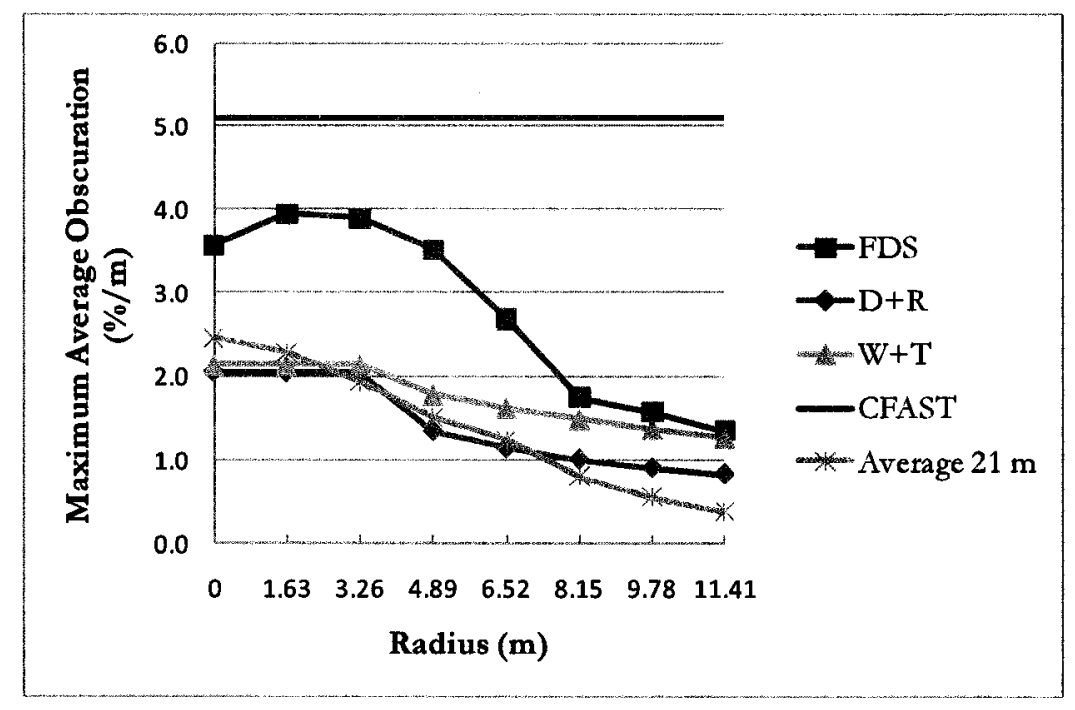

Figure 73 - Maximum Obscuration vs. Radius, 40-ml liquid fire, 21-m elevation

Table 30 lists data for the $60-\mathrm{ml}$ liquid fuel fire at the $21-\mathrm{m}$ elevation. The average maximum obscuration between the three tests is plotted along with the other data from the table and the maximum value reported by the CFAST model of $5.61 \% / \mathrm{m}$ in Figure 74.

The maximum obscuration values were highest for Test 66 . Both Test 65 and Test 66 had higher maximum obscuration values in the second row than the first row. The remainder of the test data show lower obscuration results at increased radial distance from the fire source. The results from the tests in this series were equivalent to the values from the smaller fire tests at this elevation. FDS and CFAST predicted initial obscuration values approximately double the measured values. The algebraic models $W+T$ and $D+R$ predicted obscuration values very close to those measured during testing for the first two rows. Outside the second row, the algebraic models began predicting higher than measured values for obscuration. 
Table 30 - Liquid fuel $(60-\mathrm{ml})$ maximum obscuration results at $21-\mathrm{m}$ elevation

\begin{tabular}{ccccccccr}
\hline & & Alarm & \multicolumn{7}{c}{ Maximum Obscuration } \\
\hline & & & Test & Test & Test & & W+T & D+R \\
Row & Radius & Threshold & 64 & 65 & 66 & FDS & & \\
\hline & $(\mathrm{m})$ & $(\% / \mathrm{m})$ & $(\% / \mathrm{m})$ & $(\% / \mathrm{m})$ & $(\% / \mathrm{m})$ & $(\% / \mathrm{m})$ & $(\% / \mathrm{m})$ & $(\% / \mathrm{m})$ \\
\hline 1 & 0 & 6.23 & 3.06 & 2.65 & 3.19 & 6.46 & 3.07 & 2.95 \\
2 & 1.63 & 6.45 & 2.48 & 3.00 & 3.56 & 6.67 & 3.07 & 2.95 \\
3 & 3.26 & 6.78 & 1.70 & 2.03 & 2.41 & 5.73 & 3.07 & 2.95 \\
4 & 4.89 & 7.27 & 1.80 & 1.17 & 1.71 & 4.69 & 2.57 & 1.94 \\
5 & 6.52 & 7.00 & 1.12 & 1.07 & 1.47 & 3.54 & 2.34 & 1.65 \\
6 & 8.15 & 6.84 & 0.73 & 0.96 & 0.90 & 2.95 & 2.15 & 1.45 \\
7 & 9.78 & 6.67 & 0.52 & 0.60 & 0.86 & 2.25 & 1.98 & 1.31 \\
8 & 11.41 & 7.00 & 0.23 & 0.23 & 0.53 & 1.98 & 1.84 & 1.20 \\
\hline
\end{tabular}

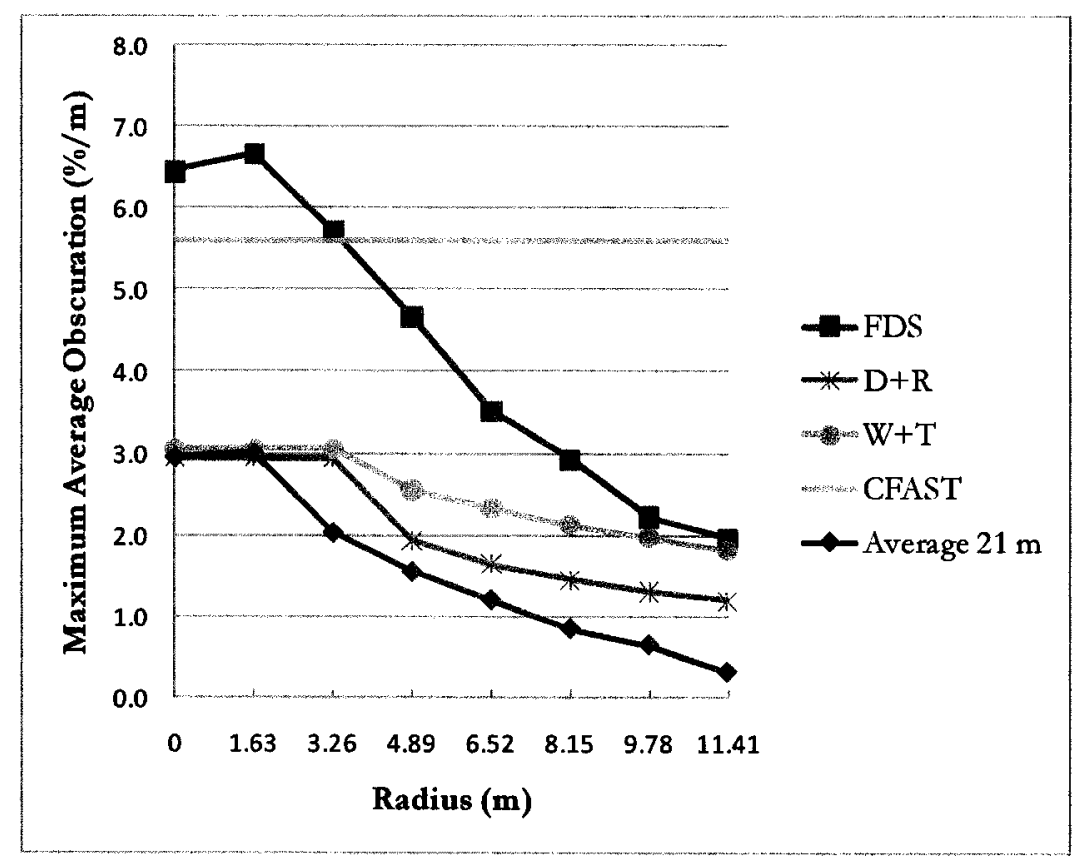

Figure 74 - Maximum Obscuration vs. Radius, 60-ml liquid fire, 21-m elevation

Table 31 lists data for the 100-ml liquid fuel fire at the $21-\mathrm{m}$ elevation. The average maximum obscuration between the three tests is plotted along with the 
other data from the table and the maximum value reported by the CFAST model of $15.95 \% / \mathrm{m}$ in Figure 75.

The maximum obscuration values were highest for Test 67 in the second row of detectors. The remainder of the testing produced lower obscuration results at increased radial distance from the fire source. The results from the tests in this series were slightly higher than the values from the smaller fire tests at this elevation. Again, FDS and CFAST predicted higher obscuration values than measured. The algebraic models $\mathrm{W}+\mathrm{T}$ and $\mathrm{D}+\mathrm{R}$ predicted obscuration values slightly lower than those produced during testing for the first two rows. Outside the second row, the $\mathrm{W}+\mathrm{T}$ model predicted higher than measured values, while the $\mathrm{D}+\mathrm{R}$ model continued predict measured values for obscuration quite closely.

Table 31 - Liquid fuel $(100-\mathrm{ml})$ maximum obscuration results at $21-\mathrm{m}$ elevation

\begin{tabular}{ccccccccc}
\hline & \multicolumn{9}{c}{ Alarm } & \multicolumn{7}{c}{ Maximum Obscuration } \\
\hline Row & Radius & Threshold & Test 67 & Test 68 & Test 69 & FDS & W+T & D+R \\
\hline & $(\mathbf{m})$ & $(\% / \mathrm{m})$ & $(\% / \mathrm{m})$ & $(\% / \mathrm{m})$ & $(\% / \mathrm{m})$ & $(\% / \mathrm{m})$ & $(\% / \mathrm{m})$ & $(\% / \mathrm{m})$ \\
\hline $\mathbf{1}$ & 0 & 6.23 & 3.97 & 3.46 & 4.36 & 11.60 & 3.41 & 3.27 \\
2 & 1.63 & 6.45 & 5.07 & 3.13 & 3.42 & 12.44 & 3.41 & 3.27 \\
3 & 3.26 & 6.78 & 3.15 & 2.38 & 3.03 & 12.17 & 3.41 & 3.27 \\
$\mathbf{4}$ & 4.89 & 7.27 & 2.34 & 1.85 & 2.02 & 10.79 & 2.86 & 2.15 \\
5 & $\mathbf{6 . 5 2}$ & 7.00 & 1.98 & 1.60 & 1.95 & 7.96 & 2.60 & 1.83 \\
$\mathbf{6}$ & 8.15 & 6.84 & 1.56 & 1.20 & 1.63 & 6.00 & 2.39 & 1.61 \\
7 & 9.78 & 6.67 & 0.97 & 1.19 & 1.39 & 5.07 & 2.20 & 1.46 \\
8 & 11.41 & 7.00 & 1.47 & 0.96 & 1.09 & 4.33 & 2.04 & 1.33 \\
\hline
\end{tabular}




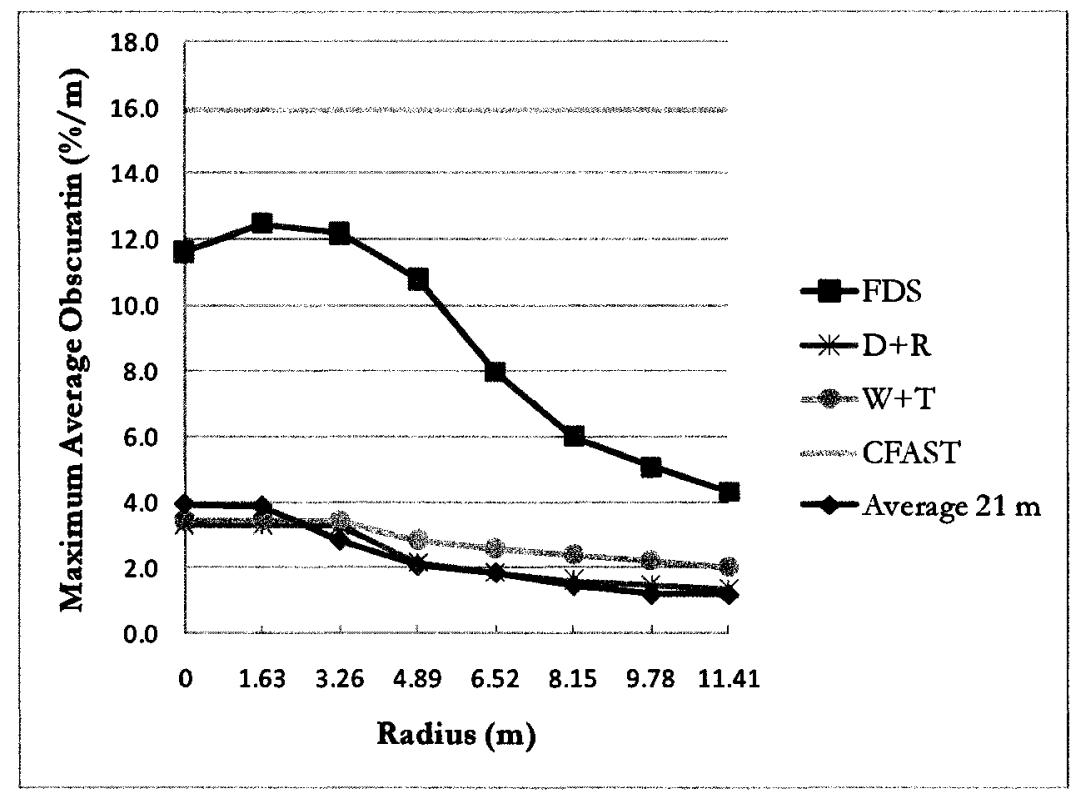

Figure 75 - Maximum Obscuration vs. Radius, 100-ml liquid fire, 21-m elevation

The average obscuration values for each row plotted against time are shown for Test 62 in Figure 76, for Test 65 in Figure 77, and for Test 68 in Figure 78. The figures show that the time when maximum values are achieved are fairly close together which shows that time to reach maximum obscuration has little dependence on the fire size for these fire types. The shape of the data is similar to the other liquid fuel fire tests. The first indication of a change in obscuration is a sharp rise at approximately 30 seconds into the test and the first rise reaches close to the overall peak value reached. The larger fires with more fuel produce larger responses from detectors further away from the centre than do the smaller fires. This result is similar to that shown for the tests at lower elevations. 


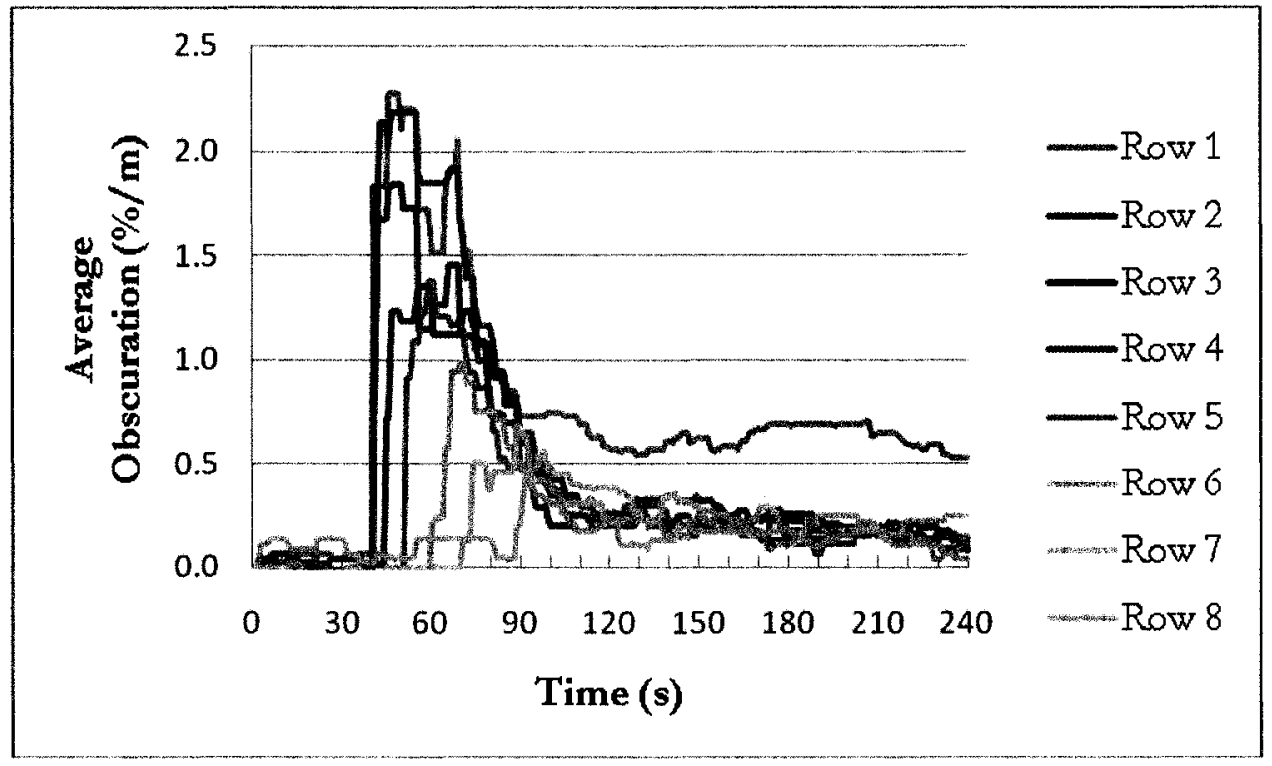

Figure 76 - Average Obscuration vs Time for each row of detectors, Test 62

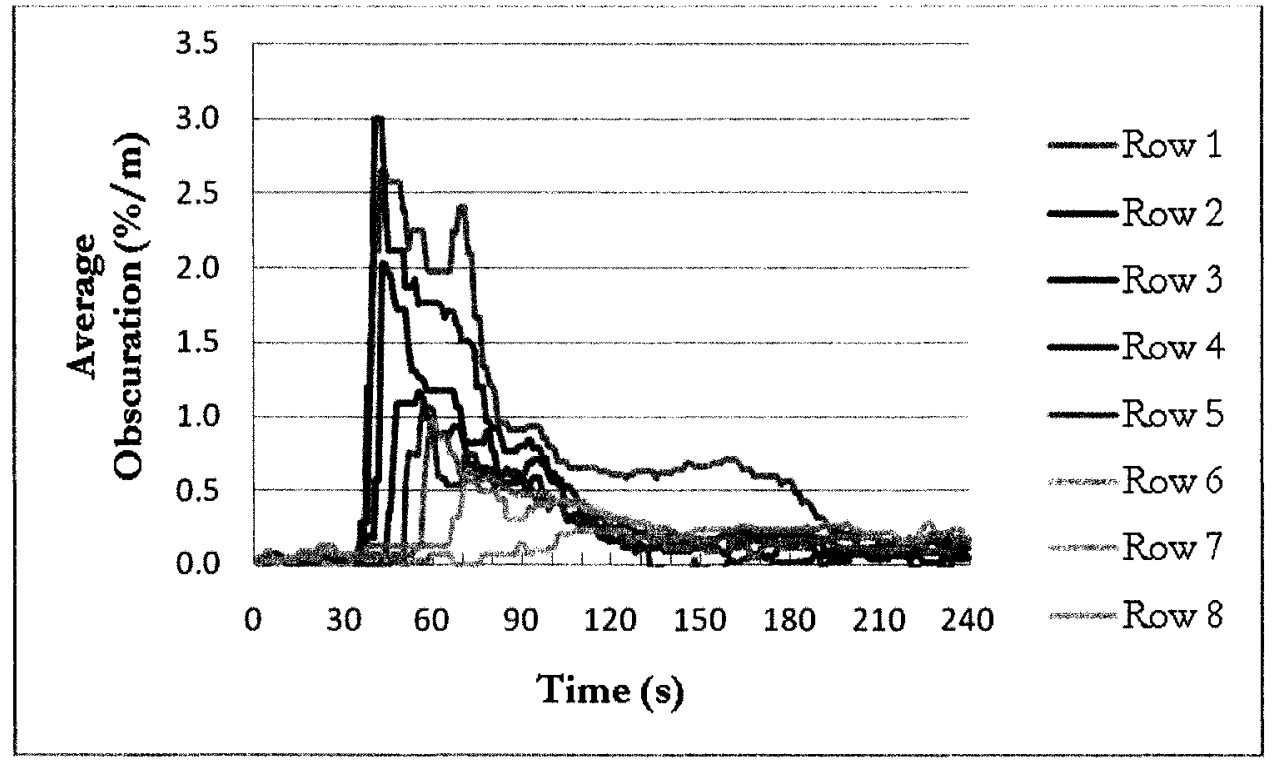

Figure 77 - Average Obscuration vs Time for each row of detectors, Test 65 


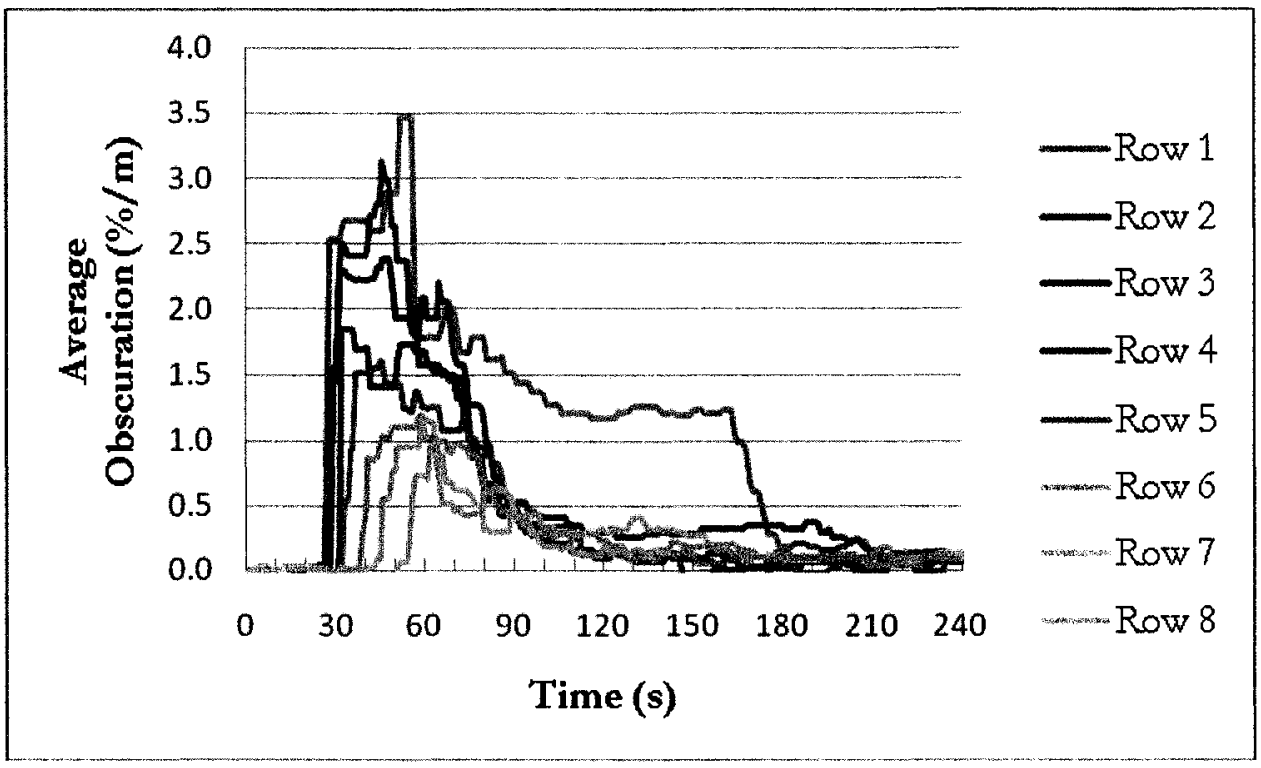

Figure 78 - Average Obscuration vs Time for each row of detectors, Test 68

\subsection{Effects of Elevation}

In this section of the report, each fire type is compared against all of the elevations it was tested at to get an indication of the effects of elevation on each fire type.

\subsubsection{Paper fires}

The newsprint fire tests produced alarm level obscuration values in the smoke detectors for 5 of the 13 tests recorded. The maximum obscuration levels were averaged for each row over all tests at each elevation and are listed in Table 32. The data is plotted in Figure 79. Higher values were not associated with any particular elevation. Sometimes the highest values were obtained from the first row, but sometimes came from the second or third row. The highest values were recorded at an elevation of $9 \mathrm{~m}$ for some row, but $12 \mathrm{~m}$ for others. The expected highest value should have been recorded at the 3-m elevation. This is attributed to the type of fire and the success of igniting the flame in such a way as to just 
begin the process. When the initial portion of the fire is mostly smouldering a considerable amount of smoke is produced, that is not buoyant. Once flames break out, a buoyant plume carries the existing smoke to the ceiling elevation. However, when flaming ignition begins early on in the process, not nearly as much obscuration is recorded. This variance is reflected in the results shown below.

Table 32 - Maximum Obscuration Dependence on Height, paper fires

\begin{tabular}{cccccc}
\hline Height $(\mathrm{m})$ & 3 & 6 & 9 & 12 & 15 \\
\hline Radius $(\mathrm{m})$ & \multicolumn{5}{c}{ Maximum } \\
\hline 0 & 3.32 & 5.34 & 8.18 & 4.19 & 4.14 \\
1.63 & 1.01 & 5.10 & 8.58 & 3.89 & 4.16 \\
3.26 & 0.32 & 3.98 & 7.03 & 4.75 & 2.34 \\
4.89 & 0.16 & 1.81 & 3.56 & 4.32 & 0.94 \\
6.52 & 0.11 & 1.18 & 1.21 & 2.20 & 0.68 \\
8.15 & 0.10 & 0.83 & 0.70 & 1.23 & 0.46 \\
9.78 & 0.11 & 0.48 & 0.60 & 0.37 & 0.06 \\
11.41 & 0.09 & 0.44 & 0.51 & 0.10 & 0.07 \\
\hline
\end{tabular}




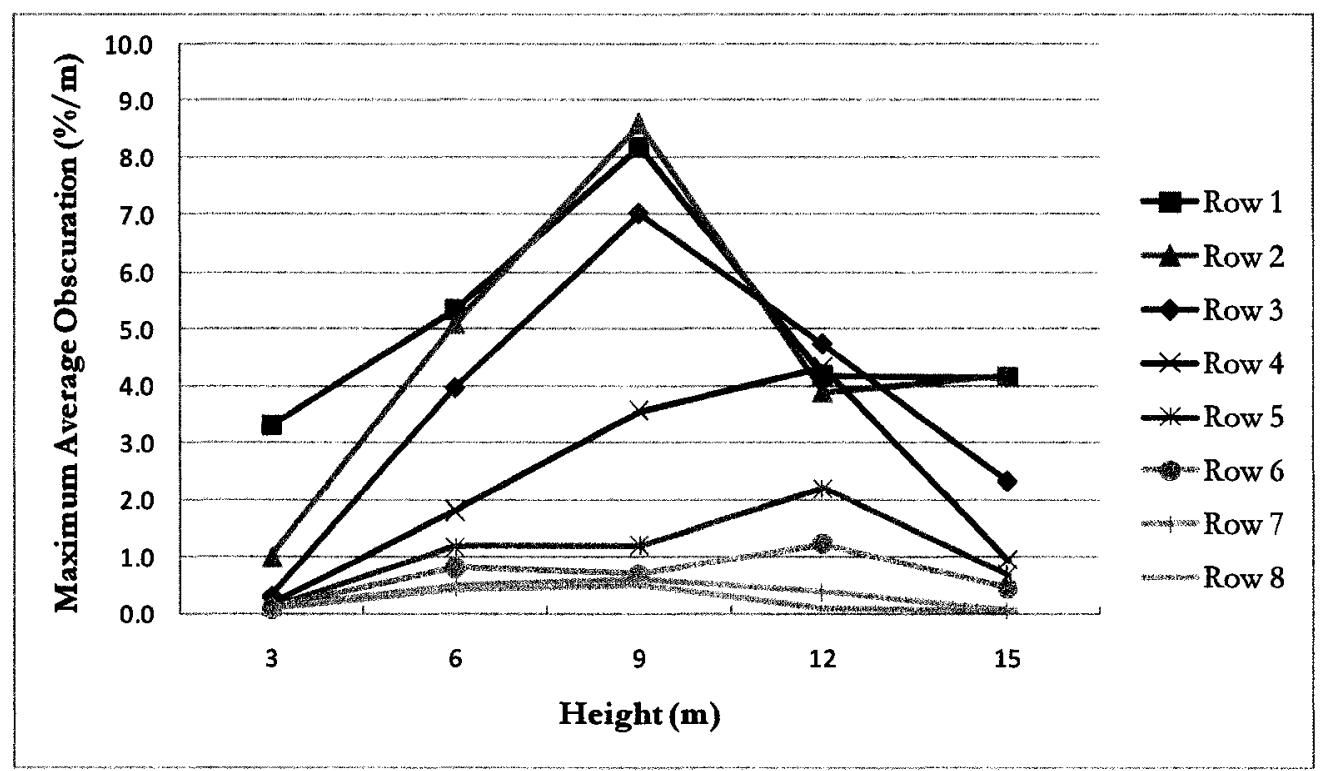

Figure 79 - Maximum Average Obscuration vs. Height, paper fires

\subsubsection{0-ml liquid fuel fires}

Data for 13 test fires using the $20-\mathrm{ml}$ liquid fuel package was collected. The maximum obscuration levels were averaged for each row over all tests at each elevation and are listed in Table 33. The data is plotted in Figure 80. Maximum obscuration values are generally lower with increased elevation for the same fire type. The dependence on height appears to be almost linear for elevations up to $9 \mathrm{~m}$ for the first 4 rows of detectors. For the higher elevations and further radii, there is almost no dependence on elevation. All of the values where a correlation with height or radius is not obvious are lower than $1 \% / \mathrm{m}$ which may indicate that these values are within the error range of the instruments. 
Table 33 - Maximum Obscuration Dependence on Height, 20-ml liquid fires

\begin{tabular}{clllll}
\hline Height $(\mathrm{m})$ & 3 & 6 & 9 & 12 & 15 \\
\hline Radius $(\mathrm{m})$ & \multicolumn{5}{c}{ Maximum } \\
\hline 0 & 9.55 & 4.93 & 1.44 & 1.34 & 1.56 \\
1.63 & 6.18 & 3.36 & 1.15 & 1.23 & 1.31 \\
3.26 & 2.41 & 1.66 & 0.97 & 1.11 & 0.93 \\
4.89 & 1.14 & 0.86 & 0.47 & 0.98 & 0.64 \\
6.52 & 1.23 & 0.58 & 0.48 & 0.84 & 0.48 \\
8.15 & 0.66 & 0.40 & 0.26 & 0.50 & 0.28 \\
9.78 & 0.28 & 0.27 & 0.17 & 0.39 & 0.17 \\
11.41 & 0.14 & 0.17 & 0.14 & 0.14 & 0.05 \\
\hline
\end{tabular}

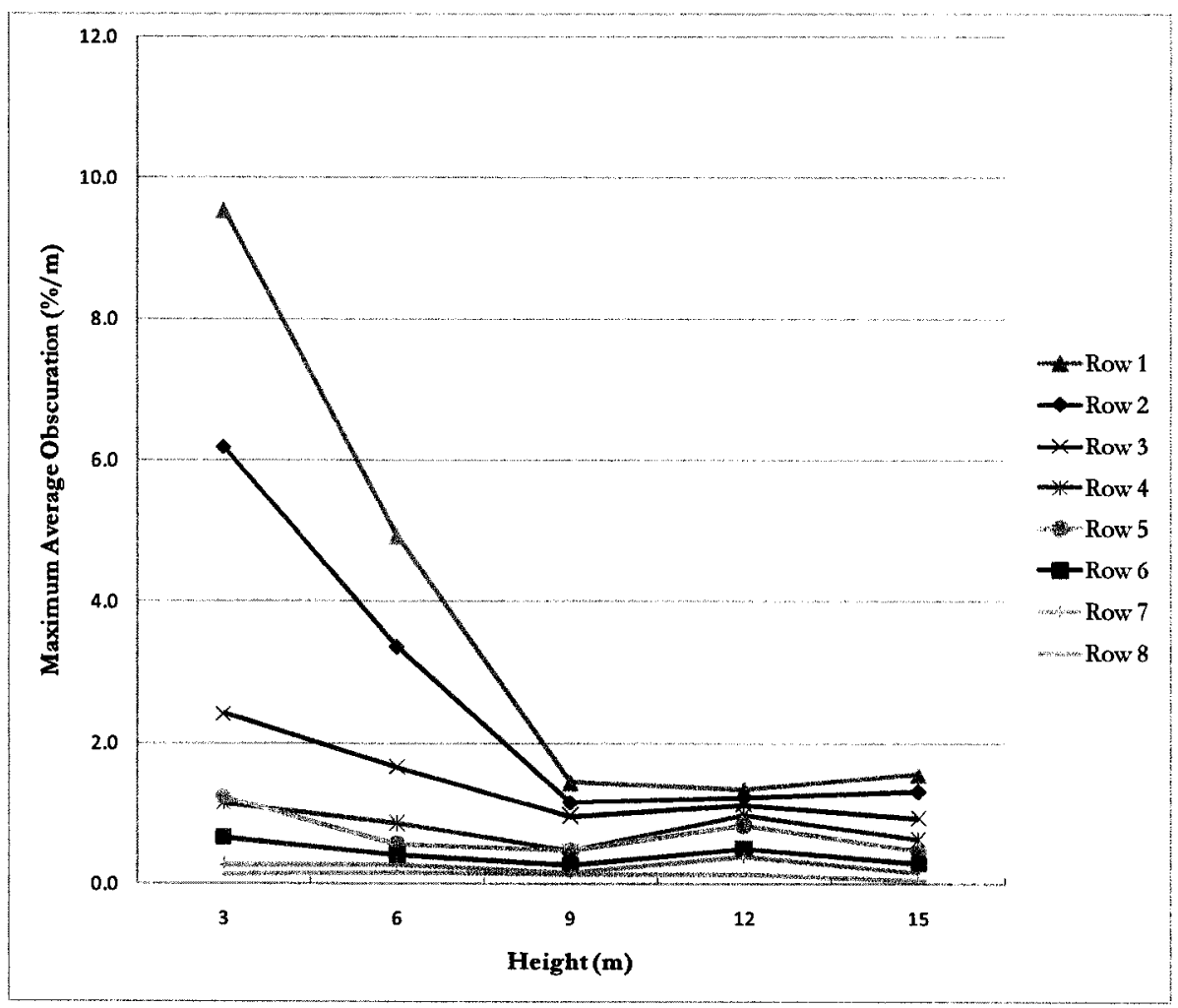

Figure 80 - Maximum Average Obscuration vs. Height, 20-ml liquid fuel fires 


\subsubsection{0-ml liquid fuel fires}

Data for 10 test fires using the $40-\mathrm{ml}$ liquid fuel package was collected. The maximum obscuration levels were averaged for each row over all tests at each elevation and are listed in Table 34. The data is plotted in Figure 81. This fire type shows reduced maximum obscuration values with increased height for Rows 1 and 2. The fires conducted with the platform at the $21-\mathrm{m}$ elevation produced higher obscuration in smoke detectors than the tests at the 18-m elevation for Rows 3 to 8 . This fluctuation may be attributed to the fluctuation of the smoke characteristics. There are not enough elevations for this series of tests using this fuel package to make a definitive statement about the trend observed.

Table 34 - Maximum Obscuration Dependence on Height, 40-ml liquid fires

\begin{tabular}{cccr}
\hline Height $(\mathrm{m})$ & 15 & 18 & 21 \\
\hline Radius $(\mathrm{m})$ & Maximum Average & Obscuration $(\% / \mathrm{m})$ \\
\hline 0 & 4.54 & 2.99 & 2.46 \\
1.63 & 4.04 & 2.60 & 2.29 \\
3.26 & 2.91 & 1.77 & 1.94 \\
4.89 & 2.06 & 1.27 & 1.51 \\
6.52 & 1.48 & 1.05 & 1.24 \\
8.15 & 1.17 & 0.49 & 0.80 \\
9.78 & 0.67 & 0.21 & 0.55 \\
11.41 & 0.31 & 0.08 & 0.38 \\
\hline
\end{tabular}




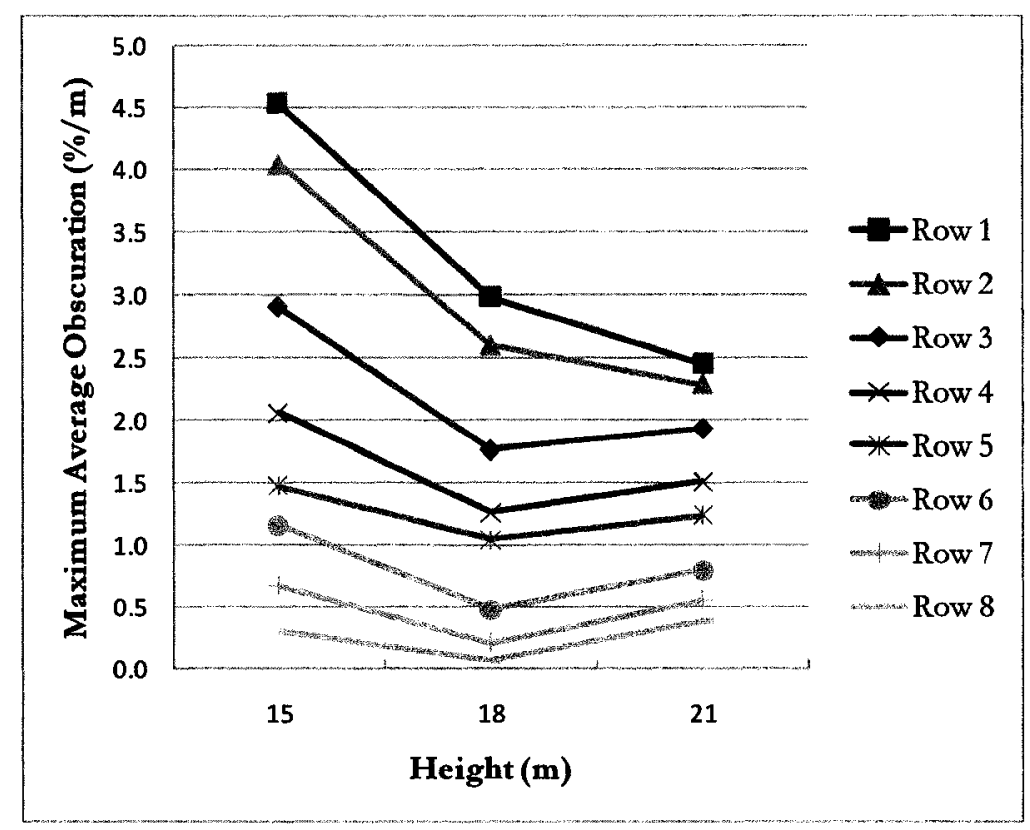

Figure 81 - Maximum Average Obscuration vs. Height, 40-ml liquid fuel fires

\subsubsection{0-ml liquid finel fires}

Data for 6 test fires using the 60-ml liquid fuel package was collected. The maximum obscuration levels were averaged for each row over all tests at each elevation and are listed in Table 35.

Table 35 - Maximum Obscuration Dependence on Height, 60-ml liquid fires

\begin{tabular}{ccc}
\hline Height $(\mathrm{m})$ & 18 & 21 \\
Radius $(\mathrm{m})$ & Maximum Average & Obscuration $(\% / \mathrm{m})$ \\
\hline 0 & 3.53 & 2.97 \\
1.63 & 3.31 & 3.01 \\
3.26 & 2.44 & 2.05 \\
4.89 & 2.07 & 1.56 \\
6.52 & 1.41 & 1.22 \\
8.15 & 1.01 & 0.86 \\
9.78 & 0.44 & 0.66 \\
11.41 & 0.29 & 0.33 \\
\hline
\end{tabular}

$-135-$ 


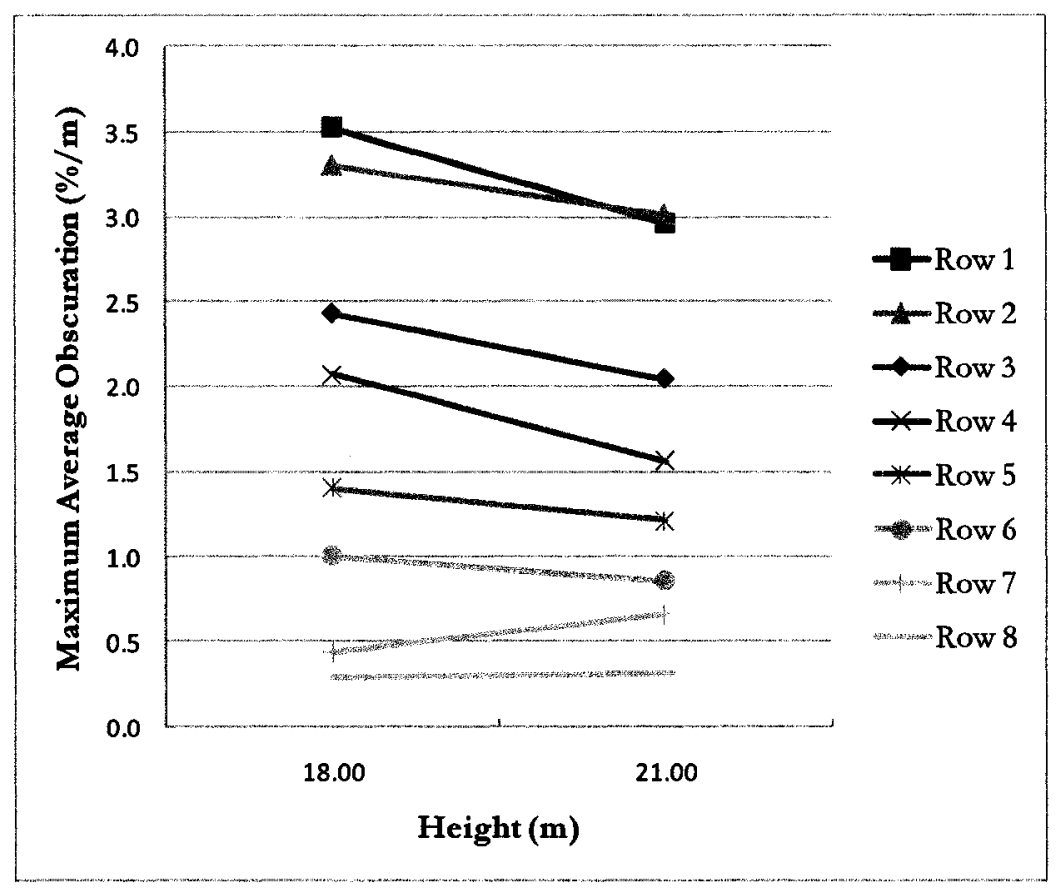

Figure 82 - Maximum Average Obscuration vs. Height, 60-ml liquid fuel fires

The data is plotted in Figure 82. This fire type also shows reduced maximum obscuration values with increased height.

\subsubsection{0-ml liquid fuel fires}

Data for 6 test fires using the 100-ml liquid fuel package was collected. The maximum obscuration levels were averaged for each row over all tests at each elevation and are listed in Table 36. The data is plotted in Figure 83. This fire type also shows reduced maximum obscuration values with increased height. Given the wider difference in elevation between $15 \mathrm{~m}$ and $21 \mathrm{~m}$, there is a clearer indication of the trended observed than with the $60-\mathrm{ml}$ fuel fire results.

$-136-$ 
Table 36 - Maximum Obscuration Dependence on Height, 100-ml liquid fires

\begin{tabular}{ccc}
\hline $\begin{array}{c}\text { Height }(\mathrm{m}) \\
\text { Radius }(\mathrm{m})\end{array}$ & $\begin{array}{c}15 \\
\text { Maximum }\end{array}$ & $\begin{array}{c}21 \\
\text { Average }\end{array}$ \\
\hline 0 & 7.41 & 3.93 \\
1.63 & 6.22 & 3.87 \\
3.26 & 3.81 & 2.85 \\
4.89 & 3.64 & 2.07 \\
6.52 & 2.61 & 1.84 \\
8.15 & 2.15 & 1.46 \\
9.78 & 1.34 & 1.19 \\
11.41 & 1.39 & 1.17 \\
\hline
\end{tabular}

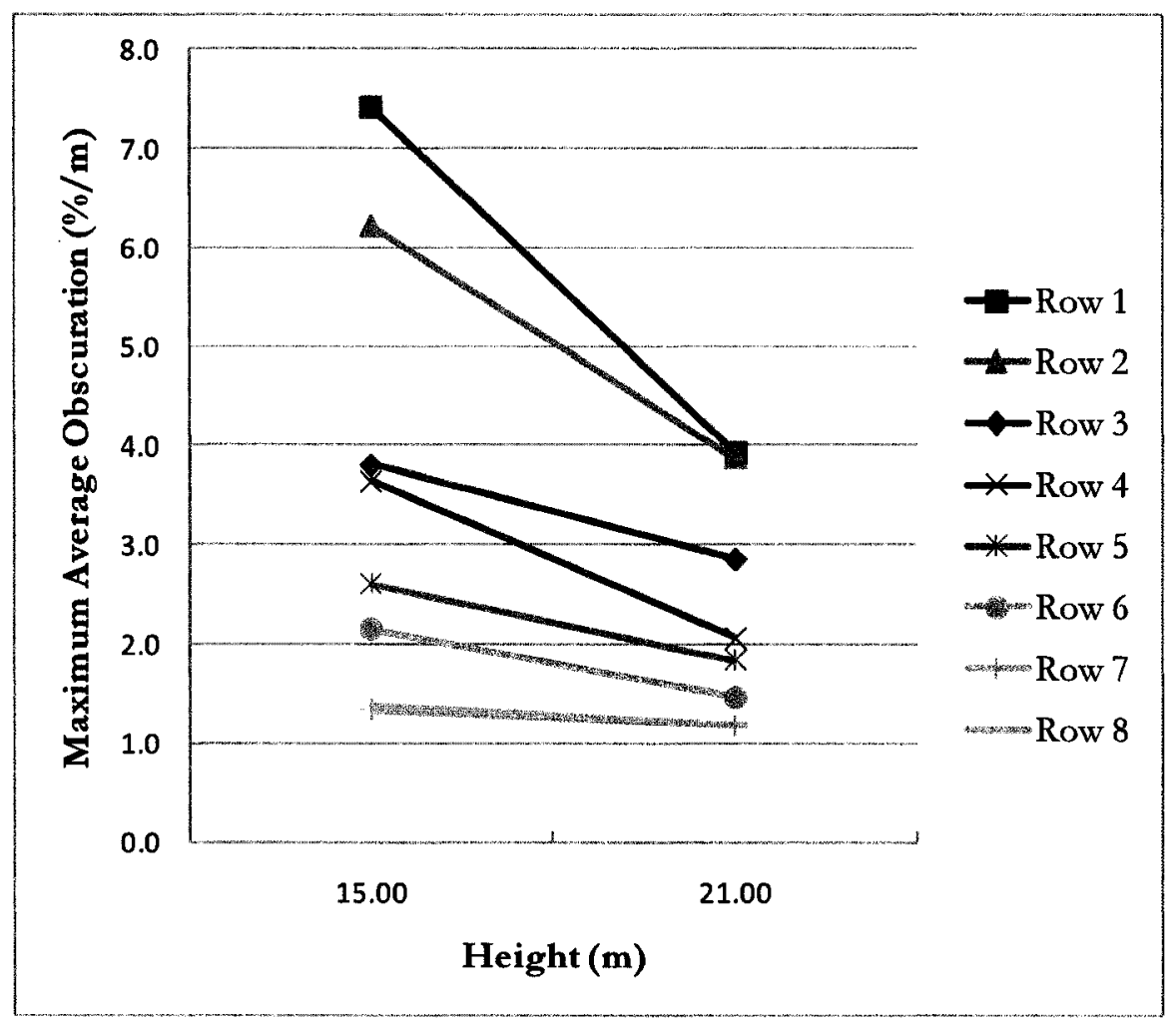

Figure 83 - Maximum Average Obscuration vs. Height, 100-ml liquid fuel fires $-137-$ 


\subsubsection{Wood crib fires}

Data for 11 test fires using the wood crib fuel package was collected. The maximum obscuration levels were averaged for each row over all tests at each elevation and are listed in Table 37. The data is plotted in Figure 84. This fire shows reduced maximum obscuration values with increased height. The trend shown by the data plot appears linear. The first three rows, when the data is averaged across all of the tests are clustered close together, indicating that there is a relatively weak dependence on radial distance from source for these three rows.

Table 37- Maximum Obscuration Dependence on Height, wood crib fires

\begin{tabular}{|c|c|c|c|c|c|}
\hline Height $(\mathrm{m})$ & 3 & 6 & 9 & 12 & 15 \\
\hline Radius (m) & \multicolumn{5}{|c|}{ Maximum Average Obscuration $(\% / \mathrm{m})$} \\
\hline 0 & 9.65 & 5.60 & 2.30 & 1.43 & 0.09 \\
\hline 1.63 & 9.90 & 5.69 & 2.73 & 1.38 & 0.05 \\
\hline 3.26 & 8.66 & 6.57 & 2.96 & 0.70 & 0.05 \\
\hline 4.89 & 5.43 & 2.82 & 1.69 & 0.14 & 0.04 \\
\hline 6.52 & 4.50 & 1.75 & 1.12 & 0.11 & 0.12 \\
\hline 8.15 & 2.66 & 1.06 & 0.35 & 0.05 & 0.07 \\
\hline 9.78 & 1.27 & 0.77 & 0.07 & 0.06 & 0.06 \\
\hline 11.41 & 0.62 & 0.36 & 0.05 & 0.06 & 0.11 \\
\hline
\end{tabular}




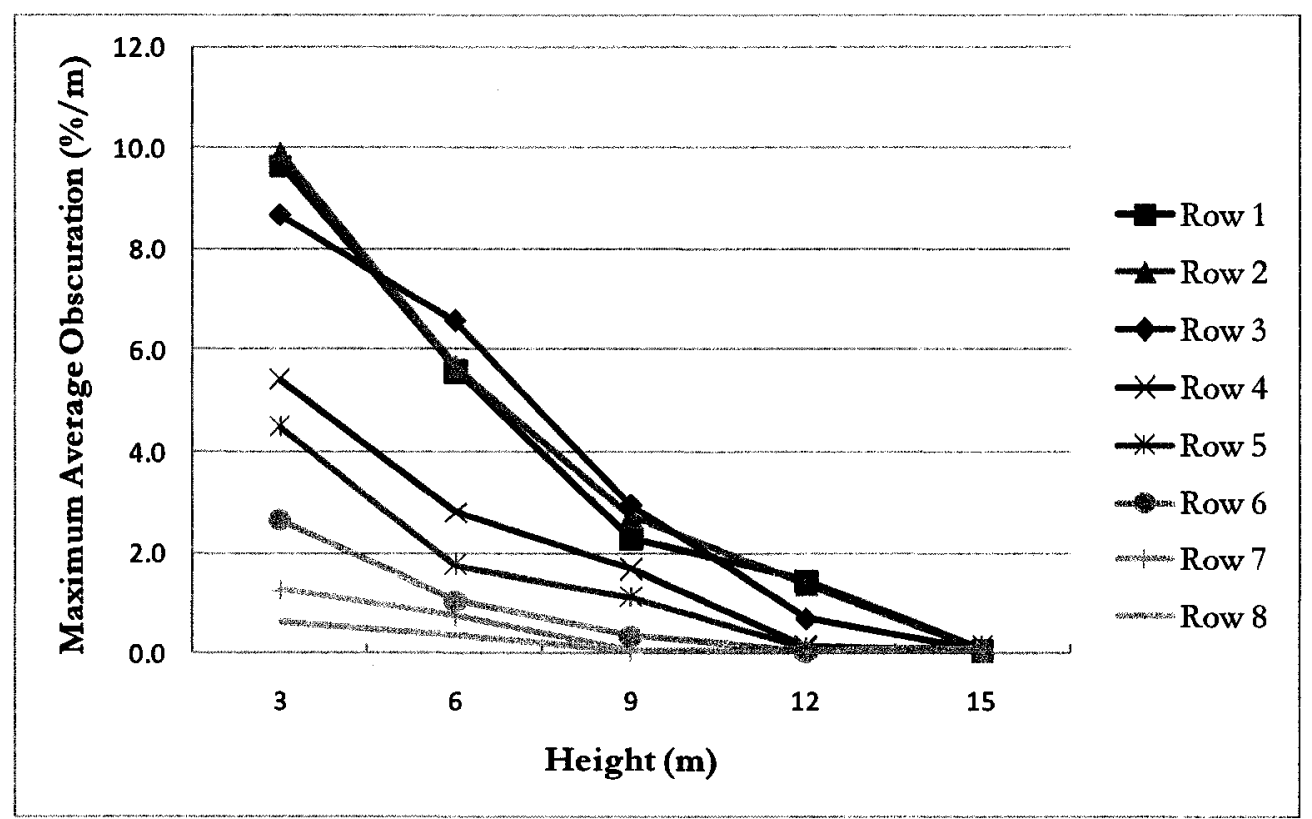

Figure 84 - Maximum Average Obscuration vs. Height, wood crib fires

\subsection{Selected Results and Discussion}

It is evident from these results that the paper fire is not very well resolved given that the expected results were not observed. The liquid fuel and wood fires provided results that were as expected, with obscuration levels that decrease coincidentally with height and radial distance.

A typical chart for comparison of obscuration values is shown in Figure 85. The figure shows the model results and the averaged values of all $20 \mathrm{ml}$ liquid fuel fire tests conducted with the platform at an elevation of $3 \mathrm{~m}$. The model results shown are from the Watanabe and Tanaka correlation $(\mathrm{W}+\mathrm{T})$, the Davis and Reneke correlation (D+R), the FDS simulation (FDS) and the CFAST simulation (CFAST). The computer models over predict the recorded maximum value of obscuration for this series, returning values more than double those measured above the fire. The algebraic models provided the closest to actual measured 
values, with initial under prediction near the fire, moving towards over prediction at increased radial distances.

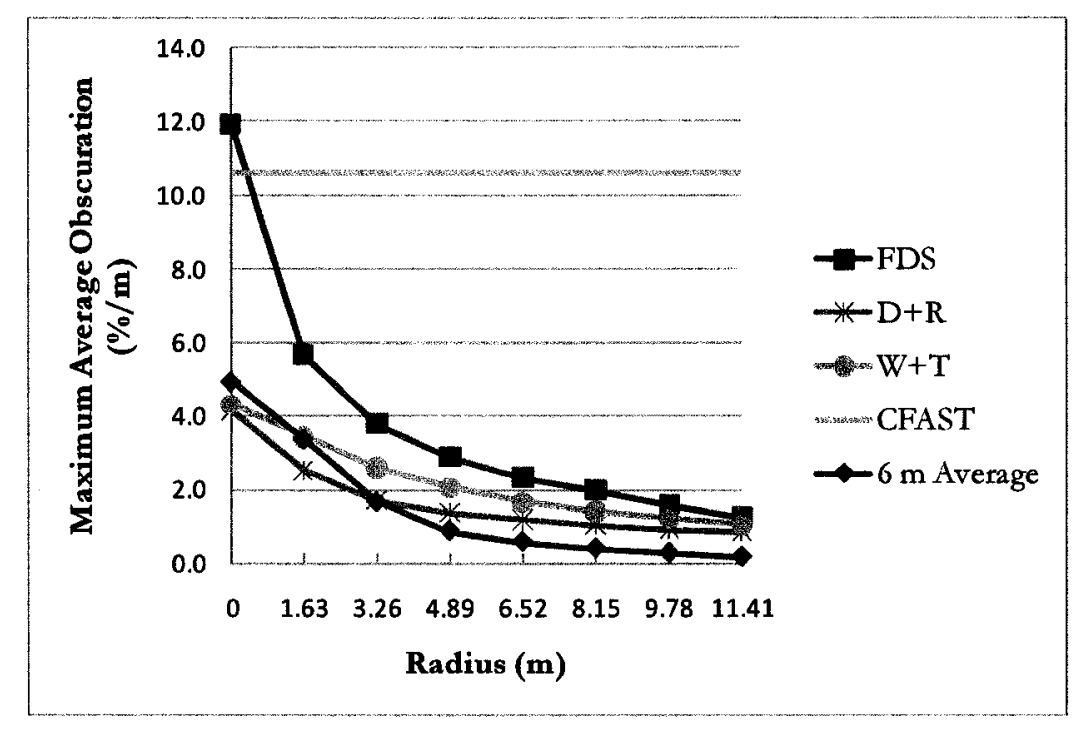

Figure 85 - Maximum Obscuration Comparison, 20-ml liquid fuel fire, 6-m elevation

For all of the liquid fuel fires studied, the model predictions have similar results to those shown in Figure 85. CFAST and FDS generally over predict results while the closest values to those actually measured are from the algebraic models. The tendency for these models is to slightly under predict the measured values closer to the fire source, but as the radial distance increases the correlations begin to over predict the measured results.

All of the models under predicted the newsprint test results. This is attributed to the method of burning of this fire with an initial dense smoke concentration lifted by a later open flame condition as discussed earlier. The fact that this fire cannot accurately be described in the model inputs affects the results.

$-140-$ 
The wood fire models all under predicted measured obscuration values except for the $15 \mathrm{~m}$ elevation tests, where the models over predicted results. This is also attributed to the mixed smouldering and flaming burn modes experienced for these fire types, even though there was no defined transition from smouldering to open flame with the wood cribs. Again, the fact that this fire cannot accurately be described in the model inputs affects the results.

Liquid fuel fire model inputs were based on actual test fires for the 40-ml, 60-ml and $100-\mathrm{ml}$ fires. The fires modeled were from tests 52,58 and 67 respectively. The maximum averaged obscuration results for the tests and the associated models are listed in Table 38. For these models, FDS over predicted the maximum obscuration results by $7 \%$ for the $40 \mathrm{ml}$ liquid fuel fire, by $85 \%$ for the $60 \mathrm{ml}$ liquid fuel fire and by $145 \%$ for the $100 \mathrm{ml}$ liquid fuel fire. CFAST over predicted the result from test 52 by $58 \%$, test 58 by $34 \%$, and test 67 by $215 \%$. The Davis and Reneke model under predicted the test results by $7.5 \%, 7.5 \%$, and $36 \%$ respectively. The Watanabe and Tanaka model under predicted the test results by $3.6 \%, 3.7 \%$ and $33 \%$ respectively.

Table 38 - Selected obscuration results

\begin{tabular}{cccc}
\hline & $\begin{array}{c}40 \mathrm{ml} \text { liquid fuel } \\
\text { fire (Test 52) }\end{array}$ & $\begin{array}{c}60 \mathrm{ml} \text { liquid fuel } \\
\text { fire (Test 58) }\end{array}$ & $\begin{array}{c}100 \mathrm{ml} \text { liquid fuel } \\
\text { fire (Test 67) }\end{array}$ \\
\hline $\begin{array}{c}\text { Test Fire Max } \\
\text { Obscuration }\end{array}$ & 3.87 & 4.11 & 5.07 \\
FDS Max & & & \\
Obscuration & 6.72 & 7.61 & 12.44 \\
\hline
\end{tabular}




\begin{tabular}{cccc}
\hline & $\begin{array}{c}40 \mathrm{ml} \text { liquid fuel } \\
\text { fire (Test 52) }\end{array}$ & $\begin{array}{c}60 \mathrm{ml} \text { liquid fuel } \\
\text { fire (Test 58) }\end{array}$ & $\begin{array}{c}100 \mathrm{ml} \text { liquid fuel } \\
\text { fire (Test 67) }\end{array}$ \\
\hline $\begin{array}{c}\text { CFAST Max } \\
\text { Obscuration }\end{array}$ & 6.11 & 5.51 & 15.95 \\
D+R Max & & & \\
Obscuration & 3.58 & 3.80 & 3.27 \\
W+T Max & & & \\
Obscuration & 3.73 & 3.96 & 3.41 \\
\end{tabular}

For the newsprint fires, none of the models were accurate in predicting results, usually grossly under predicting the maximum obscuration values measured by one or more orders of magnitude. This is attributed to the method of combustion for these tests. For wood crib fires a similar result as with the newsprint fires was obtained with slightly more accurate predictions. This result cannot be attributed to the mixed method of combustion with both smouldering and flaming fire occurring simultaneously throughout the tests.

For liquid fuel fires, the algebraic values were usually much closer to actual values than the FDS or CFAST results. Algebraic models seem to under predict obscuration values near the plume and then tend to over predict values further away from the fire source. FDS and CFAST values were consistently higher than measured values.

The $D+R$ correlation data that is reported with the experimental results take the initial value from the maximum measured results from the tests or FDS as the 
case may be. The purpose for including this information was to determine the accuracy of the ceiling jet predictions independent of the original plume predictions from the algebraic model. The $\mathrm{D}+\mathrm{R}$ ceiling jet correlation tends to over predict actual detector response at larger radial distances from the fire and under predicts these values closer to the source. These results are true for both measured values and FDS models. The transition from under to over prediction occurs between 4 and $6 \mathrm{~m}$ radial distance for elevations at or below $15 \mathrm{~m}$, but closer to $9 \mathrm{~m}$ radial distance for liquid fuel fires at the higher elevations.

Although the test scenario is different than standard test fires in so much as there were no walls for these tests, it should be noted that smoke development measured was nowhere near the maximum allowable values from the testing standards at the standard ceiling heights. The image shown in Figure 28 shows that it is likely that a smoke layer does develop in standard test rooms, thereby producing higher levels of obscuration in those situations than experienced here. It also indicates that smoke detector models should account for a smoke layer component, at least for smaller rooms with higher ceilings.

The smoke detectors tested did provide alarm level responses to fires at elevations above the originally tested level of $3 \mathrm{~m}$. Although the test set up was different than standard tests due to the fact that there were no walls, and given the minor differences in test fires, it is noteworthy to point out that the detectors did not provide alarm level responses at the standard test height $3 \mathrm{~m}$ and radius from the fire of $4.9 \mathrm{~m}$. This result calls into question the performance criteria for acceptance of these devices if the intent is to expect them to activate under similar conditions in actual use, that being $3 \mathrm{~m}$ ceiling height and $24 \mathrm{~m}^{2}$ coverage under a large ceiling with much more area than the standard room test size.

$-143-$ 
Smoke detectors did provide a positive detection of the smoke developed during standard test fires up to $15 \mathrm{~m}$ for newsprint fires, up to $12 \mathrm{~m}$ for wood crib fires and up to $15 \mathrm{~m}$ for $20 \mathrm{ml}$ liquid fuel fires. This suggests that, should these devices be equipped with detection algorithms that could recognize fire signatures at lower than standard obscuration levels they can be used at higher than standard elevations with spacing reduced accordingly.

The CFD modeling done by FDS resolves the visibility field using the dependence between smoke production and fire size suggested through Eq.11. The specific extinction area and the specific extinction coefficient are related together to give smoke yield. This relationship necessarily depends on the assumption that the specific extinction coefficient is constant. In fact this value has shown to be constant for a large number of experiments as described by Mulholland and Croarkin [23]. The standard test fires are described as flaming $[19,20]$, but the observations made during the tests conducted indicate that the paper fires and wood crib fires are in fact hybrid fires with both a flaming and a smouldering portion. This observation makes the use of a constant value for specific extinction coefficient questionable in this case. In order to make the CFD predictions more accurate, there needs to be a separate estimate of smoke yield as a function of time. The smoke produced can then be transported using the flow field predictions of the model to better predict visibility in time and space. Measurements of actual smoke production for test fires like those conducted as part of the Smoke Characterization Project [18] could be used as model inputs to provide the smoke yield input to the model. In order to achieve this kind of modeling using FDS a ramp function would need to be added for the mass extinction coefficient value within the model and the smoke production would need to be modeled independently from the heat release rate using the species feature in FDS. 
FDS predicted the first indication of a significant change in obscuration very well indicating that the smoke transport feature of the model is accurate. As expected, algebraic models returned detection times lower than measured. Both FDS and test records show that the transport time for smoke for the $100 \mathrm{ml}$ liquid fuel fire at the $21 \mathrm{~m}$ elevation is approximately 30 seconds and rises almost linearly to approximately 60 seconds at radial distances of $11 \mathrm{~m}$.

For fires with ceiling elevations between $9 \mathrm{~m}$ and $15 \mathrm{~m}$, detection time does not appear to be a factor that could affect the acceptance test results. The time delay for initial detection of smoke just above the fire rose not more that 5 seconds for each 3-m elevation change for all of the tests at these elevations. The time to detection at locations furthest away from the fire was not affected by the change in elevation, remaining relatively constant for each fuel type. Only the wood fire at the ceiling height of $12 \mathrm{~m}$ failed to produce some level of detection at the furthest location within 240 seconds.

When assessing whether results are conservative, the answer depends on whether predictive results or measurement results are considered. From the detection standpoint under prediction of measured results is conservative, since detectors will return alarm results more often than predicted. From a safety standpoint over prediction of obscuration levels is conservative, since atmospheric conditions will not reach predicted levels thereby causing less harm to humans. So for the application of smoke detectors, the design fire should be smaller than the design fire used for other fire protection engineering activities, and the models used should be as close to accurate as possible without over predicting results. Only the algebraic models produce this kind of result, and only for the liquid fuel fires. 


\section{Conclusions and Recommendations}

Smoke detectors have the ability to detect smoke at higher elevations and at spacing in excess of the standard listing criteria. Based on results of tests conducted, smoke detectors are recommended for use in ceiling heights up to 6 $\mathrm{m}$ with spacing reduced to $\mathrm{r} / \mathrm{H} \leq 0.2$

The acceptance testing criteria for smoke detectors should be reviewed with the results of these experiments to ensure that continued application of these devices in large rooms even at ceiling heights as low as $3 \mathrm{~m}$ is warranted.

Two algebraic models were presented and compared against CFAST and FDS computer models for the prediction of smoke detector activation in ceilings up to $21 \mathrm{~m}$ in elevation and detectors located as far away as $11.4 \mathrm{~m}$. The models were also compared against tests conducted of standard and non-standard test fires.

The models reviewed are not accurate enough to recommend using to adjust detector spacing at varying ceiling height and detector spacing. 


\section{Future Work}

The prediction of smoke concentration in the ceiling jet in the presence of a smoke layer could be useful when estimating the time to activation of a smoke detector in enclosures with small flaming fires or smouldering fires. Where rooms are not occupied and there is very limited air movement the time lag of smoke detectors is known to affect detection time. The estimation of the lag time to detection and the relationship with that time and the size of a fire would assist in predicting the available safe egress time. Experimental work that extends the research presented here to large enclosures with varying ceiling heights that makes use of the Davis and Reneke as well as the Watanabe and Tanaka predictors is recommended.

The uncertainty of temperature measurements and the variation in fire time/temperature profiles for identical fire scenarios is quite large. From a predictive standpoint, consensus on the values used to model detector activation is necessary. A conservative, yet realistic model for smoke generation and transport that can be related to detector activation from the standard smoke box testing should be developed for use in application of commercial smoke detectors.

The ability to model both smoke production using either volumetric smoke production or time varying smoke yield data along with heat release rate would improve predictability of smoke extinction area or smoke density and thereby improve predictions of obscuration values. Further work is required to characterize smoke development and add it to the existing database.

Predicting delays in the activation of smoke detectors due to device geometry could be improved if more data were available on detector lag times and dwell 
times. An additional test is recommended for listing purposes of smoke detectors using the FE/DE so that the constants could be reported with smoke detectors.

Refinements in the experimental methods could have produces better results.

1. The construction and placement of a thermocouple tree above the fire to estimate the fire's heat release rate.

2. The inclusion of thermocouples at each detector location.

3. Improvements in the data gathering methods including synchronization amongst various data logging equipment used.

These changes in the test set up should be considered for future testing. 


\section{REFERENCES}

\section{References}

[01] Shifiliti, Meacham and Custer, "Design of Detection systems" SFPE Handbook of Fire Protection Engineering, $3^{\text {rd }}$ Edition, Section 4, Chapter 1, Quincy MA, 2002.

[02] CAN/ULC-S524-06 Standard for the Installation of Fire Alarm Systems, $5^{\text {th }}$ Edition 1

[03] NFPA 72 National Fire Alarm Code 2002 Edition 1

[04] Joseph E. Gott, Darren L. Lowe, Kathy A. Notarianni, William Davis, "Analysis of High Bay Hangar Facilities For Fire Detector Sensitivity and Placement", NIST TN1423 2

[05] William D. Davis and Kathy A. Notarianni "Prediction Based Design of Fire Detection for Buildings with Ceiling Heights Between $9 \mathrm{~m}$ and 18 m", NISTIR 6199, National Institute of Standards and Technology, Gaithersburg MA July 1998

[06] John M. Cholin and Chris Marrion, "Performance Metrics for Fire Detection", Fire Protection Engineering Issue 11, Summer 2001 pp 21-30

[07].William E. Pucci "Modeling Spot Type Smoke Detector Response" Fire Protection Engineering, Issue 7, pp36-42

[08] Heskestad, G. J., and Delichatsios, M.A., "Environments of Fire Detectors, Phase I: Effects of Fire Size, Ceiling Heights, and Material”, Volume II - Analysis Technical Report Serial Number 11427, RC-T-11, Factory Mutual Research Corp., Norwood M.A. 1977

[09] Kathy A Notarianni and William D. Davis, "The use of Computer Models to Predict Temperature and Smoke Movement in High Bay Spaces" NISTIR 5304 National Institute of Standards and Technology, Gaithersburg MA, December 1993

[10]W.D. Davis, B.P. Forney, R.W. Bukowski, "Developing Detector Siting Rules from Computational Experiments in Spaces with Complex Geometries" University of Duisburg. International Conference on Automatic Fire Detection "AUBE '95", 10th. April 4-6, 1995, Duisburg, Germany, Luck, H., Editor(s), 419-428 pp, 1995.Fire Safety Journal, Vol. 29, 129-139, 1997.

[11] Heskestad, G. Report Serial No. 21017, Factory Mutual Research Corp., Norwood MA, 1974

[12] William D. Davies, Thomas Cleary, Michelle Donnelly and Samuel Hellerman, "Prediction Smoke and Carbon Monoxide Detector Response in the Ceiling Jet in the 
Presence of a Smoke Layer", NISTIR 6976, National Institute of Standards and Technology, July 2003[

[13] Thomas Cleary, Artur Chernovosky, William Grosshandler and Melissa Anderson, "Particle Entry Lag in Spot-Type Smoke Detectors Fire Safety Science", Proceedings of $6^{\text {th }}$ International Symposium, International Association for Fire Safety Science, July 1999 _ 2

[14] Richard W. Bukowski and Jason D. Averill, "Methods for Predicting Smoke Detector Activation", Proceedings of Fire Suppression and Detection Research Application Symposium, Research and Practice: Bridging the Gap, February 1998

[15] Roby et Al. "A Smoke Detector Algorithm for Large Eddy Simulation Modeling" NIST GCR 07-911 National Institute of Standards and Technology, July 2007

[16] Jun-ichi Watanabe and Takeyoshi Tanaka, "Prediction of Ceiling Jet Smoke Concentration under Two Layer Environment", Fire Science and Technology Vol 24 No.3 pp 151-164, 2005

[17] William D. Davis and Paul Reneke "Predicting Smoke Concentration in the Ceiling Jet", NISTIR 6480, National Institute of Standards and Technology, Gaithersburg, MD, May 2000

[18] Thomas Z. Fabian and Pravinray D. Gandhi, "Smoke Characterization Project", The Fire Protection Research Foundation, Quincy MA, April 2007 passim

[19]CAN/ULC-S529 "Standard for Smoke Detectors for Fire Alarm Systems" 1 st Edition, Amended June, 2000

[20]ANSI/UL 268-2006 "Standard for Smoke Detectors for Fire Alarm Signaling Systems", $5^{\text {th }}$ Edition, September 2006

[21] Klote John H. and Milke James A., 'Principles of Smoke Management', ASHRAE 2002.3

[22] Jin, T., "Visibility Through Fire Smoke," J. of Fire and Flammability, Vol. 9, 1978, pp. 135-155

[23]George W. Mullholland and Carroll Croarkin, "Specific Extinction Coefficient of Flame Generated Smoke", Fire and Materials, Fire Mater Vol. 24 No. 5, pp227-230, September/October 2000

[24] George W. Mullholland, "How Well Are We Measuring Smoke?", Fire and Materials, Vol. 6, No. 2, pp 65-67, 1982 4

[25]George Crampton, NRC Work Instruction, "Pulsed 940 Smoke Density Meter", National Research Council of Canada - Institute for Research in Construction, Fire Risk Management Lab, 1997 
[26] George P. Crampton and G.D.Lougheed, "Comparison of Smoke Measurements With Standard and Non-Standard Systems", Research Report Nop.183, Institute for Research in Construction, National Research Council of Canada, Ottawa ON, 2004

[27] J.D. Seader and I.N. Einhorn, "16 $6^{\text {th }}$ International Symposium on Combustion", Combustion Institute, Pittsburgh, PA (1976)

[28]ASTM E1354, "Standard Test Method for heat and Visible Smoke Release Rates for Material and Products Using an Oxygen Consumption Calorimeter 8

[29] Douglas Drysdale, pp120-125 “An Introduction to Fire Dynamics”, $2^{\text {nd }}$ Ed., Jon Wiley \& Sons, 1998

[30]Gunnar Heskestad, "Fire Plumes, Flame Height, and Air Entrainment", SFPE Handbook of Fire Protection Engineering, $3^{\text {td }}$ Ed. Section 2, Chapter 1, 2002 10

[31]Naeem Iqbal, Mark Henry Salley, "Analysis Methods for the U.S. Nuclear Regulatory Commission Fire Protection Inspection Program", U.S. Nuclear Regulatory Commission, Washington DC, 2004

[32]B. Najafi, F. Joglar, J. Dreisbach "Verification and Validation of Selected Fire Models for Nuclear Power Plant Applications", U.S. Nuclear Regulatory Commission and Electrical Power Research Institute, May 2007

[33]Walter W. Jones, Richard D. Peacock, Glenn P. Forney, Paul A. Reneke, "CFAST Consolidated Model of Fire Growth and Smoke Transport (Version 6) - Technical Reference Guide", NIST Special Publication 1026, National Institute of Standards and Technology, 2005

[34]Richard D. Peacock, Walter W. Jones, Paul A. Reneke, Glenn P. Forney, "CFAST Consolidated Model of Fire Growth and Smoke Transport (Version 6) - User's Guide", NIST Special Publication 1041, National Institute of Standards and Technology, 2005

[35]Kevin McGrattan, Simo Hostikka, Jason Floyd, Howard Baum, Ronald Rehm, "Fire Dynamics Simulator (Version 5) Technical Reference Guide", NIST Special Publication 1018-5, National Institute of Standards and Technology, 2007

[36]Kevin McGrattan, Bryan Klein, Simo Hostikka, Jason Floyd, "Fire Dynamics Simulator (Version 5) User's Guide", NIST Special Publication 1019-5, National Institute of Standards and Technology, 2007

[37] McCaffrey, B.J., "Momentum Implications for Buoyant Diffusion Flames", Combustion and Flame 52, 149 (1982)

[38] Karlsson, B., Quintiere J.G. “Enclosure Fire Dynamics”, CRC Press LLC, 2000 11

[39]NFPA 92B, "Standard for Smoke Managemenr Systems in Malls, Atria, and Large Spaces", National Fire Protection Association, 2005 
[40] R.L. Alpert, "Calculation of Response Time of Ceiling-Mounted Fire Detectors", Fire Technology 8, pp181-195, 1972

[41]G. Heskestad and M.A. Delichatsios, "The Initial Convective Flow in Fire", $17^{\text {th }}$ International Symposium on Combustion, Combustion Institute, Pittsburgh, PA, 1978_ 16

[42] Yukio Yamauchi, Atsushi Mammoto, Manabu Dohi, Hiromichi Ebata, and Massahiro Morita, "A Calculation Method for Predicting Heat and Smoke Detector's Response", Fire Scince and Technology Vol. 24 No.4 pp179-210, 2005.

[43] Ronald L. Alpert, "Ceiling Jet Flows", SFPE Handbook of Fire Protection Engineering, $3^{\text {rd }}$ Edition, Section 2, Chapter 2, Society of Fire Protection Engineers, 2002

[44] Mowrer, F., "Lag Time Associated With Fire Detection and Suppression," Fire Technology, Volume 26,No. 3, pp. 244-265, August 1990.

[45] Osami Sugawa, Takashi Hosozawa, Naoto Nakamura, Akyako Itoh and Yoshiyki Matsubara, "Flow Behaviour under Sloped Ceiling", Fifteenth Meeting of the UJNR Panel on Fire Research and Safety, Volume 2, November 2000 21

[46] Vettori, Robert L., "Effect of Beamed, Sloped and Sloped Beamed Ceilings on the Activation Time of a Residential Sprinkler", December 2003

[47] O'Connor et al, Ming et al "Smoke Detector Performance For Level Ceilings With Deep Beams and Deep Beam Pocket Configurations" April 2006

[48] Mealy, Floyd and Gottuk "Smoke Detector Spacing Requirements Complex Beamed and Sloped Ceilings" April 28, 2008

[49] Vettori, Robert L., "Effect of an Obstructed Ceiling on the Activation Time of a Residential Sprinkler", November 1998

[50] Cooper, L.Y. "Combined Buoyancy and Pressure Driven Flow Through a Horizontal Vent" NISTIR 5384 National Institute of Standards and Technology, April 1994 22

[51] Heskestad, G. Report Serial No. 21017, Factory Mutual Research Corp., Norwood MA, 1974

[52] Cleary, T., Anderson M., Averill J. and Grosshandler W, "Evaluating Multi-Sensor Fire Detectors in the Fre Emulator/Detector Evaluator", National Institute of Standards and Technology, 1999

[53] Brozovski, E. "A Preliminary Approach to Siting Smoke Detectors Based on Design Fire Size and Detector Aerosol Entry Lag Time" Master's thesis, Worcester Polytechnic, Worcester, MA, 1989

[54] Keski-Rahkonen, O. "Revisiting modelling of fluid penetration into smoke detectors for low speed ceiling jets" VTT Building and Transport, Finland, 2001 
[55] Cleary T., Grosshandler W., Chrsnovsky A. "Smoke Detector Response to Nuisance Aerosols" National Institute of Standards and Technology 1999

[56] "Fire-Induced Vulnerability Evaluation model" (FIVE-Rev1) TR-1002981, Electrical Power Research Institute, Palo Alto, CA August 2001

[57] "Verification and Validation of Selected Fire Models for Nuclear Power Plant Applications, Volume 1: Main Report, U.S. Nuclear Regulatory Commission, Office of Nuclear Regulatory Research (RES), Rockville, MD: 2005 and Electric Power Research Institute (EPRI), Palo Alto, CA. NUREG-1824 and EPRI 1011999

[58] Hamins et al "Report of Experimental Results for the International Fire Model Benchmarking and Validation Exercise \#3", NUREG/CR-6905, NIST SP 1013-1 2006_ 29

[59] Yamauchi, Yukio, "Prediction of Response Time of Smoke Detectors in Enclosure Fires", National Institute of Standards and Technology, NBSTR88-3707, 1988, pp1-46

[60] Davis, W.D., and Cooper, L.Y., "Estimating the Environment and the Response of Sprinkler Links in Compartment Fires with Draft Curtains and Fusible Link-Actuated Ceiling Vents - Part II; User Guide for the Computer Code LAVENT', National Institute of Standards and Technology, NISTIR 89-4122, 1989

[61] Davis, D, Notarianni K.A., McGrattan K.B. "Comparison Of Fire Model Predictions With Experiments Conducted In A Hangar With A 15m Ceiling" National Institute of Standards and Technology, 1996

[62] Cooper, L.Y., "Fire-Plume-Generated Ceiling Jet Characteristics and convective Heat Transfer to Ceiling and Wall Surfaces in a Two-Layer Zone-Type Fire Environment" National Institute of Standards and Technology, NISTIR 4705, 1991

[63] McCaffrey, B.J., "Momentum Implications for Buoyant diffusion Flames" Combustion and Flame No. 52, 149, 1983

[64] Bounagui, A., Bénichou, N. "Literature Review on the Modeling of Fire Growth and Smoke Movement” IRC-RR-139, National Research Council of Canada, 2003

[65]Ierardi, J.A., Barnett J.R. “A Methodology for Predicting Smoke Detector Response" Worster Polytechnic Institute Centre for Firesafety Studies, Performance-Based Codes and Fire Safety Design Methods, 4th International Conference. Proceedings. March 20-22, 2002, Melbourne, Australia, Almand, K.; Coate, C.; England, P.; Gordon, J., Editors, pp235-240, 2002

[66]Gobeau, N., Zhou X.X. "Evaluation of CFD to predict smoke movement in complex enclosed spaces", Research Report 255 Fire and Explosion Group, Health and Safety Laboratory 2004

[67] HARWELL FLOW3D, Release 2.3: User Manual, CFD Department, AEA Industrial Tehcnolgy, Harwell Laborotory, Oxfordshire, Unitited Kingdom, July 1990 
[68] Pope S.B., "Ten questions concerning the large-eddy simulation of turbulent flows" New Journal of Physics 6 (2004) 35 March 2004

[69] "FSP-851, FSP-851T and FAPT-851 Intelligent Photoelectric Smoke Sensors Installation and Maintenance Instructions" Document No. 156-1925-004R, Notifier, Northford CT, 2007

[70] 'B501 Plug-in Detector Base Instllation and Maintenance Instructions”' Document No. 156-357-06R, Notifier, Northford CT, 2002

[71] FSP-200, FSP-200S Single-ended Reflected Beam Smoke Detector Installation and Maintenance Instructions" Document No. 156-2424-04R, Notifier, Northford CT, 200437

[72] "SFPE Handbook of Fire Protection Engineering $3^{\text {rd }}$ Edition", Philip J. DiNenno, P.E., Editor-in-Chief, Society of Fire Protection Engineers 2002 47 


\section{Appendix A - Fuel Properties}

Fuel properties from SFPE handbook 3rd Edition, table 3-4.14. Chapter 4, section 3 by Archibald Tewarson and Shell chemicals data sheets. and table B.7

\begin{tabular}{|l|l|l|l|l|l|l|}
\hline Fuel & Heptane & Toluene & $\begin{array}{l}75 / 25 \\
\text { Heptane } \\
/ \text { Toluene } \\
\text { Mix }\end{array}$ & Douglas Fir & Newsprint & Units \\
\hline Formula & $\mathrm{C}_{7} \mathrm{H}_{16}$ & $\mathrm{C}_{7} \mathrm{H}_{8}$ & & $\mathrm{CH}_{1.7} \mathrm{O}_{74} \mathrm{~N}_{.002}$ & & \\
\hline$\Delta \mathrm{H}_{\mathrm{ch}}$ & 41.2 & 27.7 & 40.7 & 13.0 & 14.4 & $\mathrm{~kJ} / \mathrm{g}$ \\
\hline$\Delta \mathrm{H}_{\mathrm{con}}$ & 27.6 & 11.2 & & 8.1 & & $\mathrm{~kJ} / \mathrm{g}$ \\
\hline$\Delta \mathrm{H}_{\mathrm{rad}}$ & 13.6 & 16.5 & & 4.9 & & $\mathrm{~kJ} / \mathrm{g}$ \\
\hline$\chi_{\text {rad }}$ & 0.330 & 0.596 & .3965 & 0.38 & & \\
\hline $\mathrm{Ys}$ & 0.037 & 0.178 & 0.07075 & 1.31 & & $\mathrm{~g} / \mathrm{g}$ \\
\hline $\mathrm{Yco}_{\mathrm{rco}}$ & 0.010 & 0.066 & 0.024 & 0.004 & & $\mathrm{~g} / \mathrm{g}$ \\
\hline $\mathrm{YcO}{ }_{2}$ & 2.85 & 2.34 & 2.72 & 1.31 & & $\mathrm{~g} / \mathrm{g}$ \\
\hline $\mathrm{Ych}$ & 0.004 & 0.018 & .0075 & 0.001 & & $\mathrm{~g} / \mathrm{g}$ \\
\hline$\rho$ & 711 & 871 & 751 & 420 & & $\mathrm{~kg} / \mathrm{m}^{3}$ \\
\hline $\mathrm{Mol}_{\mathrm{wt}}$ & 99 & 92 & & & $\mathrm{~g} / \mathrm{mol}$ \\
\hline $\mathrm{c}_{\mathrm{p}}$ & 2.1 & 1.6 & 1.98 & 2.72 & & $\mathrm{~kJ} / \mathrm{kg} . \mathrm{K}$ \\
\hline $\mathrm{k}$ & 0.12 & 0.14 & 0.125 & 0.11 & 0.11 & $\mathrm{~W} / \mathrm{m} . \mathrm{K}$ \\
\hline
\end{tabular}


Data from small scale smoke characterization tests [18]

\begin{tabular}{|l|l|l|l|l|}
\hline Fuel & Heptane/Toluene & Douglas Fir & Newsprint & Units \\
\hline Qmax & 12 & 10 & 6 & $\mathrm{~kW}$ \\
\hline Peak SRR & 0.34 & .24 & 1.04 & $\mathrm{~m}^{2} / \mathrm{s}$ \\
\hline Total smoke & 29 & 11 & 39 & $\mathrm{~m}^{2}$ \\
\hline $\begin{array}{l}\text { Total mass } \\
\text { loss }\end{array}$ & 15 & 165 & 42.5 & $\mathrm{~g}$ \\
\hline $\mathrm{SEA}$ & .492 & .016 & .007 & $\mathrm{~m}^{2} / \mathrm{g}$ \\
\hline$\Delta \mathrm{H}_{\mathrm{ch}}$ & 40.7 & 11.4 & 13.8 & $\mathrm{~kJ} / \mathrm{g}$ \\
\hline $\mathrm{Ys}$ & .0565 & .00184 & .000804 & $\mathrm{~g} / \mathrm{g}$ \\
\hline $\mathrm{Yco}$ & .069 & .093 & .264 & $\mathrm{~g} / \mathrm{g}$ \\
\hline $\mathrm{Yco}$ & 2.143 & 0.928 & 1.203 & $\mathrm{~g} / \mathrm{g}$ \\
\hline $\mathrm{Ych}$ & & 0.004 & 0.018 & $\mathrm{~g} / \mathrm{g}$ \\
\hline $\mathrm{Ys} / \mathrm{YcO}_{2}$ & 0.00264 & 0.00198 & 0.000668 & $\mathrm{~g} / \mathrm{g}$ \\
\hline $\mathrm{Yco} / \mathrm{Yco}_{2}$ & 0.0322 & 0.1 & 0.219 & $\mathrm{~g} / \mathrm{g}$ \\
\hline & & & & \\
\hline
\end{tabular}

Peak hrr, srr and total smoke from table 13.

specific extinction area, heat of combustion from table 7

Yco, $\mathrm{Y}_{\mathrm{C} 02}$ from table 9

Eq 20 in report indicates smoke yield is 8.5/sea quoting Babrauskas and Mulholland discovery of consistent extinction coefficient of $8500 \mathrm{~m}^{2} / \mathrm{kg}$ smoke yield calculated by reported specific extinction area divided by 8.71 from Mulholland and Croakin [23]. 


\section{Appendix B - TEST PARAMETERS}

\begin{tabular}{|c|c|c|c|c|c|c|c|}
\hline $\begin{array}{l}\text { Test } \\
\text { No. }\end{array}$ & $\begin{array}{l}\text { Fuel } \\
\text { Type }\end{array}$ & $\begin{array}{c}\text { Liquid } \\
\text { Fuel } \\
\text { Quantity } \\
\text { (ml) } \\
\end{array}$ & $\begin{array}{l}\text { Surface } \\
\text { Area } \\
\left(\mathrm{cm}^{2}\right) \\
\end{array}$ & $\begin{array}{l}\text { Platform } \\
\text { Elevation } \\
(\mathrm{m})\end{array}$ & $\begin{array}{c}\text { Pressure } \\
(\mathrm{kPa})\end{array}$ & $\begin{array}{c}\text { Humidity } \\
(\%)\end{array}$ & $\begin{array}{c}\text { Temp } \\
\text { (C) }\end{array}$ \\
\hline 1 & Liquid & 20 & 196.07 & 3 & 99.6 & 44 & 14.32 \\
\hline 2 & Liquid & 20 & 196.07 & 3 & 99.6 & 44 & 14.39 \\
\hline 3 & Liquid & 20 & 196.07 & 3 & 99.6 & 44 & 14.64 \\
\hline 4 & Paper & & 78.54 & 3 & 99.53 & 48 & 14.72 \\
\hline 5 & Paper & & 78.54 & 3 & 99.53 & 48 & 14.74 \\
\hline 6 & Paper & & 78.54 & 3 & 99.48 & 48 & 14.29 \\
\hline 7 & Wood & & 231.04 & 3 & 99.48 & 48 & 14.68 \\
\hline 8 & Wood & & 231.04 & 3 & 99.48 & 48 & 14.54 \\
\hline 9 & Wood & & 231.04 & 3 & 99.45 & 48 & 14.77 \\
\hline 10 & Liquid & 20 & 196.07 & 6 & 99.38 & 76 & 12.77 \\
\hline 11 & Liquid & 20 & 196.07 & 6 & 99.4 & 71 & 12.06 \\
\hline 12 & Liquid & 20 & 196.07 & 6 & 99.4 & 71 & 12.06 \\
\hline 13 & Paper & & 78.54 & 6 & 99.4 & 71 & 12.13 \\
\hline 14 & Paper & & 78.54 & 6 & 99.4 & 71 & 11.96 \\
\hline 15 & Paper & & 78.54 & 6 & 99.42 & 62 & 11.83 \\
\hline 16 & Wood & & 231.04 & 6 & 99.42 & 62 & 11.93 \\
\hline 17 & Wood & & 231.04 & 6 & 99.42 & 62 & 11.79 \\
\hline 18 & Wood & & 231.04 & 6 & 99.42 & 62 & 11.59 \\
\hline 19 & Liquid & 20 & 196.07 & 9 & 99.48 & 81 & \\
\hline 20 & Liquid & 20 & 196.07 & 9 & 99.48 & 81 & 11.83 \\
\hline 21 & Liquid & 20 & 196.07 & 9 & 99.48 & 81 & 11.93 \\
\hline 22 & Paper & & 78.54 & 9 & 99.56 & 93 & 11.97 \\
\hline 23 & Paper & & 78.54 & 9 & 99.56 & 93 & 11.4 \\
\hline 24 & Paper & & 78.54 & 9 & 99.56 & 93 & 11.02 \\
\hline 25 & Wood & & 231.04 & 9 & 99.56 & 93 & 11.32 \\
\hline 26 & Wood & & 231.04 & 9 & 99.6 & 81 & 11.35 \\
\hline 27 & Wood & & 231.04 & 9 & 99.6 & 81 & 11.37 \\
\hline 28 & Liquid & 20 & 196.07 & 12 & 99.99 & 87 & 11.45 \\
\hline 29 & Liquid & 20 & 196.07 & 12 & 99.99 & 87 & 10.71 \\
\hline 30 & Liquid & 20 & 196.07 & 12 & 99.99 & 87 & 10.69 \\
\hline
\end{tabular}




\begin{tabular}{|c|c|c|c|c|c|c|c|}
\hline $\begin{array}{l}\text { Test } \\
\text { No. }\end{array}$ & $\begin{array}{l}\text { Fuel } \\
\text { Type }\end{array}$ & $\begin{array}{c}\text { Liquid } \\
\text { Fuel } \\
\text { Quantity } \\
\text { (ml) }\end{array}$ & $\begin{array}{c}\text { Surface } \\
\text { Area } \\
\left(\mathrm{cm}^{2}\right) \\
\end{array}$ & $\begin{array}{c}\text { Platform } \\
\text { Elevation } \\
(\mathrm{m})\end{array}$ & $\begin{array}{c}\text { Pressure } \\
(\mathrm{kPa})\end{array}$ & $\begin{array}{c}\text { Humidity } \\
(\%)\end{array}$ & $\begin{array}{c}\text { Temp } \\
\text { (C) }\end{array}$ \\
\hline 31 & Paper & & 78.54 & 12 & 100.02 & 82 & 11.53 \\
\hline 32 & Paper & & 78.54 & 12 & 100.02 & 82 & 11.16 \\
\hline 33 & Paper & & 78.54 & 12 & 100.02 & 82 & 10.63 \\
\hline 34 & Wood & & 231.04 & 12 & 100.02 & 82 & 10.66 \\
\hline 35 & Wood & & 231.04 & 12 & 100.03 & 82 & 10.05 \\
\hline 36 & Wood & & 231.04 & 12 & 100.03 & 82 & 10.07 \\
\hline 37 & Wood & & 231.04 & 15 & 100.03 & 77 & 12.89 \\
\hline 38 & Wood & & 231.04 & 15 & 100.03 & 77 & 12.02 \\
\hline 39 & Wood & & 231.04 & 15 & 100.6 & 82 & 11.49 \\
\hline 40 & Paper & & 78.54 & 15 & 100.6 & 82 & 11.49 \\
\hline 41 & Paper & & 78.54 & 15 & 100.6 & 82 & 11.57 \\
\hline 42 & Paper & & 78.54 & 15 & 100.6 & 82 & 11.76 \\
\hline 43 & Liquid & 20 & 196.07 & 15 & 100.1 & 77 & 11.7 \\
\hline 44 & Liquid & 20 & 196.07 & 15 & 100.1 & 77 & 11.77 \\
\hline 45 & Liquid & 20 & 196.07 & 15 & 100.1 & 77 & 12.2 \\
\hline 46 & Liquid & 100 & 967.74 & 15 & 101.52 & 100 & 18.89 \\
\hline 47 & Liquid & 200 & 1935.48 & 15 & 101.52 & 100 & 19.15 \\
\hline 48 & Liquid & 100 & 967.74 & 15 & 101.56 & 100 & 19.3 \\
\hline 49 & Liquid & 100 & 967.74 & 15 & 101.56 & 100 & 19.35 \\
\hline 50 & Liquid & 40 & 338.56 & 15 & 102.06 & 69 & 22.74 \\
\hline 51 & Liquid & 40 & 338.56 & 15 & 102.05 & 65 & 22.95 \\
\hline 52 & Liquid & 40 & 338.56 & 15 & 102.05 & 65 & 23.12 \\
\hline 53 & Liquid & 40 & 338.56 & 15 & 102.05 & 65 & 23.32 \\
\hline 54 & Liquid & 40 & 338.56 & 18 & 101.99 & 61 & 25.02 \\
\hline 55 & Liquid & 40 & 338.56 & 18 & 101.99 & 61 & 25.71 \\
\hline 56 & Liquid & 40 & 338.56 & 18 & 101.97 & 54 & 25.71 \\
\hline 57 & Liquid & 60 & 448.56 & 18 & 101.97 & 54 & 26.4 \\
\hline 58 & Liquid & 60 & 448.56 & 18 & 101.97 & 54 & 26.16 \\
\hline 59 & Liquid & 60 & 448.56 & 18 & 101.97 & 54 & 26.45 \\
\hline 60 & Liquid & 40 & 338.56 & 21 & 101.48 & 88 & 22.92 \\
\hline 61 & Liquid & 40 & 338.56 & 21 & 101.48 & 88 & 22.25 \\
\hline 62 & Liquid & 40 & 338.56 & 21 & 101.48 & 88 & 22.23 \\
\hline 63 & Liquid & 40 & 338.56 & 21 & 101.48 & 88 & 23.33 \\
\hline 64 & Liquid & 60 & 448.56 & 21 & 101.48 & 88 & 22.55 \\
\hline
\end{tabular}




\begin{tabular}{|c|c|c|c|c|c|c|c|}
\hline $\begin{array}{l}\text { Test } \\
\text { No. }\end{array}$ & $\begin{array}{l}\text { Fuel } \\
\text { Type }\end{array}$ & $\begin{array}{c}\text { Liquid } \\
\text { Fuel } \\
\text { Quantity } \\
\text { (ml) } \\
\end{array}$ & $\begin{array}{l}\text { Surface } \\
\text { Area } \\
\left(\mathrm{cm}^{2}\right) \\
\end{array}$ & $\begin{array}{c}\text { Platform } \\
\text { Elevation } \\
(\mathrm{m})\end{array}$ & $\begin{array}{c}\text { Pressure } \\
(\mathrm{kPa})\end{array}$ & $\begin{array}{c}\text { Humidity } \\
(\%)\end{array}$ & $\begin{array}{c}\text { Temp } \\
\text { (C) }\end{array}$ \\
\hline 65 & Liquid & 60 & 448.56 & 21 & 101.44 & 88 & 22.72 \\
\hline 66 & Liquid & 60 & 448.56 & 21 & 101.44 & 88 & 23.14 \\
\hline 67 & Liquid & 100 & 967.74 & 21 & 101.44 & 88 & 23.37 \\
\hline 68 & Liquid & 100 & 967.74 & 21 & 101.44 & 88 & 23.37 \\
\hline 69 & Liquid & 100 & 967.74 & 21 & 101.44 & 88 & 23.41 \\
\hline 70 & Liquid & 20 & 196.07 & & 101.6 & 55 & 14.47 \\
\hline 71 & Liquid & 20 & 196.07 & & 101.6 & 55 & 14.67 \\
\hline 72 & Liquid & 20 & 196.07 & & 101.6 & 55 & 14.88 \\
\hline
\end{tabular}




\section{Appendix C}

\section{Typical CFAST and FDS}

Data Entry Files 
CFAST $20 \mathrm{ml}$ fire with $12 \mathrm{~m}$ ceiling elevation model input file

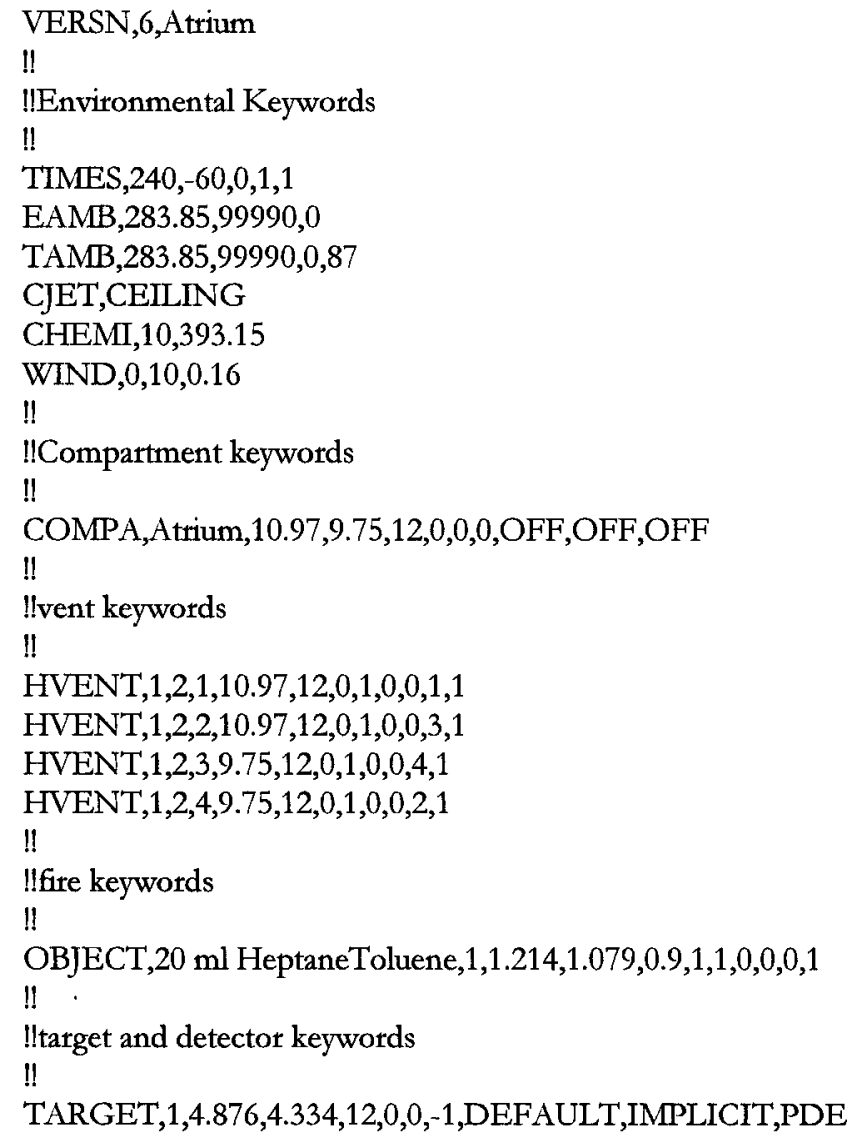

\section{CFAST $20 \mathrm{ml}$ liquid fuel fire data input file}

$20 \mathrm{ml}$ HeptaneToluene

$20,0,0,0,0.9,0.01960668,0,0,0,0.02635875,0,0,0$

$0.098,5,153.9628,1.360936 \mathrm{E}-05,0.9,0.01960668,0,0,0,0.02635875,0,0,0$

$393.15,10,823.7312,4.29528 \mathrm{E}-05,0.9,0.01960668,0,0,0,0.02635875,0,0,0$

$293.15,15,1184.95,3.852963 \mathrm{E}-05,0.9,0.01960668,0,0,0,0.02635875,0,0,0$

$327000,20,1157.892,2.990678 \mathrm{E}-05,0.9,0.01960668,0,0,0,0.02635875,0,0,0$

$0.3228,25,1352.083,3.313297 \mathrm{E}-05,0.9,0.01960668,0,0,0,0.02635875,0,0,0$

$0.01502,30,1776.659,3.65243 \mathrm{E}-05,0.9,0.01960668,0,0,0,0.02635875,0,0,0$

$0.158,35,1906.69,3.565319 \mathrm{E}-05,0.9,0.01960668,0,0,0,0.02635875,0,0,0$

$0.158,40,1601.989,3.04871 \mathrm{E}-05,0.9,0.01960668,0,0,0,0.02635875,0,0,0$

$0.001,45,1348.278,2.643776 \mathrm{E}-05,0.9,0.01960668,0,0,0,0.02635875,0,0,0$

$4.07 \mathrm{E}+07,50,1097.173,2.109495 \mathrm{E}-05,0.9,0.01960668,0,0,0,0.02635875,0,0,0$

HeptaneToluene,55,946.6595,1.908783E-05,0.9,0.01960668,0,0,0,0.02635875,0,0,0

$, 60,766.5561,1.507411 \mathrm{E}-05,0.9,0.01960668,0,0,0,0.02635875,0,0,0$

$, 65,660.2017,1.357584 \mathrm{E}-05,0.9,0.01960668,0,0,0,0.02635875,0,0,0$ 
$, 70,444.2982,1.006318 \mathrm{E}-05,0.9,0.01960668,0,0,0,0.02635875,0,0,0$

$, 75,228.8266,6.11145 \mathrm{E}-06,0.9,0.01960668,0,0,0,0.02635875,0,0,0$

$, 80,197.0277,4.582563 \mathrm{E}-06,0.9,0.01960668,0,0,0,0.02635875,0,0,0$

$, 85,156.1419,4.535847 \mathrm{E}-06,0.9,0.01960668,0,0,0,0.02635875,0,0,0$

$, 90,147.9709,4.233064 \mathrm{E}-06,0.9,0.01960668,0,0,0,0.02635875,0,0,0$

$, 95,0,0,0.9,0.01960668,0,0,0,0.02635875,0,0,0$

\section{CFAST $\log$ file for $20 \mathrm{ml}$ liquid fuel fire with $12 \mathrm{~m}$ ceiling height}

Date stamp from CFAST initialization 2009/04/13

The project files are based on the root: liquid, $20 \mathrm{ml}, 12 \mathrm{~m}$

Version 6.0.10 Created 2006/10/18, Run 2009/04/13

Opening a version 6 file in normal mode

$\begin{array}{llllllll}\text { Key word TIMES parameter(s) }=240 & -60 & 0 & & 1 & 1 \\ \text { Key word EAMB parameter(s) }=283.85 & 99990 & 0 & & \\ \text { Key word TAMB parameter(s) }=283.85 & 99990 & 0 & & 87\end{array}$

Key word CJET parameter(s) = CEILING

Ceiling jet calculation has been set: T F F F T

Key word CHEMI parameter(s) $=10 \quad 393.15$

Key word WIND parameter(s) $=\begin{array}{lll}0 & 10 & 0.16\end{array}$

$\begin{array}{lllllllll}\text { Key word COMPA parameter(s) = Atrium } & 10.97 & 9.75 & 12 & 0 & 0 & 0 & \mathrm{OFF}\end{array}$

OFF OFF

Compartment 1 Atrium $11.0 \quad 9.8 \quad 12.0 \quad 0.0 \quad 0.0 \quad 0.0$ FFFF OFF $\quad$ OFF $\quad$ OFF $\mathrm{OFF}$

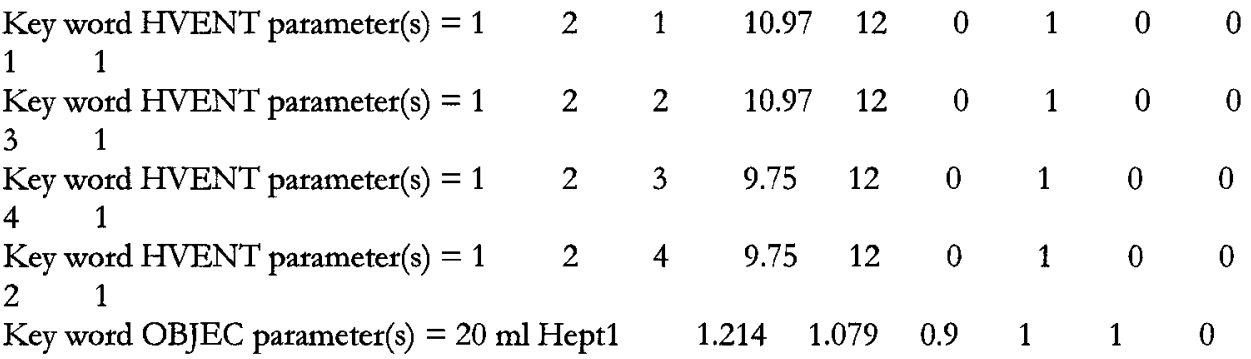

$\begin{array}{lll}0 & 0 & 1\end{array}$

Key word TARGE parameter(s) = $\begin{array}{llllllll}4.876 & 4.334 & 12 & 0 & 0 & -1\end{array}$

DEFAULT IMPLICIT PDE

Open the output file C: $\backslash$ Documents and Settings $\backslash$ William $\backslash$ My Documents $\backslash$ Fire Safety

Engineering $\backslash$ Thesis $\backslash$ Report $\backslash C F A S T \backslash$ liquid, $20 \mathrm{ml}, 12 \mathrm{~m}$.out

Open the smokeview files - C: $\backslash$ Documents and Settings $\backslash W$ illiam $\backslash$ My Documents $\backslash$ Fire Safety

Engineering $\backslash$ Thesis $\backslash$ Report $\backslash C F A S T \backslash$ liquid, $20 \mathrm{ml}, 12 \mathrm{~m} . \mathrm{smv}$ C: $\backslash$ Documents and

Settings $\backslash$ William $\backslash$ My Documents $\backslash$ Fire Safety Engineering $\backslash$ Thesis $\backslash$ Report $\backslash C F A S T \backslash$ liquid,20ml, $12 \mathrm{~m} . \mathrm{plt}$

Open the spreadsheet files - C: $\backslash$ Documents and Settings $\backslash$ William $\backslash$ My Documents $\backslash$ Fire Safety

Engineering $\backslash$ Thesis $\backslash$ Report $\backslash \mathrm{CFAST} \backslash$ liquid, $20 \mathrm{ml}, 12 \mathrm{~m} . n . c s v \quad \mathrm{C}: \backslash$ Documents and

Settings $\backslash$ William $\backslash$ My Documents $\backslash$ Fire Safety Engineering $\backslash$ Thesis $\backslash$ Report $\backslash C F A S T \backslash$ liquid,20ml, 12m.f.csv C: $\backslash$ Documents and Settings $\backslash$ William $\backslash$ My Documents $\backslash$ Fire Safety

Engineering $\backslash$ Thesis $\backslash$ Report $\backslash C F A S T \backslash$ liquid, $20 \mathrm{ml}, 12 \mathrm{~m}$.s.csv $\mathrm{C}: \backslash$ Documents and

Settings $\backslash$ William $\backslash$ My Documents $\backslash$ Fire Safety Engineering $\backslash$ Thesis $\backslash$ Report $\backslash C F A S T \backslash$ liquid, 20ml, $12 \mathrm{~m} . w . c s v$ 
Open the object fire file C: \Documents and Settings $\backslash W$ illiam $\backslash$ My Documents $\backslash$ Fire Safety Engineering $\backslash$ Thesis $\backslash$ Report $\backslash C F A S T \backslash 20 \mathrm{ml}$ HeptaneToluene.o

Object $20 \mathrm{ml}$ HeptaneToluene position set to $1.2141 .079 \quad 0.900$; Maximum HRR per $\mathrm{m}^{\wedge} 3$ is $3.247 \mathrm{E}+05$

Open the thermophysical properties file C: $\backslash$ Documents and Settings $\backslash W$ illiam $\backslash$ My

Documents $\backslash$ Fire Safety Engineering $\backslash$ Thesis $\backslash$ Report $\backslash C F A S T \backslash$ thermal.csv

Total execution time $=73.3$ seconds

Normal exit from CFAST 
FDS $20 \mathrm{ml}$ fire with $12 \mathrm{~m}$ ceiling elevation model input file

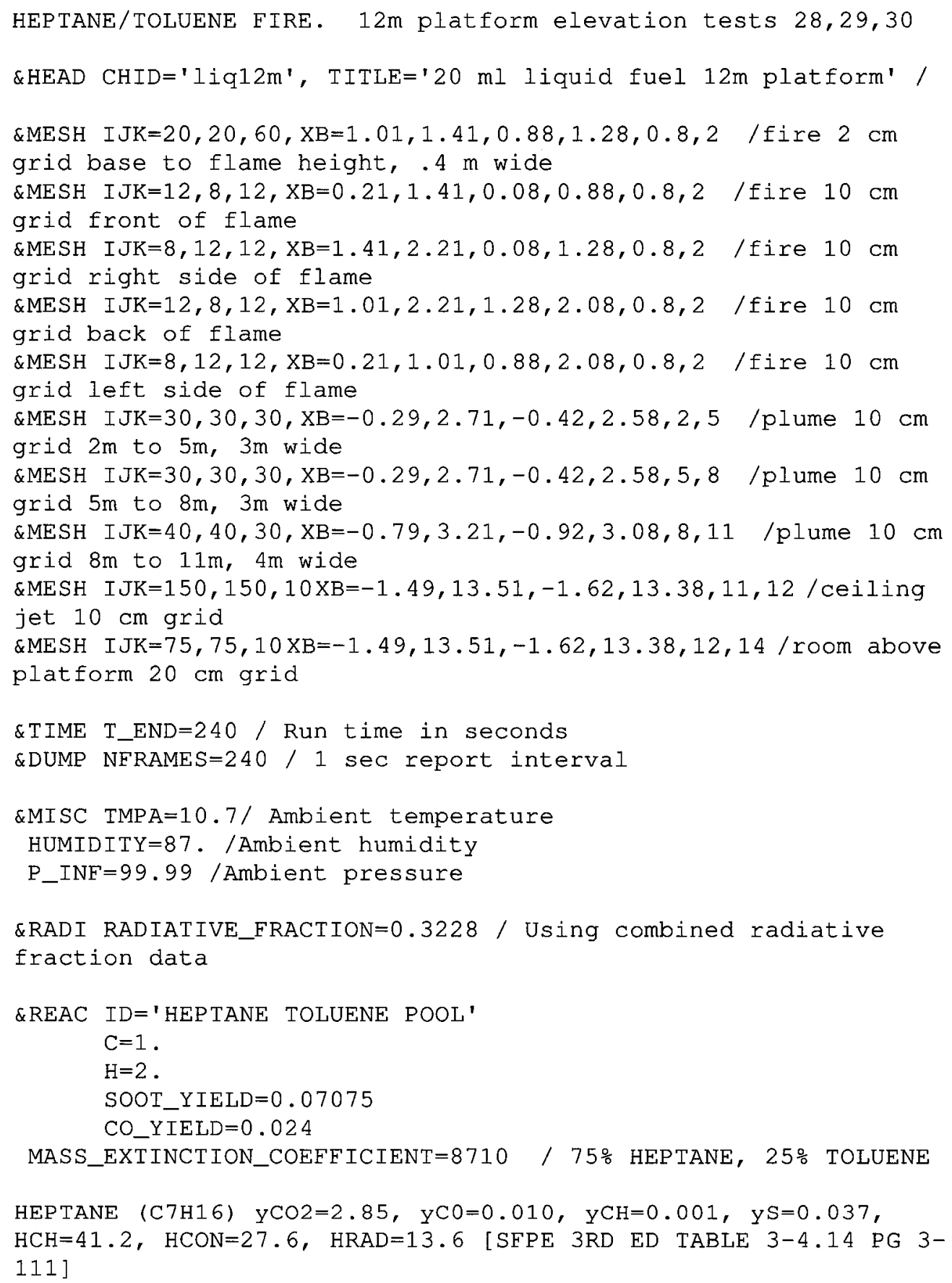




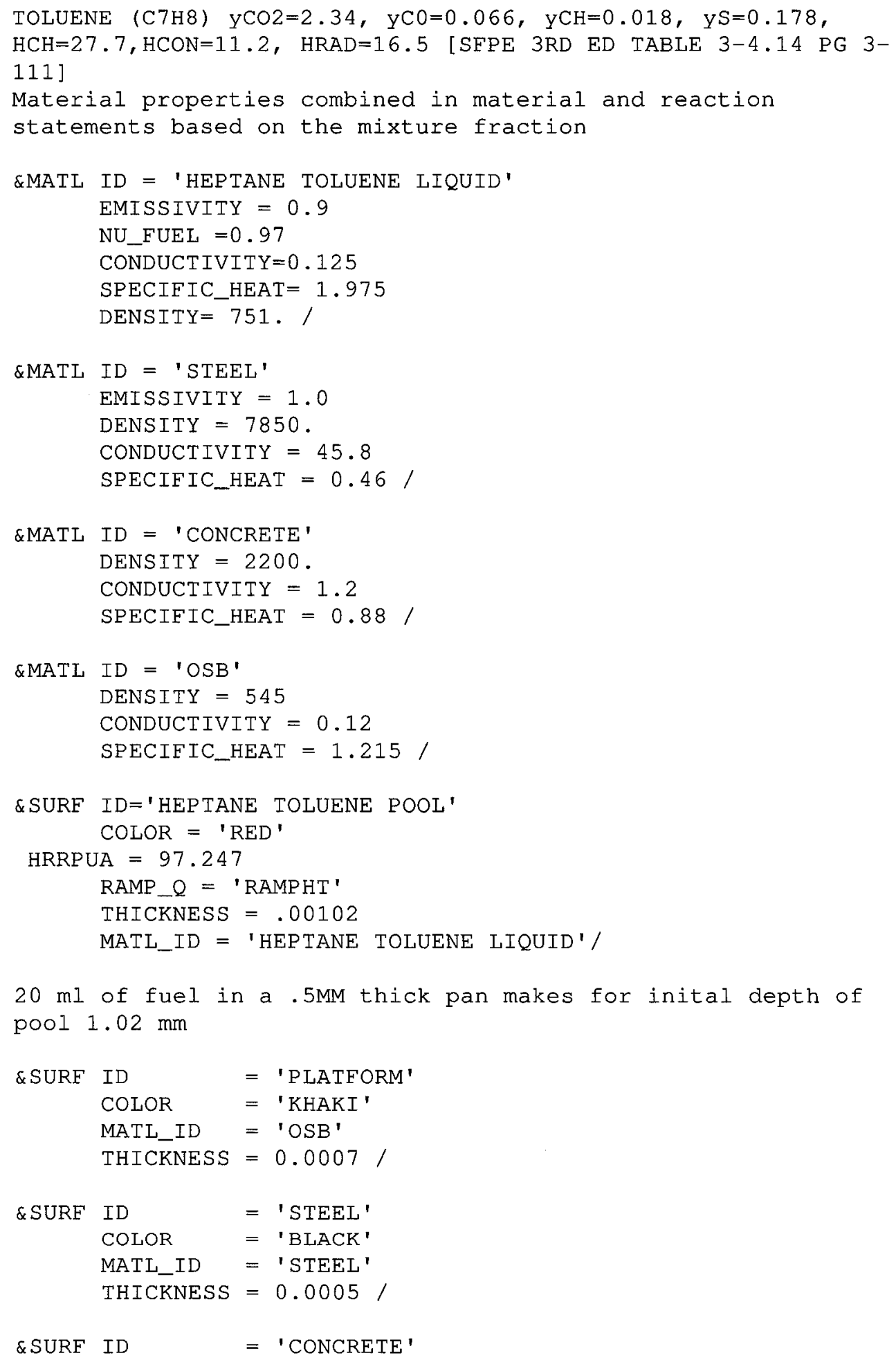




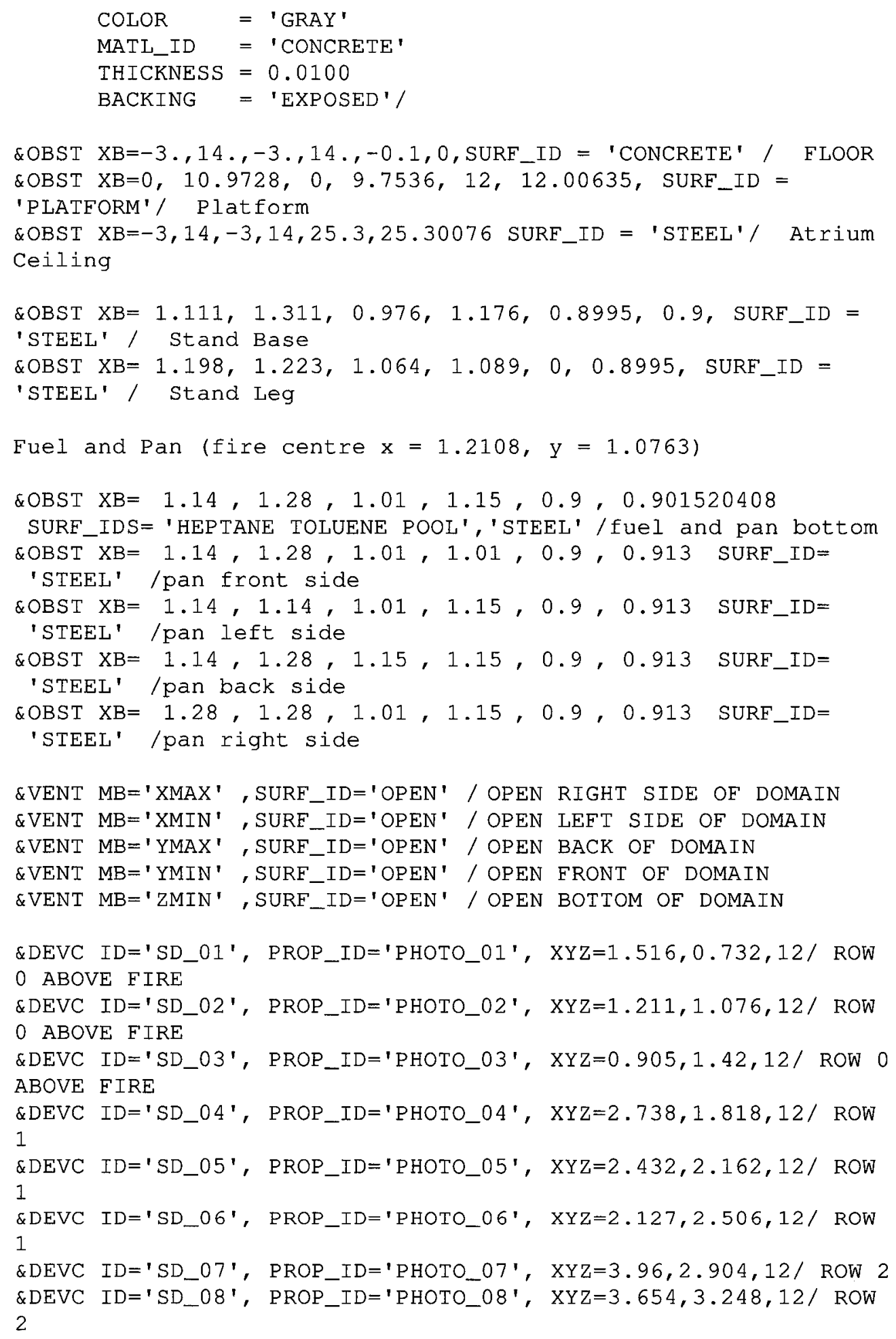




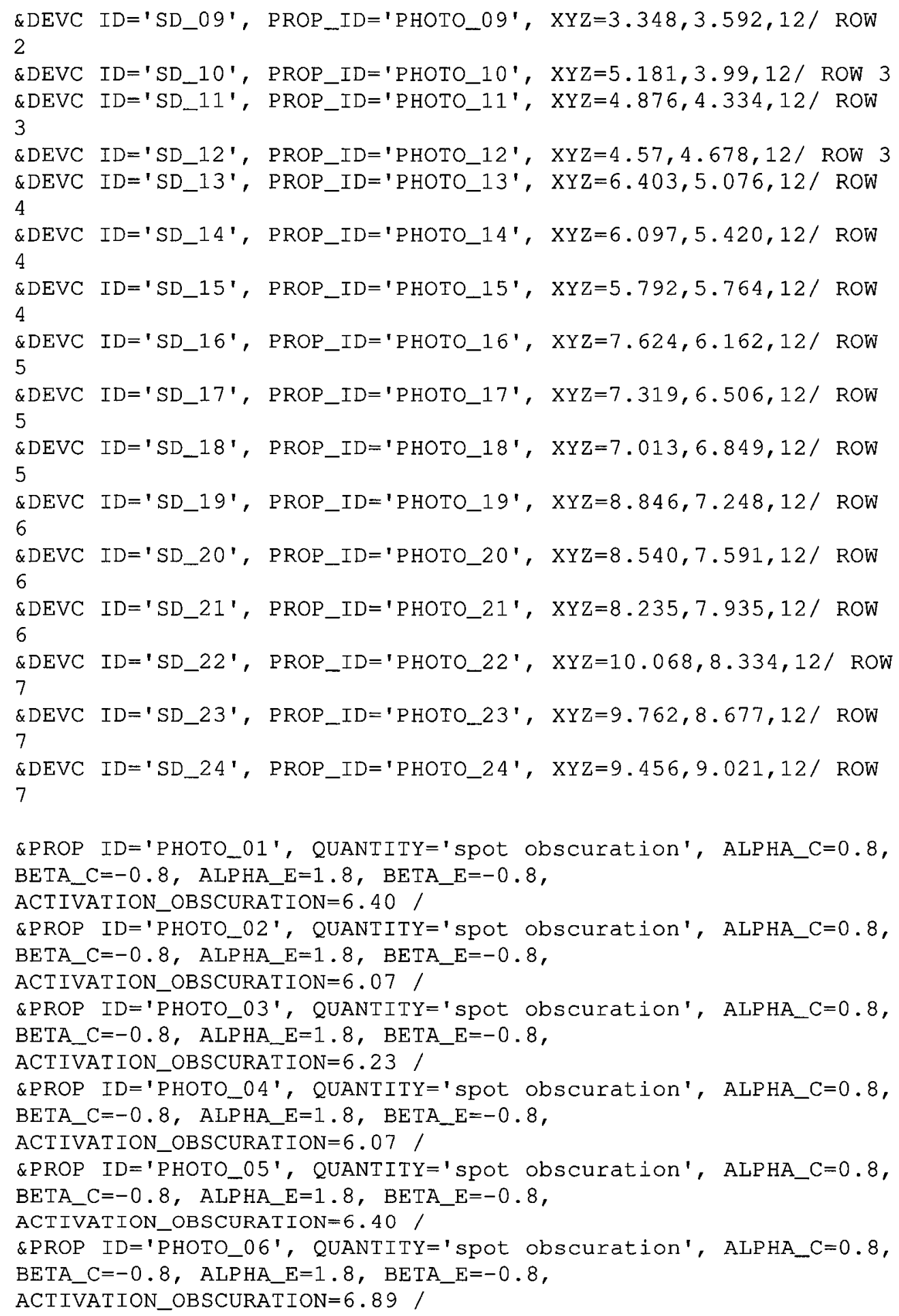




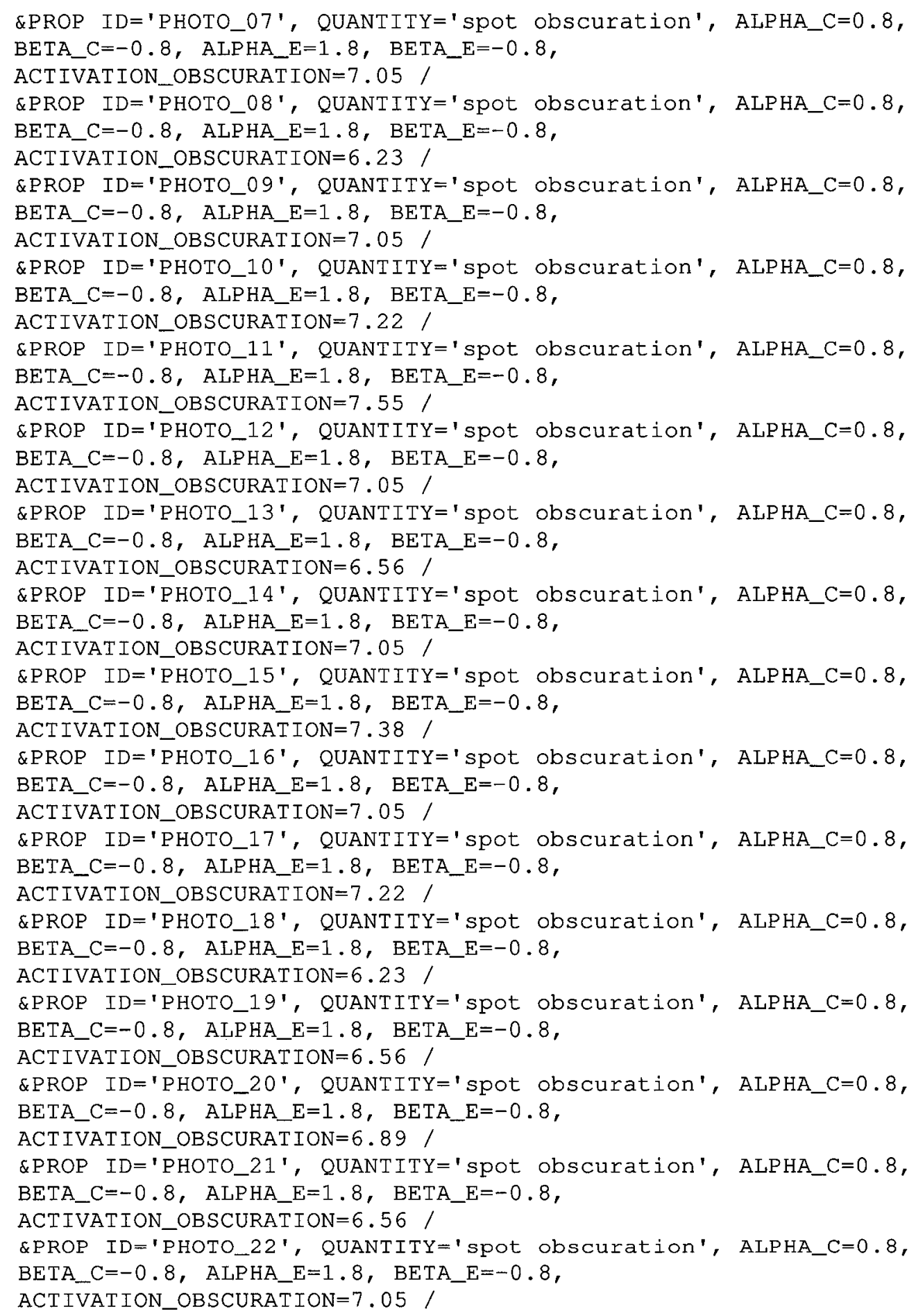




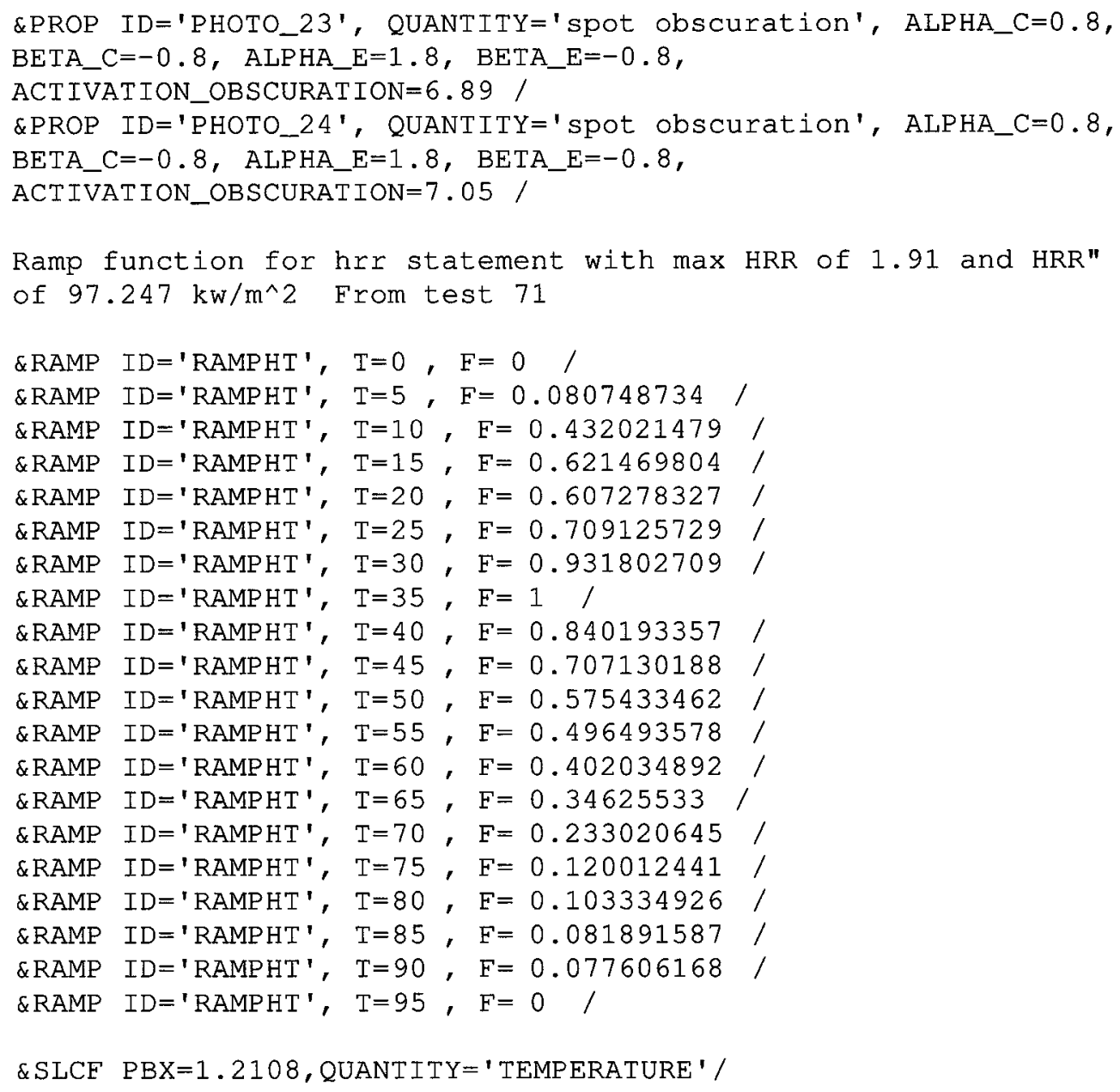

